\title{
Comparison between human perception of risk of injury and NIOSH WPG for lifting tasks
}

\author{
Viviana Carolina Baggio \\ West Virginia University
}

Follow this and additional works at: https://researchrepository.wvu.edu/etd

\section{Recommended Citation}

Baggio, Viviana Carolina, "Comparison between human perception of risk of injury and NIOSH WPG for lifting tasks" (2006). Graduate Theses, Dissertations, and Problem Reports. 4213.

https://researchrepository.wvu.edu/etd/4213

This Thesis is protected by copyright and/or related rights. It has been brought to you by the The Research Repository @ WVU with permission from the rights-holder(s). You are free to use this Thesis in any way that is permitted by the copyright and related rights legislation that applies to your use. For other uses you must obtain permission from the rights-holder(s) directly, unless additional rights are indicated by a Creative Commons license in the record and/ or on the work itself. This Thesis has been accepted for inclusion in WVU Graduate Theses, Dissertations, and Problem Reports collection by an authorized administrator of The Research Repository @ WVU. For more information, please contact researchrepository@mail.wvu.edu. 


\section{COMPARISON BETWEEN HUMAN PERCEPTION OF RISK OF INJURY AND NIOSH WPG FOR LIFTING TASKS}

Viviana Carolina Baggio

Thesis submitted to the

College of Engineering and Mineral Resources

at West Virginia University

in partial fulfillment of the requirements

for the degree of

Master of Science

In Industrial Engineering

Steven Wiker, Ph.D., Committee Chairperson

Wafik Iskander, Ph.D.

Majid Jaraieidi, Ph.D.

Department of Industrial \& Management Systems Engineering

Morgantown, West Virginia

2006

Keywords: NIOSH WPG, risk of injury perception 


\title{
ABSTRACT \\ COMPARISON BETWEEN HUMAN PERCEPTION OF RISK OF INJURY AND NIOSH WPG FOR LIFTING TASKS
}

\author{
Viviana Baggio
}

Low back injuries are highly prevalent in industry, recreational environs and in work at home. It is believed that humans are not able to judge the biomechanical risk of injury inherent with performing lifting tasks. This experiment studies the impact of lifting geometry (e.g., the horizontal, vertical and travel distances of a lift), frequency, gender and age upon an observer's perception of injury risk when looking at a task before attempting a lift. Subjects completed a questionnaire with a series of 54 pictures showing different lifting tasks; subjects then ranked their perceived risk of injury on a scale of $0=$ no risk of injury through $10=$ maximum risk of injury. Results showed that people misjudge the risk of injury based on NIOSH WPG 1981 guidelines by overestimating the risk of injury. Also results reflected that people's responses were based on physiological aspects. 


\section{ACKNOWLEDGMENTS}

Special thanks to God for giving me supporting parents, sister and family. They have always inspired me and loved me through my entire career in spite of the distance. I would also like to thank my husband for his love and encouragement during the toughest times and for accompanying me all along the way.

I also like to express sincere thanks to committee advisors Dr. Wiker, Dr. Iskander and Dr. Jaraieidi for their support during this project. Thanks to all the subjects, friends and people that helped and participated in the study. 


\section{TABLE OF CONTENTS}

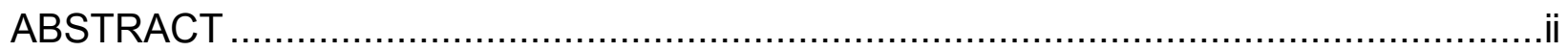

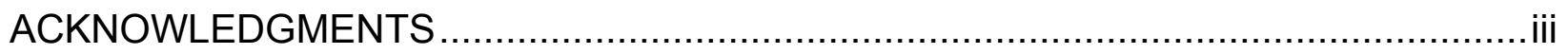

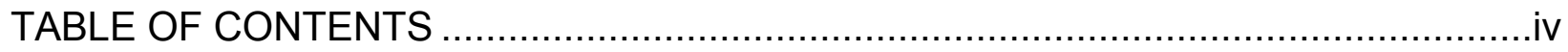

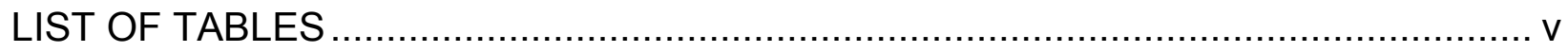

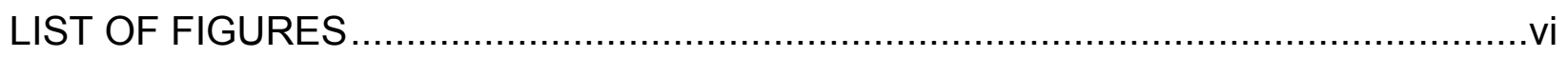

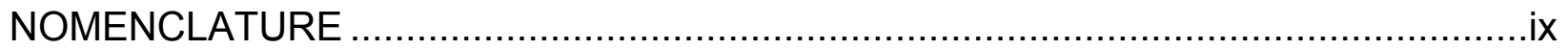

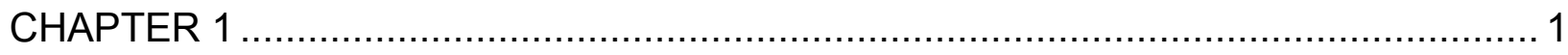

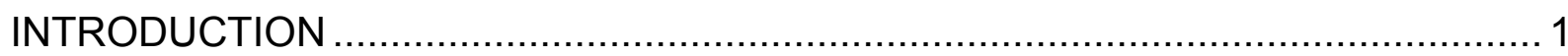

CHAPTER 2

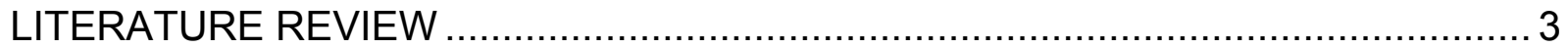

1981 NIOSH WORK PRACTICE GUIDE FOR MANUAL LIFTING TASKS.............. 5

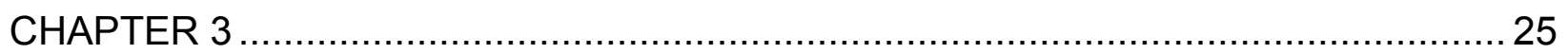

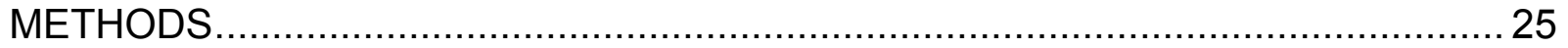

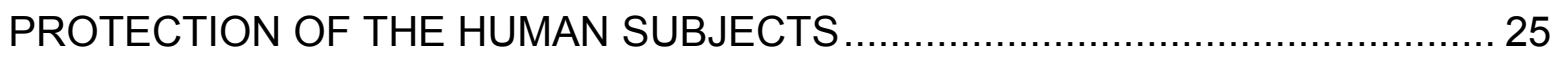

METHODS FOR CREATION OF THE QUESTIONNAIRES …............................ 25

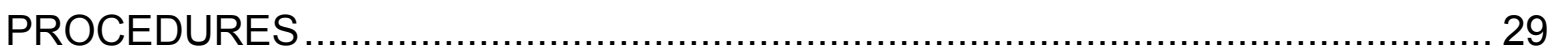

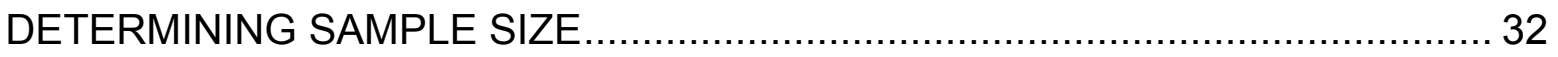

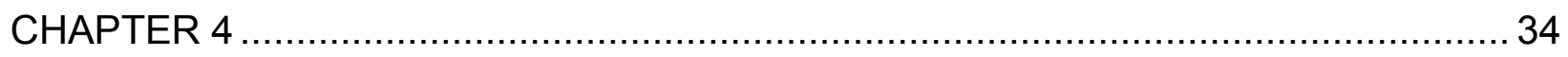

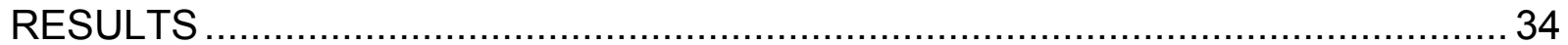

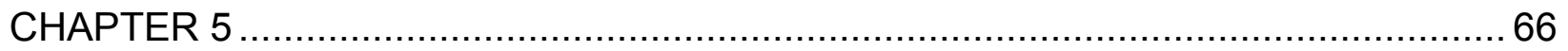

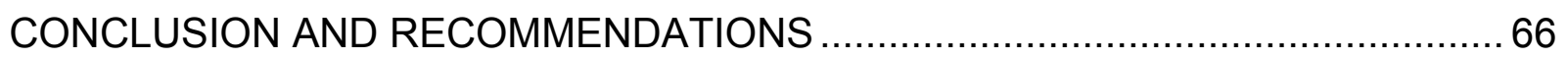

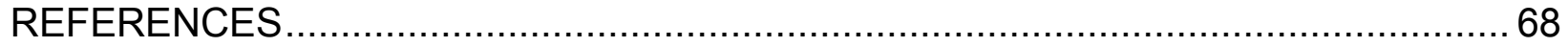

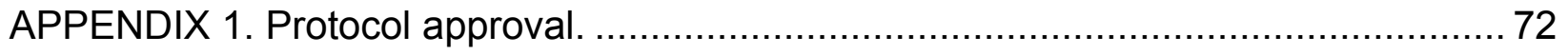

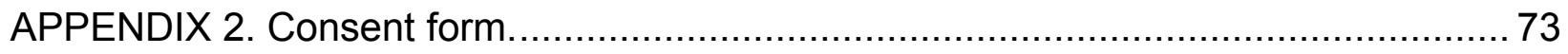

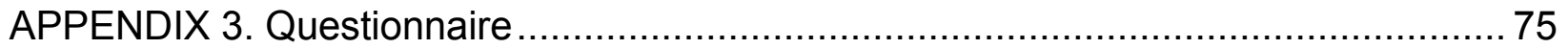

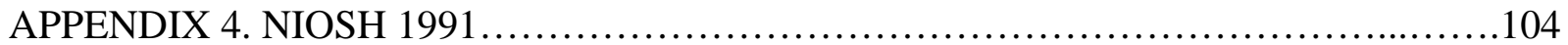




\section{LIST OF TABLES}

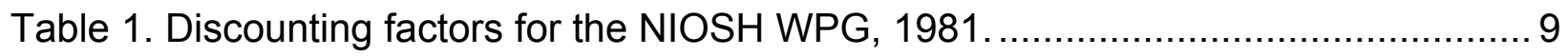

Table 2. $\mathrm{F}_{\max }$ value based on the vertical location and work period (NIOSH WPG 1981).

Table 3. Job Severity Index for each task generated based on NIOSH WPG (1981) equation and used in the questionnaire. ............................................... 28

Table 4. Complete randomized fixed effect with 4 lifting task variables and 2 subject variables. 31

Table 5. Male and female subjects characteristics. 33

Table 6. Means and Standard deviation of Perceived Risk of injury for vertical distance, horizontal distance, frequency of lift, travel distance. 35

Table 7. Analysis of variance for the perceived risk of injury in lifting tasks. 36

Table 8. Analysis of variance for the perceived risk of injury in lifting tasks. 40

Table 9. Analysis of variance for the perceived risk of injury in lifting tasks for the NIOSH 1981 factors.

Table 10. Analysis of variance for the perceived risk of injury in lifting tasks for the NIOSH 1991 factors 


\section{LIST OF FIGURES}

Figure 1. Graphic representation of vertical and horizontal measurement based on

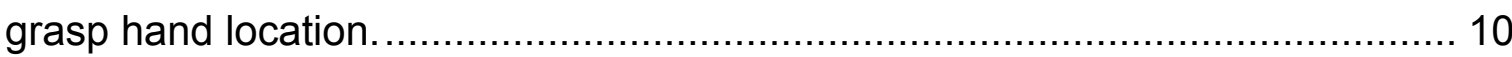

Figure 2. Horizontal Factor Multiplier for different horizontal distances as allowed by

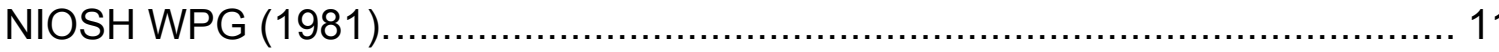

Figure 3. Travel Distance Factor Multiplier for different distances traveled as allowed

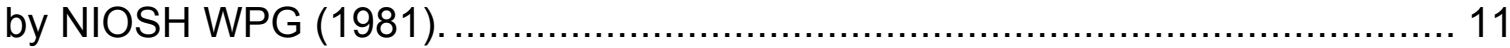

Figure 4. Vertical Factor Multiplier for different vertical distances as allowed by NIOSH WPG (1981)

Figure 5. Frequency Factor Multiplier for different frequencies of lift as allowed by NIOSH WPG (1981).

Figure 6. Picture example of how to interpret instruction on the questionnaire. 29

Figure 7. Perceived risk of injury versus Job Severity Index. 34

Figure 8. Means and standard deviations of perceived risk of injury and Job Severity Index plotted across horizontal distances of lift.

Figure 9. Means and standard deviations of perceived risk of injury and Job Severity Index plotted across vertical distances of lift.

Figure 10. Means and standard deviations of perceived risk of injury and Job Severity Index plotted across frequencies of lift.

Figure 11. Means and standard deviations of perceived risk of injury and Job Severity Index plotted across travel distances of lift

Figure 12. Means and standard deviation of perceived risk of injury for the two travel distances across the vertical distances.

Figure 13. Means and standard deviation of perceived risk of injury for the two groups of age across the vertical distances.

Figure 14. Means and standard deviations of perceived risk of injury for the two groups of age across frequency of lifts.

Figure 15. Means and standard deviations of perceived risk of injury for the two groups of age across gender. 
Figure 16. Means and standard deviations of perceived risk of injury for gender across travel distances for each of the vertical distances.

Figure 17. Means and standard deviations of perceived risk of injury for the two groups of age across gender for each of the vertical distances.

Figure 18. Means and standard deviations of perceived risk of injury for the two groups of age across gender for each of the travel distances.

Figure 19. Means and standard deviations of perceived risk of injury for the two travel distances across of horizontal distances for the different frequency of lifts and vertical distances

Figure 20. Predicted lifting strength of a large strong male, (Chaffin, 1974).............. 50

Illustration from Work Practice Guide for Manual Lifting, 1981_............................. 50

Figure 21. Means and standard deviation of perceived risk of injury for the two travel distances across the frequency of lifts.

Figure 22. Scatter plots of perceived risk of injury versus Job Severity Index for the vertical travel distances and vertical distances.

Figure 23. Means and standard deviations of perceived risk of injury for the two travel distance factor multipliers across of horizontal factor multipliers for the different frequency and vertical factor multipliers for $\mathrm{NIOSH} 1981$.

Figure 24. Means and standard deviations of perceived risk of injury for the two travel distance factor multipliers across of horizontal factor multipliers for the different frequency and vertical factor multipliers for $\mathrm{NIOSH} 1991$. 58

Figure 25. Means and standard deviations of perceived risk of injury for horizontal factor multipliers for NIOSH 1981 and 1991.

Figure 26. Means and standard deviations of perceived risk of injury for the vertical factor multipliers for NIOSH 1981 and 1991

Figure 27. Means and standard deviations of perceived risk of injury for frequency factor multipliers for NIOSH 1981 and 1991. 60

Figure 28. Means and standard deviations of perceived risk of injury for travel distance factor multipliers for NIOSH 1981 and 1991. 
Figure 29. Means and standard deviations of perceived risk of injury for the two travel distance factor multipliers across of vertical factor multipliers for NIOSH 1981 and 1991

Figure 30. Means and standard deviations of perceived risk of injury for the two travel distance factor multiplier across of vertical factor multiplier for NIOSH 1981 and 1991

Figure 31. Means and standard deviations of perceived risk of injury for the two groups of age across of frequency factor multipliers for NIOSH 1981 and 1991. 62

Figure 32. Means and standard deviations of perceived risk of injury for the two groups of age across gender for NIOSH 1981 and 1991.

Figure 33. Means and standard deviations of perceived risk of injury for genders across of travel distance factor multipliers for the different vertical factor multipliers of NIOSH 1981 and 1991

Figure 34. Means and standard deviations of perceived risk of injury for the two groups of age across vertical factor multipliers for gender for NIOSH 1981 and 1991

Figure 35. Means and standard deviations of perceived risk of injury for the two groups of age across of travel distance factor multipliers for NIOSH 1981 and 1991 for gender. 


\section{NOMENCLATURE}

$(\mathrm{AL})$ Action Limit

(ANOVA) Analysis of Variance

(BLE) Biomechanical Lifting Equivalent

(D) Distance Traveled

(DFM) Travel Distance Factor Multiplier

(F) Frequency of Lift

(FFM) Frequency Factor Multiplier

(HFM) Horizontal Distance Factor Multiplier

(IRB) Institutional Review Board

(JSI) Job Severity Index

(LBP) Low Back Pain

(LI) Lifting Index

(MAW) Maximum Acceptable Weight

(MAWOL) Maximum Acceptable Weight of Lift

$(\mathrm{MMH})$ Manual Material Handling

(MVC) Maximal Voluntary Contraction

(MPL) Maximum Permissible Limit

(NIOSH) National Institute for Occupational Safety and Health

(NLE) NIOSH Lifting Equation 
(PPE) Perceived Physical Effort

(PRLI) Perceived Risk of Lifting Injury

(RPE) Rating of Perceived Exertion

(RWL) Recommended Weight Limit

(ST) Strength Training

(UEMSD) Upper Extremity Musculoskeletal Disorders

(V) Vertical Distance

(VFM) Vertical Distance Factor Multiplier

(WPG) Work Practice Guide 


\section{CHAPTER 1}

\section{INTRODUCTION}

Lifting tasks are prevalent in work environments, homes or recreational activities. In some cases, lifting tasks may be the cause of injuries. Statistics have shown that from all the injuries in the work place, almost $20 \%$ are related to back injuries contributing $25 \%$ of the annual compensation expenses (Department of Labor, 1982). Based on facts like this, the National Institution for Occupational Safety and Health (NIOSH) in 1981, created the Work Practices Guide for Manual Work (WPG) and a following modification in 1991, published in 1993 by NIOSH and named the Revised NIOSH Lifting Equation (NLE), to gage risk of overexertion injuries when performing lifting and lowering tasks (Waters et al. 1993, Waters et al. 1998).

The NIOSH WPG and NLE equations may not reflect what people believe is the risk of injury of a specified task. Tasks may have a high risk of injury, but people may not be able to perceive it, sometimes misjudging the tasks as less risky, as a result performing the lift as safe, and once the lift is performed, people can harm themselves.

In this study it is hypothesized that people are not able to recognize the risk of injury that a lifting task may cause them from a biomechanical point of view before attempt to do the lifting task. A comparison between the Job Severity Index (JSI) from NIOSH Work Practices Guide for Manual Lifting and the human perception of risk of injury will examine this relationship to show if there is a mismatch. The mismatch can result in injury if the people underestimate the actual risk of a task and attempt to do the lift. It would be much better if people overestimate the risk, and therefore ideally perform the lift more carefully.

A questionnaire was created with a series of pictures with lifting tasks created with the factors taken into account in the NIOSH WPG (1981), horizontal distance, vertical distance, travel distance and frequency of the lift. Subjects were asked to rank the risk of injury of the specific tasks, from $0=$ no risk of injury through $10=$ maximum risk of injury. 
A comparison between perceived risk of injury and $\mathrm{JSI}$ will determine if there is a mismatch. In addition, analysis of variance will help to determine which factors people care about the most for assessing the risk of injury in lifting tasks.

NIOSH WPG 1981 equation was mostly based on biomechanics by professionals who developed the equation. Other areas such as physiological, epidemiological and psychophysical helped with the construction of this equation. In this study, the biomechanical area as well as the other areas are studied to determine how people perceive the risk of injury. 


\section{CHAPTER 2}

\section{LITERATURE REVIEW}

Manual Material Handling ( $\mathrm{MMH})$ has been one of the major causes of injuries since it is quite a common activity in industries. Some of the tasks include lifting, lowering, pushing and pulling, holding and carrying materials. One of the principal injuries is low back pain, becoming a concern to occupational health professionals, workers and employees. In general, Manual Material Handlings injuries represent $37 \%$ of a sample of 883,015 worker's compensation claims reflected in a large number of claims und the US Workman's Compensation Act of 1970 (Waikar et al., 1991).

Low Back Pain (LBP) can also occur by direct trauma, a single exertion or potentially as the result of multiple exertions. The development of LBP is also associated with pushing or pulling activities, extreme postures and whole body vibration (Dempsey, 1998, Waters et al., 1994). Low back pain has often been associated with Manual Material Handling has one of the most costly injuries with occupational origins, (Dempsey 1998, Dempsey and Hashemi, 1999). Back injuries are the major reason for lost time and compensation claims (NIOSH WPG, 1981). Back injuries are not the only body part hurt as consequences of $\mathrm{MMH}$, also the upper back and shoulders can be injured because of the material handling (Nielsen et al., 1998).

Regardless of the widespread automation and mechanization, $\mathrm{MMH}$ still remains a significant part of industrial work; which results in a paradox to encounter low back problems and this problem to arise each year (Dempsey, 1998, Yeung et al., 2002).

Investigators have developed tools that are proposed to recognize jobs that will probably be associated with an elevated risk of low back pain disorders. These tools have a number of benefits. For example they are used to identify high risk jobs useful for developing solutions for the problems encountered in the workplace. Also, these tools can 
be used to evaluate the effectiveness of potential ergonomic solutions considered in a work environment (Marras et al., 1999).

One of these tools was created by The National Institute for Occupational Safety and Health (NIOSH) in 1981, an equation that estimates lifting demands in the sagittal plane to assist safety and health of practitioners (NIOSH Work Practice Guide 1981). The equation gives a practical method for computing a weight limit for manual lifting tasks. The limitation of the equation is that it can only be applied to a certain class of tasks.

In 1991, a revision to the 1981 Guide was published. This 1991 Revised NIOSH Lifting Equation was designed to work in the same manner as the 1981 Guide in which a constant load was mediated by several multipliers (Waters et al., 1993). However, in the 1991 Lifting Equation, the load constant as well as the form of the multipliers were changed and two additional multipliers were included to assist with a larger sample of tasks. The additional factors consisted of an asymmetry and a coupling multiplier. The objective of both equations is to avoid or decrease the incidence of lifting related to low back pain in workers.

Four criteria were used to define the components of the original and revised lifting equation: epidemiologic, biomechanical, physiological, and psychophysical areas (PutzAnderson and Waters, 1991). Equally, both equations set up a weight limit, a constant, that remains the same under ideal conditions when all lifting risk factors are equal to 1.0; but in a realistic situation, when task-related variables are taken into account, the ideal rarely exists, and consequently, either the Action Limit (AL) for the 1981 WPG or the Recommended Weight Limit (RWL) for the 1991 Revised NIOSH Lifting equation values will usually be less than 1.0 .

The AL or RWL for a specific task represent the load that a healthy person could execute over a period of time without the risk of increasing low back injury. These two weight limits are also used for the computation of the risk for specific tasks, based on the 
actual load carried, Job Severity Index and Lifting Index respectively for each $\mathrm{NIOSH}$ equation.

For the purposes of this study, the 1981 NIOSH WPG will be used as a basis for comparison of the subject's perception and the risk of lifting task, since the Revised 1991 $\mathrm{NIOSH}$ equation has not been fully validated and more research is necessary to validate the equation (Waters et al., 1993).

\section{NIOSH WORK PRACTICE GUIDE FOR MANUAL LIFTING TASKS}

NIOSH WPG 1981 defines lifting task as the act of physically grasping and raising or lowering an object of definable size without mechanical aids (i.e., hoists, conveyors, block and tackle, etc.).

The NIOSH equation represents one technique for performing a task analysis of manual materials handling exposures involving lifting and lowering. Indeed, the equation requires an implicit form of the task description for the exposure being analyzed.

The equation establishes a safe limit for lifting named Action Limit ( $A L)$ as well as an upper limit for lifting, which is three times the Action Limit and named the Maximum Permissible Limit (MPL). According to this guide, musculoskeletal injury rates have been shown to increase significantly in populations where work is performed above the Maximum Permissible Limit (NIOSH WPG, 1981).

The Action Limit and Maximum Permissible Limit examine the impact of lifting and lowering task geometry and load characteristics upon LBI risk based on biomechanical, work physiological, psychophysical and epidemiological risk criteria. These characteristics are used to set load limits for a given lift or lower task geometry, the frequency and duration of such tasks. The guidelines were designed to assess only certain lifting and lowering tasks; some assumptions may be applied for tasks, for example: 
- the lift was smooth,

- the lift was two-handed and occurring in the sagittal plane,

- the load was of moderate width,

- the lifting posture was unrestricted,

- good coupling,

- a favorable ambient environment

The four different criteria, on which the $\mathrm{NIOSH}$ equation is based, have different goals. The biomechanical criterion goal looks for the designing of tasks that do not exceed the capacity of the musculoskeletal system. The physiological criterion seeks to design tasks in which the physiological response of the body is within acceptable limits. The goal of the psychophysical criterion is to design tasks that are "acceptable" to the majority of workers performing a task. Last, the epidemiology criterion goal seeks to determine the etiology significance of a given variable, to verify the validity of a criterion by establishing the relationship between a specific variable and the probability of injury (Dempsey, 1998).

The most frequent criteria used for the biomechanical approach are the compression force limits at the $L_{5} / S_{1}$ joint, and/or maximum joint torques. The typical physiological responses of interest are related to whole-body fatigue, and local muscle fatigue and the most used criterion to set acceptable limits is the rate of energy expenditure, in terms of oxygen consumption. The psychophysical approach has the need of workers to adjust the weight, force, or frequency of a particular task to 'maximum acceptable' values, (Dempsey, 1998).

The assessment of the AL and the MPL will define the severity of the job. The risk of the job is assessed depending on the range obtained by the AL and the MPL. A job in which it is required to lift loads below the $A L$ do not represent a risk for back pain for the majority of workers and can be lifted by $99 \%$ of men and $75 \%$ of women; jobs with a lift load between the AL and the MPL represent a risk for some workers and can be lifted by only $25 \%$ of men and $1 \%$ of women; finally jobs with lift loads above the MPL represent a risk for the majority of the workers (ICMR Bulletin, 2000, NIOSH WPG, 1981). 
Biomechanical approach also suggest that working above the MPL, people are at a higher risk of injury because compression forces at the $L_{5} / S_{1}$ are $650 \mathrm{~kg}$ or greater, and above the AL and less than the MPL values, compression forces at the $L_{5} / S_{1}$ exceeds 350 kg, (NIOSH WPG, 1981).

Tasks presenting high values weights between the Action Limit (AL) and the Maximum Permissible Limit (MPL) require administrative and engineering controls, (ICMR, 2000). This can be accomplished by the use of mechanical aids and good workstation design.

The NIOSH lifting equation takes into account different factor multipliers like: Horizontal Distance Factor Multiplier (HFM), Vertical Distance Factor Multiplier (VFM), Travel Distance Factor Multiplier (DFM), Lifting Frequency Factor Multiplier (FFM) and a Load Constant (LC). The Action Limit is determined as follow:

$$
A L=L C^{*} H F M^{*} V F M^{*} D F M^{*} F F M
$$

The MPL is calculated as follows, by the use of the Action Limit found previously:

$$
M P L=3^{*} A L
$$

A Job Severity Index (JSI) can also be calculated based on the real weight of the load and the found AL. JSI is assumed to be nominal if less than 1, if the JSI is between 1 and 3 , an increase risk is expected, and if more than 3 there is much higher risk.

$$
\text { JSI= Load / AL }
$$

Each of the 4 criteria that helped in the creation of the equation has made used of the different factors to explain their emphasis. Epidemiological studies made used of the horizontal location, vertical location and frequency of the lift; biomechanical by the use of the horizontal and vertical location with respect to the load; and psychophysical and 
physiological by the use of horizontal location, vertical location, travel distance and frequency of the lifts.

There are guidelines on how to measure and the allowable ranges of each factor multiplier. Variation may be found on the Action Limit if there is discordance on the way that the factors are measured (Waters et al., 1998). Factor multiplier calculations may be made by either metric units or the U.S. customary system as represented in Table 1. The factors used in the $1981 \mathrm{NIOSH}$ equation are:

- Load constant (LC): The Load Constant is fixed at $90 \mathrm{lbs}(40 \mathrm{~kg})$. This corresponds to the maximum recommended weight under optimal conditions. Selection of the load constant is based on biomechanical and psychophysical criteria. This corresponds to a weight that would be acceptable to $90 \%$ of the male and $75 \%$ of the female population and the disc compression forces resulting from such a lift would be less than 3-4 KN.

- Horizontal distance $(\mathrm{H}): \mathrm{H}$ is based on the position of the hands at the origin of the lift position. The distance is measured from the midpoint between the ankles to the midpoint of the hands grasping the object. The value of $\mathrm{H}$ has to be between the ranges of $15 \mathrm{~cm}$ to $80 \mathrm{~cm}$ (6 in to $32 \mathrm{in}$ ), since measurements smaller than $15 \mathrm{~cm}$ can get in the way with the body and above $80 \mathrm{~cm}$ cannot be reached by many people.

- Vertical distance (V): $\mathrm{V}$ is the measure from the floor level to the midpoint between the hands at the origin of the lift position. The value of $\mathrm{V}$ has to fall in the range of $0 \mathrm{~cm}$ to $175 \mathrm{~cm}$ ( 0 in to 70 in) since this range represents the value of the vertical reach for most people. Ideal condition is at $75 \mathrm{~cm}$.

- Travel distance (D): $D$ is the vertical measure from the origin to the final position of the midpoints of the hands. The value of $D$ is assumed to be in the range of $25 \mathrm{~cm}$ to $(200-\mathrm{V}) \mathrm{cm}$ or 10 in to $(80-\mathrm{V})$ in, in the case when the travel distance is less than $25 \mathrm{~cm}$, a value of $25 \mathrm{~cm}$ has to be used.

- Lifting Frequency (F): $F$ is the average number of lifts per minute. $F$ is assumed to be between 0.2 and $F_{\max }$. For lifting less frequently than 1 per 5 
min, a value of 0 has to be used. $F_{\max }$ is established based on the work period and the vertical distance (see Table 2).

Table 1. Discounting factors for the NIOSH WPG, 1981.

\begin{tabular}{|c|c|c|}
\hline \multirow{2}{*}{ Factor Multiplier } & \multicolumn{2}{|c|}{ NIOSH WPG 1981 } \\
\cline { 2 - 3 } & $\begin{array}{c}\text { Metric Units } \\
\mathbf{( k g , ~ c m )}\end{array}$ & $\begin{array}{c}\text { U.S. Customary System } \\
\text { (lb, in) }\end{array}$ \\
\hline Load Constant (LC) & $40 \mathrm{~kg}$ & $90 \mathrm{lb}$ \\
\hline Horizontal Distance Multiplier (HFM) & $\frac{15}{H}$ & $\frac{6}{H}$ \\
\hline Vertical Distance Multiplier (VFM) & $1-.004 *|V-75|$ & $1-.01^{*}|V-30|$ \\
\hline $\begin{array}{c}\text { Travel Distance Multiplier (DFM) } \\
\text { Frequency Multiplier (FFM) } \\
\left.\text { (See Table 2 for } F_{\text {max }}\right)\end{array}$ & $1-\frac{F}{F_{\text {max }}}$ & $1-\frac{3}{D}$ \\
\hline
\end{tabular}

Table 2. $\mathrm{F}_{\max }$ value based on the vertical location and work period (NIOSH WPG 1981).

\begin{tabular}{|c|c|c|}
\hline $\begin{array}{c}\text { Work Period } \\
\text { (hr.) }\end{array}$ & $\begin{array}{c}\text { V }>\mathbf{7 5 ~ c m ~ ( 3 0 ~ i n ) ~} \\
\text { Standing }\end{array}$ & $\begin{array}{c}\text { V } \mathbf{5 7 5} \text { cm (30 in) } \\
\text { Stooped }\end{array}$ \\
\hline 1 & 18 & 15 \\
\hline 8 & 15 & 12 \\
\hline
\end{tabular}


Figure 1 shows the sagittal plane and the correct way to perform the measurements for the horizontal distance and vertical distance for the calculation of the vertical factor multiplier and horizontal factor multiplier.

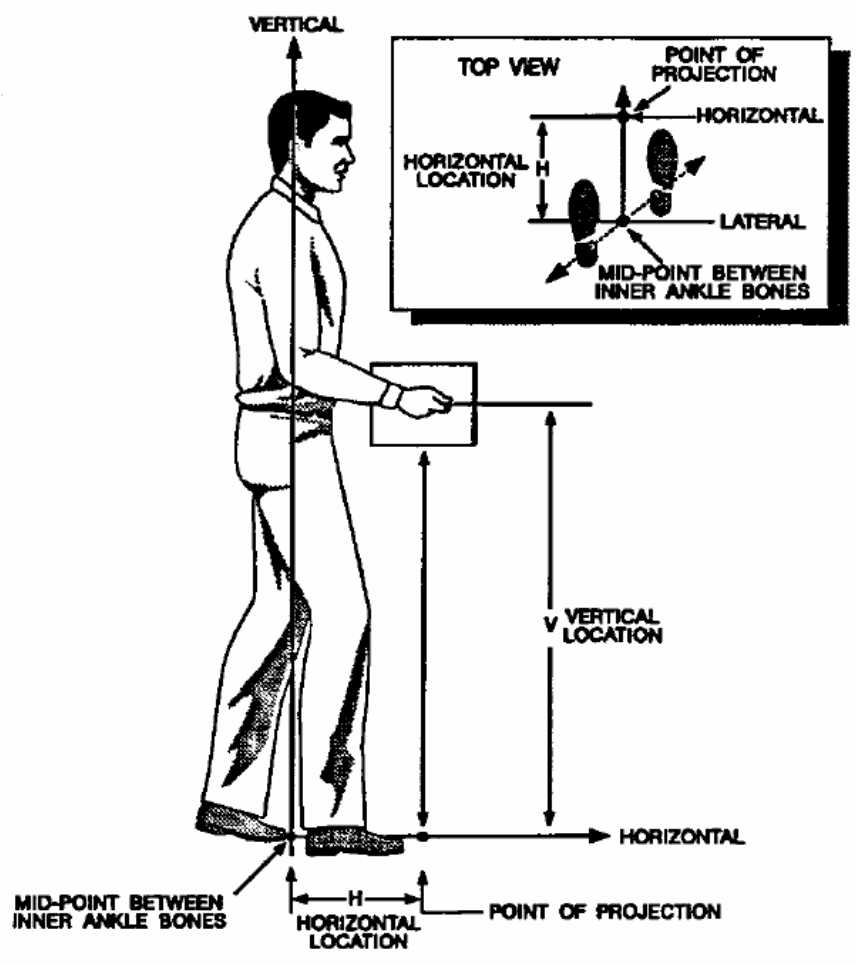

Figure 1. Graphic representation of vertical and horizontal measurement based on grasp hand location.

Illustration from Waters, T. et al. 1994, page 7.

Plots of the factors multipliers help to visualize the impact from the ideal case to the worst case allowed for each factor by the NIOSH WPG (1981) equation. Figures 2 through 5 illustrate the values for horizontal multiplier (HFM), travel distance multiplier (DFM), vertical multiplier (VFM), and frequency multiplier (FFM) respectively when changing values based on the range allowed by NIOSH WPG for each factor. As may be noticed from the plots, factors multipliers decline with the increment of the distances or the frequency of lift in the case of the frequency multiplier (FFM); only the vertical multiplier (VFM) has a different tendency, as the distance goes away from the waist level (ideal vertical distance at $75 \mathrm{~cm}$ ) either to a lower level or higher level, VFM declines. 


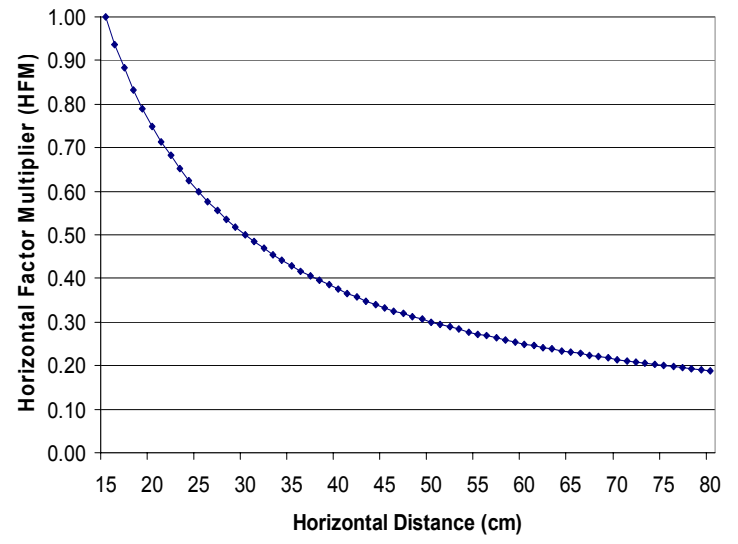

Figure 2. Horizontal Factor Multiplier for different horizontal distances as allowed by NIOSH WPG (1981).

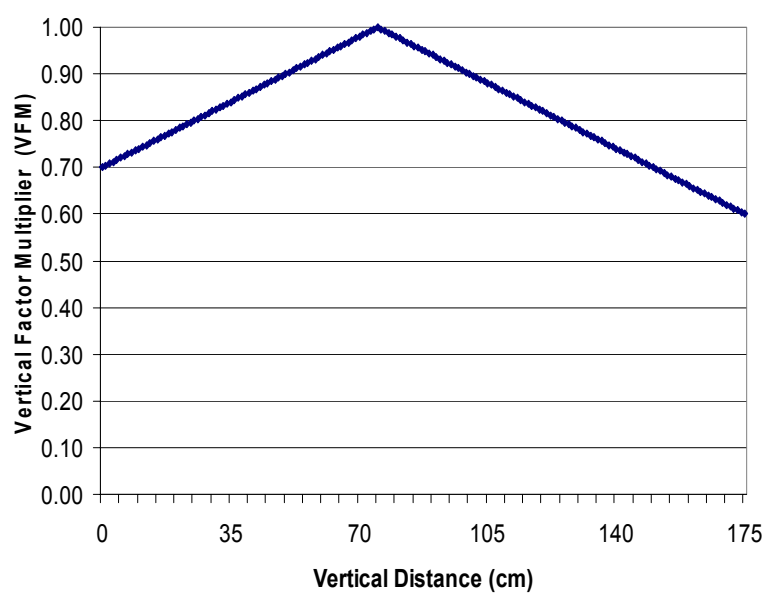

Figure 4. Vertical Factor Multiplier for different vertical distances as allowed by NIOSH WPG (1981).

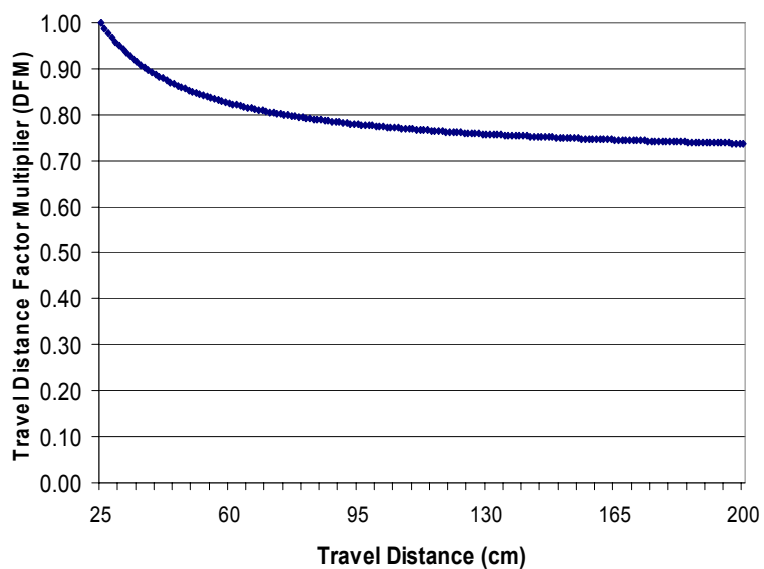

Figure 3. Travel Distance Factor Multiplier for different distances traveled as allowed by NIOSH WPG (1981).

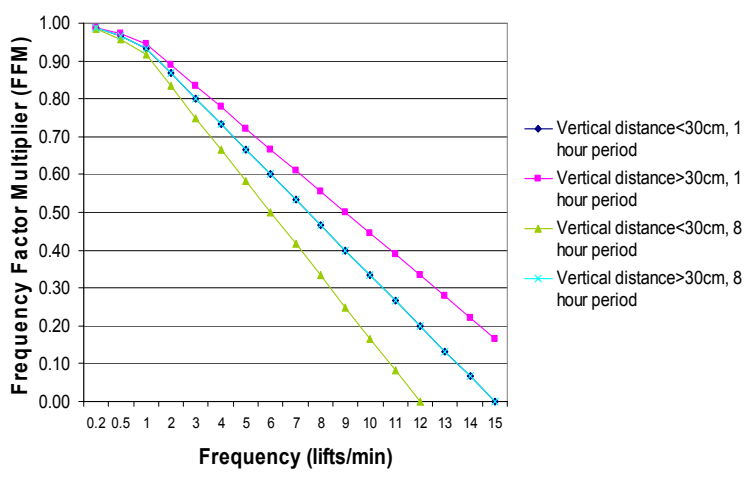

Figure 5. Frequency Factor Multiplier for different frequencies of lift as allowed by NIOSH WPG (1981). 
Many researches have studied lifting factors used in the NIOSH lifting equations with the use of biomechanical, psychophysical and physiological approaches or combination of these methods Mital and Ayoub (1981), Asfour et al. (1983), Garg (1989), Genaidy and Asfour (1989), Waikar et al. (1991), Nielsen et al. (1998), Hattori et al. (2000) and Cheng and Lee (2005).

Mital and Ayoub (1981) examined in their study the changes in metabolism and heart rate caused by variation of tasks parameters. Four male subjects participated in the study in where a total of 432 lifting and lowering tasks were used by the authors by changing task parameters such as frequency ( 2 and $6 \mathrm{lifts} / \mathrm{min}$ ), weight of load (11.36, 15.91 and 20.45 $\mathrm{kg}$ ), height of lift (floor to knuckle and knuckle to shoulder), coupling (handle and no handle), container height $(20.32$ and $30.48 \mathrm{~cm})$, container width $(38.1,50.8$ and $63.5 \mathrm{~cm})$ and container length $(35.56,50.8$ and $66.04 \mathrm{~cm})$. Analysis of variance showed that all effects are significant except for the box height and that lifting without handles resulted in extra energy expenditure. For lifting and lowering tasks, oxygen uptake increased with frequency, load and height.

Asfour et al. (1983) studied the relationship between rate of perceived exertion (RPE) and physiological cost of exertion (heart rate and oxygen consumption). Ten males participated in the study. The independent variables used in the lifting or lowering tasks were weight of load (6.8, 13.6 and $20.5 \mathrm{~kg}$ ), frequency (3, 6 and 9 lifts $/ \mathrm{min}$ ), height (floor to $76 \mathrm{~cm}$, 76 to $127 \mathrm{~cm}$ and floor to $127 \mathrm{~cm}$ ), box width in the frontal plane (38 and $66 \mathrm{~cm}$ ), box length in the sagittal plane $(38$ and $66 \mathrm{~cm})$ and angle of twist of the body $\left(0^{\circ}\right.$ and $\left.90^{\circ}\right)$ for a total of 216 tasks. Subjects were asked to rate the perceived exertion on the total amount of inner feelings of physical stress, effort and fatigue rather than on any one factor such as leg pain, shortness of breath or work intensity.

Analysis of variance on RPE showed that frequency, load, height, box width and box length are significant. For a given height, subjects underestimate the level of exertion in handling light loads and low frequency (RPE lower than heart rate); and overestimate the level of their exertion in the case of handling heavy loads and high frequencies. Authors also 
found that an increase of frequency and load resulted in an increase of RPE, subjects have better perception at high loads and that RPE appears linearly related to heart rate as well as oxygen consumption.

Garg (1989), first studied the percentage of people capable of lifting loads at the Maximum Permissible Limit (MPL) and the corresponding energy expenditure, heart rate, compressive force on the $L_{5} / S_{1}$ disc and ratings of perceived exertion (RPE); and secondly a comparison between MPL's based on measured horizontal distances with the rule of thumb from $\mathrm{NIOSH}(\mathrm{H}=15+\mathrm{w} / 2 \mathrm{~cm})$. In the study, 13 males lifted a series of lifting tasks using three different boxes (small, medium and large). Lifting tasks were in the sagittal plane using 2 heights (from floor to $.81 \mathrm{~cm}$ ) and from $.81 \mathrm{~cm}$ to $1.52 \mathrm{~cm}$ at 4 frequencies $(0.2,3,6$ and 9 lift/min). For each lifting task and subject, the horizontal distance was measured at the origin of the lift for further computation of the MPL's. A psychophysical model was used to determine the maximum weight of load acceptable to subjects, in which subjects had to adjust the weight of the box to the maximum amount that they could lift comfortably for $1 \mathrm{hr}$ at 3, 6 and $9 \mathrm{lifts} / \mathrm{min}$ and $8 \mathrm{hr}$ at $0.2 \mathrm{lifts} / \mathrm{min}$. The weight selected for subjects was not allowed to be more than the MPL corresponding to the specific task.

Results showed that all subjects selected weights that exceed the MPL. Analysis of variance of MPL showed that subject, frequency, height level and box size were significant. The energy expenditure increased as the lifting frequency increased. Rating of perceived exertion showed that the back was the body part more stressed from lower lifting tasks. Also Analysis of Variance showed that subject, frequency, height of level had a significant effect on RPE, the contrary for the box size. There was greater stress at the back when lifting from the floor and at the shoulders when lifting from a height of $.8 \mathrm{~m}$.

Based from subjective comments, it was easier to lift from the floor than from the $.8 \mathrm{~m}$ height, since jobs requiring lifting of loads above the shoulders may cause greater stress at the destination than at the origin of lift. Short subjects had trouble when lifting at $0.81 \mathrm{~m}$ to $1.5 \mathrm{~m}$ which was reflected on RPE in the shoulder, arm and wrist. The author found that the horizontal distances were greater than the rule of thumb of $\mathrm{H}=15+(\mathrm{w} / 2)$. 
Genaidy and Asfour (1989) studied the relationship between endurance time for Manual Material Handling tasks and the load and frequency of the task. Endurance time was defined as the maximum length of time that a person is able to lift a load at a specified frequency continuously. Eleven males were tested with different tasks where the load to be handled $(5,10,15$ and $20 \mathrm{~kg})$ and the frequency $(4,6,8$ and $10 \mathrm{lifts} / \mathrm{min})$ were varied at 4 levels each. Results obtained from analysis of variance showed that the endurance time was reduced as the load and the frequency increase.

Waikar et al. (1991) evaluated 5 different lifting tasks with different heights (floor to knuckle, knuckle to elbow, elbow to shoulder, shoulder to reach and reach to overreach) based on biomechanical and subjective estimation of stress at the lower back using a modified Borg's Scale from 0 to 100 . Ten male subjects participated in the study divided in three sessions. First session consisted of determining the Maximum Acceptable Weight of Lift (MAWOL) for each subject using psychophysical approach. A biomechanical model was used to ensure that there is no risk of using MAWOL in session two and three based on NIOSH WPG 1981 acceptable limits. In session two, subjects lifted a single lift with a load equal to their MAWOL determined in session one and then asked to rank the lift using the modified Borg Scale in where 0 was no discomfort and 100 a very painful feeling in the lower back, and finally in session three, subjects were asked to do same as session two, but this time using a frequency of 4 lifts/min for each lifting task. In sessions two and three, the most stressful task was ranked as 5 and the less stressful as 1 .

Results showed that tasks less severe from biomechanical point of view were evaluated to be very severe based on subjective estimation at lower back. Authors explained that maybe subjects were more concerned with the balance and did not follow the instructions to estimate stress at the lower back. Also, ANOVA showed significant difference between frequent and infrequent lifts.

Nielsen et al. (1998) studied the effect of muscular load on the back and shoulder due to different heights and frequencies in 11 males. A total of 9 lifting tasks ( 3 heights and 3 frequencies) were used. Maximal voluntary contraction (MVC) in the trunk and shoulder, 
maximal oxygen uptake $\left(\mathrm{VO}_{2}\right.$-max), volume of the expired air, content of oxygen and carbon dioxide and heart rate were the variables measured. Nonparametric statistics were applied to test differences between related samples. Results explained that maximum load on the low back occurred at low lifting heights while maximum load on the shoulders were reported at high levels. Heart rate was significantly higher for tasks at high and low level in comparison with the medium level; it was also larger while lifting at high frequency. The author recommended taking age into consideration, since one subject can reach critical load levels before other subjects.

Hattori et al. (2000) tested 16 Japanese female in 12 different lifting tasks. Factors were height of load: floor to knuckle ( 0 to $71 \mathrm{~cm})$, knee to chest $(45.7$ to $116.8 \mathrm{~cm})$, elbow to shoulder (104.1 to $129.5 \mathrm{~cm}$ ), weight (10 and $15 \mathrm{~kg}$ ) and symmetry (mid-sagittal plane and $90^{\circ}$ right lateral plane). Lido lift System was used to simulate lifting tasks and to collect peak force, average upward acceleration peak velocity and height at peak force in each lift; also heart rate was measured simultaneously. At the end of each lift, subjects were asked to give a rating following a category scale with ratio properties at 10 sites of the body (left and right shoulders, arms, backs, thighs, and whole bodies) while lifting.

Results from analysis of variance demonstrated higher ratings for bilateral arms and shoulders when lifting at higher levels, suggesting that heights at the shoulder level increase the load on the arms and shoulders and comparing with lower levels gives higher loads at the back and legs.

Cheng and Lee (2005) studied maximum two handled isometric at back, arm, shoulder and upper body lifting strength at 3 different horizontal distances of objects to be lifted (toes anterior to, aligned with and posterior to the exert handle) with 11 males and 13 females. Results showed that human lifting strength decreased significantly as the position shifted from anterior to posterior of the vertical plane of the exerted handle. The strength relationship between back and upper body lifting strength depended on the horizontal distance. 
Gender and age factors have also been studied in different researches, conclusions about these factors had showed different responses, concluding that more research needs to be done to make final decisions, ether if there is or there is not any difference about age and gender.

A study by Genaidy et al. (1998) estimated the amounts of loads of different levels of load heaviness. In the study, 20 males and 20 females, estimated the most representative amount of load that can be assigned to different load heaviness defined in accordance with the Borg Scale. The distribution of loads within each heaviness levels was developed using a fuzzy sets theory. The information was collected in a survey form, with 10 questions, since there were 10 different levels of load heaviness. A typical question formulated was "What is the amount of load in kg which you consider as most representative for a given heaviness level?". Then analysis of variance to study the gender and load heaviness was used. In their study it was found that there was no difference between males and females for the data of "negligible" to "somewhat heavy", but there was a difference between males and females data from "heavy" to "maximum" levels.

Nindl et al. (1998) compared the peak physiological responses of men and women during repetitive lifting and treadmill running. Twenty females and 20 males participated in the study. Treadmill was used at three different intensities based on inclination, and repetitive lifting from floor to $1.32 \mathrm{~m}$ at for three different sets of lifting where boxes were changed by increasing weight for men and women. Results showed that men achieved greater values than women for the peak oxygen uptake, but no difference for heart rate.

In a study by Marras et al. (2000), loading and musculoskeletal control strategies between men and women performing lifts of varying task complexity was studied. One hundred and forty subjects, divided in two groups of 35 men and 35 women each, participated in the study, using different degrees of musculoskeletal motion control during sagittal plane lifting. First group used lifts in which motion was isolated to the torso, examining trunk mechanics above $L_{5} / S_{1}$, and second group completed whole-body freedynamic whole body lift, permitting movement of pelvis and legs. Electromyography was 
used evaluate spine loading under both conditions. It was concluded from their study, that men had greater absolute spine compression and the difference was attributed to body mass (under isolated torso). Under whole-body free style, significant difference in muscle activations resulted in greater relative compression and anterior posterior shear spine loading for women.

Karwowski (1991) studied subjective perception of load heaviness in MMH in 10 females, and compared the weights of 7 boxes associated with 7 specific categories of load heaviness to the maximum acceptable weights of lift determined using psychophysical approach. He also compared results of male subjects made previously by the same author. To achieve objectives, the study was performed in 3 stages. In the first stage, subjects had to classified 7 pre-weighted boxes $(2.3,4.5,6.8,11.3,15.9,18.2$ and $20.4 \mathrm{~kg})$ using 7 linguistic values describing load heaviness (very light, light, less-than-medium, medium, more-than-medium, heavy and very heavy. The second stage consisted of selection of loads that corresponded to the given linguistic category of load heaviness and the third stage consisted of the determination of the maximum acceptable weights of loads using psychophysical approach. From his study and the previous study from the author, it was concluded that females are better judges than males at estimating the weight of the load they could safely lift based on the psychophysical methodology.

Findings regarding gender have not been consistent; some have found women at greater risk than men and some men at greater risk than women (Treaster and Burr, 2004). Authors reviewed literature to determine the strength that women experience higher prevalence of Upper Extremity Musculoskeletal Disorders (UEMSD) than men. Fifty six articles were reviewed for gender differences in frequency, incidence or prevalence rated of UEMSD. Majority of the articles showed that women had significantly higher incidences of various types of UEMSD than men.

Gender has a distinctive influence on psychophysical handling capacity. Mital et al. (1997) stated that a female's lifting strength has an average of $60-76 \%$ of a male's lifting strength. Authors also agree that gender is a factor that divides population into two major 
groups, since the primary difference attribute is the muscle strength; in addition biomechanical linkage mechanism capacities differ between male and females.

Lindbeck, and Kjellberg, (2001) revealed significant differences between men and women in some lifting parameters making it logical to assume that movement patterns and the performance of a lift may be associated with gender. In their research, they studied whether gender differences in lifting techniques could be detected from position time-data. Ten males and 12 females were instructed to lift a box with handles, using 2 methods, squat or leg with fixed legs and stoop or back lift with straight legs, at two velocities, for a total of 4 different lifts.

Other authors such as Snook and Ciriello (1991) showed gender differences for other types of Manual Material Handling tasks. Therefore, psychophysical data should be developed for males and females independently, and workplace assessments must take this issue into account.

Related with age factor, Ayoub and Dempsey (1999) gave an overview of the psychophysical approach to Manual Material Handling. In this study, authors reviewed a series of papers and studied them from a psychophysical viewpoint. One the factors studied was age, and authors found variable results regarding this factor.

Mital et al. (1997) indicated that manual lifting capacity does not decline with age, but it is well known that with aging physical work capacities, range of lumbar spinal motion, muscle strength, muscle contraction speed, shock absorbing characteristics of the lumbar disc, intra-abdominal pressure, load supporting capacity of the spine and aerobic capacities decline.

Finally, the effect of age in epidemiological studies of low-back disorders has been somewhat variable. Mital et al. (1997) propose that workers over 50 years of age should not be allocated into physically demanding jobs, and take care of age as a possible risk factor for Manual Material Handling related injuries. 
Roth et al. (2001) examined the possible influences of age and gender on muscle volume responses to strength training (ST). Four different groups of people participated in the research, 8 young men, 6 young women, 9 old men and 10 old women. Strength training was programmed during 6 months, 3 day a week, to exercise all major groups of upper and lower body for all participants. Thigh and quadriceps muscles volumes and mid-thigh muscle cross- sectional area using magnetic resonance images before and after the strength program were measured. Outcomes of the study revealed that muscle volume for thigh and quadriceps increases significantly in all ages and gender, but no significant difference between the groups of age or gender affect muscle volume responses to whole body strength training.

Since NIOSH WPG (1981) and NLE (1991), avoid age and gender factors for the estimation of the $\mathrm{AL}$ or the RWL, more studies must be made to observe if difference exist among age and gender, for selection of workers for specific activities. The NIOSH equations were intended to avoid gender, age or fitness-based recommended weight limits proper to consideration of the Equal Employment Opportunity legislation and the Americans with Disabilities Act (Hidalgo et al., 1997).

Before the execution of the job, the person should be able to recognize the hazard of tasks by simply looking at the job to be performed. The perception of injury risk will depend on different factors at the moment the task is performed, and this is the reason why workers are frequently advised to seek assistance of mechanical aids and/or help from other fellow workers when they perceived that the task is to demanding (Genaidy et al., 1998).

Michalsen (2003) denoted risk as an individual's perception of the likelihood and the seriousness of an undesirable event. Individual perception seems to be strongly affected by personal traits and socio-cultural parameters. Before risk can be deal with, it must be identified, characterized and quantified. Human judgment is not only based on evidence, but also on experience and anecdotal knowledge such as education, experience, habitats, political orientations, beliefs and values. Understanding and influencing the individual perception may help to prevent the manifestation of the risk under consideration. Attempt to 
avoid diseases and injuries need to include the factor influencing the risk perception of the people targeted for intervention.

A number of authors have studied the effect of perception of risk of injury from different stand points. For example Engst et al. (2005) assessed the perception of risk of injury, job satisfaction and preferred patients handling methods. They assessed the frequency and type of resident handling injuries. Ceiling lift devices were installed in 75 beds in a community hospital, and a similar hospital was used as a comparison unit. A questionnaire was administrated before and after installation of the ceiling lift. Thirty four staff members participated in the unit with the ceiling lifts devices and 16 staff members in the comparison unit. The questionnaire was designed to provide information on staff perception of risk of injury using (0-10 scale), preferred methods of resident transfer and reposition (5 point Likert Scale), frequency of performing designated resident handling tasks (rank order), presence of any discomfort (0-10 scale), work organization and staff satisfaction (5 point Likert Scale). Results showed a significant decrease in the perceived risk of injury to the neck, shoulders, lower back, arms/hands when transferring residents using a ceiling lift compared to other methods. Overhead ceiling devices were found not to be beneficial in reducing the perceived risk of injury and discomfort.

Daraiseh et al. (2003) investigated the association between working conditions, intermediate work effects and psychosomatic outcomes and the onset of musculoskeletal disorders. Authors tested the hypothesis that working conditions influence the effort applied by nurses, perceived risk of injury, work satisfaction, work dissatisfaction, energy state at the end of work, psychosomatic outcomes and musculoskeletal symptoms. Thirty four nurses participated in the study. Work demand and work stimulus were the principal working condition for the nurses. Work demand was defined as "the various requirements of the workplace (including the work place environment) that place burdens on the nurses requiring the use of muscular, mental and emotional energy" and was divided into 6 categories: physical, mental, sensory, physical environmental, social and organizational demands. Work stimulus was defined as "the characteristic of work environment that encourages the nurses to attain successful and high quality job performance". Work 
stimulus was divided in two categories: social and organizational. A comprehensive questionnaire was used to assess the exposure and outcome measures, and had a week to complete the questionnaire.

The demands and stimulus were rated using an 8 point scale: "0"-negligible, "1"- very low, "2"-low, "3"-somewhat low, "4"-moderate, "5"-somewhat high, "6"-high and "7"-very high. Results showed perceived risk of injury was correlated with task as well as physicalorganizational environment demands positively, and it was negatively correlated with social stimuli. Stressful working conditions affect musculoskeletal effects in multiple body regions and that physical problems like the lower back are not only associated with physical factors but also with complex relations of working conditions.

Huang et al. (2003), evaluated the relationship between employment status (full-time and part-time employees) and job satisfaction with the focus of the roles of perceived risk of injury prior to injury incidence. In this study, a total of 1607 employees from 13 shipping and transportation companies participated in the study. In a survey, demographic data, prior injury incident, perceived risk of injury and job satisfaction was collected.

Prior incidence was assessed as yes or no answers to the question: "As an employee of this company, have you ever had a work-related injury?". Perceived risk of injury was measured by a 6 point scale from Strongly agree to Strongly disagree from the following statement: "I think there is a good chance I will get Injured on the job" and job satisfaction was measured in a 6 point scale from Strongly agree to Strongly disagree from the statement "I like working for this company and expect to be working here longer than two years from now and I recommend this company as an employee I know".

Results demonstrated a negative relation between job satisfaction and injury incidence and perceived risk of injury. Part time employees reported lower perceived risk of injury and fewer injury incidences when compared to full time employees. Interaction between work status and perception of risk of injury was significant. Conclusion from the 
work stated that a safe work environment is associated with positive job satisfaction, which results in an improvement in performance.

A study was conducted by Yeung. et al. (2002) to asses the physical effort and perceived risk in $\mathrm{MMH}$, using a linguistic approach to quantify the effects of lifting task characteristics based on the revised NIOSH lifting equation parameters with the knowledge of three experts. Each lifting task variable had 5 to 6 linguistic descriptors for a total of 16,250 different lifting tasks. Three experts evaluated the effects of lifting task parameters on physical effort and perceived risk of injury by the use of Borg's scale ("nothing at all", "very very low", "very low". "low", "moderate", "somewhat high", "high", "very high", "very very high" and "maximum"). The results demonstrated that the weight of the load is the most dominant variable and the height of lift is the least important variable. Results demonstrated that an increase in perceived physical effort was associated with an increase in perceived risk of injury.

In another research by Yeung et al. (2003), researchers tried to determine the different cognitive strategies adopted by working in assessing the effect of lifting task parameters on effort and to validate workers assessment. In this study a total of 217 male workers completed a 3 phase study. In the first stage, workers assessed the effects of lifting parameters ( 3 weight $X 3$ horizontal distances $X 3$ vertical travel distance $X 3$ twisting angle $X 2$ vertical distance) for a total of 162 different lifting tasks assuming a negligible frequency and low work duration, on perceived physical effort and using linguistic descriptor (e.g. light, heavy) and quantified the physical meaning of such descriptors. In the second stage, workers assessed on-the-job perceived effort, perceived risk of injury and work dissatisfaction, and the determination of musculoskeletal outcomes in a cross-sectional design, and finally in the third stage, worker demographic and behavioral data were collected. The assessment of workers was cross validated with the Biomechanical lifting equivalent (BLE) and the $\mathrm{NIOSH}$ lifting equation (LI).

Results showed perceived physical effort was significantly associated with lifting variables; effort increased with an increase of the lifting factors. Also three-cluster strategy 
was performed and found that weight of the load is the most important factor. In the second cluster horizontal distance, weight, and twisting angle were found not to be the most important and in the third cluster weight and travel distance were most important.

Yeung et al. (2002) tested the human knowledge in the evaluation of manual lifting tasks, specifically to document the test-retest reliability of subjects in the evaluation of manual material lifting tasks and to validate self-report with the Revised NIOSH lifting equation. Six males and 4 females from Hong Kong participated in the study. In a first stage, by the use of a questionnaire, subjects assessed the effects of 5 lifting variables (weight of load, horizontal distance, vertical distance, travel distance and twisting angle) upon perceived physical effort (PPE) and perceived risk of lifting injury (PRLI), and in the second stage to map the physical meaning of the lifting descriptors on a scale in which subjects were $100 \%$ sure that correspond to the linguistic descriptor. After one week, subjects repeated the exact study. Subjects were asked mentally to imagine lifting conditions wit the 5 variables (using three different linguistic descriptor for each variable except vertical distance which had 2 linguistic descriptors) resulting in 162 lifting conditions.

Perceived physical effort and PRLI were measured by "very very low", "very low", "low", "moderate", "high", "very high" and "very very high" descriptors. Results revealed that evaluators were more certain and consistent on the effects of risk parameters in the high ends relative to the low levels of lifting variables. Participants showed a good degree of reliability in assessing PRLI as a function of PPE between the two trials, showing that PRLI is higher than PPE. There was a linear increment of the Lifting Index (LI) from the Revised $\mathrm{NIOSH}$ lifting equation with PPE, and LI was almost the same between very very low and very low PRLI and a rapid increase in the LI from very low to low.

Genaidy et al. (1998) expressed that for Manual Material Handling, workers should be aware of the load before actually handling it. If they consider the load to be heavy, they should seek help by the use of mechanical aids or use of co-workers, but limited knowledge about perception of load heaviness is available. It could be the same case scenario for the perceived risk of injury of tasks; because not just the load can make a task harmful, also the 
geometry of the lifting tasks can increase the risk. If people are able to recognize the risk of injury before actually perform the task, they can seek the help of mechanical aids or coworkers to help reduce the risk of injury.

The aim of this study is to evaluate if there is a mismatch between the Job Severity Index and the perceived risk of injury by the subjects to find if this mismatch can generate a risk for people at the time of performing lifting tasks. 


\section{CHAPTER 3}

\section{METHODS}

\section{PROTECTION OF THE HUMAN SUBJECTS}

To protect the rights and welfare of the subjects, the study protocol, Appendix 1, was submitted to the West Virginia University Institutional Review Board (IRB). Once the protocol was approved, subjects were recruited around West Virginia University to fill out the questionnaire. Students and workers from the University participated voluntarily. By completing the questionnaire, participants joined to win a prize of $\$ 100$. Personal e-mail addresses were asked for further contact. Beyond sitting in front of a computer for approximately 20 minutes while concentrating on the tasks, subjects faced no physical risks, emotional or social discomfort for participating in this study. Subjects had a code number for use on their response questionnaire and their data were kept confidential with no means to link the data to them.

Subjects read and signed the consent form prior to filling the questionnaire. Participants were able to read the purpose of the study, researcher information, the effort required, payment, confidentiality of data, benefits and risk of discomfort. Once the subject read the consent form, the subject and researcher proceed to sign two copies of the consent form, one for each one. Appendix 2 shows the informed consent given to participants.

\section{METHODS FOR CREATION OF THE QUESTIONNAIRES}

SurveyGold is a simple program used to create surveys for different purposes, and an easy way to administrate the survey among participants for further analysis and interpretation of results. The aforementioned program was used for the design of the questionnaire in which two sections were created. The first section included demographic data of the participants such as the age, gender, weight, stature, as well as questions 
regarding their formal education, back injuries and training in safe lifting techniques. The second section corresponded to the responses of the perceived level of risk of injury of the tasks, in which a rank from 0 to 10 has to be chosen, 0 being no risk and 10 the maximum risk of injury perceived from the tasks. See Appendix 3 for a copy of the questionnaire.

A total of 54 lifting tasks were shown as pictures on the questionnaire. These 54 picture tasks were originated by creating interactions among three levels for the factors of horizontal distance $(H)$, vertical distance $(V)$, frequency of lift $(F)$ and two levels of travel distance (D). In essence, the procedure requires the subjects to imagine lifting the load shown in a specified working basis to asses the risk of injury of the tasks.

Pictures were taken all in the same room to assure the same illumination for all the pictures. The camera was mounted on a tripod and set at a distance of $4.6 \mathrm{~m}$ from the midpoint of the box and at a height of $1.54 \mathrm{~m}$ from the floor, for front and side view shots.

A regular carton box with a rectangular shape of $36 \times 22 \times 26 \mathrm{~cm}$ (width, height and depth, respectively) with good couple handle, usually as those found in warehouse environments, was used to create the pictures. Handles were placed at $16 \mathrm{~cm}$ from the bottom of the box. Weight of the box was set at $20 \mathrm{~kg}$ (44 lbs) for the computation of the expected Job Severity Index for the NIOSH Work Practice Guide.

On the pictures, two boxes with the same characteristics were presented, one blue and one yellow box, to represent the start and end positions, respectively. Feet marks on the floor represent the place in which the person needs to stand for each specific task, to assure subjects stand at a distance required to study the horizontal distance factor.

The values of $\mathrm{V}, \mathrm{H}$ and $\mathrm{F}$ were varied at three levels (low, medium and high) and $\mathrm{D}$ at two levels (low and high) based on the NIOSH WPG (1981) lifting equation range availability and geometry of the box used. It was expected to find a big difference among the levels used to cover a wider range of values. Criteria used for selection of levels for each factor were: 
- Vertical distance $(\mathrm{V})$ : values were set based on the handle of the box which is situated at a height of $16 \mathrm{~cm}$ to be carried for a person, the height of the handle will be the low vertical distance and maximum value for $V$ was $150 \mathrm{~cm}$. A medium point was set at $83 \mathrm{~cm}$.

- Travel distance (D): values chosen for this factor are $25 \mathrm{~cm}$ since this is the minimum allowed by NIOSH WPG 1981 WPG and $75 \mathrm{~cm}$ to have a wider range. Notice that the maximum value allowed by NIOSH WPG (1981) for $D$ is selected based on the $V, D=(200-$ V) $\mathrm{cm}$. The maximum value for $V$ was set at $150 \mathrm{~cm}$, consequently maximum value for $D$ should be $50 \mathrm{~cm}$. A value of $75 \mathrm{~cm}$ was selected to have a wider range and to have more difference between low and high values for this factor. Also tasks are presented as pictures; therefore subjects were not facing any risk.

- Horizontal distance $(\mathrm{H})$ : values were also based on the geometry of the box. The depth of the box is $26 \mathrm{~cm}$ and based on the place of the handle and the midpoint between the ankles, a minimum distance for the $\mathrm{H}$ was $40 \mathrm{~cm}$. The maximum value allowed for this factor is $80 \mathrm{~cm}$, and utilized as the high level; medium point was established at $60 \mathrm{~cm}$.

- Frequency of the lift $(F)$ : values chosen were based on a 1 hour work period, with a minimum lift of 1 lift every 5 minutes ( 0.2 lifts/min), minimum allowed by NIOSH WPG (1981), and maximum lift of 5 lifts/min, medium point was selected at 2 lifts/min.

Table 3 illustrates the computation of the Job Severity Index (JSI) using Equation 3 for each of the 54 tasks generated for further comparison among subjects' responses and the actual risk of the tasks based on NIOSH WPG (1981). The range of risk by the Job Severity Index equation gives results between 1.39 and 6.59 . 
Table 3. Job Severity Index for each task generated based on NIOSH WPG (1981) equation and used in the questionnaire.

\begin{tabular}{|c|c|c|c|c|c|c|c|c|}
\hline $\mathrm{H}(\mathrm{cm})$ & $V(\mathrm{~cm})$ & $\begin{array}{c}\mathbf{F} \\
\text { (lifts/min) }\end{array}$ & $D(\mathrm{~cm})$ & HFM & VFM & DFM & FFM & $\begin{array}{l}\text { Job Severity } \\
\text { Index }\end{array}$ \\
\hline 80 & 83 & 5 & 75 & 0.19 & 0.97 & 0.80 & 0.72 & 4.77 \\
\hline 40 & 150 & 0.2 & 25 & 0.38 & 0.70 & 1.00 & 0.99 & 1.93 \\
\hline 60 & 83 & 5 & 25 & 0.25 & 0.97 & 1.00 & 0.72 & 2.86 \\
\hline 80 & 16 & 5 & 75 & 0.19 & 0.76 & 0.80 & 0.67 & 6.54 \\
\hline 80 & 150 & 2 & 75 & 0.19 & 0.70 & 0.80 & 0.89 & 5.36 \\
\hline 80 & 150 & 0.2 & 25 & 0.19 & 0.70 & 1.00 & 0.99 & 3.85 \\
\hline 80 & 150 & 5 & 25 & 0.19 & 0.70 & 1.00 & 0.72 & 5.27 \\
\hline 80 & 150 & 0.2 & 75 & 0.19 & 0.70 & 0.80 & 0.99 & 4.82 \\
\hline 40 & 150 & 5 & 75 & 0.38 & 0.70 & 0.80 & 0.72 & 3.30 \\
\hline 60 & 150 & 0.2 & 75 & 0.25 & 0.70 & 0.80 & 0.99 & 3.61 \\
\hline 60 & 16 & 5 & 75 & 0.25 & 0.76 & 0.80 & 0.67 & 4.91 \\
\hline 80 & 16 & 5 & 25 & 0.19 & 0.76 & 1.00 & 0.67 & 5.24 \\
\hline 80 & 83 & 2 & 75 & 0.19 & 0.97 & 0.80 & 0.89 & 3.87 \\
\hline 60 & 150 & 0.2 & 25 & 0.25 & 0.70 & 1.00 & 0.99 & 2.89 \\
\hline 80 & 83 & 0.2 & 75 & 0.19 & 0.97 & 0.80 & 0.99 & 3.48 \\
\hline 40 & 83 & 2 & 25 & 0.38 & 0.97 & 1.00 & 0.89 & 1.55 \\
\hline 60 & 150 & 2 & 75 & 0.25 & 0.70 & 0.80 & 0.89 & 4.02 \\
\hline 40 & 83 & 5 & 25 & 0.38 & 0.97 & 1.00 & 0.72 & 1.91 \\
\hline 60 & 150 & 2 & 25 & 0.25 & 0.70 & 1.00 & 0.89 & 3.21 \\
\hline 60 & 16 & 2 & 25 & 0.25 & 0.76 & 1.00 & 0.87 & 3.02 \\
\hline 80 & 83 & 0.2 & 25 & 0.19 & 0.97 & 1.00 & 0.99 & 2.79 \\
\hline 40 & 83 & 2 & 75 & 0.38 & 0.97 & 0.80 & 0.89 & 1.94 \\
\hline 60 & 16 & 0.2 & 75 & 0.25 & 0.76 & 0.80 & 0.99 & 3.32 \\
\hline 60 & 83 & 0.2 & 25 & 0.25 & 0.97 & 1.00 & 0.99 & 2.09 \\
\hline 40 & 150 & 2 & 75 & 0.38 & 0.70 & 0.80 & 0.89 & 2.68 \\
\hline 80 & 16 & 2 & 25 & 0.19 & 0.76 & 1.00 & 0.87 & 4.03 \\
\hline 40 & 150 & 0.2 & 75 & 0.38 & 0.70 & 0.80 & 0.99 & 2.41 \\
\hline 40 & 150 & 5 & 25 & 0.38 & 0.70 & 1.00 & 0.72 & 2.64 \\
\hline 80 & 150 & 5 & 75 & 0.19 & 0.70 & 0.80 & 0.72 & 6.59 \\
\hline 40 & 16 & 5 & 75 & 0.38 & 0.76 & 0.80 & 0.67 & 3.27 \\
\hline 40 & 83 & 0.2 & 25 & 0.38 & 0.97 & 1.00 & 0.99 & 1.39 \\
\hline 40 & 83 & 0.2 & 75 & 0.38 & 0.97 & 0.80 & 0.99 & 1.74 \\
\hline 60 & 16 & 0.2 & 25 & 0.25 & 0.76 & 1.00 & 0.99 & 2.65 \\
\hline 40 & 16 & 2 & 75 & 0.38 & 0.76 & 0.80 & 0.87 & 2.52 \\
\hline 60 & 83 & 0.2 & 75 & 0.25 & 0.97 & 0.80 & 0.99 & 2.61 \\
\hline 80 & 16 & 0.2 & 25 & 0.19 & 0.76 & 1.00 & 0.99 & 3.54 \\
\hline 60 & 150 & 5 & 25 & 0.25 & 0.70 & 1.00 & 0.72 & 3.96 \\
\hline 40 & 16 & 0.2 & 75 & 0.38 & 0.76 & 0.80 & 0.99 & 2.21 \\
\hline 40 & 150 & 2 & 25 & 0.38 & 0.70 & 1.00 & 0.89 & 2.14 \\
\hline 80 & 83 & 5 & 25 & 0.19 & 0.97 & 1.00 & 0.72 & 3.81 \\
\hline 80 & 83 & 2 & 25 & 0.19 & 0.97 & 1.00 & 0.89 & 3.10 \\
\hline 60 & 16 & 2 & 75 & 0.25 & 0.76 & 0.80 & 0.87 & 3.78 \\
\hline 60 & 16 & 5 & 25 & 0.25 & 0.76 & 1.00 & 0.67 & 3.93 \\
\hline 80 & 16 & 2 & 75 & 0.19 & 0.76 & 0.80 & 0.87 & 5.03 \\
\hline 40 & 16 & 5 & 25 & 0.38 & 0.76 & 1.00 & $\begin{array}{l}0.67 \\
\end{array}$ & 2.62 \\
\hline 80 & 16 & 0.2 & 75 & 0.19 & 0.76 & 0.80 & 0.99 & 4.42 \\
\hline 60 & 83 & 5 & 75 & 0.25 & 0.97 & 0.80 & 0.72 & 3.58 \\
\hline 40 & 16 & 0.2 & 25 & 0.38 & 0.76 & 1.00 & 0.99 & 1.77 \\
\hline 80 & 150 & 2 & 25 & 0.19 & 0.70 & 1.00 & 0.89 & 4.29 \\
\hline 60 & 150 & 5 & 75 & 0.25 & 0.70 & 0.80 & 0.72 & 4.95 \\
\hline 40 & 83 & 5 & 75 & 0.38 & 0.97 & 0.80 & 0.72 & 2.38 \\
\hline 40 & 16 & 2 & 25 & 0.38 & 0.76 & 1.00 & 0.87 & 2.01 \\
\hline 60 & 83 & 2 & 75 & 0.25 & 0.97 & 0.80 & 0.89 & 2.91 \\
\hline 60 & 83 & 2 & 25 & 0.25 & 0.97 & 1.00 & 0.89 & 2.32 \\
\hline
\end{tabular}




\section{PROCEDURES}

Participants will read and sign the consent form to know the purpose of the study. After questions and explanation of the study, subjects will start filling the first part of the questionnaire corresponding to their demographic data and e-mails addresses for further contact in case they are selected for the prize of $\$ 100$. Subsequently, instructions on how to interpret the pictures are given and also an example is shown for better understanding, Figure 6 shows the example shown in the questionnaire (Appendix 3). Instruction states as follows:

"Assume that you have to perform the lifting task shown in each case scenario. Two views are presented in each case, front and side view. You are asked to rank the risk of injury of the task $(0=$ no risk of injury to10=maximum risk of injury) by imagining yourself lifting the blue box (start position) and moving it to the exact position of the yellow box (end position). The blue box is the real box to be lifted; the yellow box is just to represent the final position. You are supposed to stand on the black feet marks placed on the floor and lift the box by its handle. The frequency represents the number of repetitions for the same activity that you have to perform in each case. Notice that the frequency of the task, and feet marks change from case to case. The weight of the blue box is $20 \mathrm{Kg}$. (44 lbs.).”

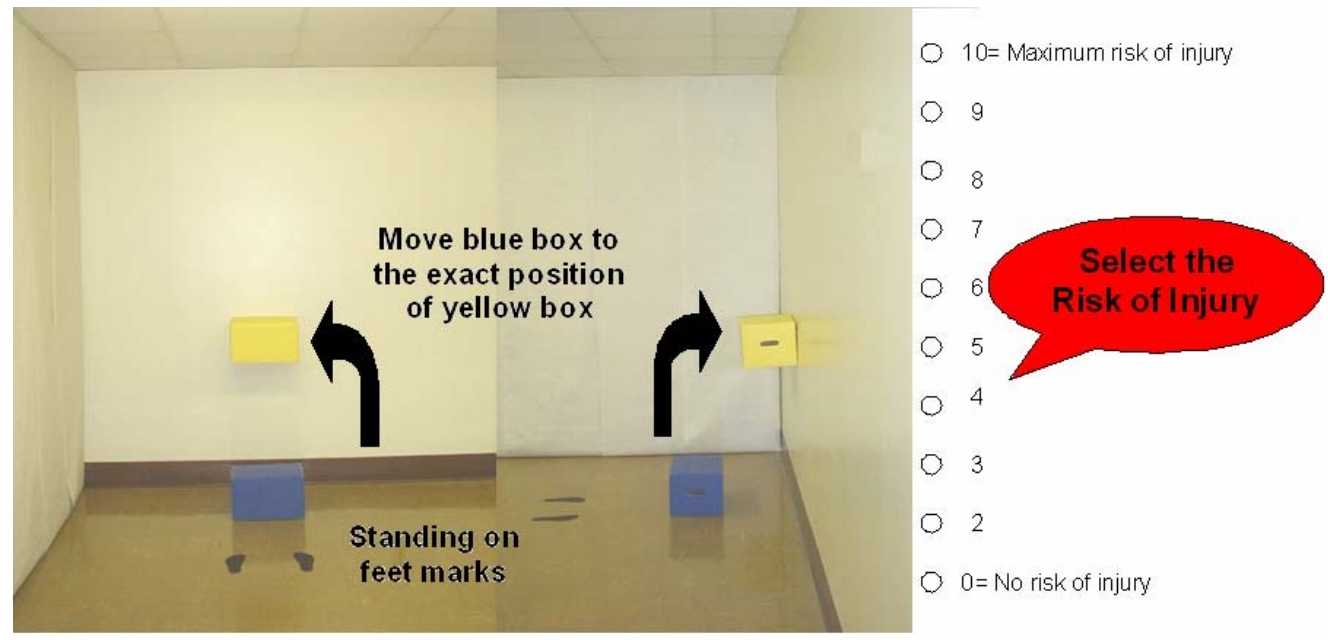

BLUE BOX=20 Kg. (44 lbs.)

12 LIFTS PER HOUR

Figure 6. Picture example of how to interpret instruction on the questionnaire. 
Data obtained from the questionnaire will be entered into the Statistical Package SPSS PC program version 11.0 for further study. A comparison will be made on the actual risk (Job Severity Index) and the results obtained from subjects on their perceived risk of injury.

Job Severity Index will be plotted against the risk of injury perceived by people. It should be expected to see a perfect relation between these two factors, but instead it is believed that people are not able to recognize the risk of injury in lifting tasks.

A complete randomized block design fixed-effect Analysis of Variance (ANOVA) will be performed to analyze the effects of gender, age, lifting geometry elements and frequency on the Risk of Injury (dependent variable). Subjects were treated as blocks, since random order for the lifting tasks was created for each subject in their questionnaires. The outcome of this analysis will provide an understanding of the effects of the various input parameters on the perceived risk associated with the performance of industrial or recreational lifting activities. The model with 6 variables is expressed in Table 4. The six factors are Horizontal distance $(H)$, Vertical distance $(V)$, Travel distance $(D)$, frequency of lift $(F)$, gender $(G)$ and age $(A)$. 
Table 4. Complete randomized fixed effect with 4 lifting task variables and 2 subject variables.

\begin{tabular}{|c|c|c|c|c|}
\hline \multirow{18}{*}{$\mathrm{H}_{1}=40 \mathrm{~cm}$} & \multirow{6}{*}{$V_{1}=16 \mathrm{~cm}$} & \multirow{2}{*}{$F_{1}=0.2 \mathrm{lifts} / \mathrm{min}$} & $D_{1}=25 \mathrm{~cm}$ & \\
\hline & & & $D_{2}=75 \mathrm{~cm}$ & \\
\hline & & \multirow{2}{*}{$F_{2}=2$ lifts $/ \mathrm{min}$} & $D_{1}=25 \mathrm{~cm}$ & \\
\hline & & & $D_{2}=75 \mathrm{~cm}$ & \\
\hline & & \multirow{2}{*}{$F_{3}=5$ lifts $/ \mathrm{min}$} & $D_{1}=25 \mathrm{~cm}$ & \\
\hline & & & $D_{2}=75 \mathrm{~cm}$ & \\
\hline & \multirow{6}{*}{$V_{2}=83 \mathrm{~cm}$} & \multirow{2}{*}{$\mathrm{F}_{1}=0.2 \mathrm{lifts} / \mathrm{min}$} & $D_{1}=25 \mathrm{~cm}$ & \\
\hline & & & $D_{2}=75 \mathrm{~cm}$ & \\
\hline & & \multirow{2}{*}{$F_{2}=2$ lifts $/ \mathrm{min}$} & $D_{1}=25 \mathrm{~cm}$ & \\
\hline & & & $D_{2}=75 \mathrm{~cm}$ & \\
\hline & & \multirow{2}{*}{$F_{3}=5$ lifts $/ \mathrm{min}$} & $D_{1}=25 \mathrm{~cm}$ & \\
\hline & & & $D_{2}=75 \mathrm{~cm}$ & \\
\hline & \multirow{6}{*}{$V_{3}=150 \mathrm{~cm}$} & \multirow{2}{*}{$F_{1}=0.2 \mathrm{lifts} / \mathrm{min}$} & $D_{1}=25 \mathrm{~cm}$ & \\
\hline & & & $D_{2}=75 \mathrm{~cm}$ & \\
\hline & & \multirow{2}{*}{$F_{2}=2$ lifts $/ \mathrm{min}$} & $D_{1}=25 \mathrm{~cm}$ & \\
\hline & & & $D_{2}=75 \mathrm{~cm}$ & \\
\hline & & \multirow{2}{*}{$F_{3}=5$ lifts $/ \mathrm{min}$} & $D_{1}=25 \mathrm{~cm}$ & \\
\hline & & & $D_{2}=75 \mathrm{~cm}$ & \\
\hline \multirow{18}{*}{$\mathrm{H}_{2}=60 \mathrm{~cm}$} & \multirow{6}{*}{$V_{1}=16 \mathrm{~cm}$} & \multirow{2}{*}{$F_{1}=0.2 \mathrm{lifts} / \mathrm{min}$} & $D_{1}=25 \mathrm{~cm}$ & \\
\hline & & & $D_{2}=75 \mathrm{~cm}$ & \\
\hline & & \multirow{2}{*}{$F_{2}=2$ lifts $/ \mathrm{min}$} & $D_{1}=25 \mathrm{~cm}$ & ธง \\
\hline & & & $D_{2}=75 \mathrm{~cm}$ & ర్ \\
\hline & & \multirow{2}{*}{$F_{3}=5$ lifts $/ \mathrm{min}$} & $D_{1}=25 \mathrm{~cm}$ & $\frac{c}{0}$ \\
\hline & & & $D_{2}=75 \mathrm{~cm}$ & லั \\
\hline & \multirow{6}{*}{$V_{2}=83 \mathrm{~cm}$} & \multirow{2}{*}{$\mathrm{F}_{1}=0.2 \mathrm{lifts} / \mathrm{min}$} & $D_{1}=25 \mathrm{~cm}$ & $\pi$ \\
\hline & & & $\mathrm{D}_{2}=75 \mathrm{~cm}$ & E \\
\hline & & & $\mathrm{D}_{1}=25 \mathrm{~cm}$ & $\bar{\sigma}$ \\
\hline & & $\mathrm{r}_{2}=2 \mathrm{lifts} / \mathrm{mIn}$ & $D_{2}=75 \mathrm{~cm}$ & Ð \\
\hline & & & $\mathrm{D}_{1}=25 \mathrm{~cm}$ & 우 \\
\hline & & $r_{3}=5 \mathrm{lits} / \mathrm{mIn}$ & $\mathrm{D}_{2}=75 \mathrm{~cm}$ & 3 \\
\hline & & $\mathrm{F}_{1}=02 \mathrm{lifts} / \mathrm{min}$ & $D_{1}=25 \mathrm{~cm}$ & $t$ \\
\hline & & $\mathrm{r}_{1}=0.2 \mathrm{IITS} / \mathrm{mIn}$ & $D_{2}=75 \mathrm{~cm}$ & 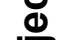 \\
\hline & & & $D_{1}=25 \mathrm{~cm}$ & 으 \\
\hline & $v_{3}=150 \mathrm{~cm}$ & $\mathrm{r}_{2}=2 \mathrm{lifts} / \mathrm{mIn}$ & $D_{2}=75 \mathrm{~cm}$ & \\
\hline & & & $D_{1}=25 \mathrm{~cm}$ & \\
\hline & & $r_{3}=5 \mathrm{lits} / \mathrm{mIn}$ & $\mathrm{D}_{2}=75 \mathrm{~cm}$ & \\
\hline & & $\mathrm{F}_{1}=02 \mathrm{lifts} / \mathrm{min}$ & $D_{1}=25 \mathrm{~cm}$ & \\
\hline & & $r_{1}=0.2 \mathrm{IIts} / \mathrm{mIn}$ & $\mathrm{D}_{2}=75 \mathrm{~cm}$ & \\
\hline & & & $D_{1}=25 \mathrm{~cm}$ & \\
\hline & $V_{1}=16 \mathrm{~cm}$ & $F_{2}=2$ lifts $/ \mathrm{min}$ & $\mathrm{D}_{2}=75 \mathrm{~cm}$ & \\
\hline & & $F_{3}=5 \mathrm{lifts} / \mathrm{min}$ & $D_{1}=25 \mathrm{~cm}$ & \\
\hline & & $r_{3}=5 \mathrm{llts} / \mathrm{mIn}$ & $\mathrm{D}_{2}=75 \mathrm{~cm}$ & \\
\hline & & $\mathrm{F}=02$ lifts $/ \mathrm{min}$ & $D_{1}=25 \mathrm{~cm}$ & \\
\hline & & $r_{1}=0.2 \mathrm{IITS} / \mathrm{mIn}$ & $\mathrm{D}_{2}=75 \mathrm{~cm}$ & \\
\hline & & & $\mathrm{D}_{1}=25 \mathrm{~cm}$ & \\
\hline $\mathrm{H}_{3}=80 \mathrm{~cm}$ & $v_{2}=83 \mathrm{~cm}$ & $F_{2}=2$ lifts $/ \mathrm{min}$ & $\mathrm{D}_{2}=75 \mathrm{~cm}$ & \\
\hline & & $F_{3}=5 \mathrm{lifts} / \mathrm{min}$ & $D_{1}=25 \mathrm{~cm}$ & \\
\hline & & $r_{3}=5 \mathrm{llts} / \mathrm{min}$ & $\mathrm{D}_{2}=75 \mathrm{~cm}$ & \\
\hline & & $F_{1}=02$ lifts $/ \mathrm{min}$ & $D_{1}=25 \mathrm{~cm}$ & \\
\hline & & $r_{1}=0.2 \mathrm{IITS} / \mathrm{mIn}$ & $\mathrm{D}_{2}=75 \mathrm{~cm}$ & \\
\hline & & & $D_{1}=25 \mathrm{~cm}$ & \\
\hline & $v_{3}=150 \mathrm{~cm}$ & $r_{2}=211 \mathrm{fts} / \mathrm{mIn}$ & $\mathrm{D}_{2}=75 \mathrm{~cm}$ & \\
\hline & & & $D_{1}=25 \mathrm{~cm}$ & \\
\hline & & $r_{3}=511 \mathrm{ts} / \mathrm{mIn}$ & $\mathrm{D}_{2}=75 \mathrm{~cm}$ & \\
\hline
\end{tabular}




\section{DETERMINING SAMPLE SIZE}

Statistical power for results of the study was analyzed as the study progressed. Once the desired power was achieved, recruitment of subjects was ended. The appropriate sample size was determined with a conservative estimate of the non-centrality parameter for the worst case of the three way interactions (Equation 4). Worst case scenario is the one obtained from the interaction of horizontal distance, vertical distance and frequency of lifts, all these factors at 3 levels each.

$$
\phi^{2}=\frac{n l m p S^{2}}{2[(i-1)(j-1)(k-1)+1] \sigma^{2}}
$$

Where $\varnothing^{2}$ is an estimate of non-centrality, $\mathrm{n}$ is the number of replicates, $\mathrm{S}$ is the desired effect size of the response variable, $i, j$ and $k$ are the number of levels for the factors with more levels to be analyzed (horizontal distance, vertical distance and frequency of lift, respectively, and all at 3 levels); I, $m$ and $p$ are the number of levels for factors of travel distance, age and gender, respectively and all at 2 levels; and $\sigma^{2}$ is the variance of the error. With the non-centrality parameter, operating characteristic curves of Type II error probability will be used to determine the number of replicates, in this case subjects needed to achieve the desire power (Montgomery, 2001). Type II error will be limited to $\beta=0.10$ and $\alpha=0.05$. $A$ sensitivity of $S=.94$ will be selected.

One hundred subjects, 50 males and 50 females, participated voluntarily in the study. Students and workers were recruited around West Virginia University. Before filling out the questionnaires, each subject read and signed the consent form. An effort was made to recruit subjects into 4 different groups, male between 18 and 44 years, males between 45 and 70 years, females between 18 and 44 and females between 45 and 70 . After computing Equation 4 , and using an estimate of $\sigma^{2}$ equal to 4.658 from the ANOVA, it was concluded that desired power was achieved using 100 subjects ( 25 replicates), and subject recruitment was ended. Table 5 present minimum, maximum, mean and standard deviation of age, weight and height for males and females. 
Table 5. Male and female subjects characteristics.

\begin{tabular}{|l|r|r|r|r|r|r|}
\cline { 2 - 7 } \multicolumn{1}{c|}{} & \multicolumn{2}{c|}{ Age } & \multicolumn{2}{c|}{ Weight (kg) } & \multicolumn{2}{c|}{ Stature (cm) } \\
\cline { 2 - 7 } \multicolumn{1}{c|}{} & Male & Female & \multicolumn{1}{c|}{ Male } & Female & Male & Female \\
\hline Minimum & 18 & 20 & 55.45 & 45 & 160.02 & 149.86 \\
\hline Maximum & 65 & 70 & 146.82 & 141.82 & 193.04 & 177.80 \\
\hline Mean & 42.16 & 43.4 & 91.15 & 72.78 & 178.28 & 163.60 \\
\hline Std. Dev. & 13.32 & 14.22 & 20.61 & 22.49 & 7.09 & 7.30 \\
\hline
\end{tabular}

Questions regarding level of education, training in safe lifting techniques and experiences with back injury were asked from the subjects. Level of education showed $46 \%$ people with high school degree, $28 \%$ with undergraduate level and $26 \%$ with graduate education. Fifty percent of subjects reported that they had had training in safe lifting technique and $50 \%$ had not had training. Back injury history was reported for $28 \%$ of subjects. 


\section{CHAPTER 4}

\section{RESULTS}

By plotting perceived risk of injury from all the subjects against the Job Severity Index for the 54 pictures shown on the questionnaires as shown in Figure 7, it was found that people tend to overestimate the risk of the tasks. Ideally, based on these findings, subjects should be more careful when doing lifting tasks. A very low $R^{2}$ of .0932 confirms the mismatch between people perception and Job Severity Index, concluding that people do not know how to judge the risk of injury associated with lifts, and the mismatch may be the cause of many work injuries. Each one of the petals in the graphic represents an observation.

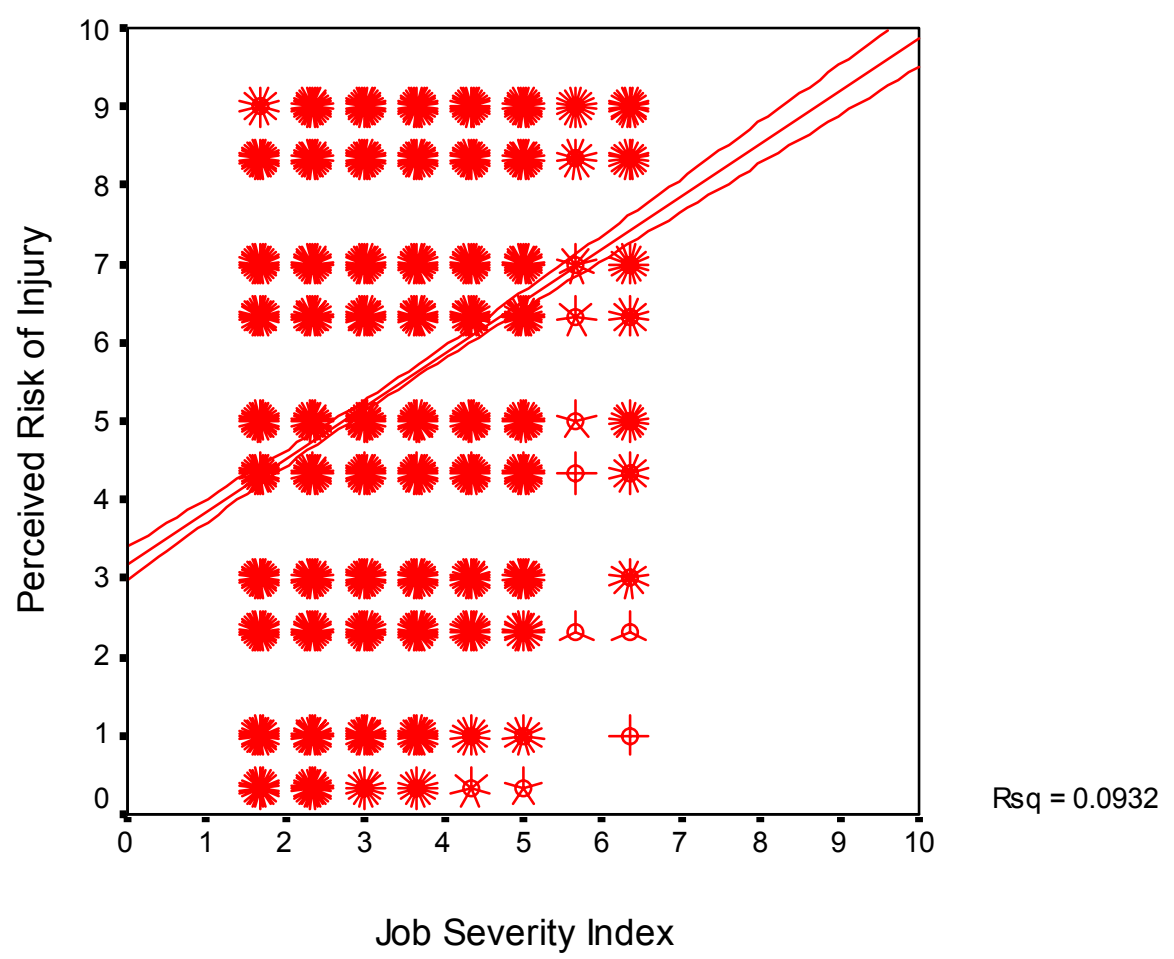

Figure 7. Perceived risk of injury versus Job Severity Index. 
Means, minimum, maximum and standard deviations for the main effects are presented in Table 6. Analysis of Variance results for perceived risk of injury are given in Table 7. At a $5 \%$ level of significance, all main effects except age were significant; $\mathrm{VxD}, \mathrm{VxA}, \mathrm{FxA}, \mathrm{GxA}$ were the significant two-way interactions; VxDxA, VxGxA, DxGxA were significant three-way interactions. All other interactions were not found to be significant and $R^{2}$ of the model is 0.370 .

Table 6. Means and Standard deviation of Perceived Risk of injury for vertical distance, horizontal distance, frequency of lift, travel distance.

\begin{tabular}{|c|l|r|r|r|r|}
\hline Main Effects & \multicolumn{1}{|c|}{ Levels } & Minimum & Maximum & Mean & St. Dev. \\
\hline \multirow{2}{*}{$\begin{array}{c}\text { Vertical distance } \\
(\mathbf{V})\end{array}$} & $16 \mathrm{~cm}$ & 0 & 10 & 4.38 & 2.56 \\
\cline { 2 - 6 } & $83 \mathrm{~cm}$ & 0 & 10 & 5.00 & 2.26 \\
\cline { 2 - 6 } & $150 \mathrm{~cm}$ & 0 & 10 & 6.96 & 2.47 \\
\hline \multirow{2}{*}{$\begin{array}{c}\text { Horizontal } \\
\text { distance (H) }\end{array}$} & $40 \mathrm{~cm}$ & 0 & 10 & 5.21 & 2.67 \\
\cline { 2 - 6 } & $60 \mathrm{~cm}$ & 0 & 10 & 5.40 & 2.66 \\
\cline { 2 - 6 } & $80 \mathrm{~cm}$ & 0 & 10 & 5.72 & 2.66 \\
\hline \multirow{2}{*}{$\begin{array}{c}\text { Frequency of lift } \\
(\text { F) }\end{array}$} & $0.2 \mathrm{lifts} / \mathrm{min}$ & 0 & 10 & 4.50 & 2.65 \\
\cline { 2 - 6 } & 2 lifts/min & 0 & 10 & 5.57 & 2.50 \\
\cline { 2 - 6 } & $5 \mathrm{lifts} / \mathrm{min}$ & 0 & 10 & 6.28 & 2.56 \\
\hline \multirow{2}{*}{\begin{tabular}{c} 
Travel distance (D) \\
\cline { 2 - 6 }
\end{tabular}} & $25 \mathrm{~cm}$ & 0 & 10 & 4.75 & 2.59 \\
\cline { 2 - 6 } & $75 \mathrm{~cm}$ & 0 & 10 & 6.14 & 2.57 \\
\hline \multirow{2}{*}{ Gender (G) } & Male & 0 & 10 & 5.32 & 2.72 \\
\cline { 2 - 6 } & Female & 0 & 10 & 5.58 & 2.62 \\
\hline \multirow{2}{*}{ Age (A) } & $18-44$ years & 0 & 10 & 5.42 & 2.57 \\
\cline { 2 - 6 } & $45-70$ years & 0 & 10 & 5.48 & 2.77 \\
\hline
\end{tabular}


Table 7. Analysis of variance for the perceived risk of injury in lifting tasks.

\begin{tabular}{|c|c|c|c|c|c|}
\hline Source & Type III Sum of Squares & df & Mean Square & $\mathbf{F}$ & $p<$ \\
\hline $\mathbf{H}$ & 237.418 & 2 & 118.709 & 25.487 & 0.000 \\
\hline $\mathbf{V}$ & 6514.316 & 2 & 3257.158 & 699.327 & 0.000 \\
\hline $\mathbf{F}$ & 2897.086 & 2 & 1448.543 & 311.009 & 0.000 \\
\hline D & 2597.227 & 1 & 2597.227 & 557.637 & 0.000 \\
\hline G & 91.000 & 1 & 91.000 & 19.538 & 0.000 \\
\hline $\mathrm{A}$ & 4.449 & 1 & 4.449 & 0.955 & 0.328 \\
\hline $\mathrm{H}^{*} \mathrm{~V}$ & 13.461 & 4 & 3.365 & 0.723 & 0.576 \\
\hline $\mathrm{H}^{*} \mathrm{~F}$ & 7.097 & 4 & 1.774 & 0.381 & 0.822 \\
\hline$H^{*} \mathrm{D}$ & 1.200 & 2 & 0.600 & 0.129 & 0.879 \\
\hline $\mathrm{H}^{*} \mathrm{G}$ & 7.565 & 2 & 3.782 & 0.812 & 0.444 \\
\hline $\mathrm{H}^{*} \mathrm{~A}$ & 5.136 & 2 & 2.568 & 0.551 & 0.576 \\
\hline$V^{*} \mathrm{~F}$ & 24.710 & 4 & 6.177 & 1.326 & 0.258 \\
\hline$V * D$ & 209.429 & 2 & 104.715 & 22.483 & 0.000 \\
\hline$V * G$ & 5.694 & 2 & 2.847 & 0.611 & 0.543 \\
\hline$V^{*} A$ & 371.027 & 2 & 185.514 & 39.831 & 0.000 \\
\hline$F * D$ & 3.361 & 2 & 1.681 & 0.361 & 0.697 \\
\hline$F^{*} G$ & 26.446 & 2 & 13.223 & 2.839 & 0.059 \\
\hline$F^{*} A$ & 58.961 & 2 & 29.481 & 6.330 & 0.002 \\
\hline$D * G$ & 2.200 & 1 & 2.200 & 0.472 & 0.492 \\
\hline$D * A$ & 0.031 & 1 & 0.031 & 0.007 & 0.935 \\
\hline$G^{*} A$ & 931.676 & 1 & 931.676 & 200.035 & 0.000 \\
\hline $\mathrm{H}^{*} \mathrm{~V}^{*} \mathrm{~F}$ & 20.604 & 8 & 2.575 & 0.553 & 0.817 \\
\hline$H^{*} V^{*} D$ & 5.799 & 4 & 1.450 & 0.311 & 0.871 \\
\hline $\mathrm{H}^{*} \mathrm{~V}^{*} \mathrm{G}$ & 6.376 & 4 & 1.594 & 0.342 & 0.850 \\
\hline$H^{*} V^{*} A$ & 7.276 & 4 & 1.819 & 0.391 & 0.816 \\
\hline$H^{*} F{ }^{*} D$ & 7.786 & 4 & 1.947 & 0.418 & 0.796 \\
\hline$H^{*} F{ }^{*} G$ & 5.097 & 4 & 1.274 & 0.274 & 0.895 \\
\hline$H^{*} F^{*} A$ & 12.029 & 4 & 3.007 & 0.646 & 0.630 \\
\hline$H^{*} D^{*} G$ & 0.267 & 2 & 0.134 & 0.029 & 0.972 \\
\hline$H^{*} D^{*} A$ & 2.327 & 2 & 1.164 & 0.250 & 0.779 \\
\hline$H^{*} G^{*} A$ & 1.216 & 2 & 0.608 & 0.131 & 0.878 \\
\hline$V^{*} F^{*} D$ & 1.061 & 4 & 0.265 & 0.057 & 0.994 \\
\hline$V^{*} F^{*} G$ & 3.965 & 4 & 0.991 & 0.213 & 0.931 \\
\hline$V^{*} F^{*} A$ & 1.141 & 4 & 0.285 & 0.061 & 0.993 \\
\hline$V^{*} D^{*} G$ & 39.287 & 2 & 19.644 & 4.218 & 0.015 \\
\hline$V^{*} D^{*} A$ & 12.225 & 2 & 6.112 & 1.312 & 0.269 \\
\hline$V^{*} G^{*} A$ & 49.307 & 2 & 24.654 & 5.293 & 0.005 \\
\hline$F * D^{*} G$ & 4.064 & 2 & 2.032 & 0.436 & 0.646 \\
\hline$F^{*} D^{*} A$ & 1.566 & 2 & 0.783 & 0.168 & 0.845 \\
\hline$F * G * A$ & 4.926 & 2 & 2.463 & 0.529 & 0.589 \\
\hline$D^{*} G^{*} A$ & 70.498 & 1 & 70.498 & 15.136 & 0.000 \\
\hline$H^{*} V^{*} F^{*} D$ & 4.781 & 8 & 0.598 & 0.128 & 0.998 \\
\hline$H^{*} V^{*} F^{*} G$ & 11.701 & 8 & 1.463 & 0.314 & 0.961 \\
\hline$H^{*} V^{*} F^{*} A$ & 14.186 & 8 & 1.773 & 0.381 & 0.931 \\
\hline$H^{*} V^{*} D^{*} G$ & 14.367 & 4 & 3.592 & 0.771 & 0.544 \\
\hline$H^{*} V^{*} D^{*} A$ & 4.645 & 4 & 1.161 & 0.249 & 0.910 \\
\hline$H^{*} V^{*} G^{*} A$ & 3.170 & 4 & 0.792 & 0.170 & 0.954 \\
\hline$H^{*} F^{*} D^{*} G$ & 3.884 & 4 & 0.971 & 0.208 & 0.934 \\
\hline$H^{*} F{ }^{*} D^{*} A$ & 4.037 & 4 & 1.009 & 0.217 & 0.929 \\
\hline$H^{*} F{ }^{*} G^{*} A$ & 1.984 & 4 & 0.496 & 0.106 & 0.980 \\
\hline$H^{*} D^{*} G * A$ & 0.483 & 2 & 0.241 & 0.052 & 0.950 \\
\hline$V * F^{*} D * G$ & 5.174 & 4 & 1.294 & 0.278 & 0.893 \\
\hline$V^{*} F^{*} D^{*} A$ & 9.696 & 4 & 2.424 & 0.520 & 0.721 \\
\hline$V^{*} F^{*} G^{*} A$ & 2.783 & 4 & 0.696 & 0.149 & 0.963 \\
\hline$V * D^{*} G * A$ & 1.803 & 2 & 0.901 & 0.194 & 0.824 \\
\hline$F * D^{*} G * A$ & 0.010 & 2 & 0.005 & 0.001 & 0.999 \\
\hline$H^{*} V^{*} F{ }^{*} D^{*} G$ & 13.341 & 8 & 1.668 & 0.358 & 0.943 \\
\hline$H^{*} V^{*} F{ }^{*} D * A$ & 3.537 & 8 & 0.442 & 0.095 & 0.999 \\
\hline$H^{*} V{ }^{*} F{ }^{*} G * A$ & 3.684 & 8 & 0.460 & 0.099 & 0.999 \\
\hline$H^{*} V^{*} D^{*} G * A$ & 8.219 & 4 & 2.055 & 0.441 & 0.779 \\
\hline$H * F * D * G * A$ & 0.757 & 4 & 0.189 & 0.041 & 0.997 \\
\hline$V{ }^{*} F * D^{*} G * A$ & 7.307 & 4 & 1.827 & 0.392 & 0.814 \\
\hline$H^{*} V{ }^{*} F{ }^{*} D^{*} G{ }^{*} A$ & 4.088 & 8 & 0.511 & 0.110 & 0.999 \\
\hline Error & 24144.800 & 5184 & 4.658 & & \\
\hline Total & 38534.746 & 5399 & & & \\
\hline
\end{tabular}


Where:

$\mathrm{H}$ : Horizontal Distance

V: Vertical Distance

F: Frequency of Lift

D: Travel Distance

G: Gender

A: Age

Tukey post hoc procedure was performed for significant main effects with more than 2 levels to determine the source of difference at $5 \%$ level and $95 \%$ confidence interval for the effects of $\mathrm{V}, \mathrm{H}$ and $\mathrm{F}$. Results illustrated differences among the three different levels for these main effects.

Figures 8 through 11 illustrate the means and standard deviations of perceived risk of injury and Job Severity Indexes for the main effects of lifting effect factors, H, V, $F$, and $D$.

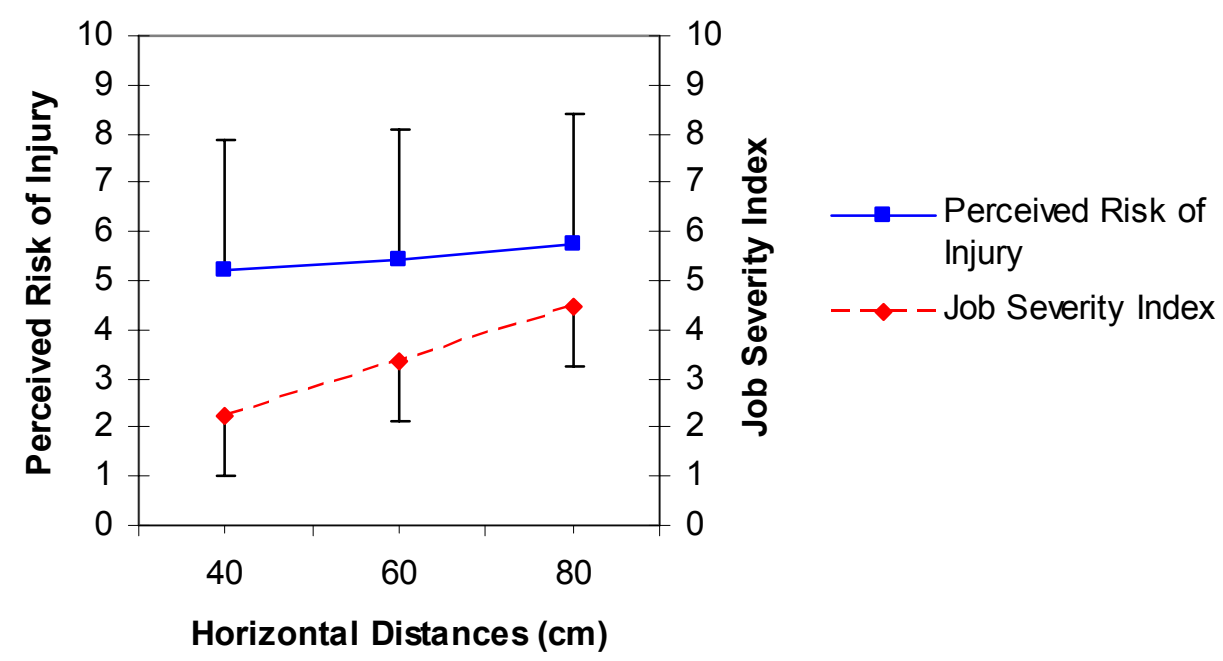

Figure 8. Means and standard deviations of perceived risk of injury and Job Severity Index plotted across horizontal distances of lift. 


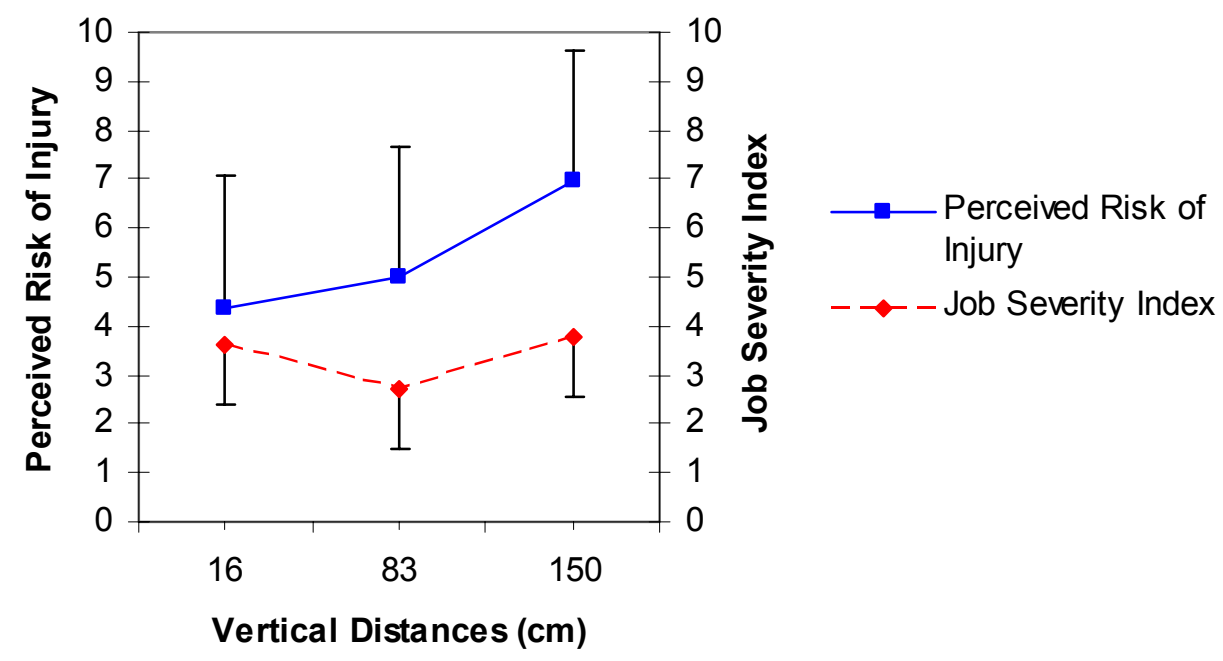

Figure 9. Means and standard deviations of perceived risk of injury and Job Severity Index plotted across vertical distances of lift.

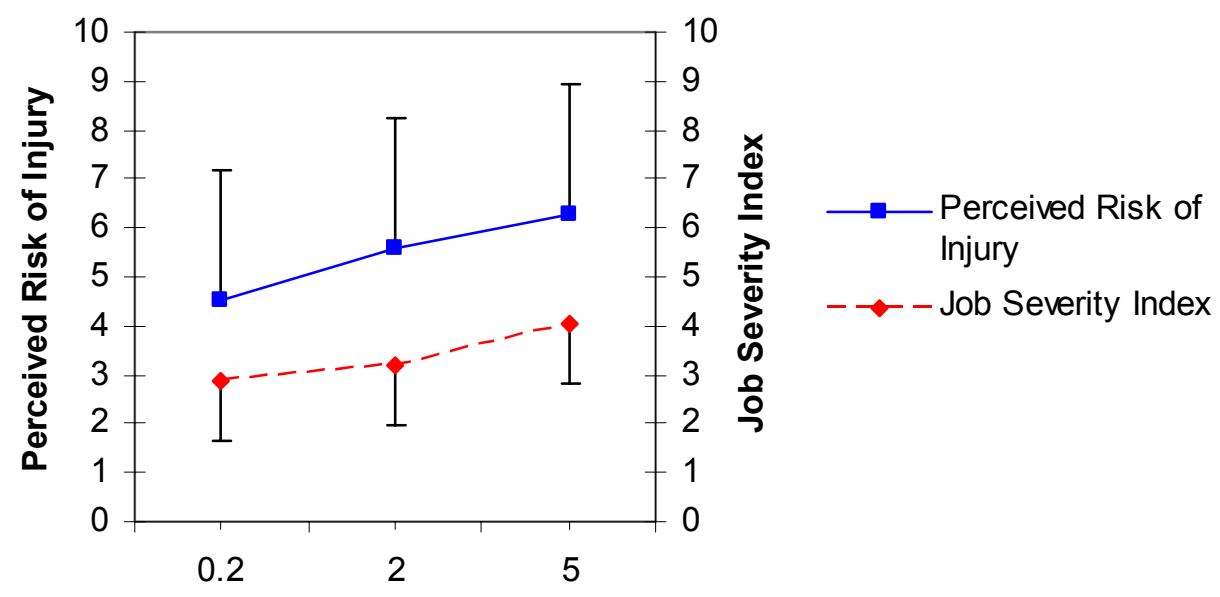

Frequency of Lifts (lifts/min)

Figure 10. Means and standard deviations of perceived risk of injury and Job Severity Index plotted across frequencies of lift. 


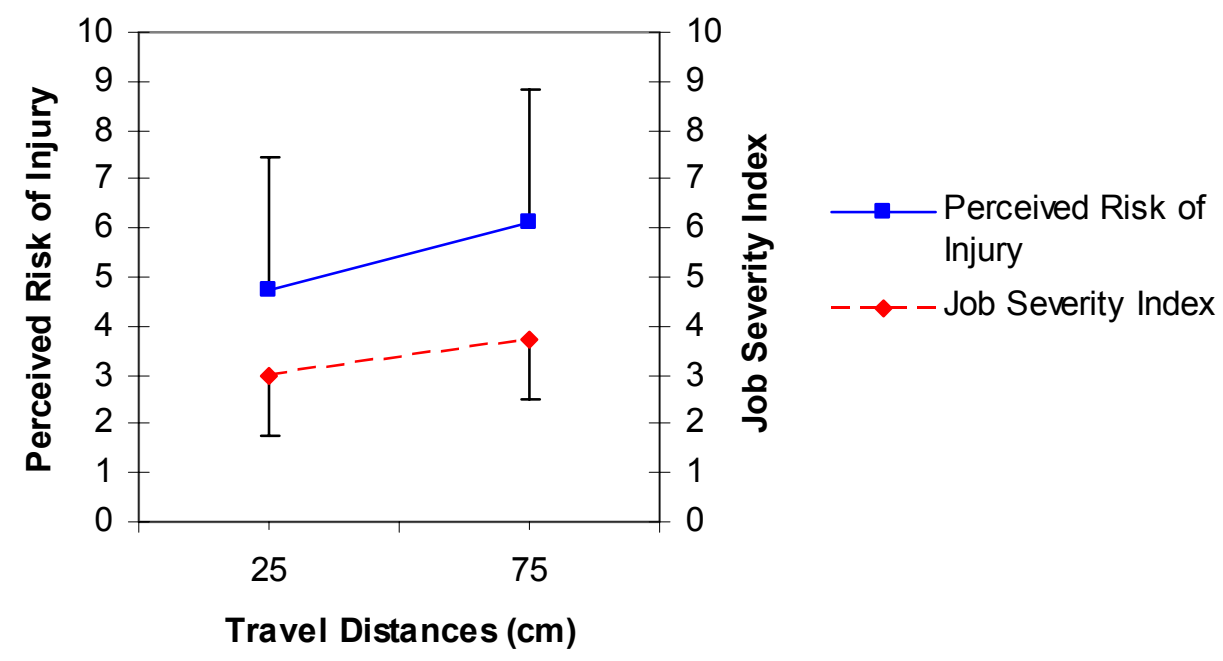

Figure 11. Means and standard deviations of perceived risk of injury and Job Severity Index plotted across travel distances of lift.

Analysis of variance (ANOVA) results showed that main effects of horizontal distance, vertical distance, travel distance and frequency of the lift are all important to human perception of risk of injury. These results are in accordance with results of Mital and Ayoub (1981), Asfour et al. (1993), Garg (1989), Yeung et al. (2003), and especially NIOSH WPG (1981).

Lindbeck and Kjellberg (2001), Mital et al. (1997) reported gender differences. We found, on average, males reported lower perception of risk of injury than females for experimental conditions (see Table 6).

The effect of body weight and stature are anthropometric contributors which possible affect perception of individual risk of injury during Manual Material Handling. Body weight has a direct effect on metabolic energy expenditure rate of a person while carrying loads; therefore, a heavier person would have a greater metabolic rate and associated circulatory load, leading to a quicker fatigue. Alternatively, a heavier person is usually stronger than a lighter person, having the mass necessary to counterbalance 
the handling of large objects, and appears that there is an association between weight and ability to lift (NIOSH WPG, 1981).

Biomechanically, women are not simply proportionally scaled-down versions of men due to differences between body masses proportions between genders (Marras et al., 2002). It was expected from tasks on the questionnaires that men and women perform the same lifting tasks, but women are smaller and have a lighter weight than men, and pictures on the questionnaire did not account for different scale factors for men and women, being the reason why results of risk of injury perception are higher for females.

Partial correlation using gender, stature and body mass and controlling for perception of risk of injury, confirm that stature and weight are significant variables that may have influenced the responses of males and females, see Table 8.

Table 8. Analysis of variance for the perceived risk of injury in lifting tasks.

\begin{tabular}{|c|r|r|r|}
\cline { 2 - 4 } \multicolumn{1}{c|}{} & \multicolumn{1}{c|}{ Gender } & Stature (cm) & Body Mass (kg) \\
\hline \multirow{4}{*}{ Gender } & 1.000 & -0.7134 & -0.3899 \\
\cline { 2 - 4 } & 0 & 5397 & 5397 \\
\cline { 2 - 4 } & $\mathrm{p}=$. & $\mathrm{p}=0.000$ & $\mathrm{p}=0.000$ \\
\hline \multirow{2}{*}{$\begin{array}{c}\text { Stature } \\
(\mathbf{c m})\end{array}$} & -0.7134 & 1.000 & 0.5368 \\
\cline { 2 - 4 } & 5397 & 0 & 5397 \\
\hline \multirow{2}{*}{$\begin{array}{c}\text { Body Mass } \\
\text { (kg) }\end{array}$} & -0.3899 & 0.5368 & $\mathrm{p}=0.000$ \\
\cline { 2 - 4 } & 5397 & 5397 & 1.000 \\
\cline { 2 - 4 } & $\mathrm{p}=0.000$ & $\mathrm{p}=0.000$ & $\mathrm{p}=$. \\
\hline
\end{tabular}


Two-way significant interactions from ANOVA are plotted in Figures 12 through $15, V x D, V x A, F x A$ and $G x A$, respectively. Figure 12 , shows that as the $V$ and $D$ increase, there is an increase in the perception of risk of injury. Figure 13 illustrates that as $V$ increases, the two groups of age tended to increase their perception of risk of injury, but notice that from lower level of $\mathrm{V}$ to waist level, there is no substantial increase in the perception of risk of injury for the younger group. Figure 14 demonstrated that as the frequency of lifts increase there is an increase of perception of risk by the two groups of age, but no substantial difference between the groups of age. Finally, Figure 15 showed opposite effects for males and females of the two groups of, in which younger males had higher perception of risk than older males, and the opposite for females, younger females reporting lower perception of risk than older females.

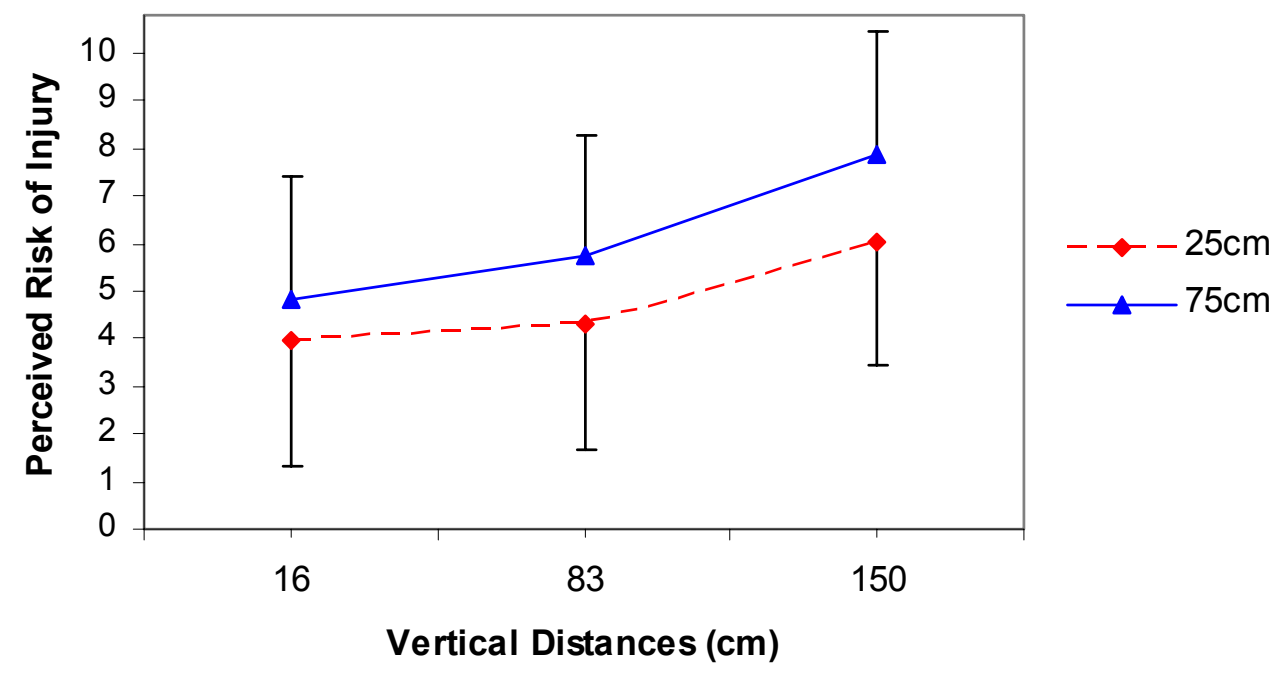

Figure 12. Means and standard deviation of perceived risk of injury for the two travel distances across the vertical distances. 


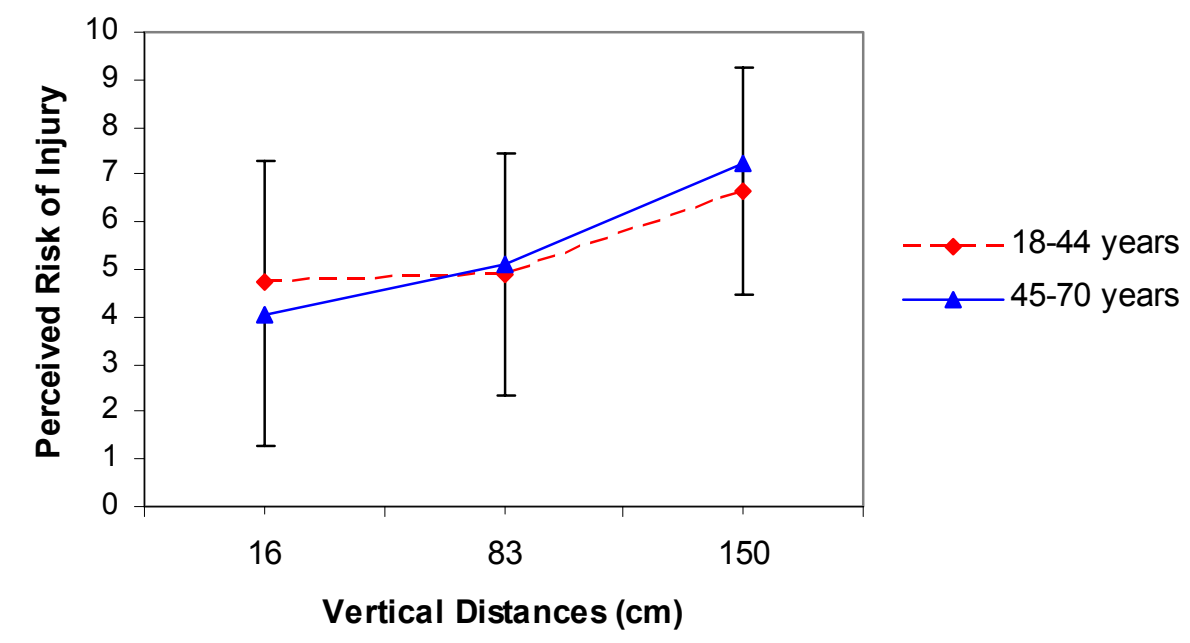

Figure 13. Means and standard deviation of perceived risk of injury for the two groups of age across the vertical distances.

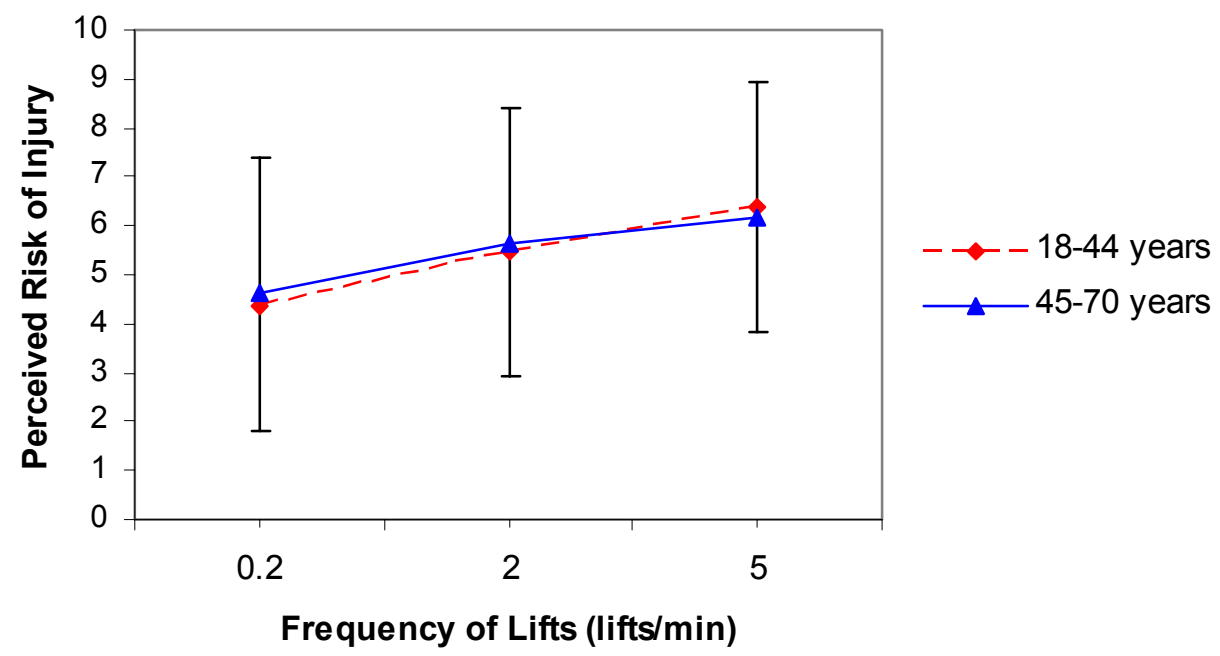

Figure 14. Means and standard deviations of perceived risk of injury for the two groups of age across frequency of lifts. 


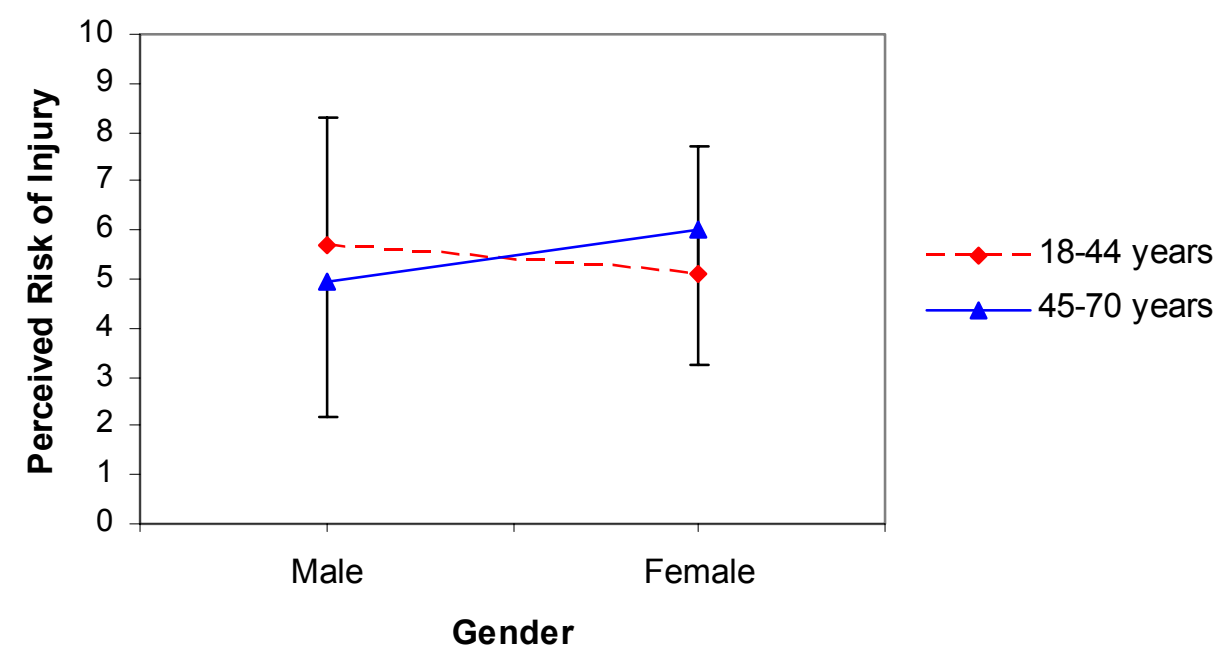

Figure 15. Means and standard deviations of perceived risk of injury for the two groups of age across gender.

Three-way significant interactions from ANOVA are plotted in Figures 16 through 18. Figure 16 shows that perception of risk of injury increase as the $V$ and $D$ increase, but not significant difference in gender.

Figure 17 shows that in the lower level of $\mathrm{V}$ younger males had higher perception of risk than younger males, but similar response for younger and older females. At waist level, males (young and old) had similar perception of risk, and older females reporting higher levels of risk of injury than younger females, and at high level of $\mathrm{V}$, men of either group of age reported almost same responses, and older females higher perception of risk than younger females. Finally, Figure 18 illustrates that either lower or higher levels of $\mathrm{D}$, older males and younger females had lower perception of risk of injury than young males and older females. 


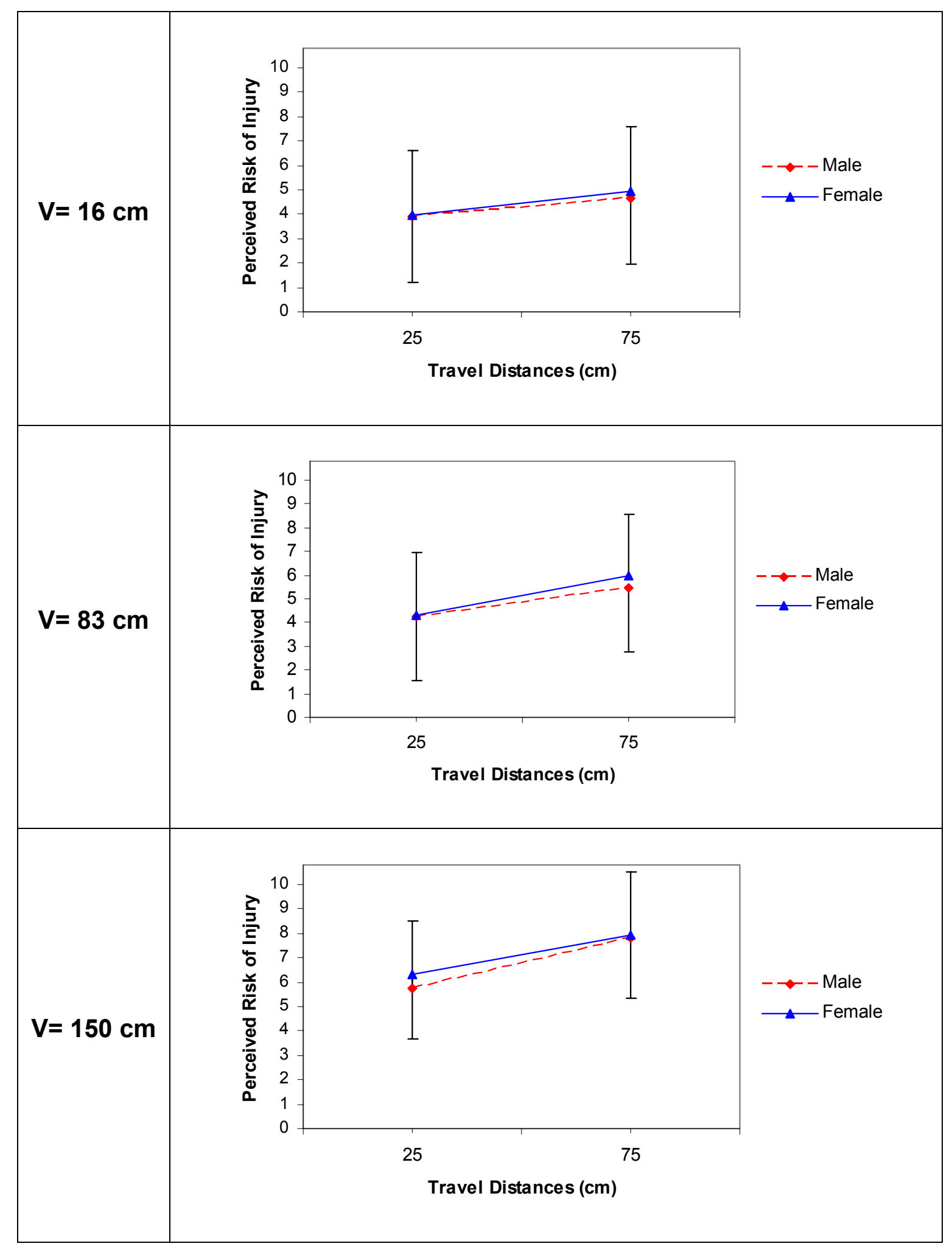

Figure 16. Means and standard deviations of perceived risk of injury for gender across travel distances for each of the vertical distances. 


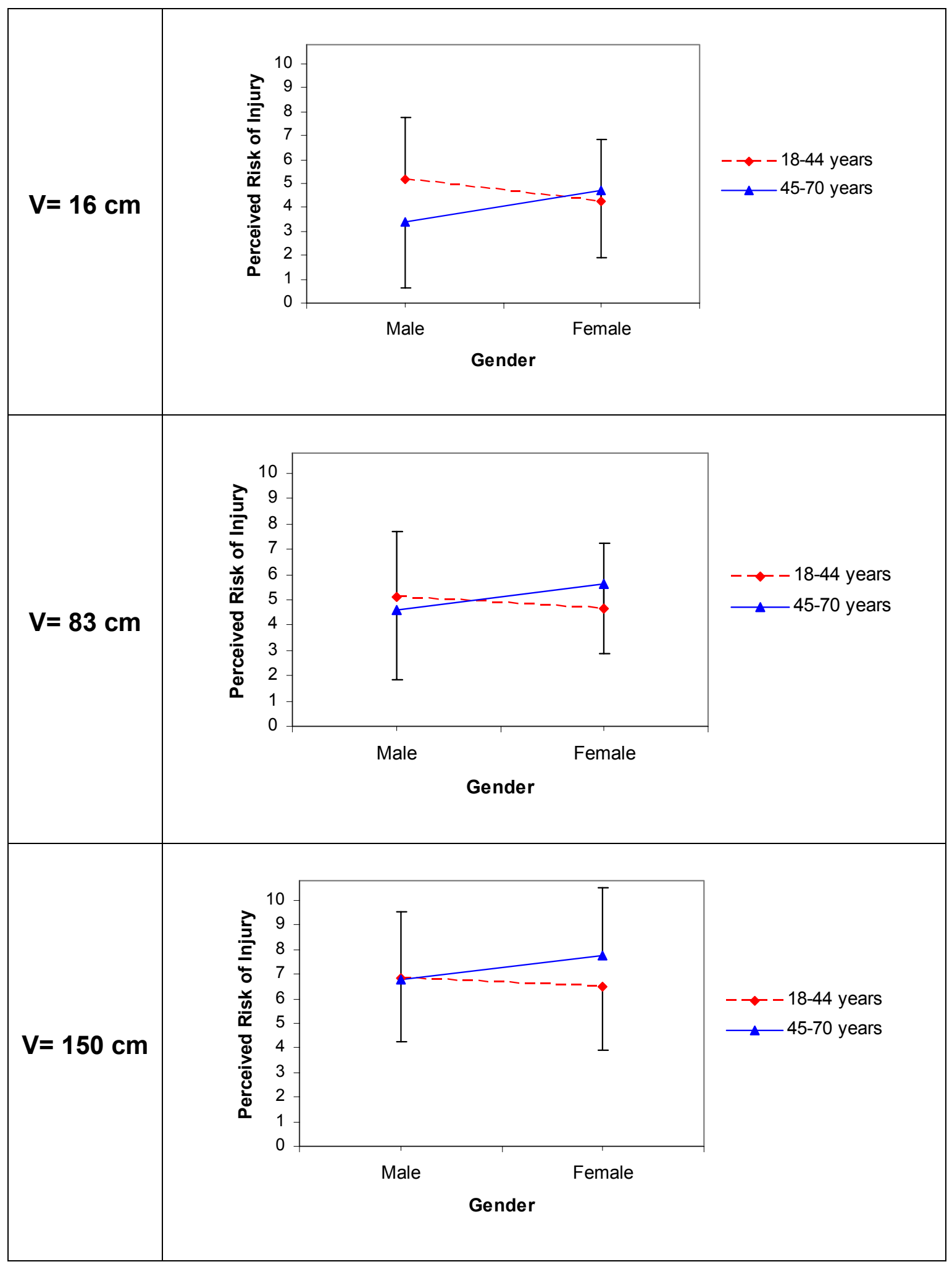

Figure 17. Means and standard deviations of perceived risk of injury for the two groups of age across gender for each of the vertical distances. 


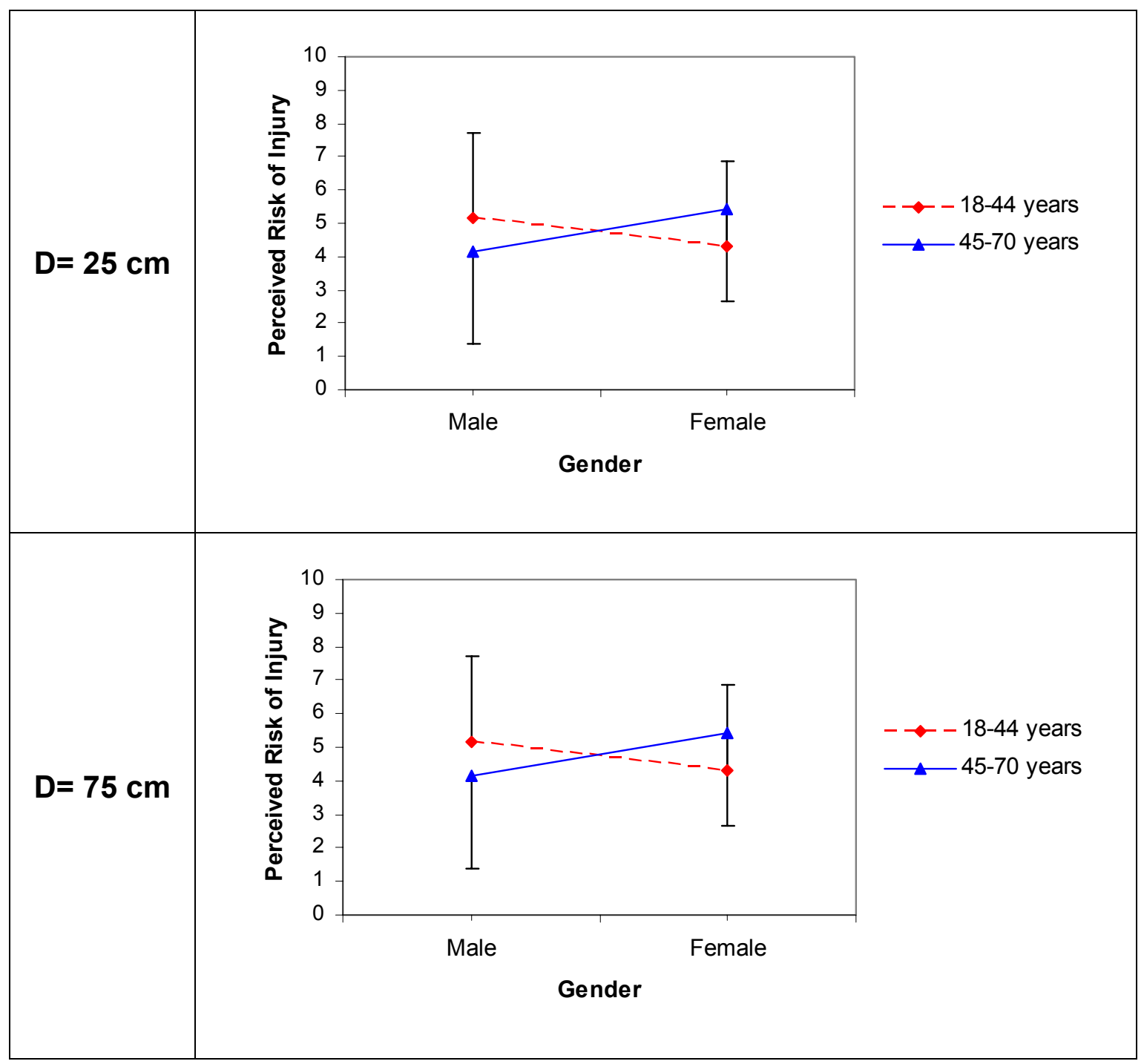

Figure 18. Means and standard deviations of perceived risk of injury for the two groups of age across gender for each of the travel distances.

Figure 19 illustrates results based on the lifting parameters $H, V, F$ and $D$, showing perceived risk of injury for the two travel distances across the horizontal distances for the different frequencies and vertical distances. As noticed from plots, as the $D, F$ and $V$ increase there is an increase in response of risk of injury, but as mentioned earlier, there is not a considerable increase in responses for $\mathrm{H}$. Also, level of $V$ at waist level $(83 \mathrm{~cm})$ should have had the lower perception of risk of injury than the other two levels of $\mathrm{V}$, since the waist height is almost the ideal height of lift. 


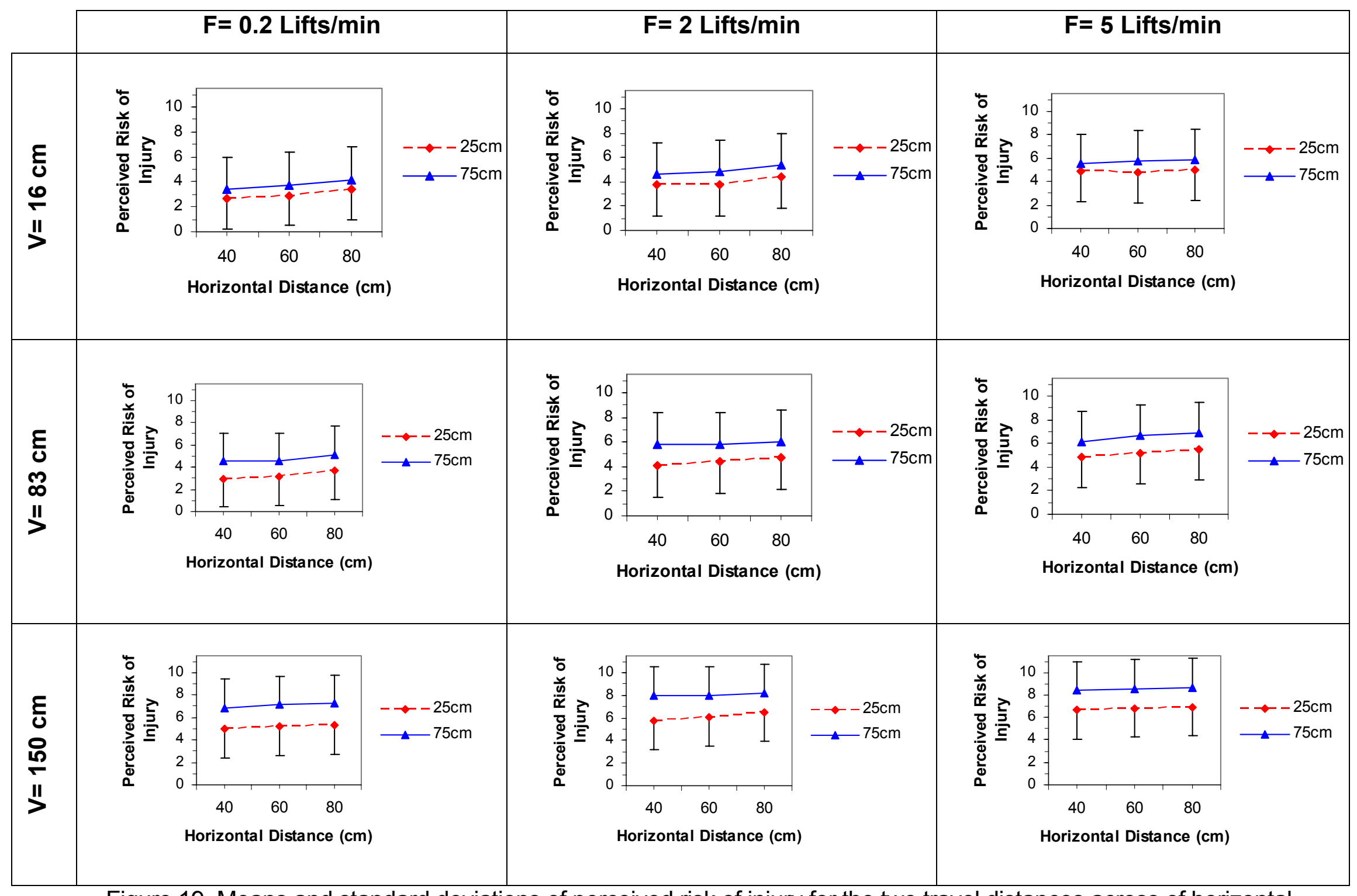

Figure 19. Means and standard deviations of perceived risk of injury for the two travel distances across of horizontal distances for the different frequency of lifts and vertical distances. 
Primarily in the study, it was essential to examine if responses might have been driven by the biomechanical approach. NIOSH WPG (1981) was mainly derived from biomechanical data, in which horizontal and vertical distances are the main focus of this approach. From the study it was concluded that people's responses were not driven by this approach, since behavior of responses of people when compared with the JSI for the horizontal and vertical distances did not behave as they should, therefore if driven by biomechanical approach, in where high compression forces are imposed to lower back and shoulders, horizontal distance should have a profound effect. From Figure 8 it is clearly noticeable that subjects do not pay too much attention to the effect of the horizontal distance since the means for each of the three different horizontal points used were almost the same, and the plot showed almost a flat line for the perceived risk of injury responses. Besides, vertical distance did not follow the pattern of the vertical distance multiplier which decreases as the vertical distance goes away from the $75 \mathrm{~cm}$. People's responses for this factor increased as the vertical distance increased (see Figure 9).

The biomechanical approach emphasizes in the weight of the object, horizontal distance $(\mathrm{H})$ and vertical distance $(\mathrm{V})$. Compressive force on the low back is proportionally increased as the load mass center gravity is moved horizontally away from the body. The most important rule in Manual Material Handling is to guarantee that the person is able to bring the torso as close as possible to the load center of gravity before lifting, hence, even light weights need to be lifted close to the body, NIOSH WPG (1981). Therefore, people's responses were not motivated by this approach.

Epidemiological literature for short and long term health effects on manual material handling, specifically in the lumbar spine disability, is the major focus for the NIOSH WPG (1981). Factors affecting this type of injury are job and personal risk factors. In this study, the theory that people based their responses on epidemiological facts was discarded. People do not have the knowledge of epidemiological literature regarding this topic, plus a large percentage of the population only had a high school diploma. 
People's responses were also compared to psychophysical approach. NIOSH WPG (1981) mentions a static strength model by Garg and Chaffin (1975) that describe a static muscular capability of a person in any posture and load combination. Static strength models are commonly used instead of dynamic model, because if high acceleration is not produced static models give reasonable estimates, plus are simpler to use (Waikar et al., 1991). However, the model has two human limitations. The first limitation is the body balance capabilities of a person. If the line of gravity created by the person and the load is outside the area bounded by the feet, the person doing the lift may fall because loss of balance.

In a study by Waikar et al. (1991), authors explained that subjects rated tasks with reach an overreach heights to be more difficult because of the fear of losing balance, despite that in the instructions they were asked to rate the difficulty based at the lumbar spine. People pay attention to balance and reach heights when high levels are presented to them.

The second limitation of the model is that the compression forces may limit a person's capabilities. Figure 20, shows an example of a strong 2.5 percentile male predicted with a two dimensional form of the model (Chaffin, 1974). Contours show that lifting strengths of a person decreases as the horizontal distance increase. The model can create similar contours of strength for different population percentiles and anthropometric characteristics. 


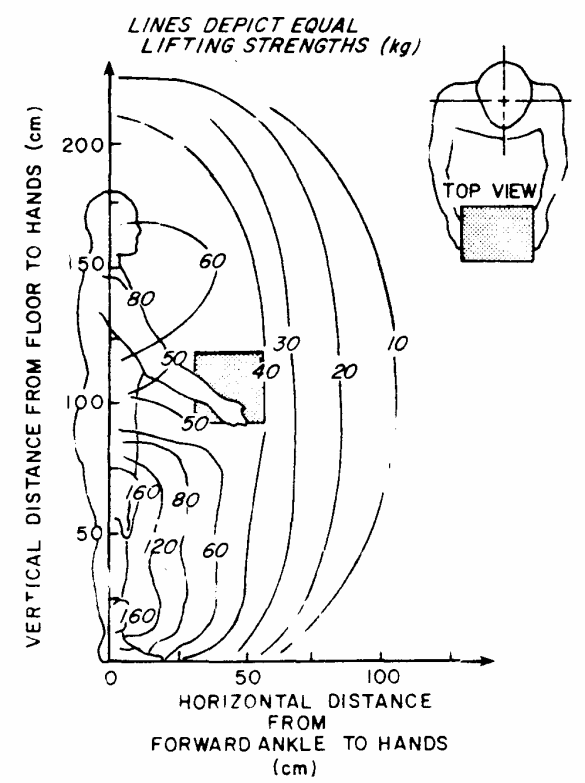

Figure 20. Predicted lifting strength of a large strong male, (Chaffin, 1974).

Illustration from Work Practice Guide for Manual Lifting, 1981.

Basically, people did not judge the risk of injury based on psychophysical approach, since it will be logical to assume that as the strength capabilities decrease with an increase of the horizontal distances, greater risks of injuries should be employed by subjects as the horizontal distance moves away from the object to be lifted, but Figure 8 shows the opposite.

Finally, subjects may have paid more attention to physiological aspects. In repetitive lifting activities, a proper design has to be achieved so that workers do not get fatigued. Different types of measurements help to prevent this issue. Mechanical work, Equation 5, affects the metabolic rate (NIOSH WPG, 1981).

$$
\text { Mechanical Work= Load X Frequency X Travel Distance }
$$

As the frequency and travel distances of the task increase, an increase in the mechanical work is produced, and subsequently a greater energy expenditure. 
Consequently, it is logical to assume that as the frequency and travel distance increase an increase in the perception of risk of injury should be reported, which is corresponded in Figure 21, that as the frequency and the travel distances increase there is an increase in the perceived risk of injury.

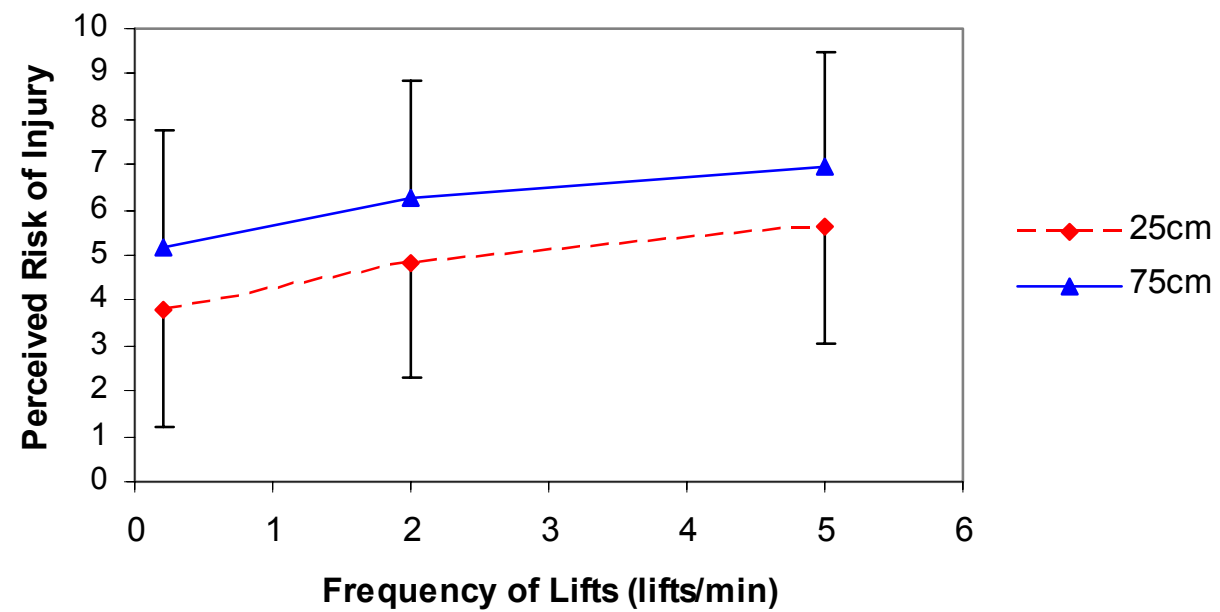

Figure 21. Means and standard deviation of perceived risk of injury for the two travel distances across the frequency of lifts.

In accordance with these results, people are more concerned with the physiological perspective coming either from previous experience, training, anecdotes or many other reasons that could get their attention physiologically.

Risk of injury perception is a field that needs more study to help design job places in accordance with ergonomics designs and taking into consideration risks perceived by people. If a task to be performed is not design well, and people feel there is no risk when there actually is, people may get injuries from their jobs. Risk perception should be identified before attempting to do the lift.

Figure 22, shows a scatter plot of the perceived risk of injury versus the Job Severity Index for the $\mathrm{VxD}$ interaction, a two-way significant interaction found on the ANOVA (Table 
7), from the figure it can be noticed that at high levels of $V$ and $D$, the trend line is almost flat, which demonstrate that subjects were more concerned at this position. Their perception might have been based on different aspects, such as injuries in the upper extremities (shoulders, arms, and neck), physiological aspects, psychophysical area (strength) and reaches and balance issues.

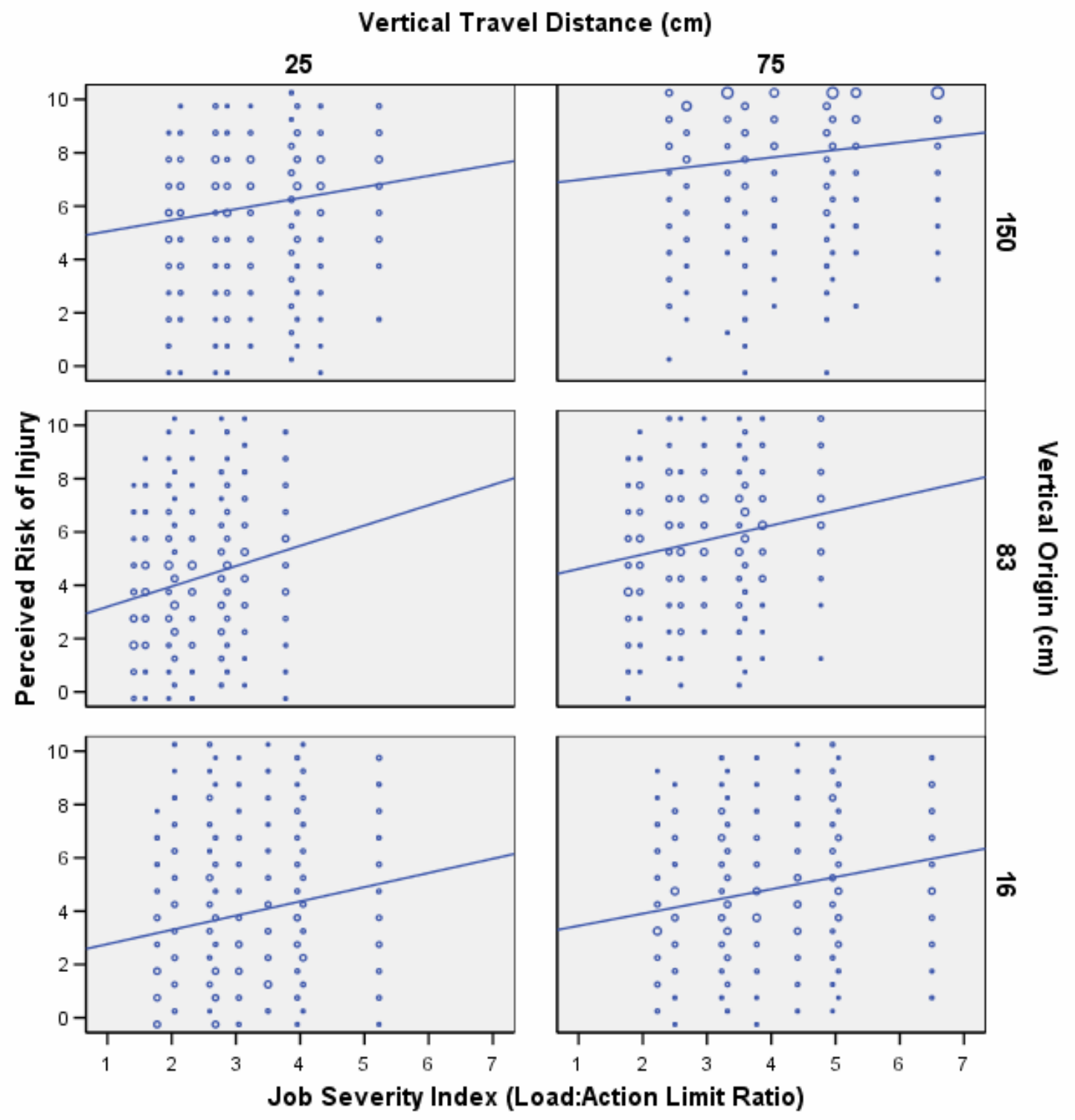

Figure 22. Scatter plots of perceived risk of injury versus Job Severity Index for the vertical travel distances and vertical distances. 
A complete randomized block design fixed-effect ANOVA for the factors of NIOSH equations, 1981 and 1991 are presented in Tables 9 and 10, respectively. Appendix 4 shows calculations and steps on how to calculate the multiplier factors. The variables used for each analysis were:

HFM: Horizontal Factor Multiplier

VFM: Vertical Factor Multiplier

FFM: Frequency Factor Multiplier

DFM: Travel Factor Multiplier

G: Gender

A: Age

In the case of the NIOSH 1981, frequency factors multipliers yield to 5 different factors, as noticed in Table 3, since the mentioned factor is based on the vertical distance and frequency of lifts; and because of this and the similarity of results for the frequency factor, similar results were grouped so that a total of 3 different levels for frequency factor multiplier were used for the ANOVA. Results of 0.67 and 0.72 form a group, 0.87 and 0.89 the second group and 0.99 the third group of frequencies used for the ANOVA.

At a $5 \%$ level of significance, all main effects except age were significant; VFMxDFM, VFMxA, FFMxA, GxA were the significant two-way interactions; VFMxDFMxA, VFMxGxA, DFMxGxA were significant three-way interactions for either the 1981 and $1991 \mathrm{NIOSH}$ equations.

Tukey post hoc procedure was performed for significant main effects with more than 2 levels to determine the source of difference at $5 \%$ level and $95 \%$ confidence interval for the effects of VFM, HFM and FFM, for both equations. Results illustrated differences among the three different levels for these main effects. 
Table 9. Analysis of variance for the perceived risk of injury in lifting tasks for the $\mathrm{NIOSH}$ 1981 factors.

\begin{tabular}{|c|c|c|c|c|c|}
\hline Source & Type III Sum of Squares & DFM & Mean Square & $\mathbf{F}$ & $p<$ \\
\hline HFM & 237.418 & 2 & 118.709 & 25.487 & 0.000 \\
\hline VFM & 6514.316 & 2 & 3257.158 & 699.327 & 0.000 \\
\hline FFM & 2897.086 & 2 & 1448.543 & 311.009 & 0.000 \\
\hline DFM & 2597.227 & 1 & 2597.227 & 557.637 & 0.000 \\
\hline G & 91.000 & 1 & 91.000 & 19.538 & 0.000 \\
\hline $\mathrm{A}$ & 4.449 & 1 & 4.449 & 0.955 & 0.328 \\
\hline $\mathrm{HFM}^{*} \mathrm{VFM}$ & 13.461 & 4 & 3.365 & 0.723 & 0.576 \\
\hline $\mathrm{HFM}^{*} \mathrm{FFM}$ & 7.097 & 4 & 1.774 & 0.381 & 0.822 \\
\hline $\mathrm{HFM}^{*} \mathrm{DFM}$ & 1.200 & 2 & 0.600 & 0.129 & 0.879 \\
\hline $\mathrm{HFM}^{*} \mathrm{G}$ & 7.565 & 2 & 3.782 & 0.812 & 0.444 \\
\hline $\mathrm{HFM}^{*} \mathrm{~A}$ & 5.136 & 2 & 2.568 & 0.551 & 0.576 \\
\hline VFM * FFM & 24.710 & 4 & 6.177 & 1.326 & 0.258 \\
\hline VFM * DFM & 209.429 & 2 & 104.715 & 22.483 & 0.000 \\
\hline $\mathrm{VFM}^{*} \mathrm{G}$ & 5.694 & 2 & 2.847 & 0.611 & 0.543 \\
\hline VFM * A & 371.027 & 2 & 185.514 & 39.831 & 0.000 \\
\hline $\mathrm{FFM}^{*} \mathrm{DFM}$ & 3.361 & 2 & 1.681 & 0.361 & 0.697 \\
\hline $\mathrm{FFM}^{*} \mathrm{G}$ & 26.446 & 2 & 13.223 & 2.839 & 0.059 \\
\hline FFM * A & 58.961 & 2 & 29.481 & 6.330 & 0.002 \\
\hline $\mathrm{DFM}^{*} \mathrm{G}$ & 2.200 & 1 & 2.200 & 0.472 & 0.492 \\
\hline $\mathrm{DFM}^{*} \mathrm{~A}$ & 0.031 & 1 & 0.031 & 0.007 & 0.935 \\
\hline$G * A$ & 931.676 & 1 & 931.676 & 200.035 & 0.000 \\
\hline $\mathrm{HFM}^{*} \mathrm{VFM}{ }^{*} \mathrm{FFM}$ & 20.604 & 8 & 2.575 & 0.553 & 0.817 \\
\hline $\mathrm{HFM}^{*}$ VFM * DFM & 5.799 & 4 & 1.450 & 0.311 & 0.871 \\
\hline $\mathrm{HFM}^{*} \mathrm{VFM}^{*} \mathrm{G}$ & 6.376 & 4 & 1.594 & 0.342 & 0.850 \\
\hline $\mathrm{HFM}^{*} \mathrm{VFM}^{*} \mathrm{~A}$ & 7.276 & 4 & 1.819 & 0.391 & 0.816 \\
\hline $\mathrm{HFM}^{*} \mathrm{FFM}{ }^{*} \mathrm{DFM}$ & 7.786 & 4 & 1.947 & 0.418 & 0.796 \\
\hline $\mathrm{HFM}^{*} \mathrm{FFM}^{*} \mathrm{G}$ & 5.097 & 4 & 1.274 & 0.274 & 0.895 \\
\hline $\mathrm{HFM}^{*} \mathrm{FFM}^{*} \mathrm{~A}$ & 12.029 & 4 & 3.007 & 0.646 & 0.630 \\
\hline $\mathrm{HFM}^{*} \mathrm{DFM}^{*} \mathrm{G}$ & 0.267 & 2 & 0.134 & 0.029 & 0.972 \\
\hline $\mathrm{HFM}^{*} \mathrm{DFM}^{*} \mathrm{~A}$ & 2.327 & 2 & 1.164 & 0.250 & 0.779 \\
\hline $\mathrm{HFM}^{*} \mathrm{G}^{*} \mathrm{~A}$ & 1.216 & 2 & 0.608 & 0.131 & 0.878 \\
\hline VFM * FFM * DFM & 1.061 & 4 & 0.265 & 0.057 & 0.994 \\
\hline VFM * FFM * G & 3.965 & 4 & 0.991 & 0.213 & 0.931 \\
\hline VFM * ${ }^{*} F M{ }^{*} A$ & 1.141 & 4 & 0.285 & 0.061 & 0.993 \\
\hline VFM * DFM * G & 39.287 & 2 & 19.644 & 4.218 & 0.015 \\
\hline VFM * DFM * A & 12.225 & 2 & 6.112 & 1.312 & 0.269 \\
\hline VFM ${ }^{*} \mathbf{G}^{*} \mathrm{~A}$ & 49.307 & 2 & 24.654 & 5.293 & 0.005 \\
\hline $\mathrm{FFM}^{*} \mathrm{DFM}^{*} \mathrm{G}$ & 4.064 & 2 & 2.032 & 0.436 & 0.646 \\
\hline $\mathrm{FFM}^{*} \mathrm{DFM}^{*} \mathrm{~A}$ & 1.566 & 2 & 0.783 & 0.168 & 0.845 \\
\hline$F F M{ }^{*} G^{*} A$ & 4.926 & 2 & 2.463 & 0.529 & 0.589 \\
\hline$D_{F M}^{*} G^{*} A$ & 70.498 & 1 & 70.498 & 15.136 & 0.000 \\
\hline $\mathrm{HFM}^{*} \mathrm{VFM}^{*} \mathrm{FFM}^{*} \mathrm{DFM}$ & 4.781 & 8 & 0.598 & 0.128 & 0.998 \\
\hline $\mathrm{HFM}^{*} \mathrm{VFM}^{*} \mathrm{FFM}^{*} \mathrm{G}$ & 11.701 & 8 & 1.463 & 0.314 & 0.961 \\
\hline $\mathrm{HFM}^{*} \mathrm{VFM}{ }^{*} \mathrm{FFM}^{*} \mathrm{~A}$ & 14.186 & 8 & 1.773 & 0.381 & 0.931 \\
\hline $\mathrm{HFM}^{*}$ VFM ${ }^{*} \mathrm{DFM}{ }^{*} \mathrm{G}$ & 14.367 & 4 & 3.592 & 0.771 & 0.544 \\
\hline $\mathrm{HFM}^{*} \mathrm{VFM}{ }^{*} \mathrm{DFM}{ }^{*} \mathrm{~A}$ & 4.645 & 4 & 1.161 & 0.249 & 0.910 \\
\hline $\mathrm{HFM}^{*} \mathrm{VFM}{ }^{*} \mathrm{G}{ }^{*} \mathrm{~A}$ & 3.170 & 4 & 0.792 & 0.170 & 0.954 \\
\hline $\mathrm{HFM}^{*}{ }^{\mathrm{FFM}}{ }^{*}{ }^{\mathrm{DFM}}{ }^{*} \mathrm{G}$ & 3.884 & 4 & 0.971 & 0.208 & 0.934 \\
\hline $\mathrm{HFM}^{*} \mathrm{FFM}{ }^{*} \mathrm{DFM}{ }^{*} \mathrm{~A}$ & 4.037 & 4 & 1.009 & 0.217 & 0.929 \\
\hline $\mathrm{HFM}^{*} \mathrm{FFM}^{*} \mathrm{G}{ }^{*} \mathrm{~A}$ & 1.984 & 4 & 0.496 & 0.106 & 0.980 \\
\hline $\mathrm{HFM}^{*} \mathrm{DFM}^{*} \mathrm{G}^{*} \mathrm{~A}$ & 0.483 & 2 & 0.241 & 0.052 & 0.950 \\
\hline VFM * FFM * DFM * G & 5.174 & 4 & 1.294 & 0.278 & 0.893 \\
\hline VFM ${ }^{*} \mathrm{FFM}^{*}{ }^{\mathrm{DFM}}{ }^{*} \mathrm{~A}$ & 9.696 & 4 & 2.424 & 0.520 & 0.721 \\
\hline VFM ${ }^{*} F F M * G * A$ & 2.783 & 4 & 0.696 & 0.149 & 0.963 \\
\hline $\mathrm{VFM}^{*} \mathrm{DFM}^{*} \mathrm{G}^{*} \mathrm{~A}$ & 1.803 & 2 & 0.901 & 0.194 & 0.824 \\
\hline $\mathrm{FFM}^{*} \mathrm{DFM}^{*} \mathrm{G}^{*} \mathrm{~A}$ & 0.010 & 2 & 0.005 & 0.001 & 0.999 \\
\hline $\mathrm{HFM}^{*} \mathrm{VFM}^{*} \mathrm{FFM}^{*} \mathrm{DFM}^{*} \mathrm{G}$ & 13.341 & 8 & 1.668 & 0.358 & 0.943 \\
\hline $\mathrm{HFM}^{*} \mathrm{VFM}^{*} \mathrm{FFM}^{*} \mathrm{DFM}^{*} \mathrm{~A}$ & 3.537 & 8 & 0.442 & 0.095 & 0.999 \\
\hline $\mathrm{HFM}^{*} \mathrm{VFM}^{*} \mathrm{FFM}^{*} \mathrm{G}^{*} \mathrm{~A}$ & 3.684 & 8 & 0.460 & 0.099 & 0.999 \\
\hline $\mathrm{HFM}^{*} \mathrm{VFM}^{*} \mathrm{DFM}^{*} \mathrm{G}^{*} \mathrm{~A}$ & 8.219 & 4 & 2.055 & 0.441 & 0.779 \\
\hline $\mathrm{HFM}^{*} \mathrm{FFM}^{*}{ }^{\mathrm{DFM}}{ }^{*} \mathrm{G}{ }^{*} \mathrm{~A}$ & 0.757 & 4 & 0.189 & 0.041 & 0.997 \\
\hline $\mathrm{VFM}^{*} \mathrm{FFM}^{*}{ }^{*} \mathrm{DFM}^{*}{ }^{*}{ }^{*} \mathrm{~A}$ & 7.307 & 4 & 1.827 & 0.392 & 0.814 \\
\hline $\mathrm{HFM}^{*} \mathrm{VFM}^{*} \mathrm{FFM}^{*}{ }^{*} \mathrm{DFM}{ }^{*} \mathrm{G}{ }^{*} \mathrm{~A}$ & 4.088 & 8 & 0.511 & 0.110 & 0.999 \\
\hline Error & 24144.800 & 5184 & 4.658 & & \\
\hline Total & 38534.746 & 5399 & & & \\
\hline
\end{tabular}


Table 10. Analysis of variance for the perceived risk of injury in lifting tasks for the NIOSH 1991 factors.

\begin{tabular}{|c|c|c|c|c|c|}
\hline Source & Type III Sum of Squares & DFM & Mean Square & $\mathbf{F}$ & $p<$ \\
\hline HFM & 237.418 & 2 & 118.709 & 25.487 & 0.000 \\
\hline VFM & 6514.316 & 2 & 3257.158 & 699.327 & 0.000 \\
\hline FFM & 2897.086 & 2 & 1448.543 & 311.009 & 0.000 \\
\hline DFM & 2597.227 & 1 & 2597.227 & 557.637 & 0.000 \\
\hline G & 91.000 & 1 & 91.000 & 19.538 & 0.000 \\
\hline $\mathrm{A}$ & 4.449 & 1 & 4.449 & 0.955 & 0.328 \\
\hline $\mathrm{HFM}^{*} \mathrm{VFM}$ & 13.461 & 4 & 3.365 & 0.723 & 0.576 \\
\hline $\mathrm{HFM}^{*} \mathrm{FFM}$ & 7.097 & 4 & 1.774 & 0.381 & 0.822 \\
\hline $\mathrm{HFM}^{*} \mathrm{DFM}$ & 1.200 & 2 & 0.600 & 0.129 & 0.879 \\
\hline $\mathrm{HFM}^{*} \mathrm{G}$ & 7.565 & 2 & 3.782 & 0.812 & 0.444 \\
\hline $\mathrm{HFM}^{*} \mathrm{~A}$ & 5.136 & 2 & 2.568 & 0.551 & 0.576 \\
\hline VFM * FFM & 24.710 & 4 & 6.177 & 1.326 & 0.258 \\
\hline VFM * DFM & 209.429 & 2 & 104.715 & 22.483 & 0.000 \\
\hline VFM $^{*} \mathrm{G}$ & 5.694 & 2 & 2.847 & 0.611 & 0.543 \\
\hline VFM * A & 371.027 & 2 & 185.514 & 39.831 & 0.000 \\
\hline FFM * DFM & 3.361 & $\overline{2}$ & 1.681 & 0.361 & 0.697 \\
\hline $\mathrm{FFM}^{*} \mathrm{G}$ & 26.446 & 2 & 13.223 & 2.839 & 0.059 \\
\hline $\mathrm{FFM}^{*} \mathrm{~A}$ & 58.961 & 2 & 29.481 & 6.330 & 0.002 \\
\hline $\mathrm{DFM}^{*} \mathrm{G}$ & 2.200 & 1 & 2.200 & 0.472 & 0.492 \\
\hline $\mathrm{DFM}^{*} \mathrm{~A}$ & 0.031 & 1 & 0.031 & 0.007 & 0.935 \\
\hline$G * A$ & 931.676 & 1 & 931.676 & 200.035 & 0.000 \\
\hline $\mathrm{HFM}^{*} \mathrm{VFM}^{*} \mathrm{FFM}$ & 20.604 & 8 & 2.575 & 0.553 & 0.817 \\
\hline $\mathrm{HFM}^{*}$ VFM * DFM & 5.799 & 4 & 1.450 & 0.311 & 0.871 \\
\hline $\mathrm{HFM}^{*} \mathrm{VFM}^{*} \mathrm{G}$ & 6.376 & 4 & 1.594 & 0.342 & 0.850 \\
\hline $\mathrm{HFM}^{*} \mathrm{VFM}{ }^{*} \mathrm{~A}$ & 7.276 & 4 & 1.819 & 0.391 & 0.816 \\
\hline $\mathrm{HFM}^{*} \mathrm{FFM}^{*}$ DFM & 7.786 & 4 & 1.947 & 0.418 & 0.796 \\
\hline $\mathrm{HFM}^{*} \mathrm{FFM}^{*} \mathrm{G}$ & 5.097 & 4 & 1.274 & 0.274 & 0.895 \\
\hline $\mathrm{HFM}^{*} \mathrm{FFM}^{*} \mathrm{~A}$ & 12.029 & 4 & 3.007 & 0.646 & 0.630 \\
\hline $\mathrm{HFM}^{*} \mathrm{DFM}^{*} \mathrm{G}$ & 0.267 & 2 & 0.134 & 0.029 & 0.972 \\
\hline $\mathrm{HFM}^{*} \mathrm{DFM}^{*} \mathrm{~A}$ & 2.327 & 2 & 1.164 & 0.250 & 0.779 \\
\hline $\mathrm{HFM}^{*} \mathrm{G}{ }^{*} \mathrm{~A}$ & 1.216 & 2 & 0.608 & 0.131 & 0.878 \\
\hline VFM * FFM * DFM & 1.061 & 4 & 0.265 & 0.057 & 0.994 \\
\hline VFM * FFM * G & 3.965 & 4 & 0.991 & 0.213 & 0.931 \\
\hline VFM * FFM *A & 1.141 & 4 & 0.285 & 0.061 & 0.993 \\
\hline VFM * DFM * G & 39.287 & 2 & 19.644 & 4.218 & 0.015 \\
\hline $\mathrm{VFM}^{*}{ }^{\mathrm{DFM}}{ }^{*} \mathrm{~A}$ & 12.225 & 2 & 6.112 & 1.312 & 0.269 \\
\hline VFM ${ }^{*} G^{*} A$ & 49.307 & 2 & 24.654 & 5.293 & 0.005 \\
\hline $\mathrm{FFM}^{*} \mathrm{DFM}^{*} \mathrm{G}$ & 4.064 & 2 & 2.032 & 0.436 & 0.646 \\
\hline $\mathrm{FFM}^{*} \mathrm{DFM}^{*} \mathrm{~A}$ & 1.566 & 2 & 0.783 & 0.168 & 0.845 \\
\hline $\mathrm{FFM}^{*} \mathrm{G}^{*} \mathrm{~A}$ & 4.926 & 2 & 2.463 & 0.529 & 0.589 \\
\hline $\mathrm{DFM}^{*} \mathrm{G}^{*} \mathrm{~A}$ & 70.498 & 1 & 70.498 & 15.136 & 0.000 \\
\hline $\mathrm{HFM}^{*} \mathrm{VFM}^{*} \mathrm{FFM}^{*} \mathrm{DFM}$ & 4.781 & 8 & 0.598 & 0.128 & 0.998 \\
\hline $\mathrm{HFM}^{*} \mathrm{VFM}^{*} \mathrm{FFM}^{*} \mathrm{G}$ & 11.701 & 8 & 1.463 & 0.314 & 0.961 \\
\hline $\mathrm{HFM}^{*} \mathrm{VFM}{ }^{*} \mathrm{FFM}^{*} \mathrm{~A}$ & 14.186 & 8 & 1.773 & 0.381 & 0.931 \\
\hline $\mathrm{HFM}^{*} \mathrm{VFM}^{*} \mathrm{DFM}^{*} \mathrm{G}$ & 14.367 & 4 & 3.592 & 0.771 & 0.544 \\
\hline $\mathrm{HFM}^{*}{ }^{*} \mathrm{FM}{ }^{*} \mathrm{DFM}^{*} \mathrm{~A}$ & 4.645 & 4 & 1.161 & 0.249 & 0.910 \\
\hline $\mathrm{HFM}^{*} \mathrm{VFM}{ }^{*} \mathrm{G}{ }^{*} \mathrm{~A}$ & 3.170 & 4 & 0.792 & 0.170 & 0.954 \\
\hline $\mathrm{HFM}^{*} \mathrm{FFM}^{*}{ }^{\mathrm{DFM}}{ }^{*} \mathrm{G}$ & 3.884 & 4 & 0.971 & 0.208 & 0.934 \\
\hline $\mathrm{HFM}^{*} \mathrm{FFM}^{*}{ }^{\mathrm{DFM}}{ }^{*} \mathrm{~A}$ & 4.037 & 4 & 1.009 & 0.217 & 0.929 \\
\hline $\mathrm{HFM}^{*} \mathrm{FFM}^{*} \mathrm{G}{ }^{*} \mathrm{~A}$ & 1.984 & 4 & 0.496 & 0.106 & 0.980 \\
\hline $\mathrm{HFM}^{*} \mathrm{DFM}{ }^{*} \mathrm{G}{ }^{*} \mathrm{~A}$ & 0.483 & 2 & 0.241 & 0.052 & 0.950 \\
\hline VFM * FFM * DFM * G & 5.174 & 4 & 1.294 & 0.278 & 0.893 \\
\hline $\mathrm{VFM}^{*} \mathrm{FFM}^{*} \mathrm{DFM}^{*} \mathrm{~A}$ & 9.696 & 4 & 2.424 & 0.520 & 0.721 \\
\hline VFM ${ }^{*} F F M * G * A$ & 2.783 & 4 & 0.696 & 0.149 & 0.963 \\
\hline $\mathrm{VFM}^{*} \mathrm{DFM}^{*} \mathrm{G}^{*} \mathrm{~A}$ & 1.803 & 2 & 0.901 & 0.194 & 0.824 \\
\hline $\mathrm{FFM}^{*} \mathrm{DFM}^{*} \mathrm{G}{ }^{*} \mathrm{~A}$ & 0.010 & 2 & 0.005 & 0.001 & 0.999 \\
\hline $\mathrm{HFM}^{*} \mathrm{VFM}^{*} \mathrm{FFM}^{*} \mathrm{DFM}^{*} \mathrm{G}$ & 13.341 & 8 & 1.668 & 0.358 & 0.943 \\
\hline $\mathrm{HFM}^{*} \mathrm{VFM}^{*} \mathrm{FFM}^{*} \mathrm{DFM}^{*} \mathrm{~A}$ & 3.537 & 8 & 0.442 & 0.095 & 0.999 \\
\hline $\mathrm{HFM}^{*} \mathrm{VFM}^{*} \mathrm{FFM}^{*} \mathrm{G}{ }^{*} \mathrm{~A}$ & 3.684 & 8 & 0.460 & 0.099 & 0.999 \\
\hline $\mathrm{HFM}^{*} V F M{ }^{*} \mathrm{DFM}{ }^{*} \mathrm{G}{ }^{*} \mathrm{~A}$ & 8.219 & 4 & 2.055 & 0.441 & 0.779 \\
\hline $\mathrm{HFM}^{*}{ }^{\mathrm{FFM}}{ }^{*} \mathrm{DFM}{ }^{*} \mathrm{G}{ }^{*} \mathrm{~A}$ & 0.757 & 4 & 0.189 & 0.041 & 0.997 \\
\hline $\mathrm{VFM}^{*} \mathrm{FFM}^{*}{ }^{\mathrm{DFM}}{ }^{*} \mathrm{G}{ }^{*} \mathrm{~A}$ & 7.307 & 4 & 1.827 & 0.392 & 0.814 \\
\hline $\mathrm{HFM}^{*}{ }^{*} F M^{*} \mathrm{FFM}^{*}{ }^{*} \mathrm{DFM}{ }^{*} \mathrm{G}^{*} \mathrm{~A}$ & 4.088 & 8 & 0.511 & 0.110 & 0.999 \\
\hline Error & 24144.800 & 5184 & 4.658 & & \\
\hline Total & 38534.746 & 5399 & & & \\
\hline
\end{tabular}


Figures 23 and 24 illustrate results of means and standard deviations of perceived risk of injury for the two travel distance factor multipliers across of horizontal factor multipliers for the different frequency and vertical factor multipliers based on NIOSH 1981 and $\mathrm{NIOSH}$ 1991, respectively. As shown in these figures, factors multipliers change for both equations, and as the factors multipliers of $H, V, D$ and $F$ increase, the perception of risk of injury decrease, which is logical since the factors multipliers are discounting factors, since it is worst as these factors decrease their values.

Significant interactions found in the analysis of variance for the factor multipliers (Table 9 and 10) were plotted. One-way interactions, Figures 25 though 28 show the means and standard deviations of the perceived risk of injury for NIOSH 1981 and 1991, for the factors multipliers of H, V, D and F, respectively. Figures 29 though 32 show means and standard deviations of the perceived risk of injury for NIOSH 1981 and 1991, the two-way interactions of VFMxDFM, VFMxA, FFMxA and GxA respectively, and Figures 33 though 35 show the means and standard deviations of the perceived risk of injury for NIOSH 1981 and 1991, VFMxDFMXG, VFMxGxA and DFMxGxA respectively, from results of three-way interactions. Results demonstrate that $\mathrm{NIOSH}$ 1981 rate the geometric characteristic of the lift as well as the frequency, more severe than NIOSH 1991. 


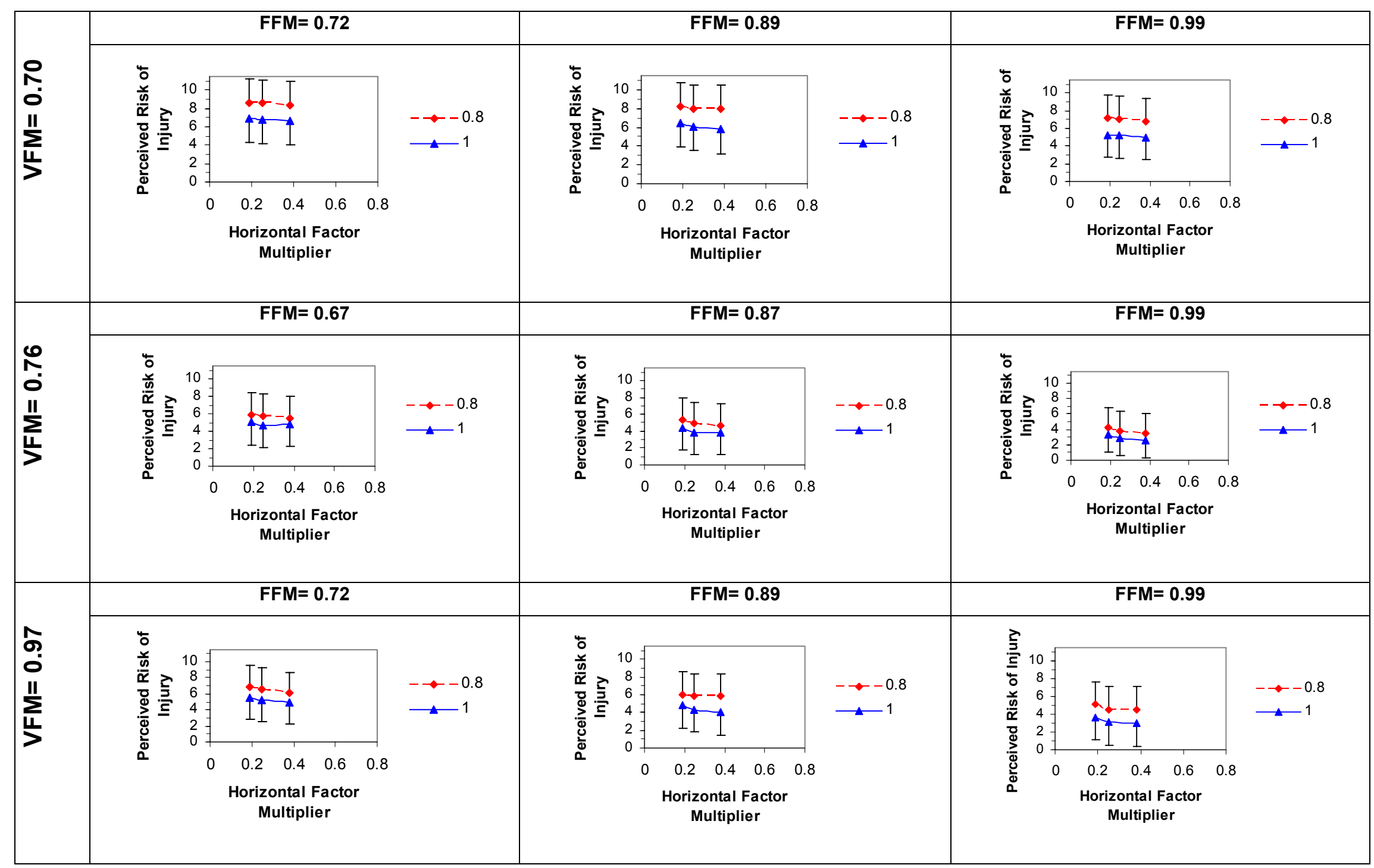

Figure 23. Means and standard deviations of perceived risk of injury for the two travel distance factor multipliers across of horizontal factor multipliers for the different frequency and vertical factor multipliers for NIOSH 1981. 


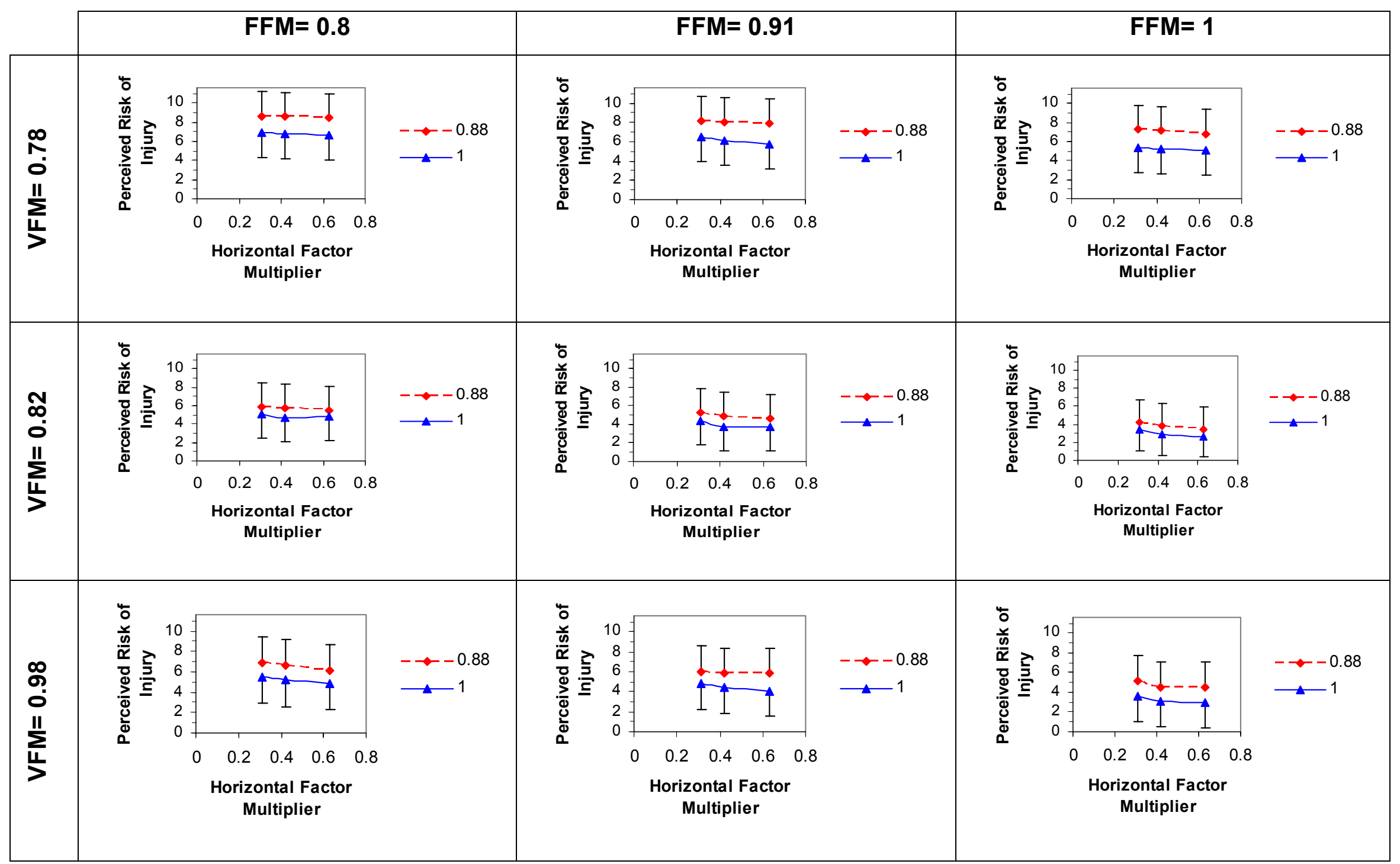

Figure 24. Means and standard deviations of perceived risk of injury for the two travel distance factor multipliers across of horizontal factor multipliers for the different frequency and vertical factor multipliers for NIOSH 1991. 


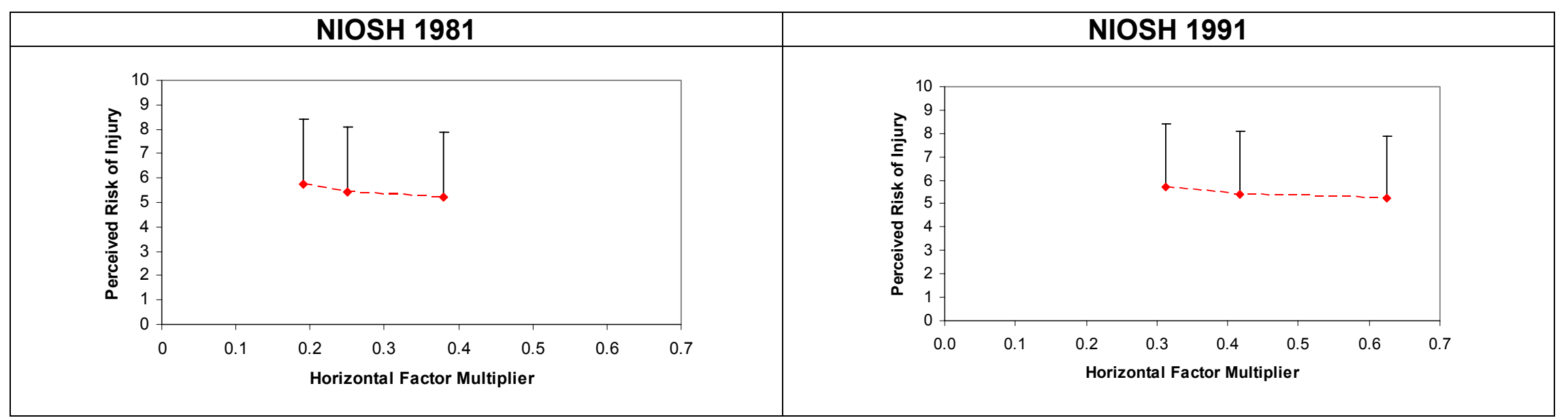

Figure 25. Means and standard deviations of perceived risk of injury for horizontal factor multipliers for NIOSH 1981 and 1991.

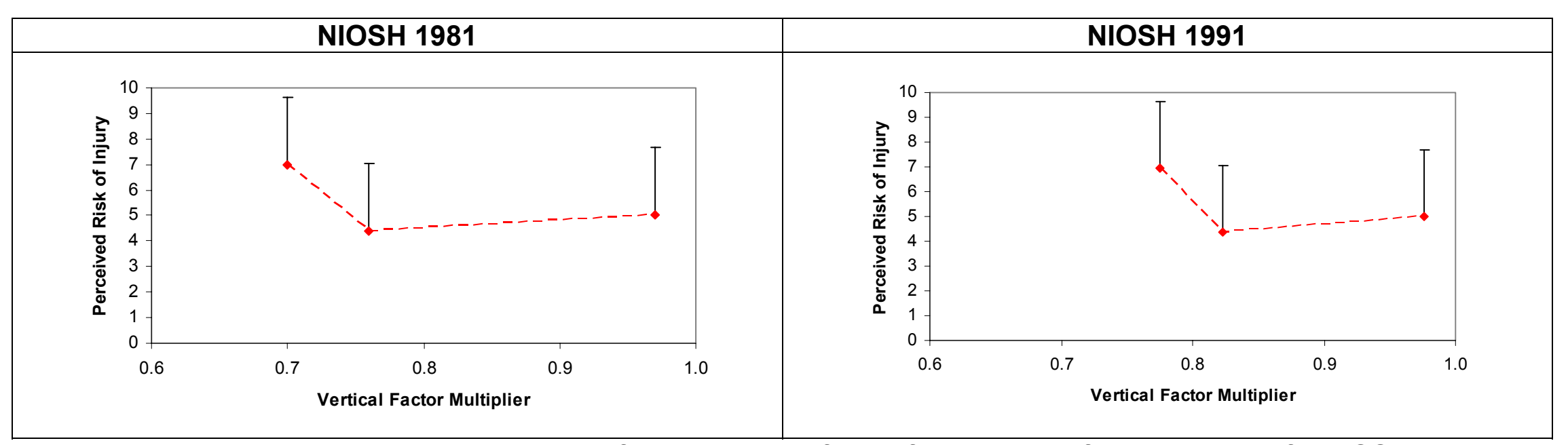

Figure 26. Means and standard deviations of perceived risk of injury for the vertical factor multipliers for NIOSH 1981 and 1991. 


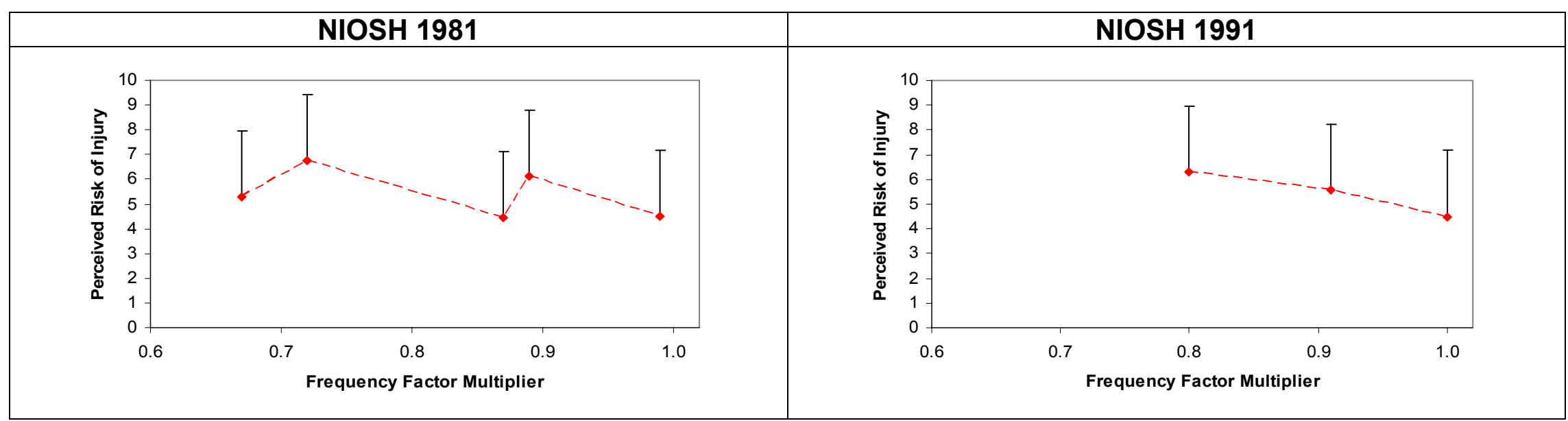

Figure 27. Means and standard deviations of perceived risk of injury for frequency factor multipliers for NIOSH 1981 and 1991.

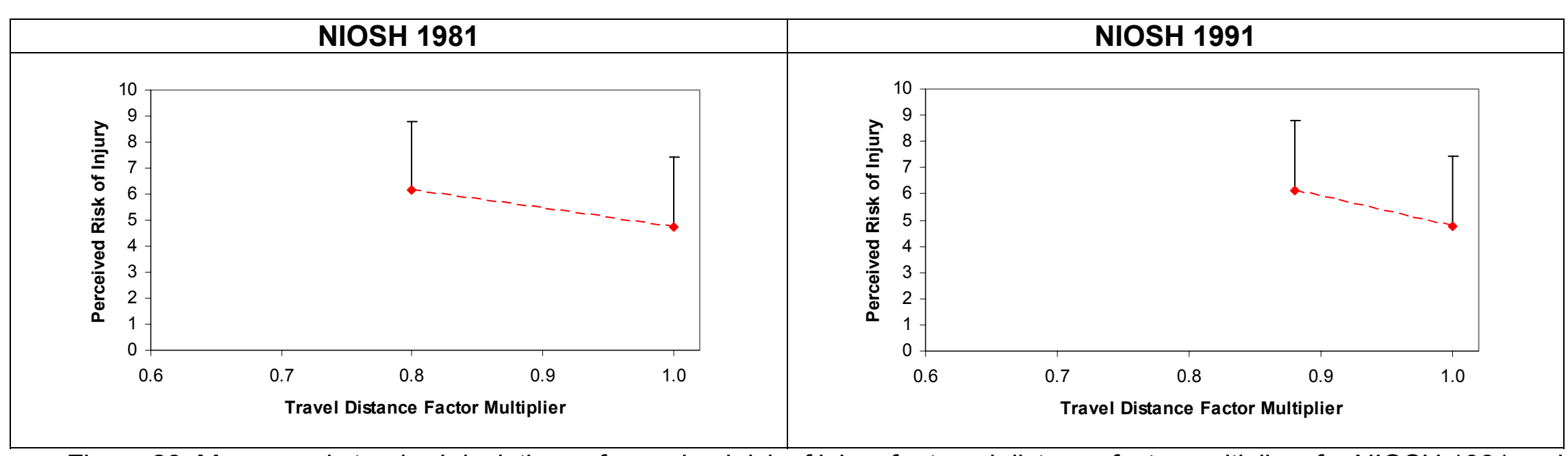

Figure 28. Means and standard deviations of perceived risk of injury for travel distance factor multipliers for NIOSH 1981 and 1991. 


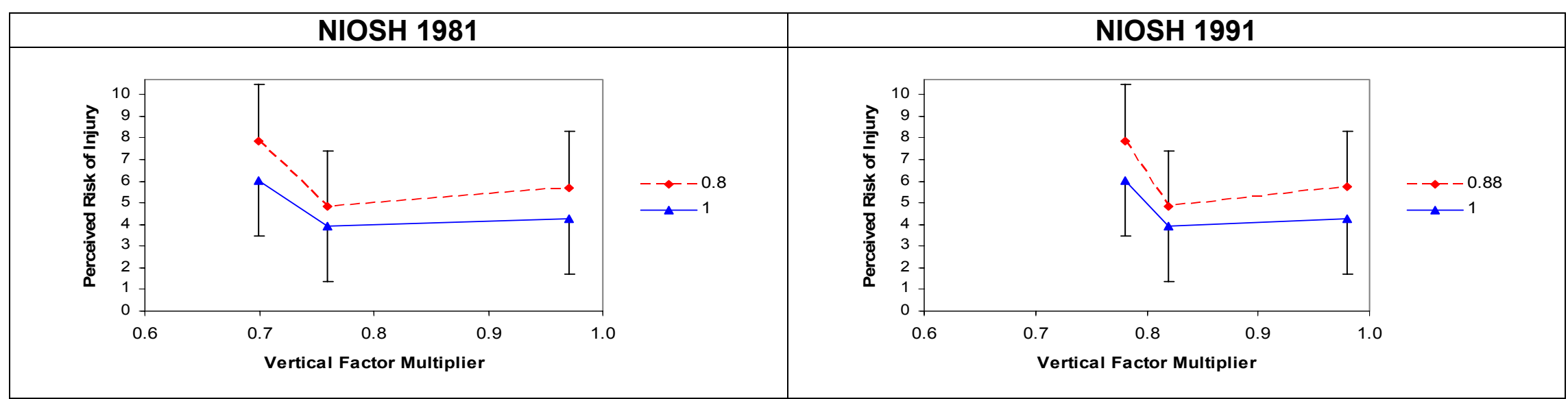

Figure 29. Means and standard deviations of perceived risk of injury for the two travel distance factor multipliers across of vertical factor multipliers for NIOSH 1981 and 1991.

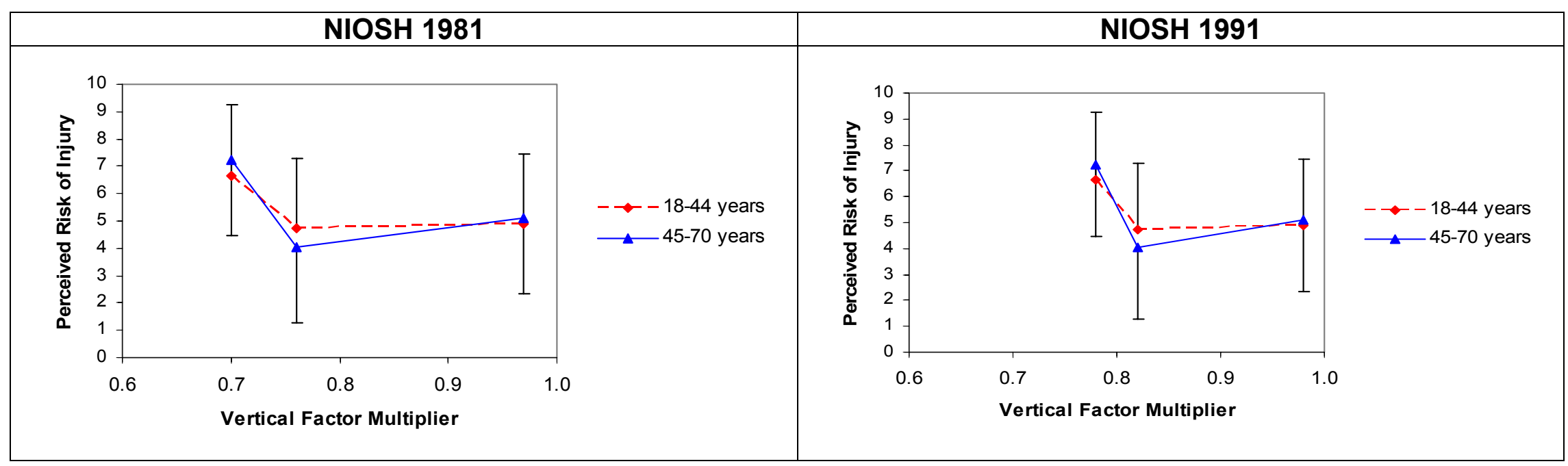

Figure 30. Means and standard deviations of perceived risk of injury for the two travel distance factor multiplier across of vertical factor multiplier for NIOSH 1981 and 1991. 


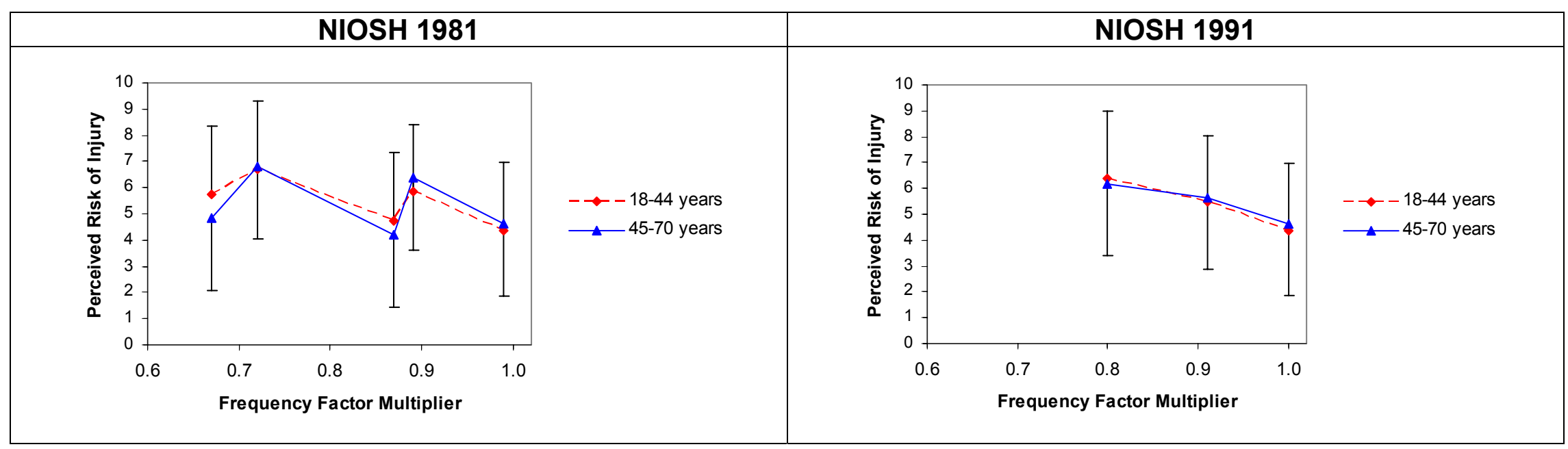

Figure 31. Means and standard deviations of perceived risk of injury for the two groups of age across of frequency factor multipliers for NIOSH 1981 and 1991.

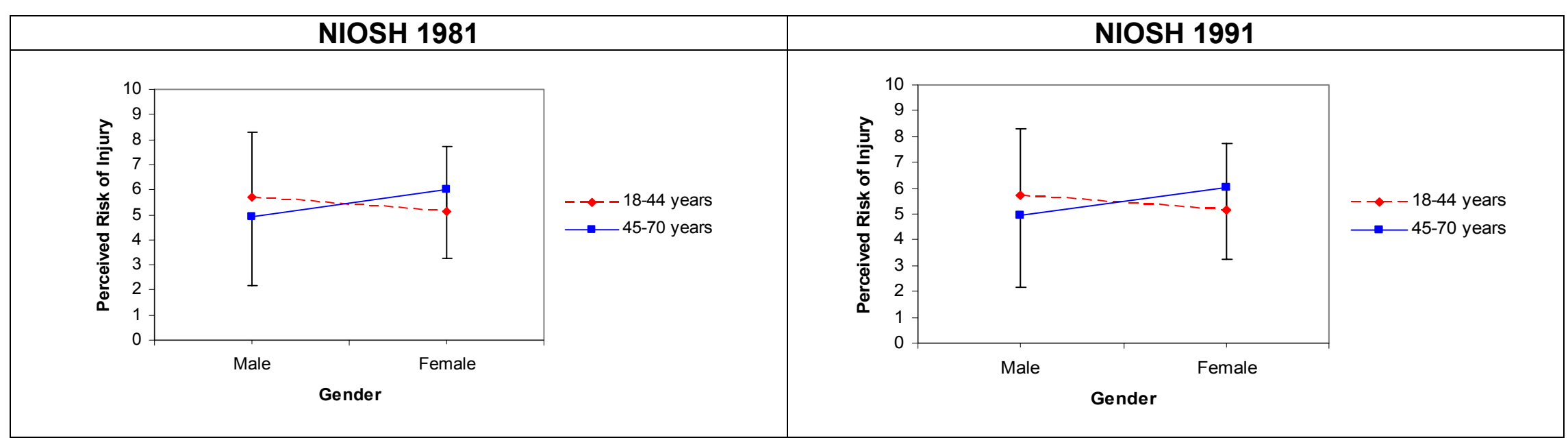

Figure 32. Means and standard deviations of perceived risk of injury for the two groups of age across gender for NIOSH

1981 and 1991. 


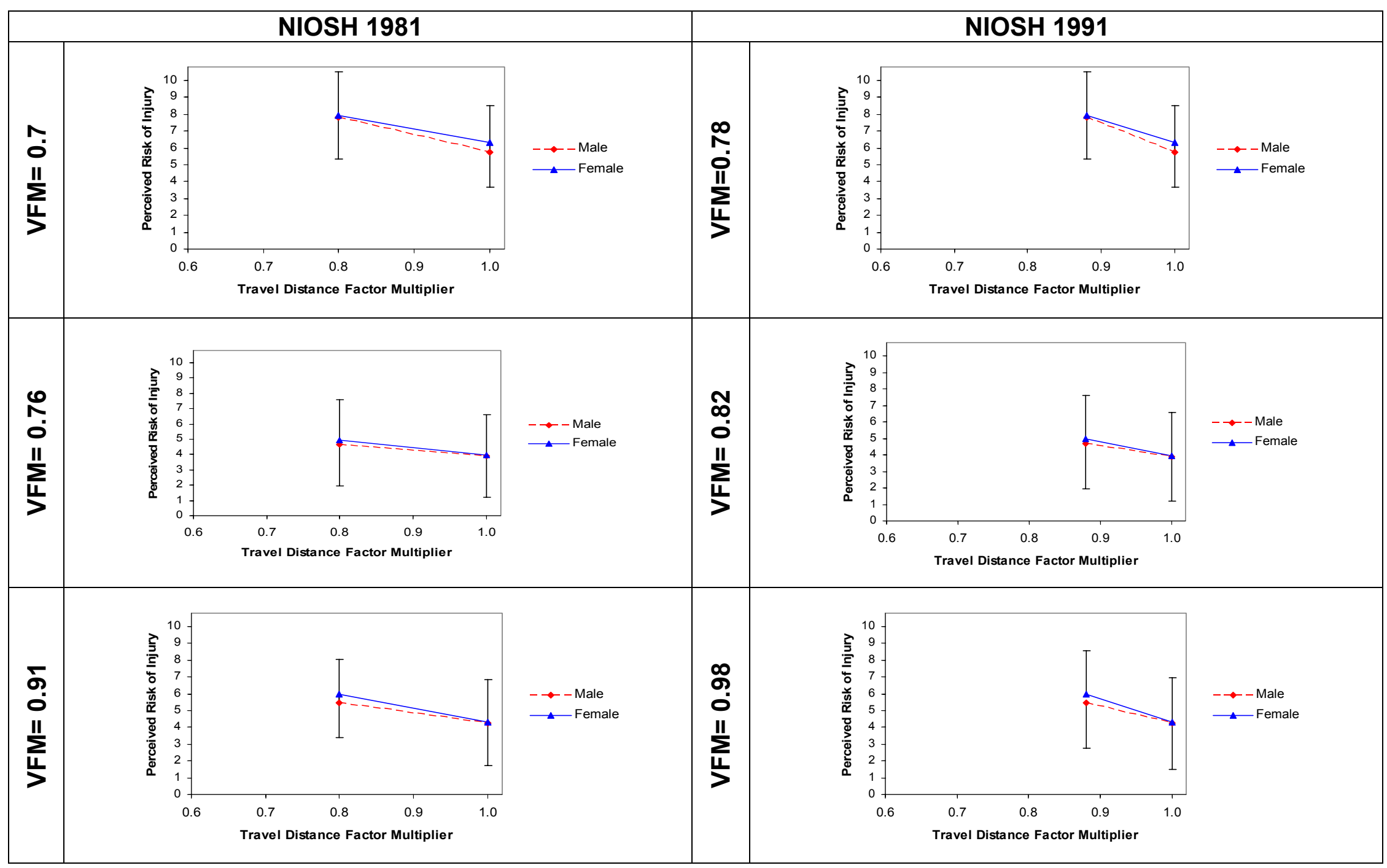

Figure 33. Means and standard deviations of perceived risk of injury for genders across of travel distance factor multipliers for the different vertical factor multipliers of NIOSH 1981 and 1991. 


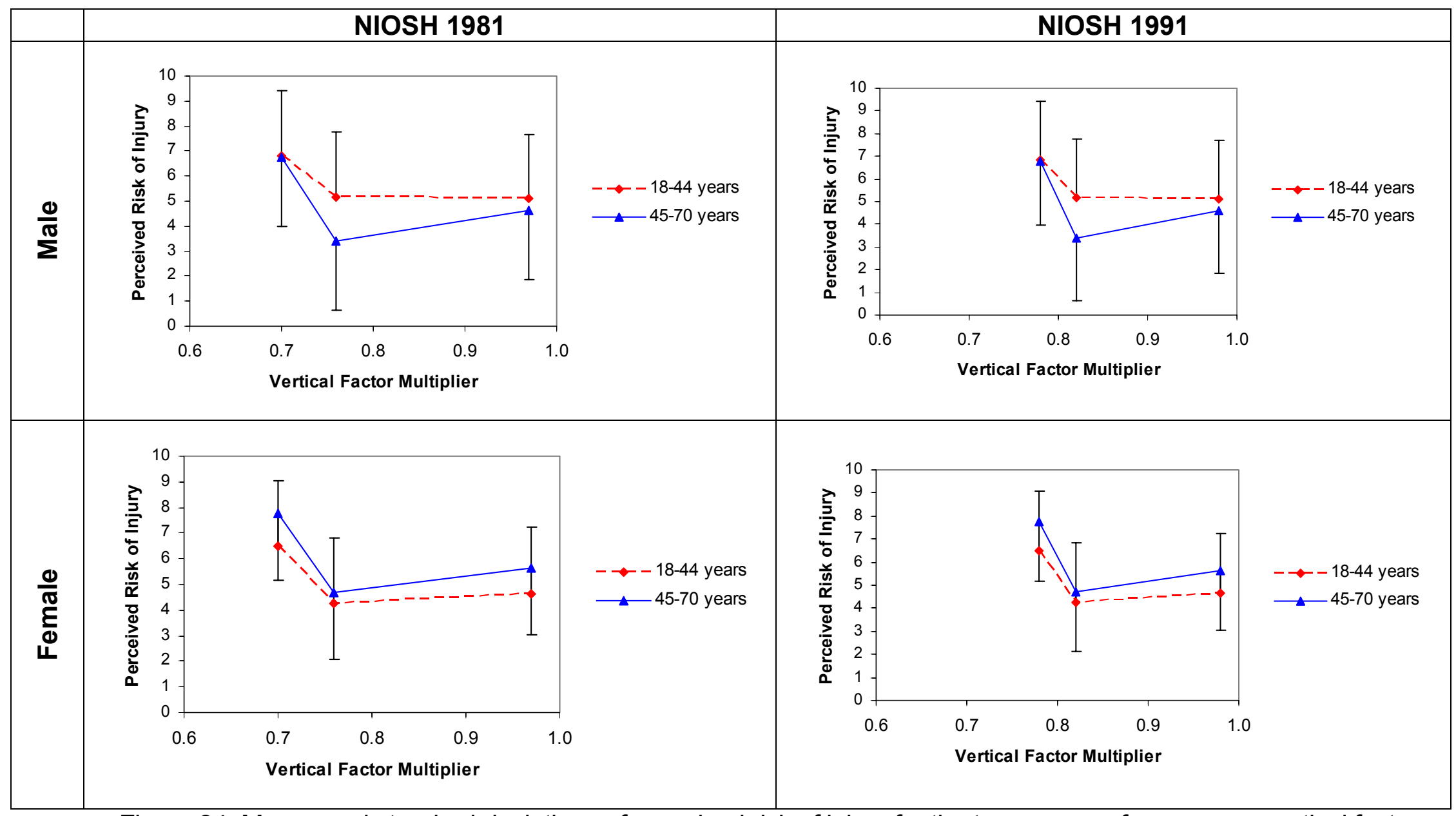

Figure 34. Means and standard deviations of perceived risk of injury for the two groups of age across vertical factor multipliers for gender for NIOSH 1981 and 1991. 


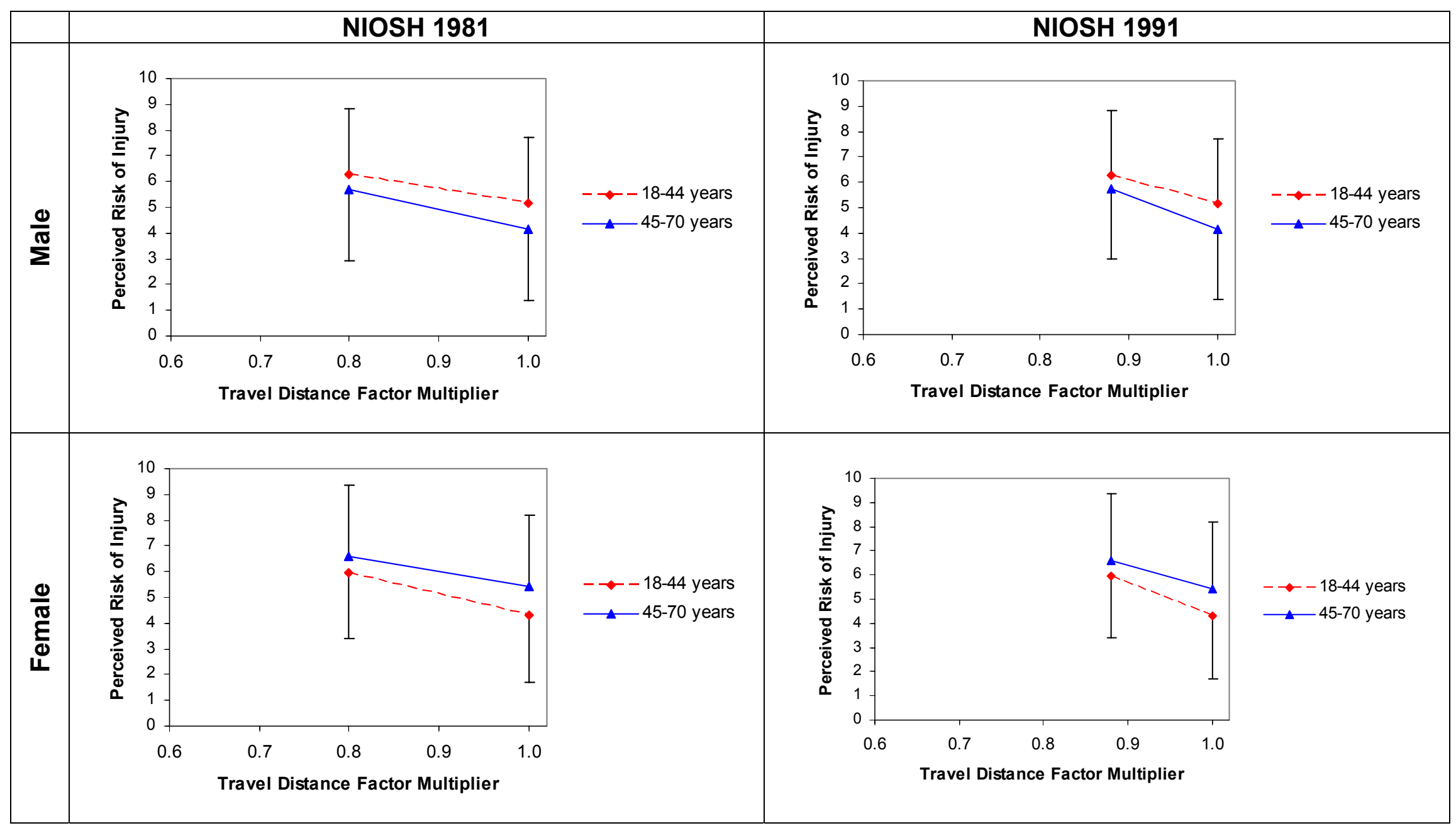

Figure 35. Means and standard deviations of perceived risk of injury for the two groups of age across of travel distance factor multipliers for NIOSH 1981 and 1991 for gender. 


\section{CHAPTER 5}

\section{CONCLUSION AND RECOMMENDATIONS}

This research revealed that people do not know how to assess the risk of injury when comparing with the Job Severity Index from the NIOSH Work Practice Guide 1981, and because of this mismatch people may hurt themselves.

Risk of injury tends to increase as the values for the Job Severity Indexes for the horizontal distance, vertical distance, travel distance and frequency of lift increase; factors employed in the NIOSH Work Practice Guide 1981. The study helped to confirm that people pay attention to the four factors used in the NIOSH WPG (1981), but it was noticed that more attention goes to the factors of vertical distance, travel distance and frequency of lift, and less attention to the horizontal distance. Gender difference exist, as opposite with the age effect, but interaction with age and gender were found, making logical to think that there is also age effect differences, and more consideration should be made when selecting workers.

Males and females had a different perception of risk if injury, related to difference in statures and body masses. Gender effect is an important factor to be addressed since females tend to have less strength than men and have lower anthropometric values.

It appears that subjects based their responses on physiological aspects. The study provided evidence that responses might have be driven by physiological area; as the mechanical work increase an increase in the energy expenditure is produced, and logically results of the risk of injury were increased as the frequency and travel distances were increased.

Subjects do not have the knowledge of biomechanical consequences to the lower back, as a cause of high horizontal distances when lifting tasks, therefore, people damage themselves because the lack of sense about this factor. Biomechanical approach suggest 
that horizontal distance is one of the mayor factor for developing high compression forces at the low back, and people do not pay as much attention to this factor as the other used in the NIOSH WPG 1981 when assessing the risk of injury. Subjects did not consider risky the horizontal value as much as the other factors, maybe because other factors were more noticeable and shocking.

Workers may not perform a well designed job using a recommended method because their judgment. Thus it is necessary to take into account people judge in workers trainings.

Further investigation needs to be done regardless people perception of risk of injury in lifting tasks to help reduce occupational injuries and provide better understanding of people perception for job designs.

\section{Recommendations}

- It would be interesting to develop this study with subjects looking personally in front of the tasks. Showing tasks as pictures may not have the same impact as making subjects observe the tasks in a real scale.

- More research is needed for the age effect, since no significance was found as a main effect but interaction with this factor were found.

- Effect of box weight was not included in the study, it will be also recommended to study perception of risk of injury when the weight of the box it is not given to subjects. 


\section{REFERENCES}

1. Asfour, S., Ayoub, M., Mital, A. and Bethea, N. 1983, Perceived exertion of physical effort for various manual handling tasks. American Industrial Hygiene Association Journal, 44 (3), 223-228.

2. Chaffin, D. 1974, Human strength capability and low back pain. Journal of occupational medicine, 16, 248-254.

3. Cheng, T. and Lee, T. 2005, Lifting strengths in different horizontal distances of objects to be lifted. Journal of Occupational Health, 47, 211-217.

4. Daraiseh, N., Genaidy, A., Karwowski, W., Davis, L., Stambough, J. and Huston, R. 2003, Musculoskeletal outcomes in multiple body regions and work effect among nurses: the effects of stressful and stimulating working conditions. Ergonomics, 46 (12), 1178-1199.

5. Dempsey, P. 1998, A critical review of biomechanical, epidemiological, physiological and psychophysical criteria for designing manual materials handling tasks. Ergonomics, 41 (1), 73-88.

6. Dempsey, P. and Hashemi, L.1999, Analysis of workers' compensation claims associated with Manual Material Handling. Ergonomics, 42 (1), 183-195.

7. Department of Labor (BLS), 1982, Back Injuries associated with lifting, Bulletin No. 2144. U.S. Department of Labor, Bureau of Labor Statistics.

8. Engst, C., Chhokar, R., Miller, A., Tate, R. and Yassi, A. 2005, Effectiveness of overhead lifting devices in reducing the risk of injury to care staff in extended care facilities. Ergonomics, 48 (2), 187-199.

9. Garg, A. 1989, An evaluation of the NIOSH Guidelines for Manual Lifting, with special reference to horizontal distance. American Industrial Hygiene Association Journal, 50 (3), 157-164.

10. Garg, A. and Chaffin D. 1975, A Biomechanical computerized simulation of human strength. AllE Transactions, 7, 1-15.

11. Genaidy, A. and Asfour, S. 1989, Effects of frequency and load of lift on endurance time. Ergonomics, 32 (1), 51-57. 
12. Genaidy, A., Karwowski, W., Christensen, D., Vogiatzis, C., Deraiseh, N. and Prins, A. 1998, What is 'heavy'? Ergonomics, 41 (4), 420-432.

13. Hattori, Y., Ono, Y., Shimaoka, M., Hiruta, S., Shibata, E., Ando, S., Hori, F., Takeuchi, Y. 2000, Effects of box weight, vertical location and symmetry on lifting capacities and ratings on category scale in Japanese female workers. Ergonomics, 43 (12), 2031-2042.

14. Hidalgo, J., Genaidy, A., Karwowski, W., Christensen, D., Huston, R. and Stambough, J. 1997, A comprehensive lifting model: beyond the NIOSH lifting equation. Ergonomics, 40 (9), 916-927.

15. Huang, Y., Chen, P., Rogers, D. and Krauss, A. 2003, Role of workplace safety: A revisit of the relationship between job satisfaction and employment status. Work, 21, 251-256.

16. ICMR Bulletin, 2000. Ergonomics in Manual Material Handling tasks, vol 30, 8, ISSN 0377-4910.

17. Karwowski, W., 1991, Pshychophysical acceptability and perception of load heaviness by females. Ergonomics, 34 (4), 487-496.

18. Lindbeck, L. and Kjellberg, K. 2001, Gender difference in lifting techniques. Ergonomics, 44 (2), 202-214.

19. Marras, W., Fine, L., Ferguson, S. and Waters, T. 1999, The effectiveness of commonly used lifting assessment methods to identify industrial jobs associated with elevated risk of low-back disorders. Ergonomics, 42 (1), 229-245.

20. Marras, W., Davis, K., Jorgensen, M. (2002), Spine loading as a function of gender. Spine, 27 (22), 2514-2520.

21. Michalsen, A. 2003, Risk assessment and perception. Injury Control and Safety Promotion, 10 (4), 201-204.

22. Mital, A and Ayoub M. 1981, Effect of task variables and their interactions in lifting and lowering loads. American Industrial Hygiene Association Journal, 42 (2), 134142.

23. Mital, A., Nicholson, A. and Ayoub, M. 1997, A Guide to Manual Materials Handling. $2^{\text {nd }}$ Ed. (London: Taylor \& Francis). 
24. Montgomery, D. 2001. Design and Analysis of Experiments. $5^{\text {th }}$ Ed. (New York: John Wiley \& Sons).

25. Nielsen, P., Andersen, L. and Jørgensen K. 1998, The muscular load on the lower back and shoulders due to lifting at different lifting heights and frequencies. Applied Ergonomics, 29 (6), 445-450.

26. Nindl, B., Sharp, M., Mello, R., Rice, V., Murphy, M., Patton, J. 1998, Gender comparison of peak oxygen uptake: repetitive lifting versus treadmill running. European Journal of Applied Physiology, 77, 112-117.

27. NIOSH WPG 1981. Work practices guide for manual materials handling. Cincinnati, OH: U.S. Department of Health and Human Services, Public Health Service, Centers for Disease Control, National Institute for Occupational Safety and Health, DHHS (NIOSH) Publication 81-122.

28. Putz-Anderson, V. and Waters, T. 1991, Revisions in NIOSH Guide to Manual Lifting, paper presented at national conference entitled "A National Strategy for Occupational Musculoskeletal Injury Prevention- Implementation Issues and Research Needs", University of Michigan.

29. Roth, S., Ivey, F., Martel, G., Lemmer, J., Hurlburt, D. et al. 2001, Muscle size responses to strength training in young and older men and women. Journal of the American Geriatrics Society, 49, 1428-1433.

30. Snook, S. and Ciriello, V. 1991, The design of manual handlings tasks: revised tables of maximum acceptable weights and forces. Ergonomics, 34 (9), 1197-13.

31. Treaster, D. and Burr, D. 2004, Gender differences in prevalence of upper extremity musculoskeletal disorders. Ergonomics, 47 (5), 495-526.

32. Waikar, A., Lee, K., Aghazadeh, F. and Parks C. 1991, Evaluating lifting tasks using subjective and biomechanical estimates of stress at the lower back. Ergonomics, 34 (1), 33-47.

33. Waters, T., Baron, S. and Kemmlert, K. 1998, Accuracy of measurements for the revised NIOSH lifting equation. Applied Ergonomics, 29 (6), 433-438.

34. Waters, T., Putz-Anderson, V., Garg, A. 1994, Applications manual for the revised $\mathrm{NIOSH}$ lifting equation. Cincinnati, OH: U.S. Department of Health and Human Services, Public Health Service, Centers for Disease Control and Prevention, 
National Institute for Occupational Safety and Health, DHHS (NIOSH) Publication No. 94-110.

35. Waters, T., Putz-Anderson, V., Garg, A., Fine, L. J. 1993, Revised NIOSH equation for the design and evaluation of manual lifting tasks. Ergonomics, 36 (7), 749-776.

36. Yeung, S., Genaidy, A., Huston, R. and Karwowski, W. 2002, An expert cognitive approach to evaluate physical effort and injury risk in manual lifting- a brief report of a pilot study. Human Factors and Ergonomics in Manufacturing, 12 (2), 227-234.

37. Yeung, S., Genaidy, A., Karwowski, W. and Leung, P. 2002, Reliability and validity of self-reported assessment of exposure and outcome variables for manual lifting tasks: a preliminary investigation. Applied Ergonomics, 33 (5), 463-469.

38. Yeung, S., Genaidy, A., Deddens, J., Leung, P. 2003, Worker's assessment of manual lifting tasks: cognitive strategies and validation with respect to objective indices and musculoskeletal symptoms. International Archives of Occupational and Environmental Health, 76 (7), 505-516. 


\title{
APPENDIX 1. Protocol approval.
}

\author{
West VirginiaUniversity \\ Office of Research Compliance
}

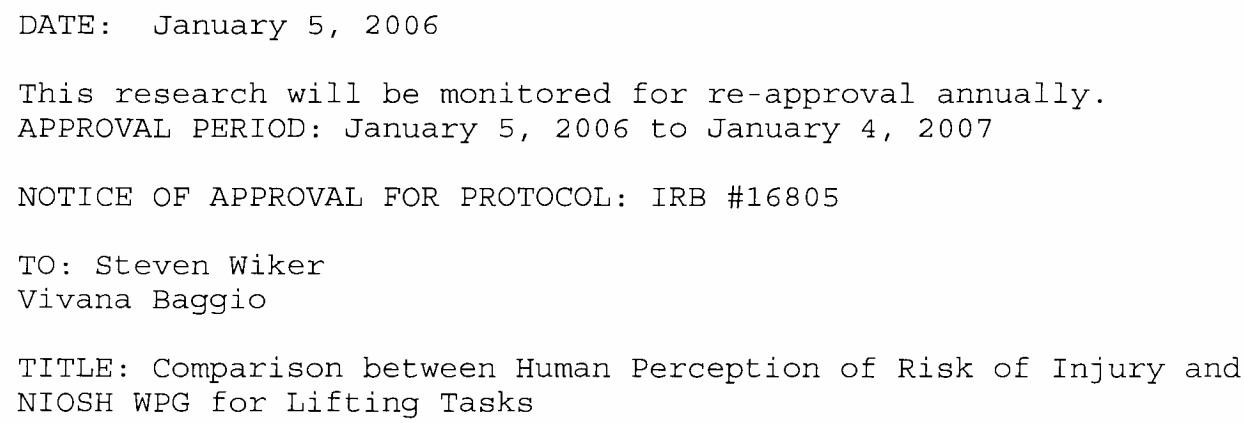

According to the Code of Federal Regulations, Section 312.32, investigators are required to notify the FDA and the study sponsor of any adverse experience associated with the use of an investigational drug that is serious and unexpected. A serious adverse experience is considered any event that is fatal or lifethreatening, is permanently disabling, requires inpatient hospitalization, or is a congenital anomaly, cancer, or overdose. An unexpected adverse experience is an event that is not identified in nature, severity, or frequency in the current investigator brochure. Any experience reportable to FDA and the sponsor must also be reported immediately to the IRB. If the study is funded, initiation of the protocol may not begin until the contract is finalized. 


\section{APPENDIX 2. Consent form.}

$w$

WesthrginiaUniversity

College of Engineering and Mineral Resources

\section{CONSENT AND INFORMATION FORM}

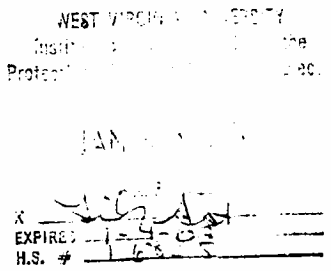

exp.

\section{Comparison between human perception of risk of injury and NIOSH WPG for lifting tasks}

Introduction: I, have been asked to participate in this research study. I have received an explanation of the study by Ms. Viviana Baggio, B.S. from the Department of Industrial and Management Systems Engineering, West Virginia University and understand that this research is being done to fulfill requirements for a master's thesis. Dr. Wiker is supervising this study and serves as Ms. Baggio's thesis advisor.

Purposes of the Study: The survey is designed to asses your perception of risk of injury in manual material handling tasks. You will be asked to see a series of pictures and rate the risk of injury you believe the task can cause you. A comparison will be made between human responses with NIOSH Work Practice Guide (WPG) to see if people are able to recognize the risks generated by lifting tasks.

This study will give information about the perception of humans in manual material handling to understand human perception before attempting lifting tasks.

Description of Procedures: This study involves looking at tasks pictures and scoring the level of lifting-related injury risk I think is associated with each proposed lift. The rating process will take less than 30 minutes for me to complete.

This study presents 54 pictures for me to score or grade, and I will answer a few questions about my gender, age and previous training in safe lifting. I will score the risk of injury of a task in a range that will vary from 0 to 10 , (0 "No risk of injury" to 10 "Maximum risk of injury").

I understand that the data will be coded to eliminate any possibility of identifying my data or my participation. Approximately 300 subjects are expected to participate in this study.

Risks and Discomforts: No risk to your safety and health are associated with your participation. Ycu are not required to answer all the questions and you can stop your participation at any time.

Version date $01 / 02 / 06$

Page 1 of 2

Initials Date 


\section{APPENDIX 2. Consent form (cont.)}

\section{Comparison between human perception of risk of injury and NIOSH WPG for lifting tasks}

Alternatives: I understand that I do not have to participate in this study. I can withdraw from the study at any moment without consequences.

Benefits: I understand that this study is not expected to be of direct benefit to me, but the knowledge gained may be of benefit to others. I also understand that I have a chance to win a prize for $\$ 100$.

Contact Persons: This study is being conducted by Dr. Steven Wiker and Ms. Viviana Baggio of the West Virginia University Ergonomics Laboratory, Department of Industrial and Management Systems Engineering, PO BOX 6070, West Virginia University, Morgantown, WV, 26505.

Confidentiality: All e-mail address will be treated in a confidential manner. After the random selection is made to award the $\$ 100$, all e-mail addresses will be destroyed and your responses will be entered into a database for analysis. We will have no means to identify your responses and there will be no possibility of determining who participated in the study.

Voluntary Participation: Participation in this study is voluntary. I understand that I am free to withdraw my consent to participate in this study at any time and that such refusal to participate will not affect my future care. Refusal to participate or withdrawal will involve no penalty to me. Upon signing this form, I will receive a copy.

I willingly consent to participate in this research.

Signature of Subject

Signature of Investigator

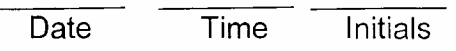

Date - Time - Initials Date 


\section{COMPARISON BETWEEN HUMAN PERCEPTION OF RISK OF INJURY AND NIOSH WPG FOR LIFTING TASKS}

\section{INFORMATION}

1. Subject Code (mmddyy of birthday and last two digit of your social security number) Example (07177814)

\section{Age}

3. Gender
C Male
C Female

4. Weight (lbs.)

5. Height (ft.)

6. Level of education

C High School diploma

C College degree

C Graduate degree

7. Have you had formal training in safe lifting techniques?
C Yes
C No

8. Have you had a back injury that has restricted your activities for two or more days?
C Yes
C No

9. Please provide the e-mail address if you want to compete for the $\$ 100$. 
Read carefully each case scenario. Assume that you have to perform the lifting task shown in each case scenario. Two views are presented in each case, front and side view. You are asked to rank the risk of injury of the task $(0=$ no risk of injury to10=maximum risk of injury) by imagining yourself lifting the blue box (start position) and moving it to the exact position of the yellow box (end position). The blue box is the real box to be lifted; the yellow box is just to represent the final position. You are supposed to stand on the black feet marks placed on the floor and lift the box by its handle. The frequency represents the number of repetitions for the same activity that you have to perform in each case. Notice that the frequency of the task, and feet marks change from case to case. The weight of the blue box is $20 \mathrm{Kg}$. (44 Lbs.). See the example shown below.

\section{EXAMPLE}

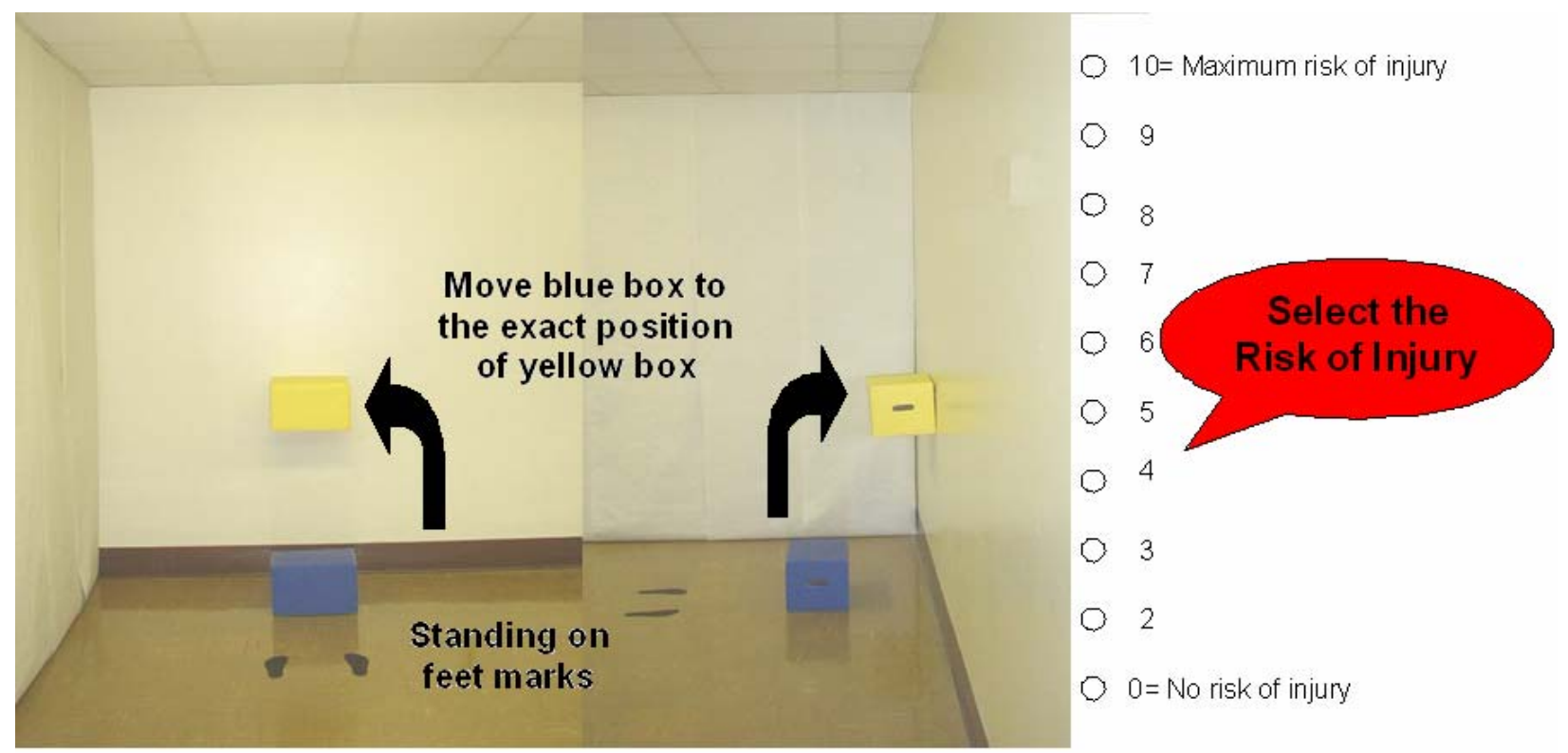

BLUE $B O X=20 \mathrm{Kg}$. (44 lbs.)

12 LIFTS PER HOUR 


\section{Lifting Task 1}

\section{RATE THE RISK OF INJURY}

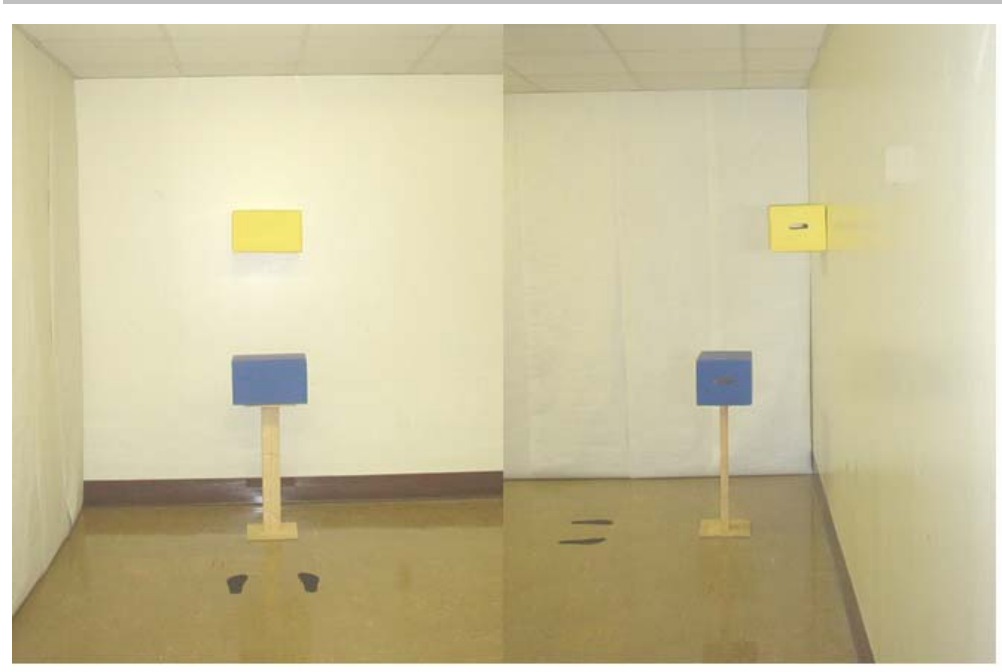

BLUE BOX= 20 Kg. (44 lbs.)

300 LIFTS PER HOUR
C $10=$ Maximum risk of injury

C 9

C 8

C 7

C 6

C 5

C 4

C 3

$\mathrm{C}_{2}$

$\mathrm{C}_{1}$

C $0=$ No risk of injury

\section{Lifting Task 2}

\section{RATE THE RISK OF INJURY}

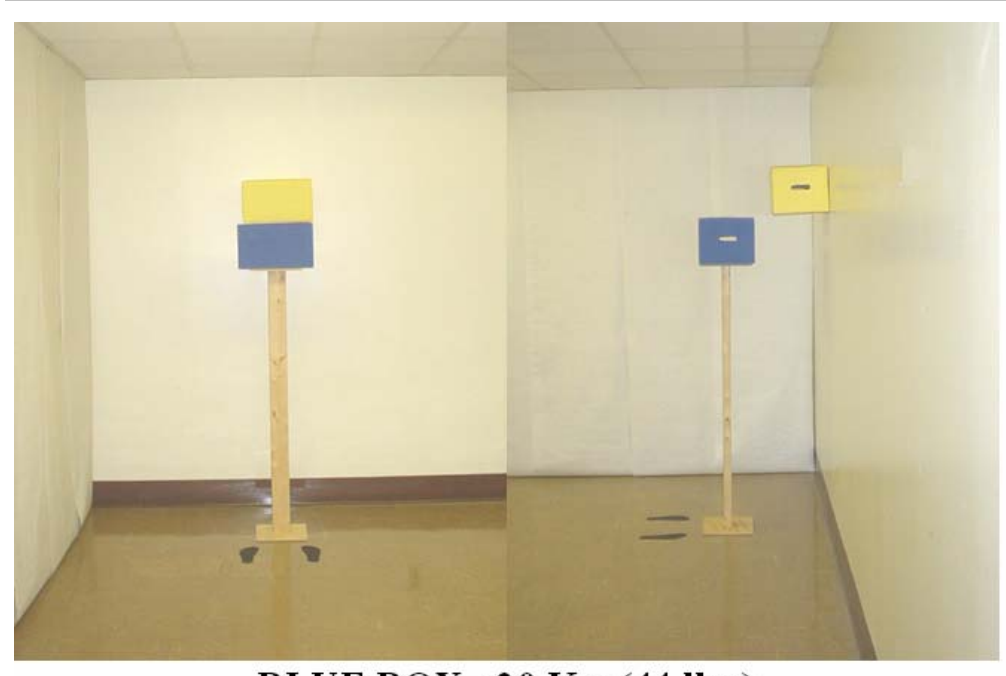

BLUE BOX= $20 \mathrm{Kg}$. (44 lbs.)

12 LIFTS PER HOUR
C 10 = Maximum risk of injury

C 9

C 8

C 7

C 6

C 5

C 4

$\mathrm{C}_{3}$

C 2

C 1

C $0=$ No risk of injury 


\section{Lifting Task 3}

\section{RATE THE RISK OF INJURY}

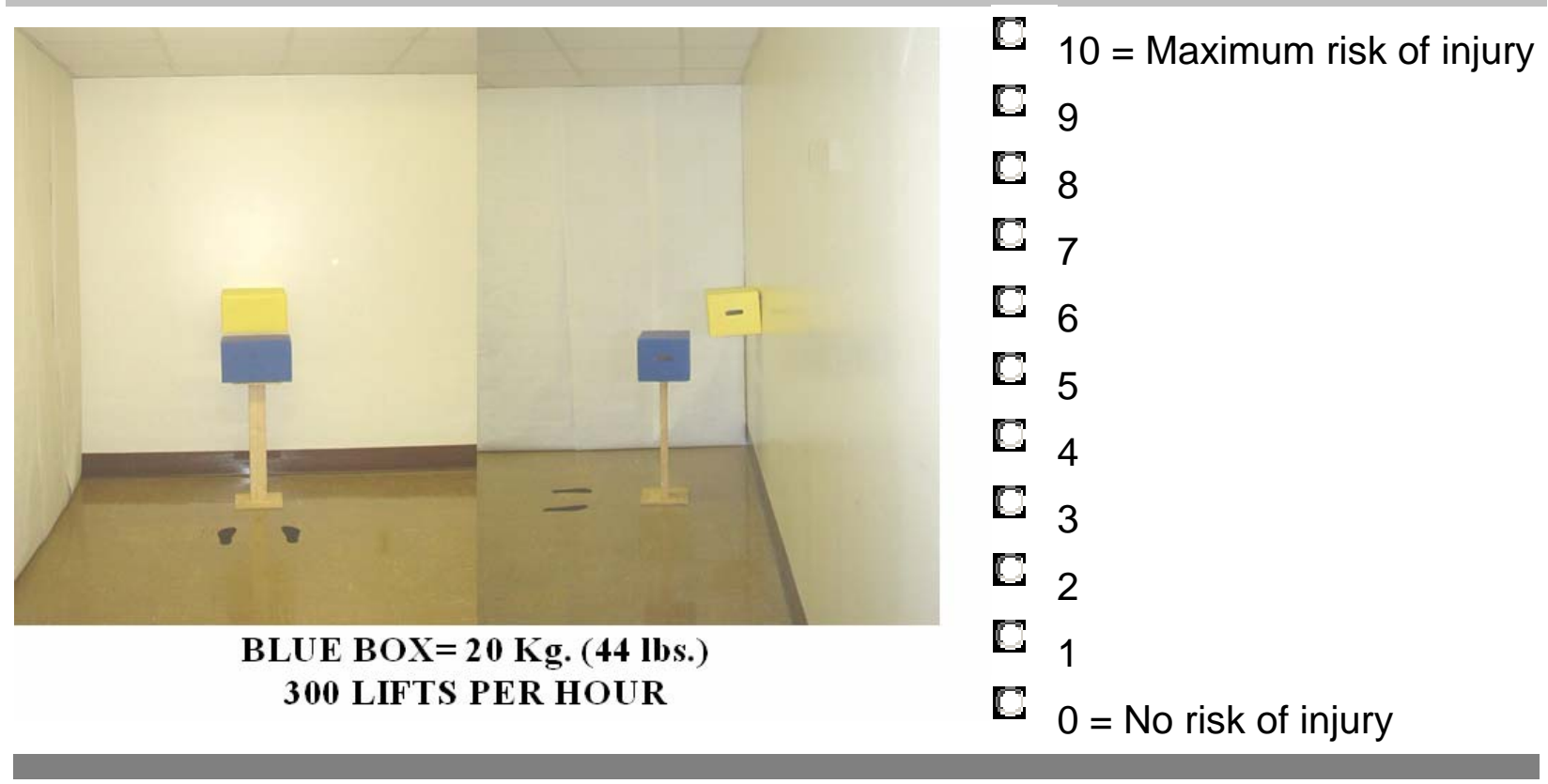

\section{Lifting Task 4}

\section{RATE THE RISK OF INJURY}

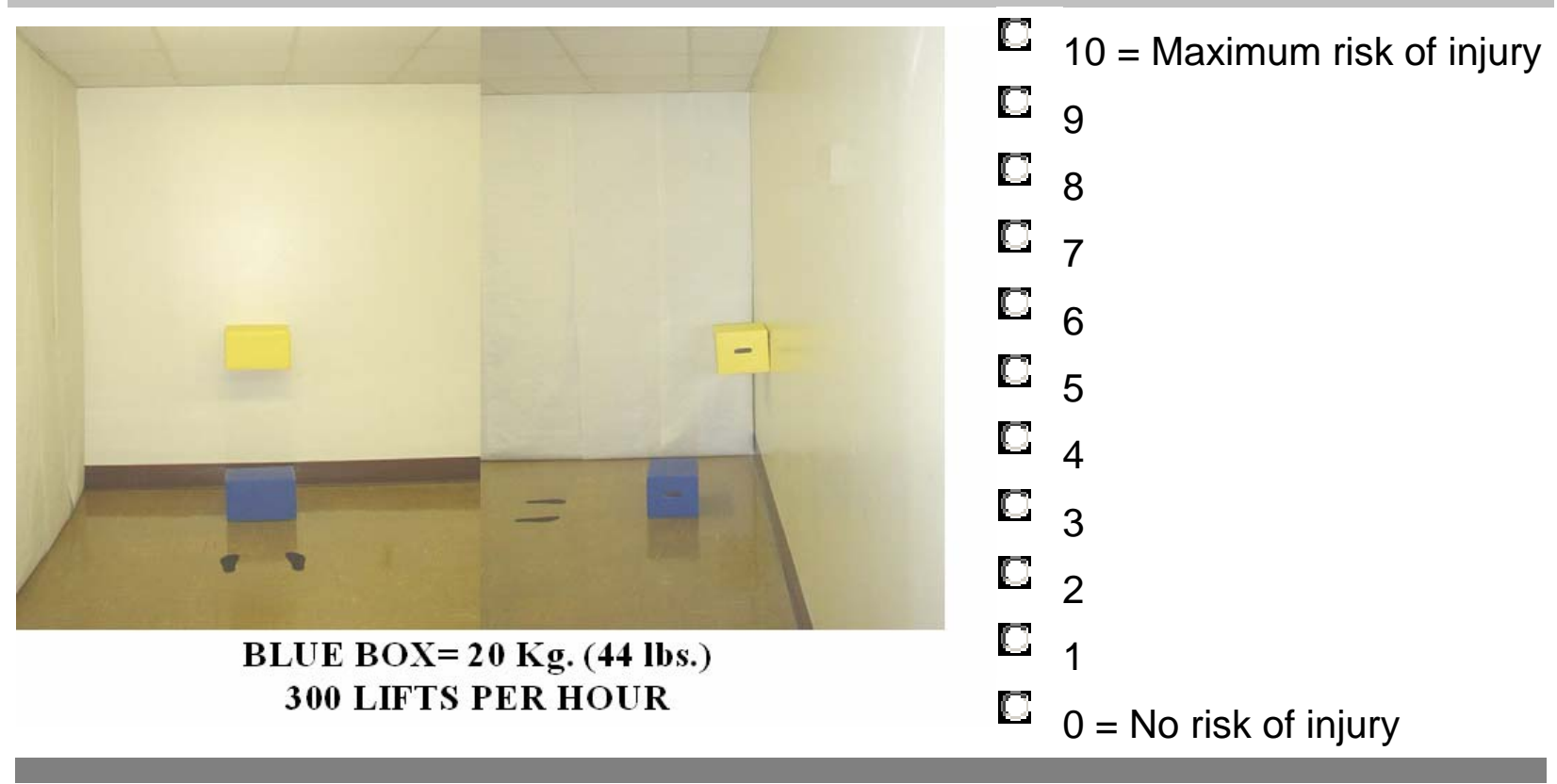




\section{Lifting Task 5}

\section{RATE THE RISK OF INJURY}

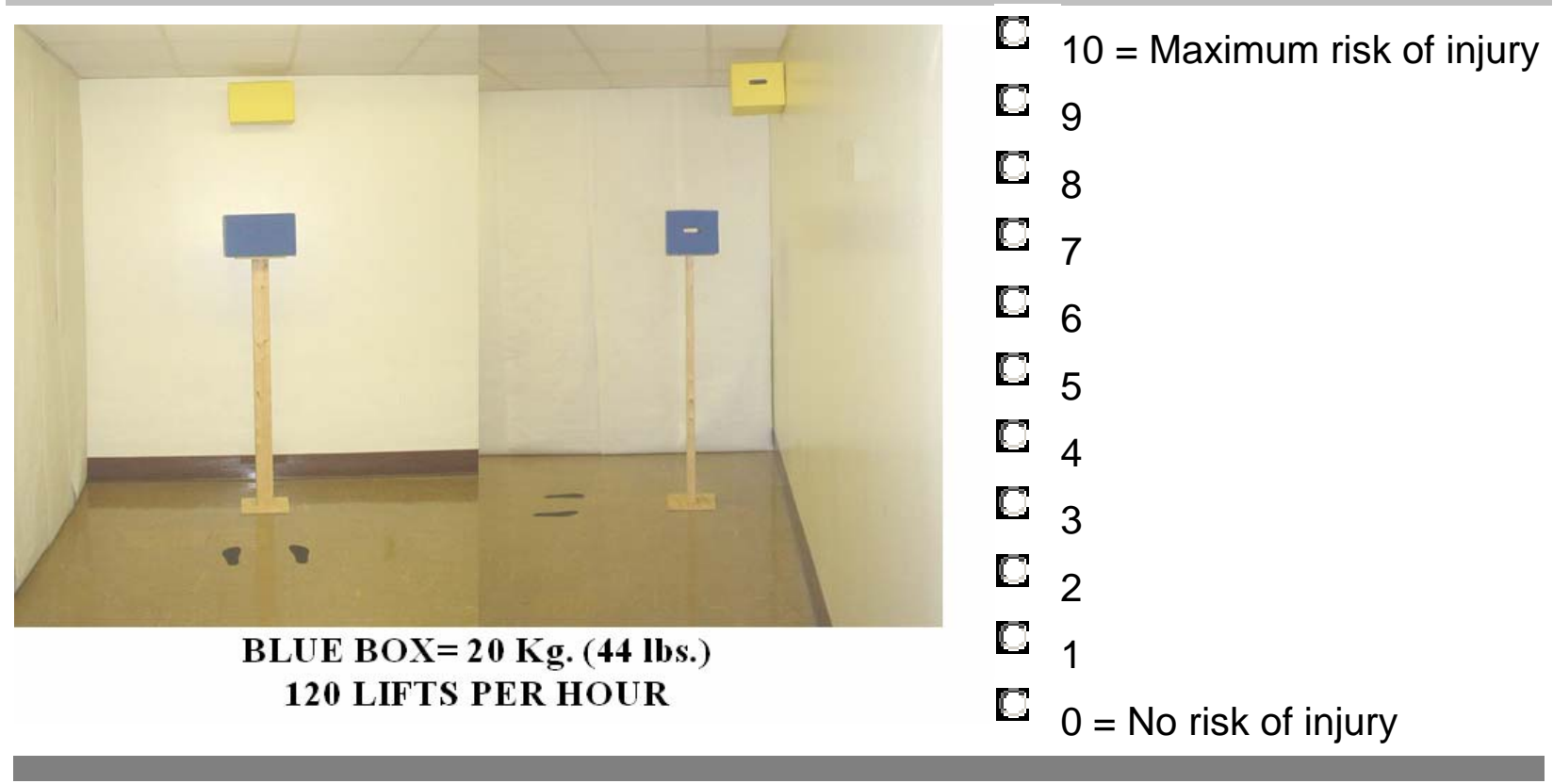

\section{Lifting Task 6}

\section{RATE THE RISK OF INJURY}

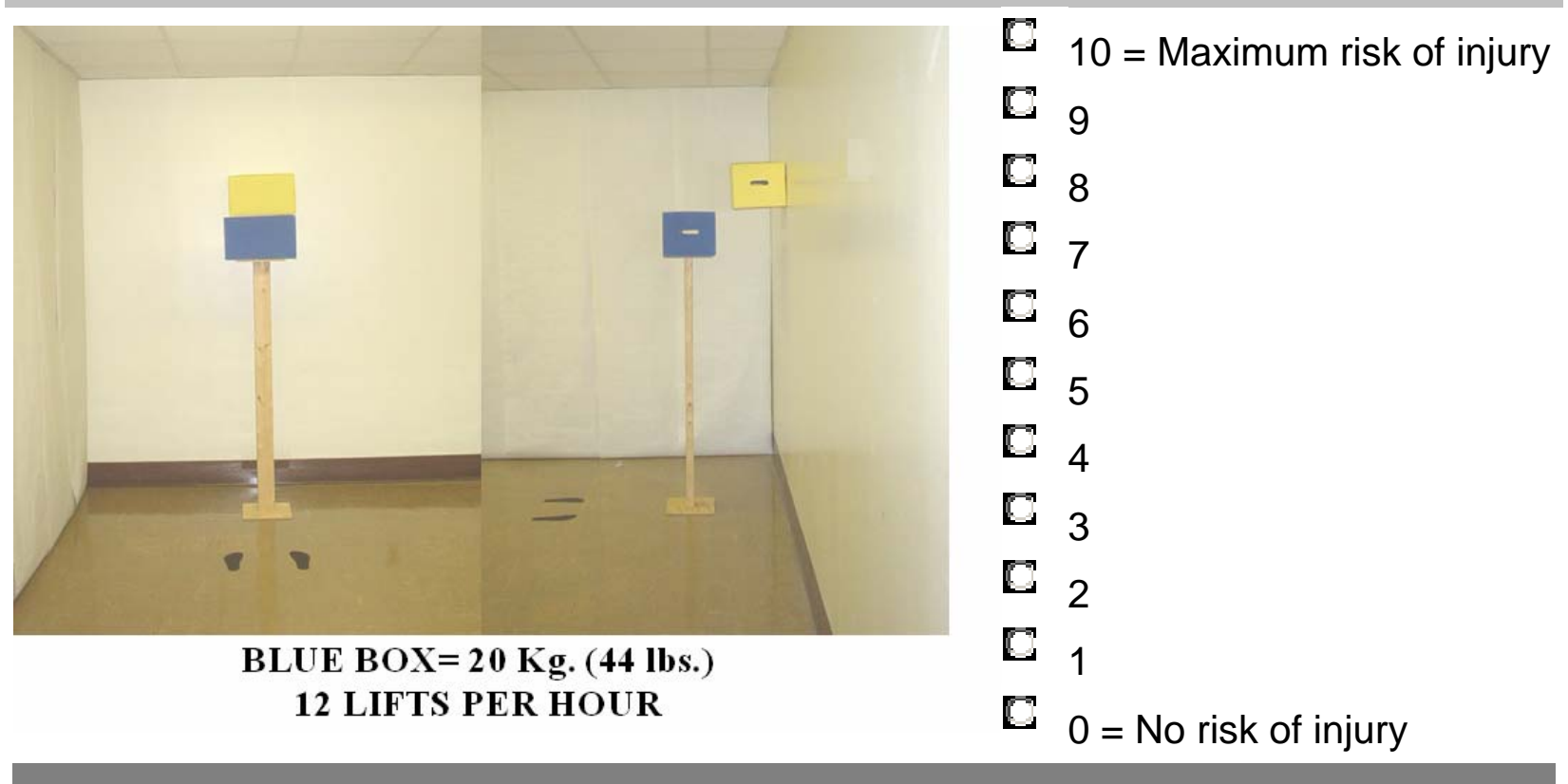




\section{Lifting Task 7}

\section{RATE THE RISK OF INJURY}

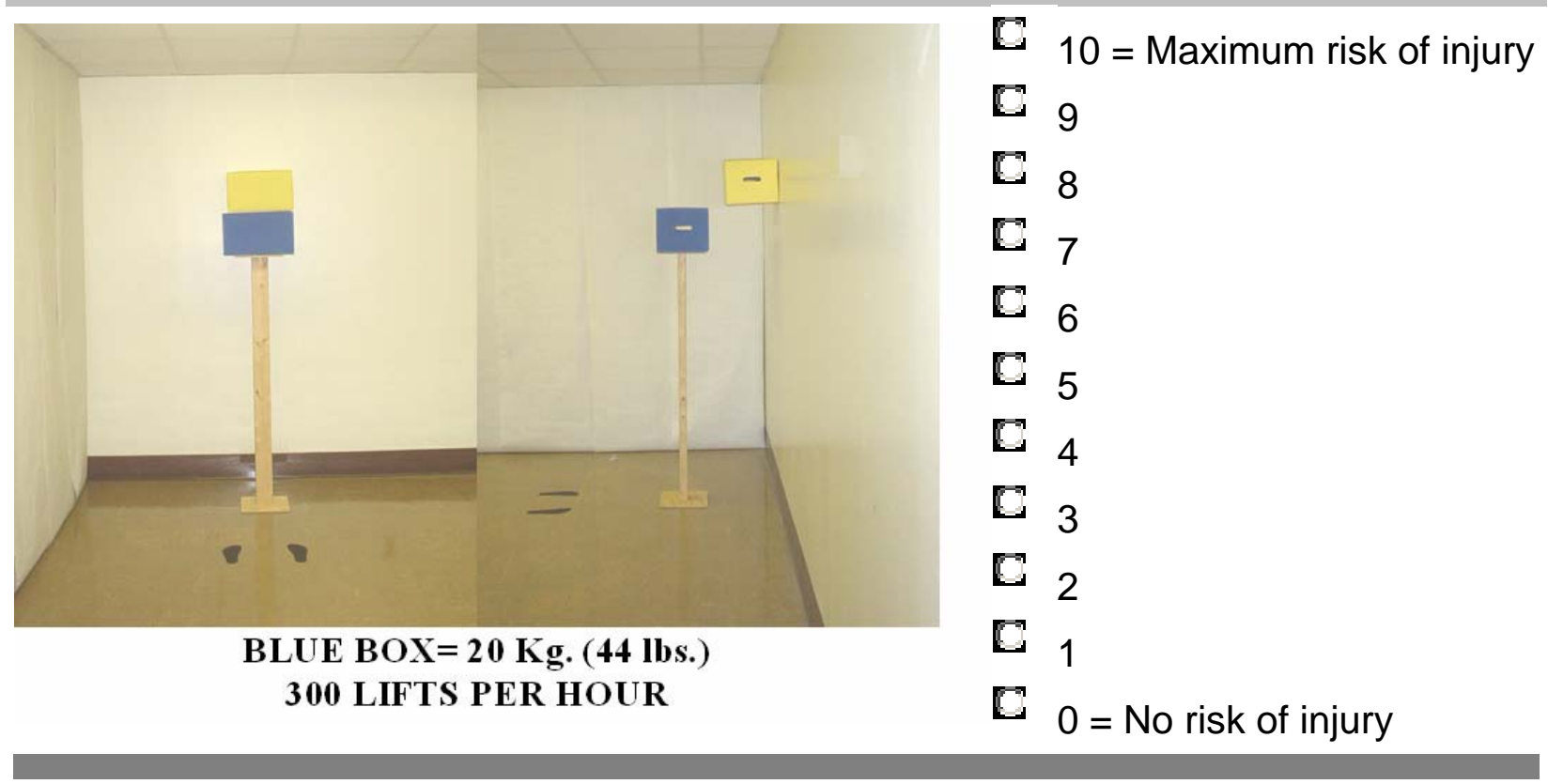

\section{Lifting Task 8}

\section{RATE THE RISK OF INJURY}

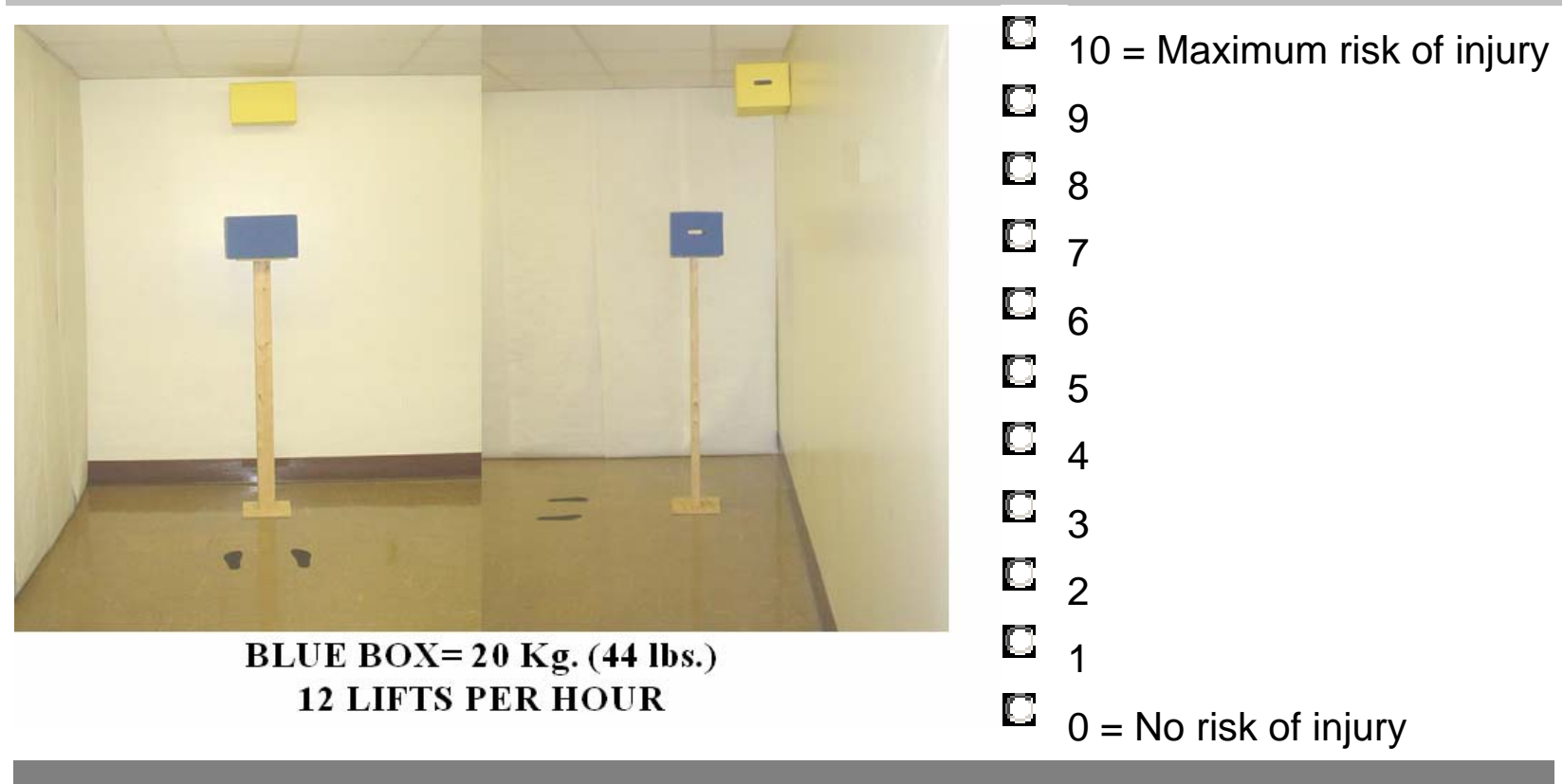




\section{Lifting Task 9}

18. RATE THE RISK OF INJURY

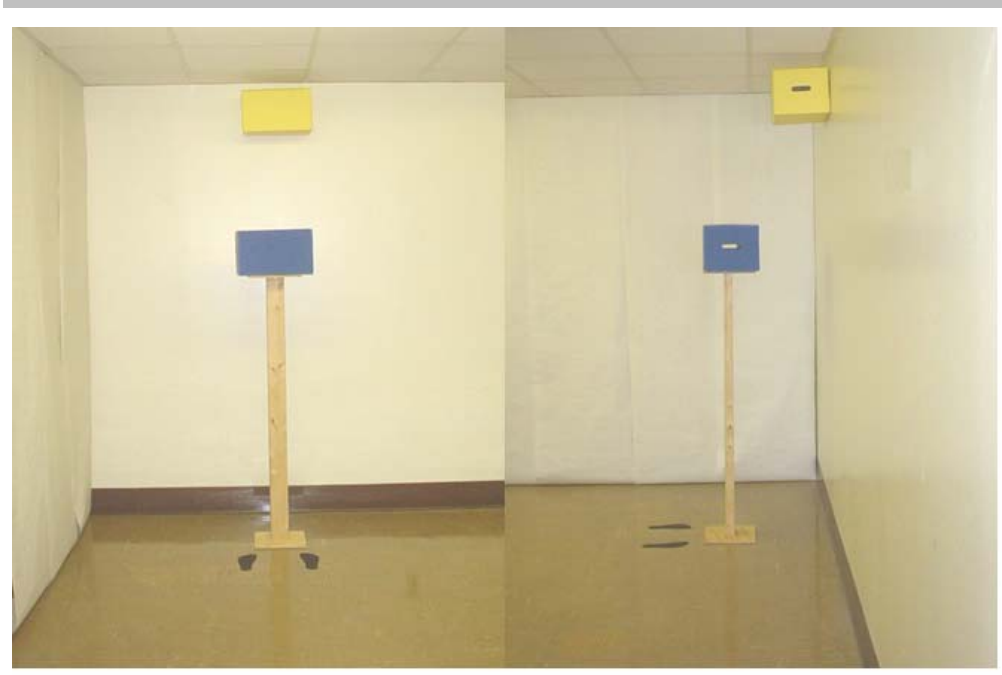

BLUE BOX= 20 Kg. (44 lbs.)

300 LIFTS PER HOUR
C $10=$ Maximum risk of injury

C 9

C 8

C 7

C 6

C 5

C 4

C 3

$\mathrm{C}_{2}$

$\mathrm{C}_{1}$

C $0=$ No risk of injury

\section{Lifting Task 10}

\section{RATE THE RISK OF INJURY}

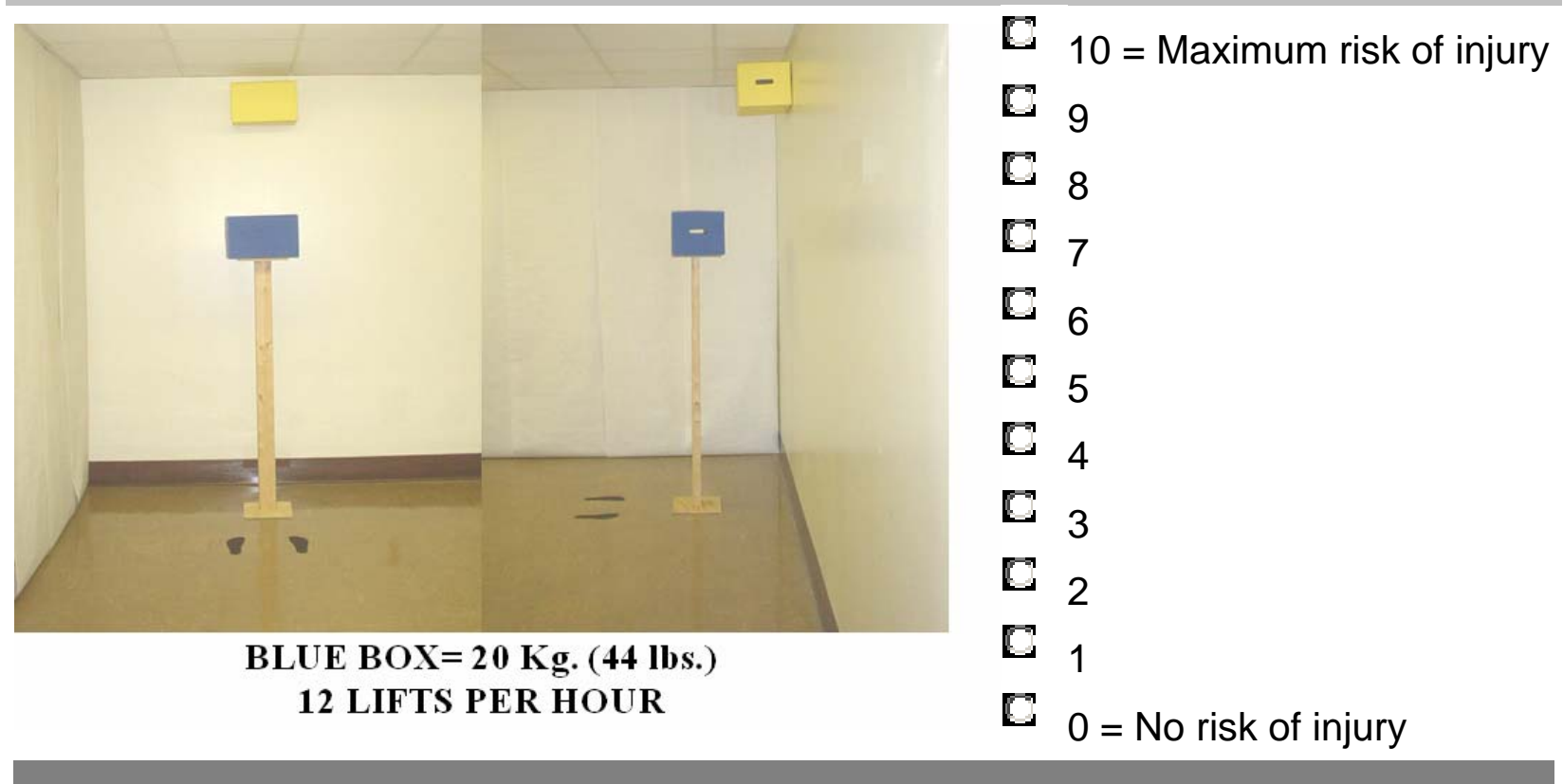




\section{Lifting Task 11}

20. RATE THE RISK OF INJURY

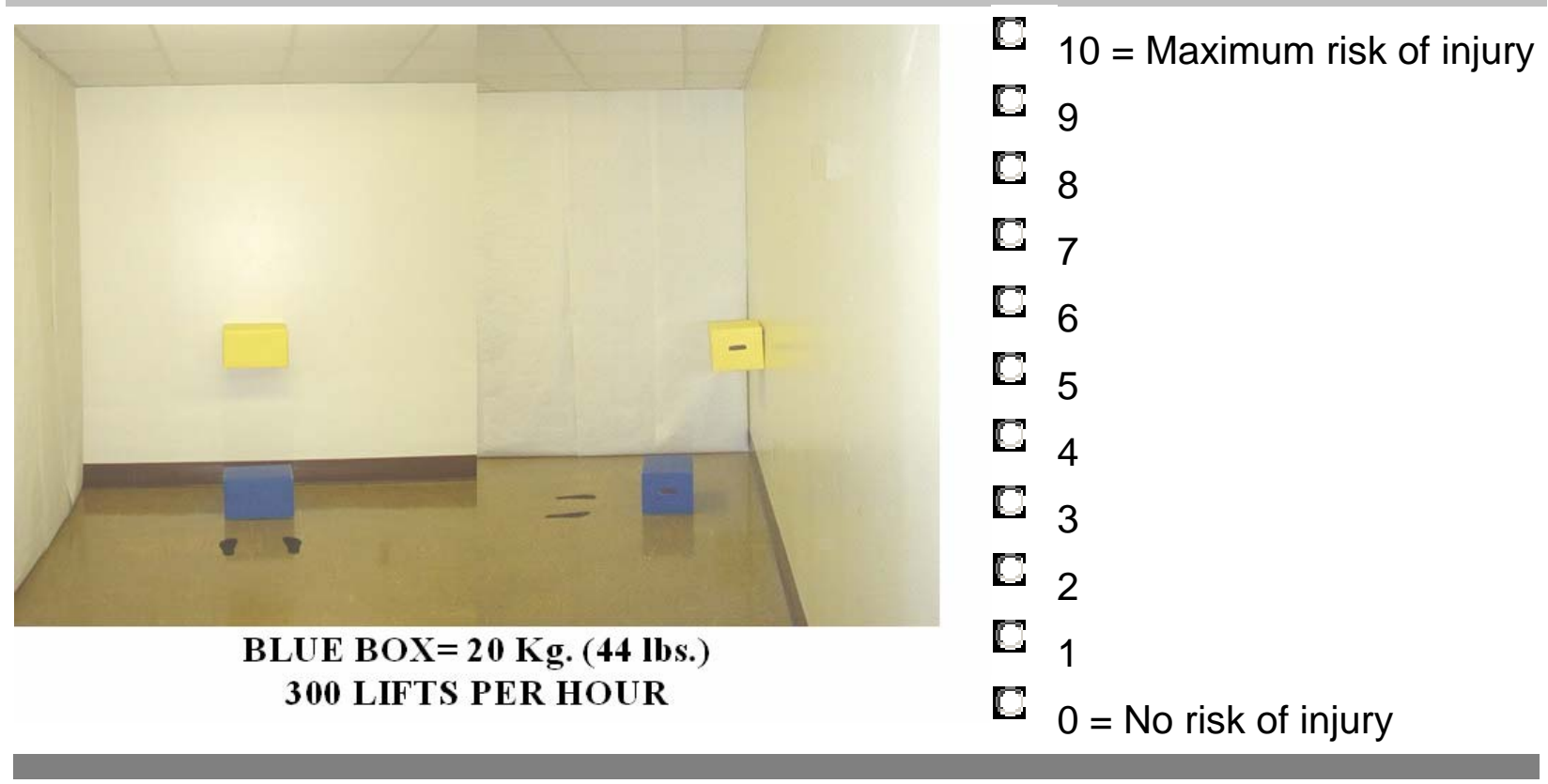

\section{Lifting Task 12}

\section{RATE THE RISK OF INJURY}

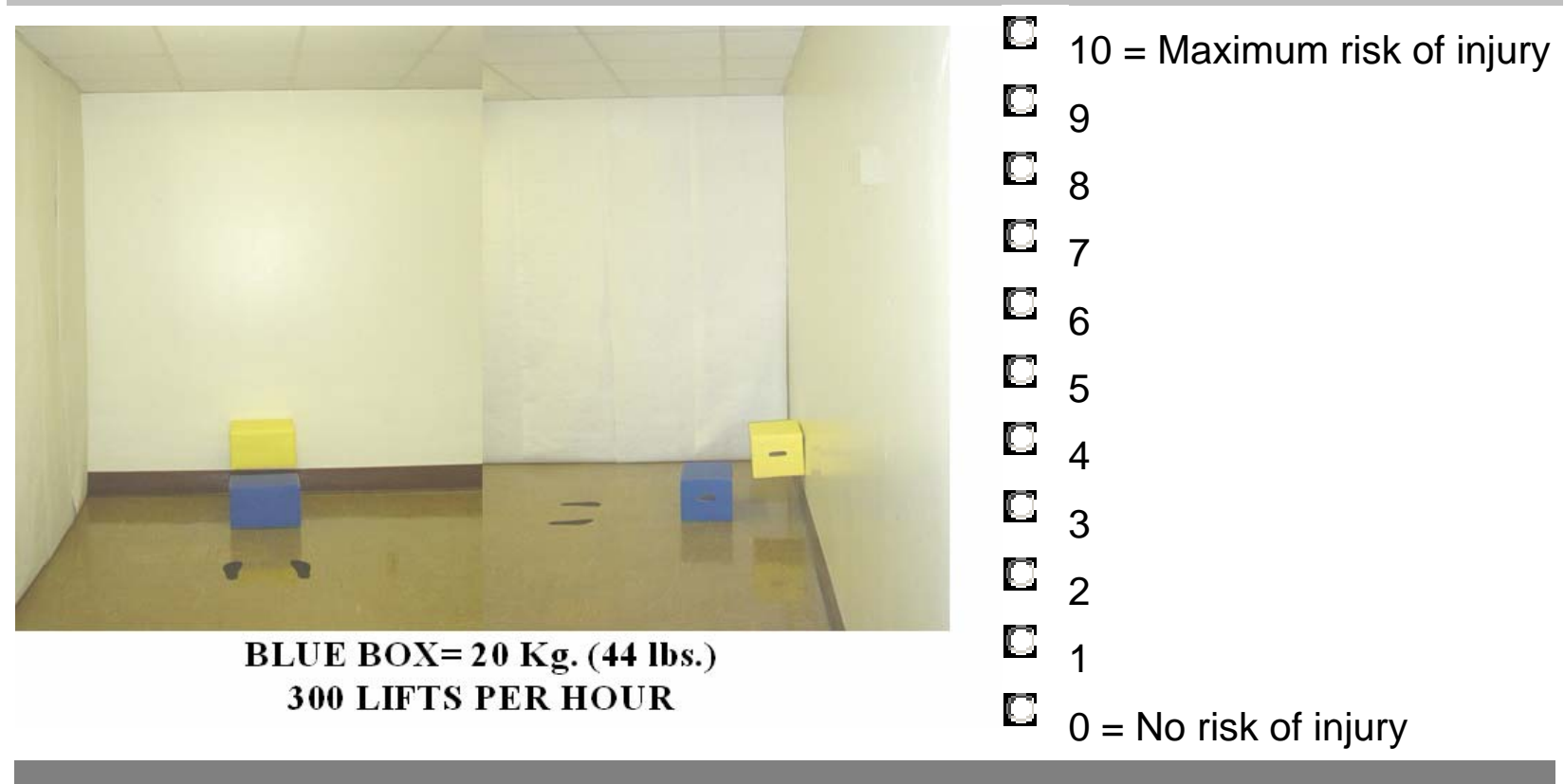




\section{Lifting Task 13}

22. RATE THE RISK OF INJURY

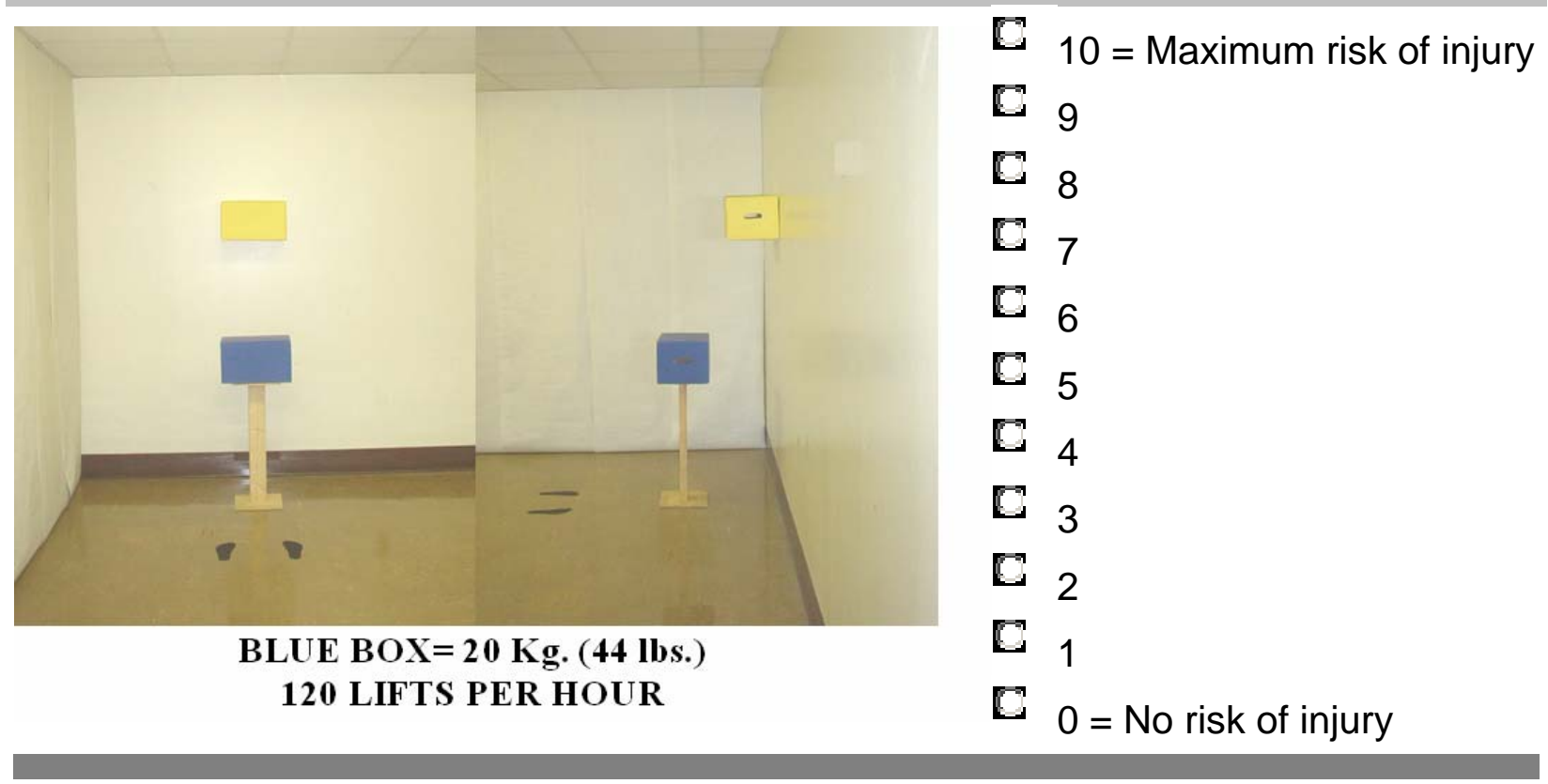

\section{Lifting Task 14}

\section{RATE THE RISK OF INJURY}

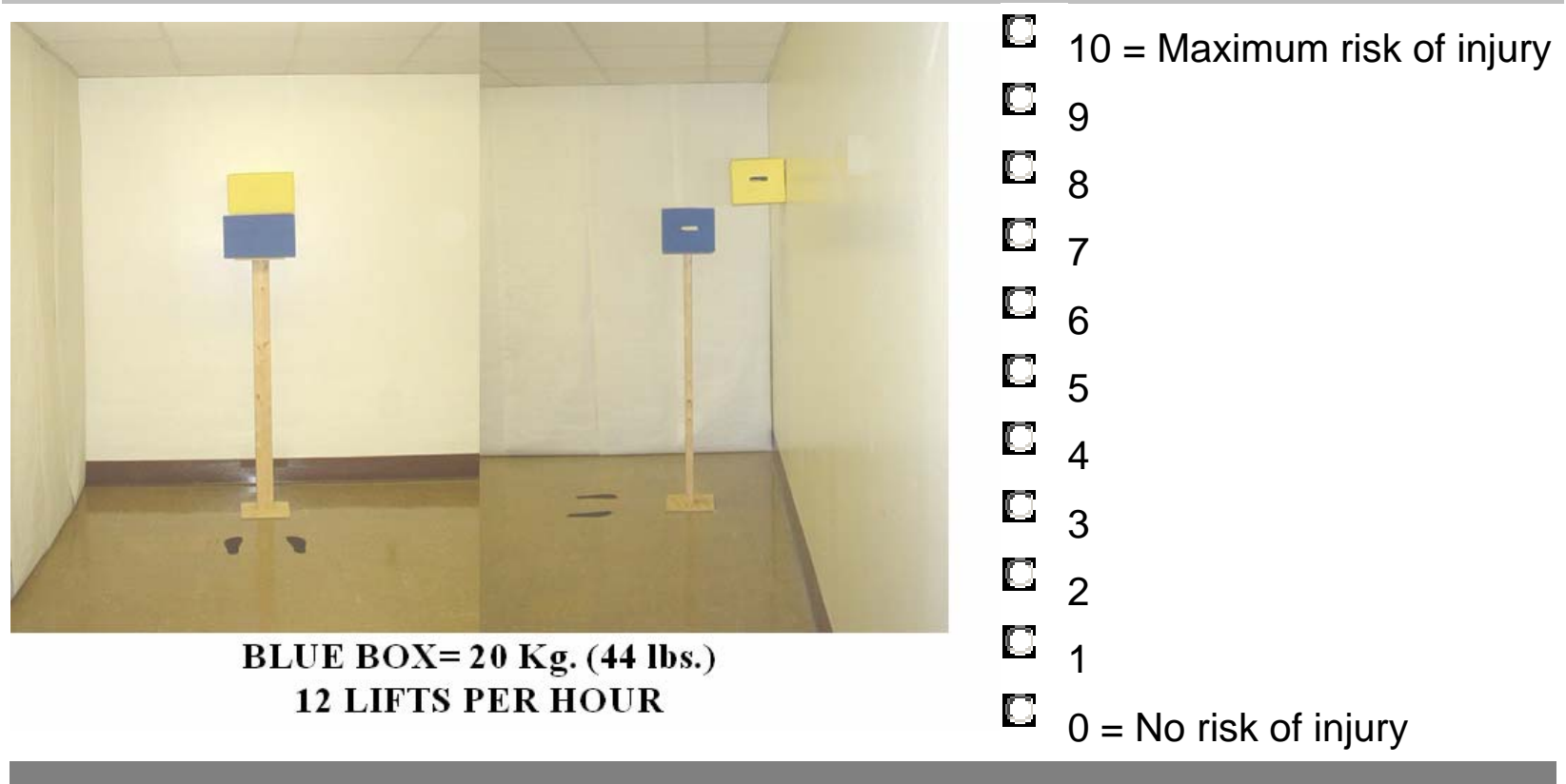




\section{Lifting Task 15}

\section{RATE THE RISK OF INJURY}

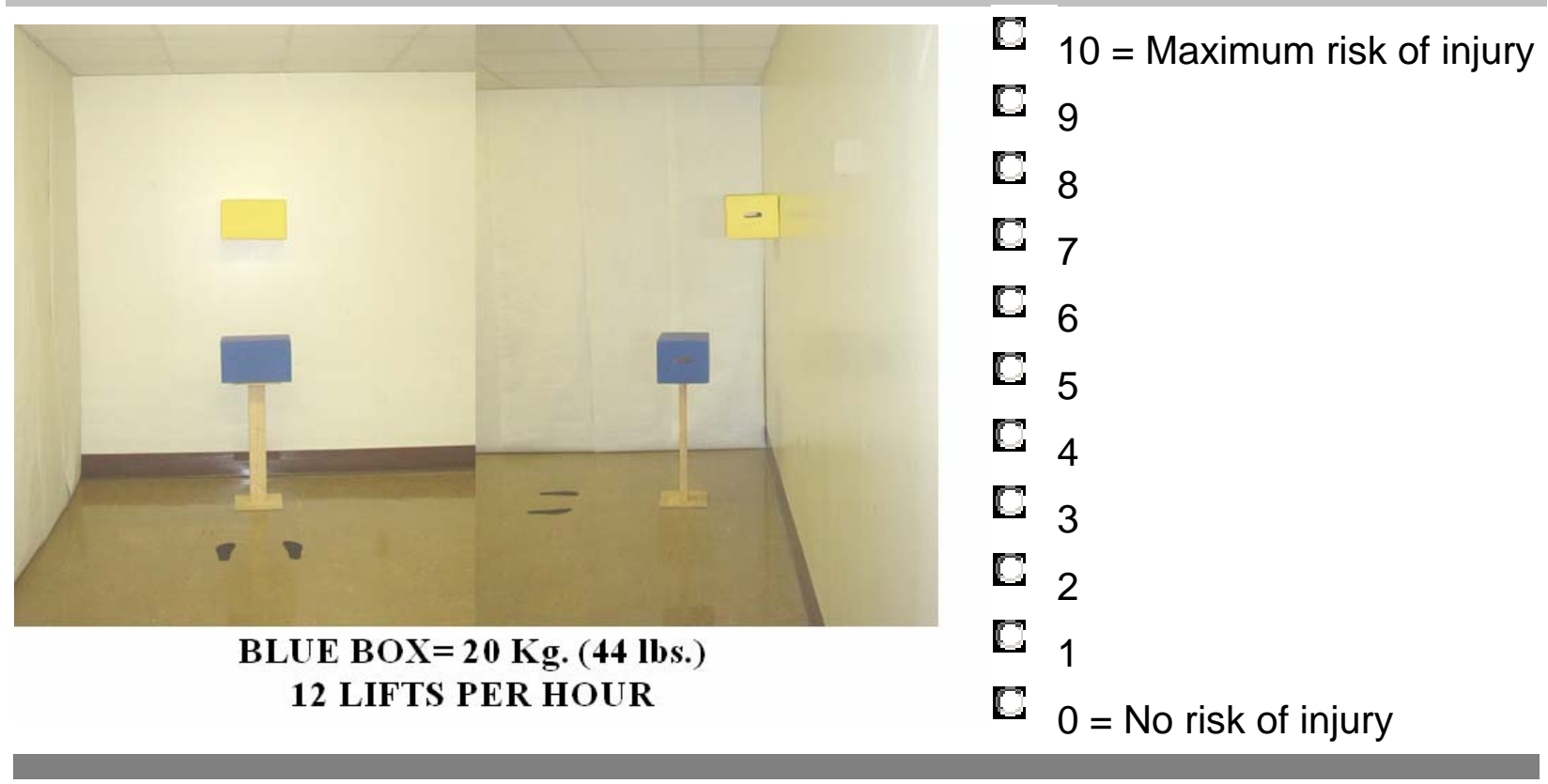

\section{Lifting Task 16}

\section{RATE THE RISK OF INJURY}

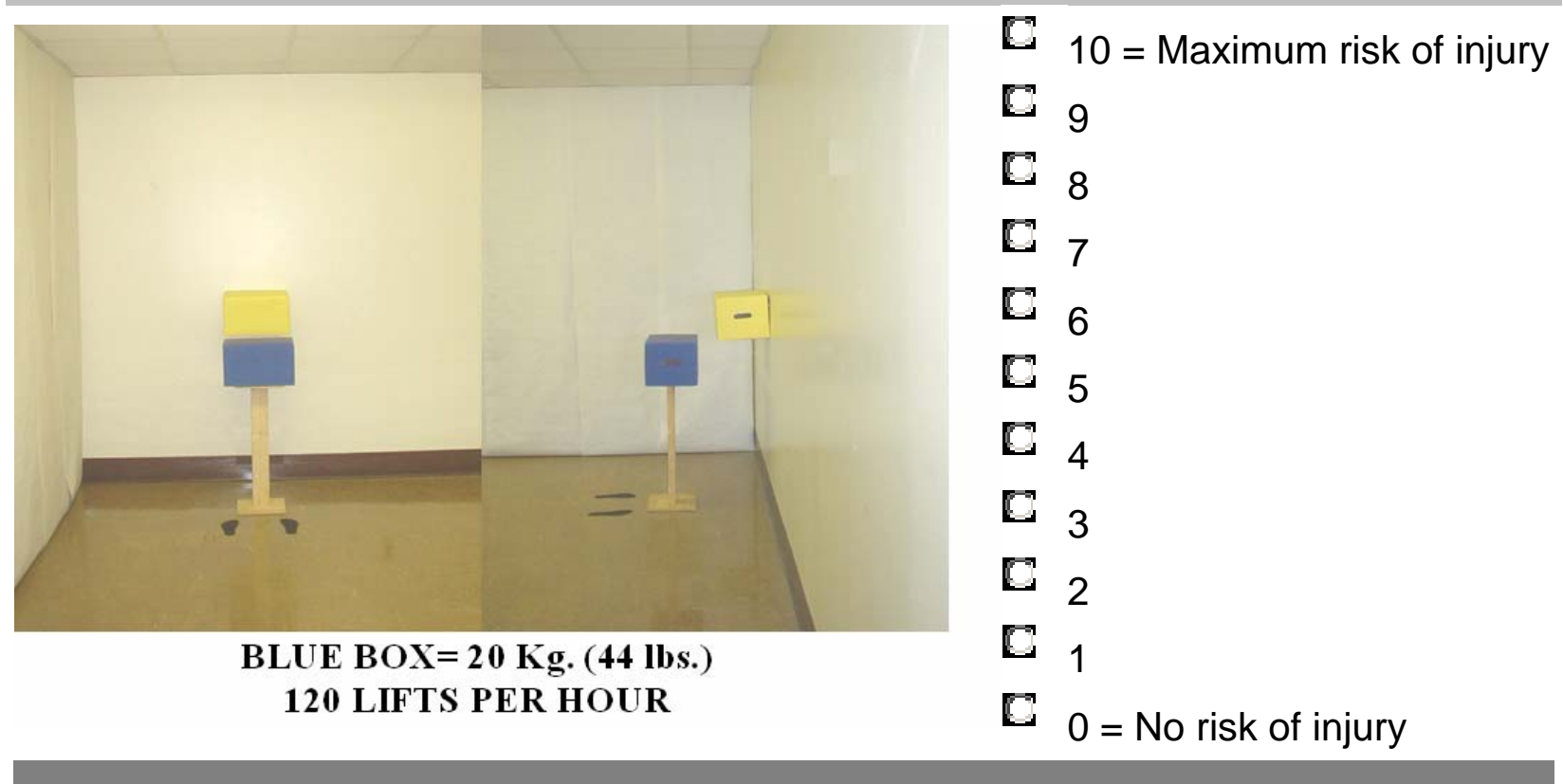




\section{Lifting Task 17}

\section{RATE THE RISK OF INJURY}

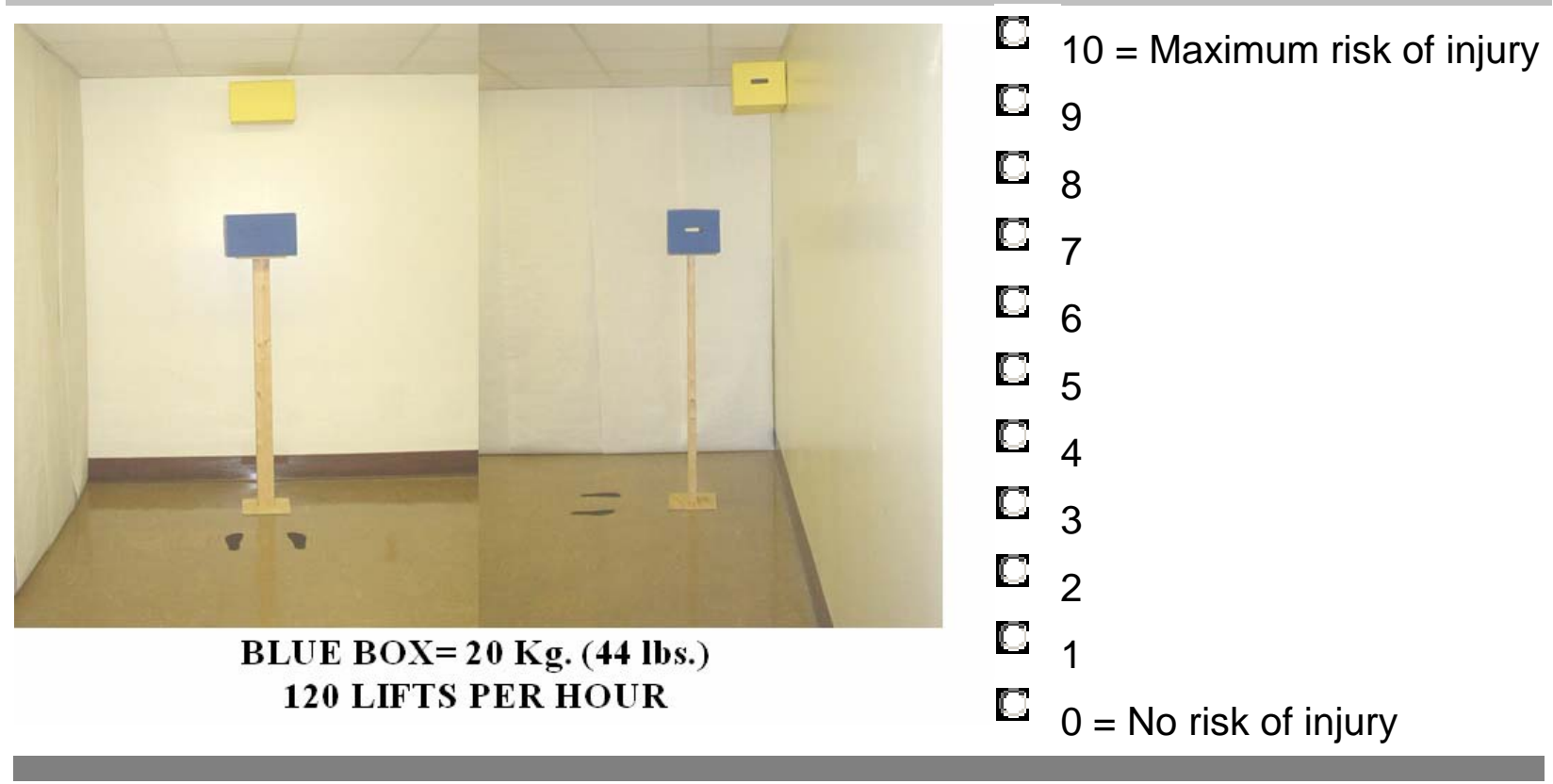

\section{Lifting Task 18}

\section{RATE THE RISK OF INJURY}

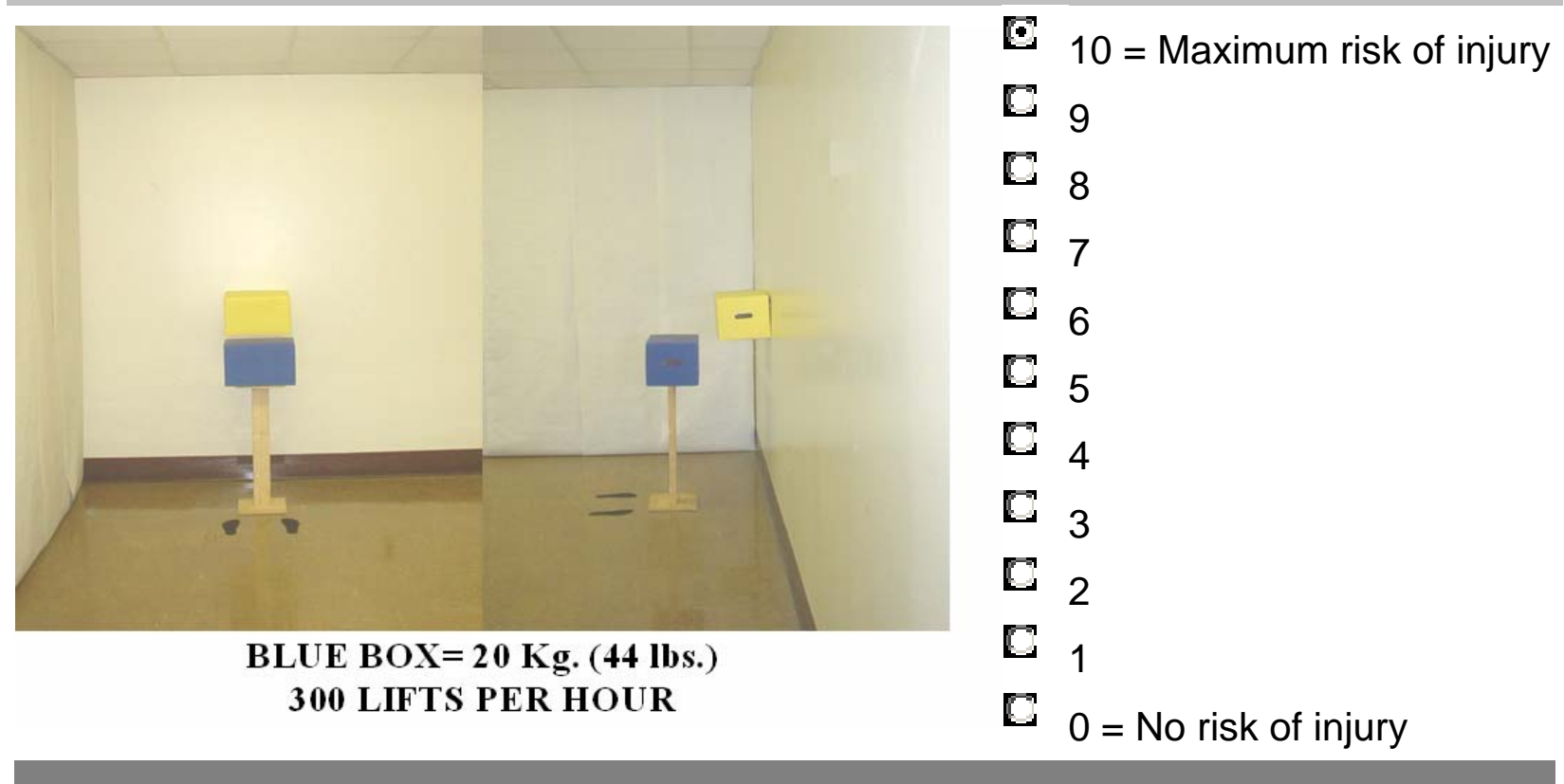




\section{Lifting Task 19}

28. RATE THE RISK OF INJURY

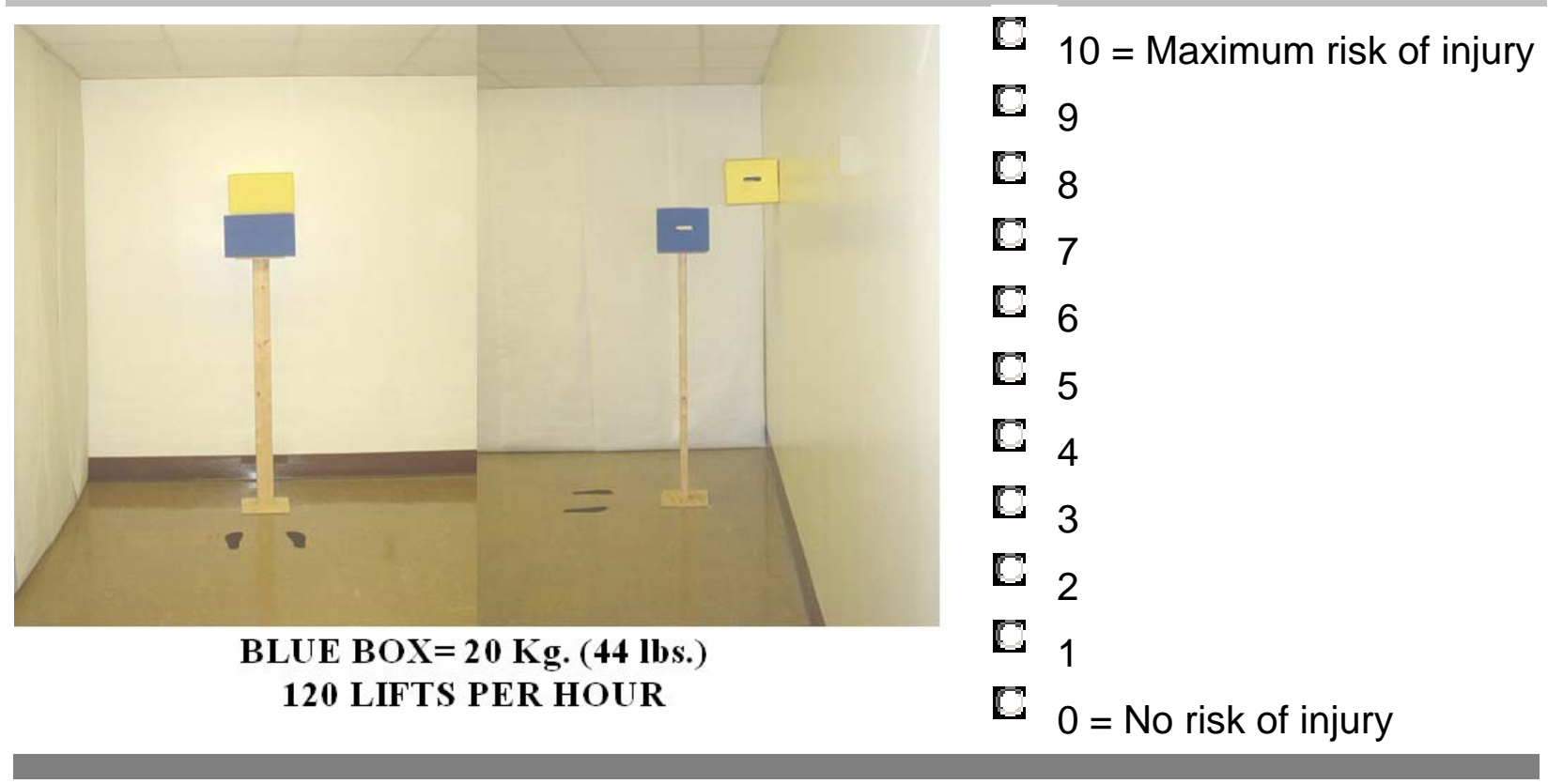

\section{Lifting Task 20}

\section{RATE THE RISK OF INJURY}

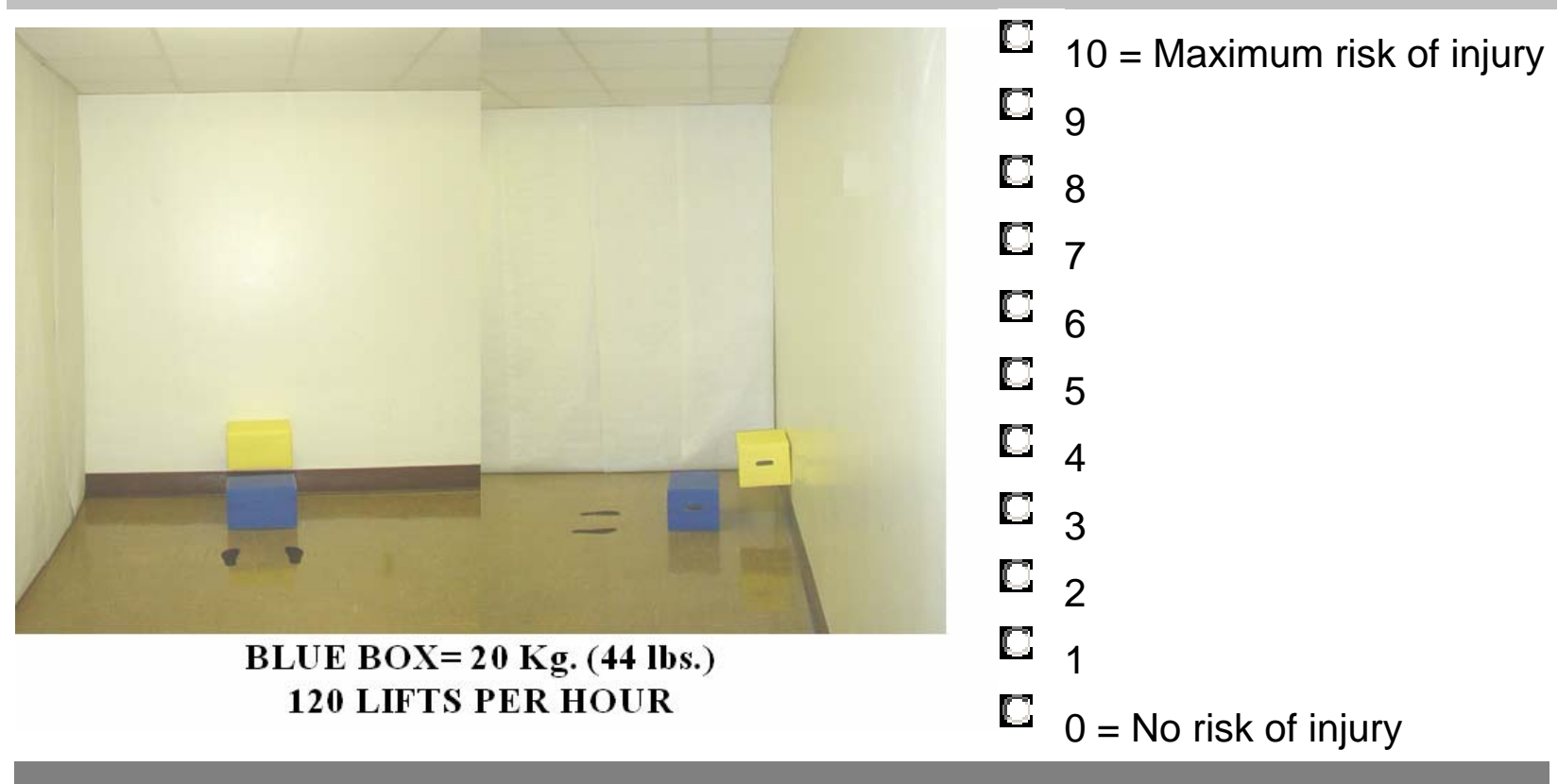




\section{Lifting Task 21}

30. RATE THE RISK OF INJURY

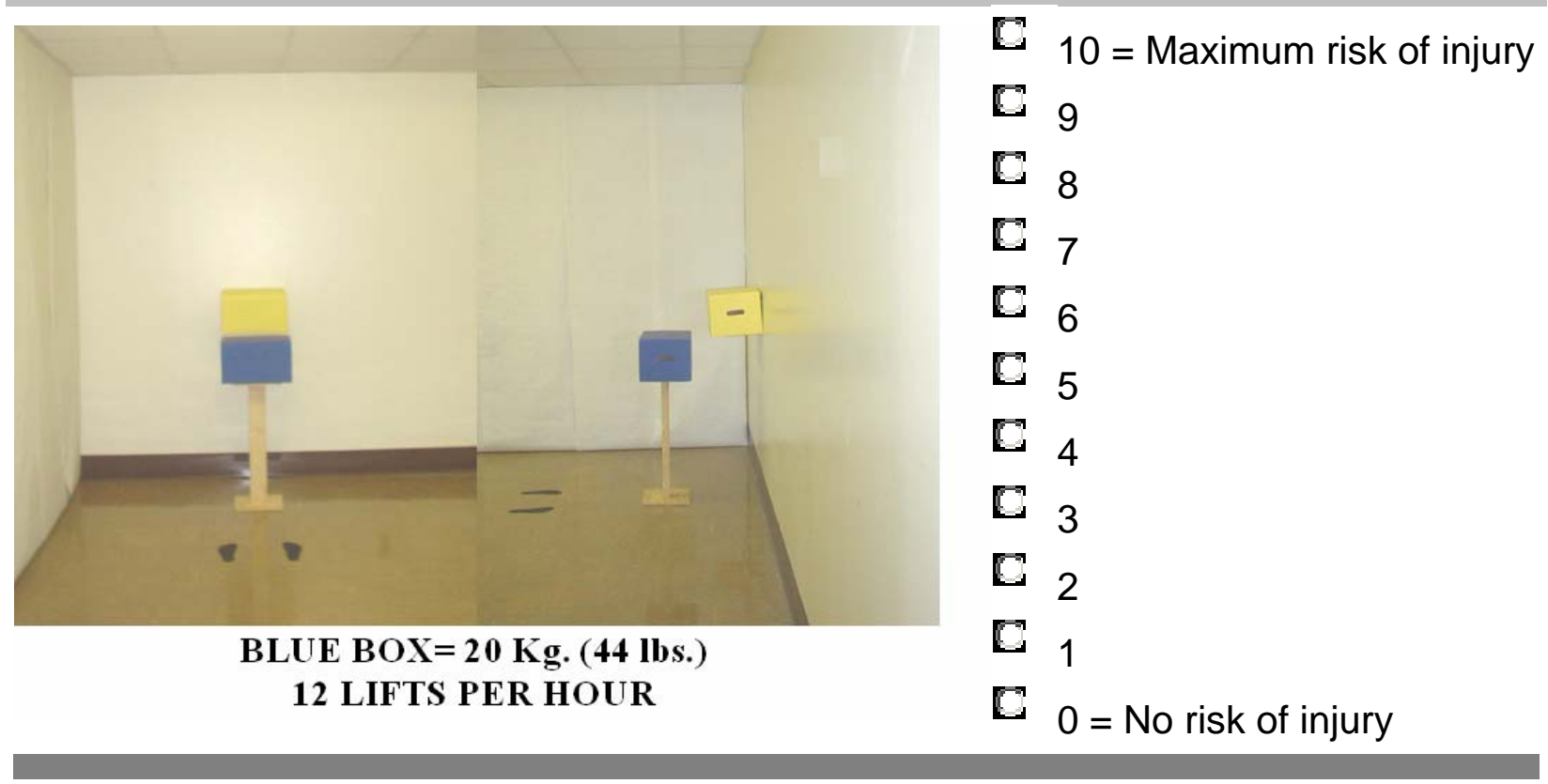

\section{Lifting Task 22}

\section{RATE THE RISK OF INJURY}

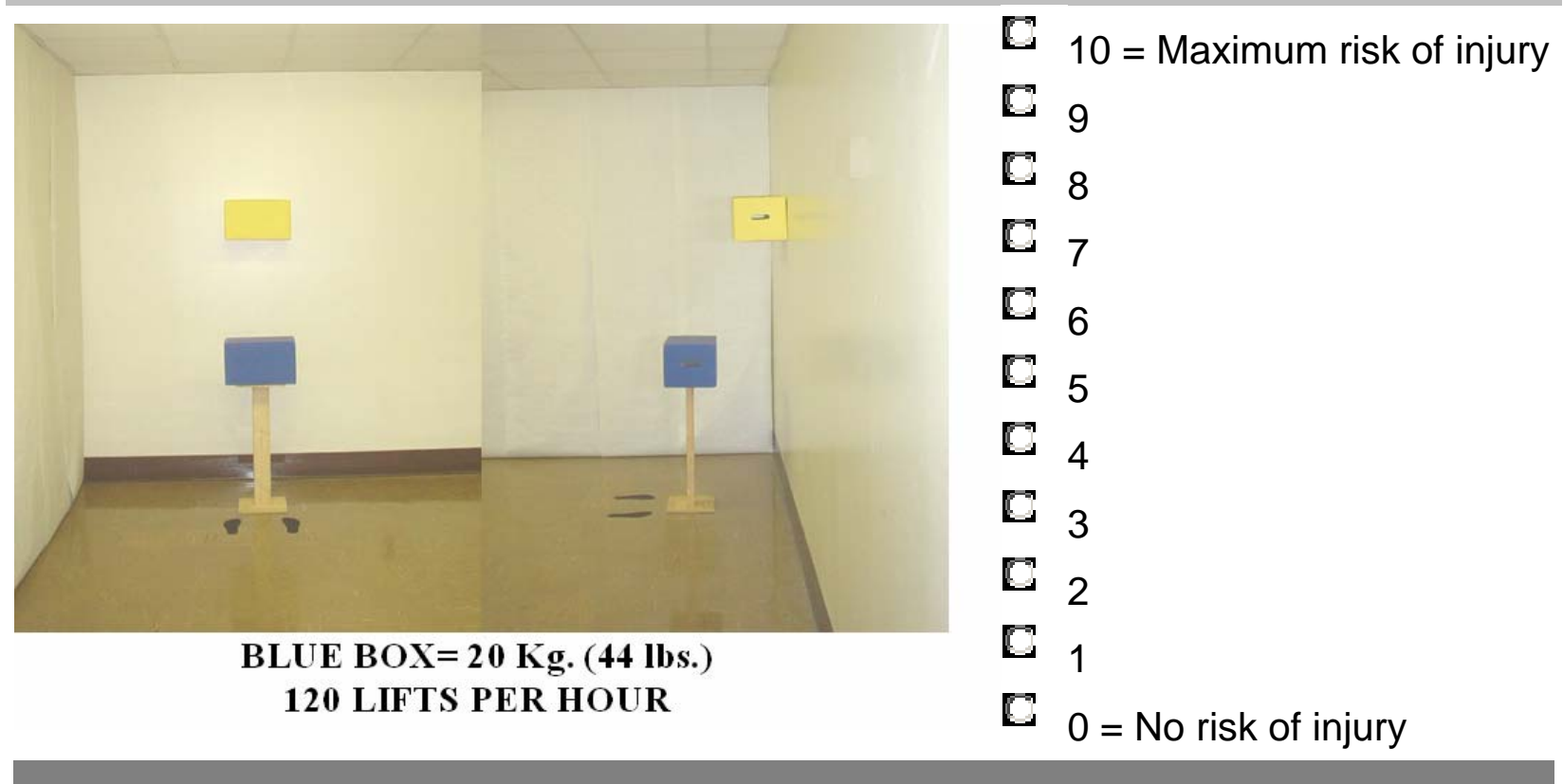




\section{Lifting Task 23}

32. RATE THE RISK OF INJURY

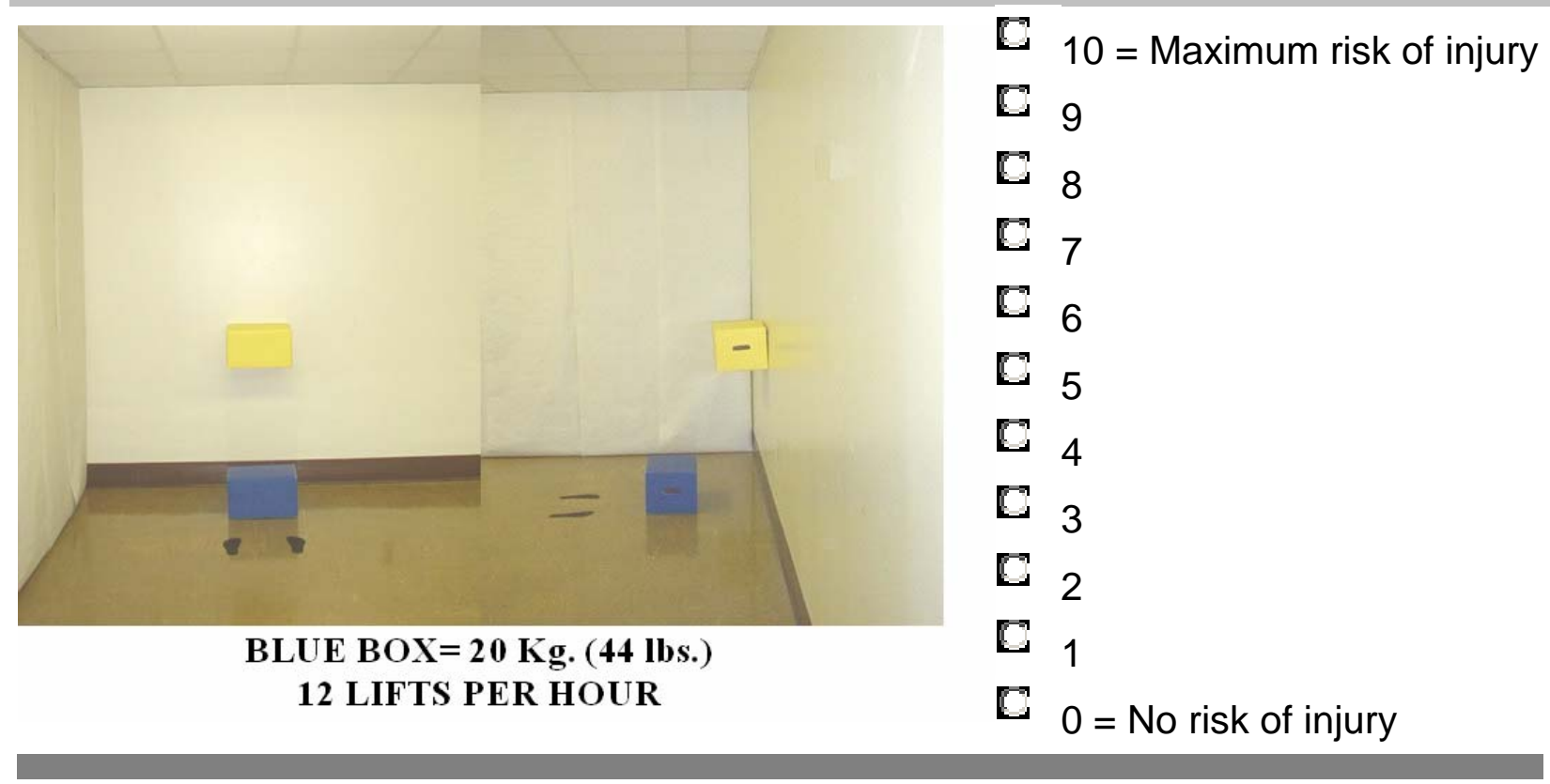

\section{Lifting Task 24}

33. RATE THE RISK OF INJURY

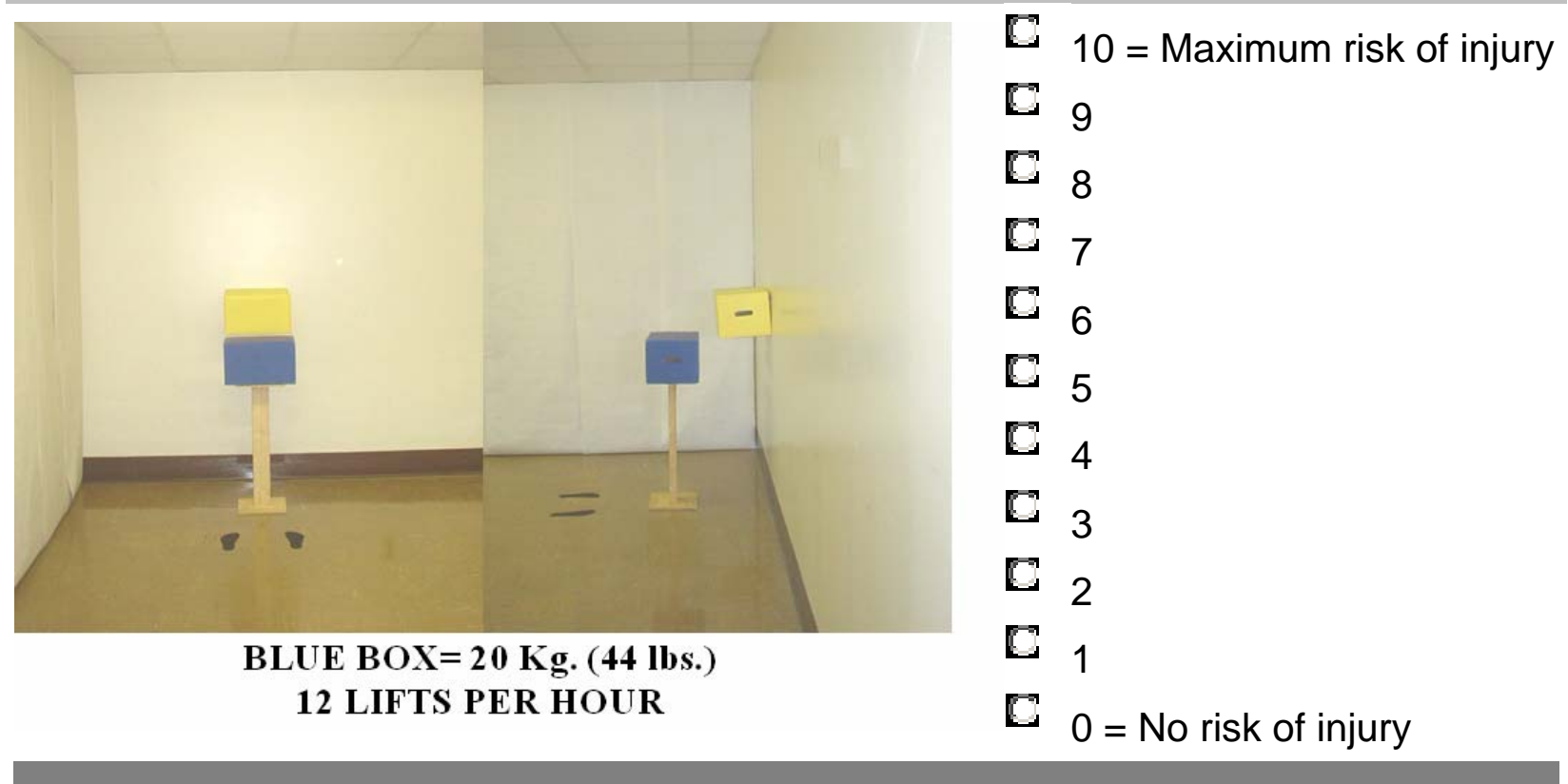




\section{Lifting Task 25}

\section{RATE THE RISK OF INJURY}

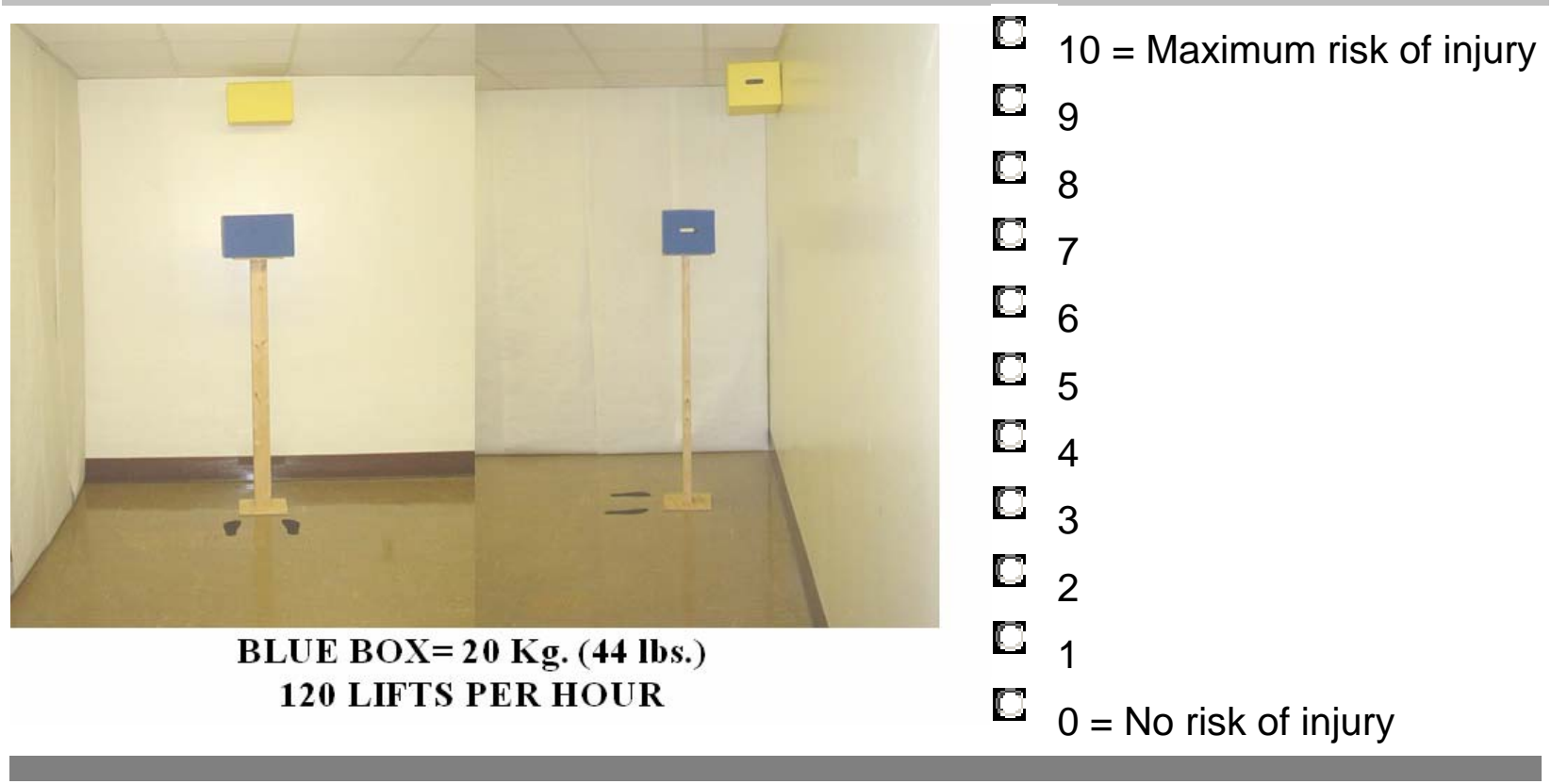

\section{Lifting Task 26}

\section{RATE THE RISK OF INJURY}

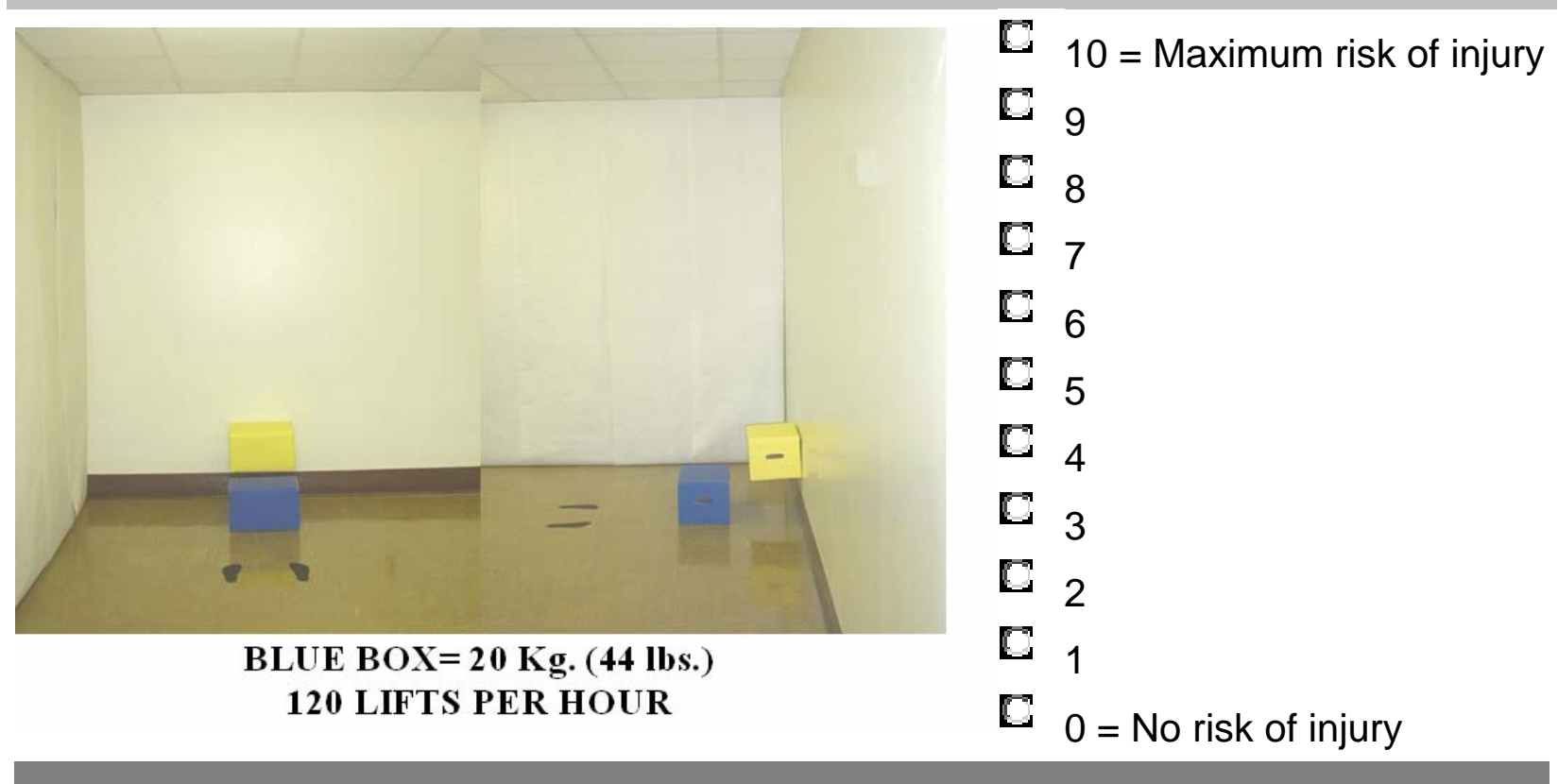




\section{Lifting Task 27}

36. RATE THE RISK OF INJURY

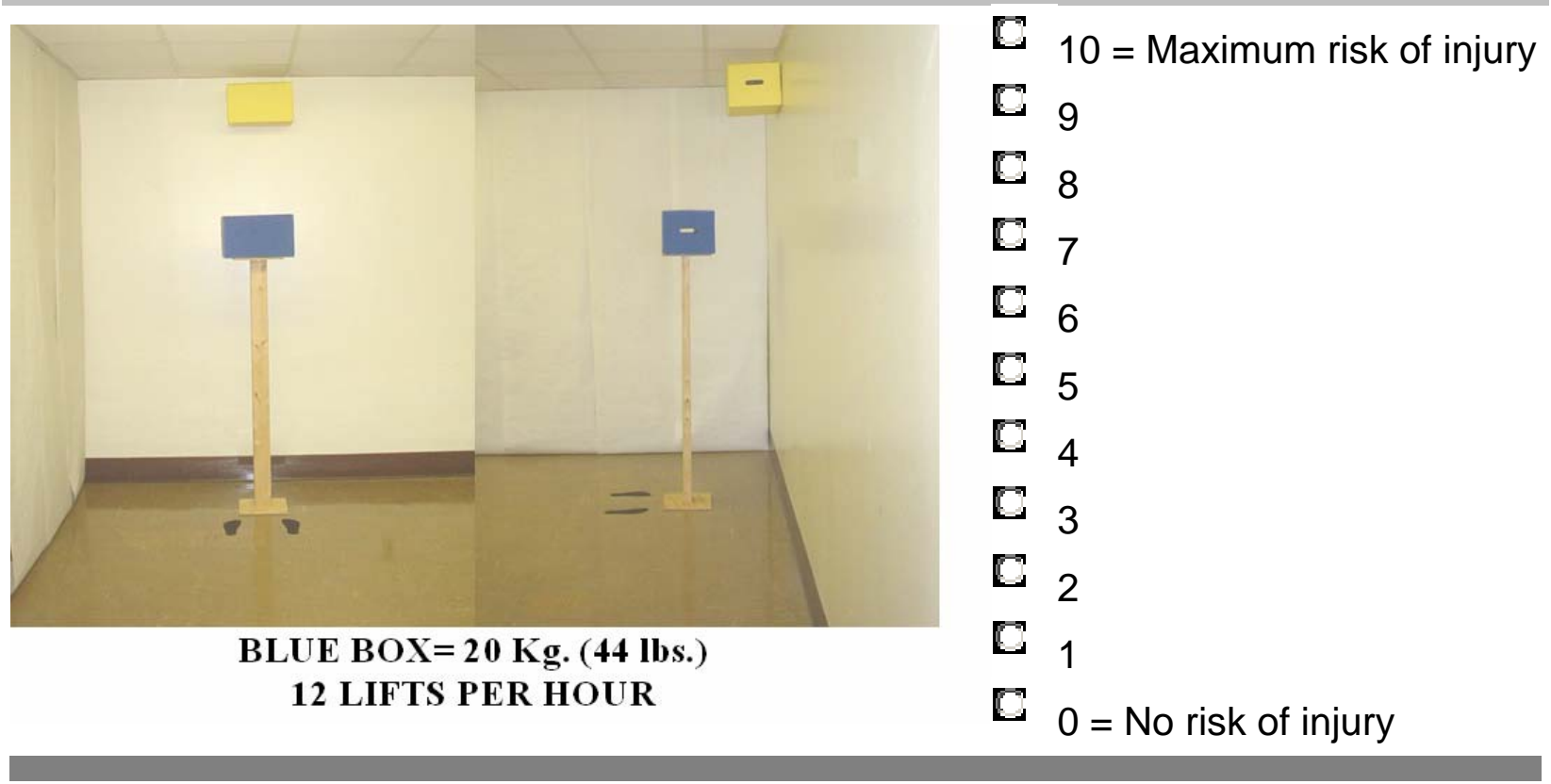

\section{Lifting Task 28}

\section{RATE THE RISK OF INJURY}

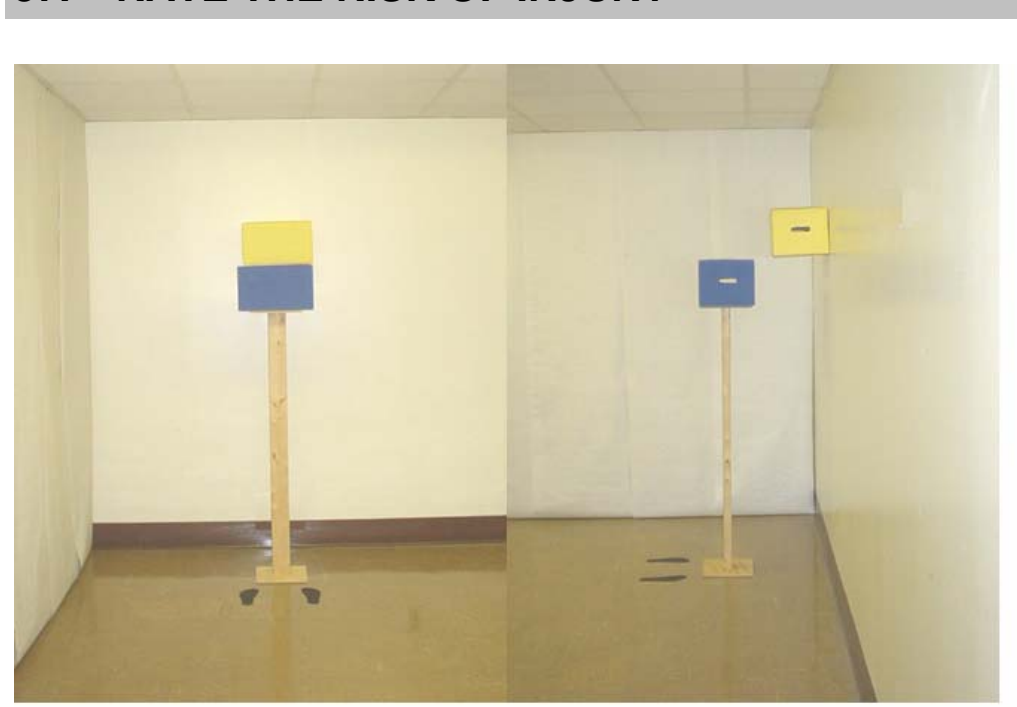

C $10=$ Maximum risk of injury

C 9

C 8

C 7

C 6

C 5

$\mathrm{C}_{4}$

C 3

$\mathrm{C}_{2}$

BLUE BOX= $20 \mathrm{Kg} .(44 \mathrm{lbs}$. 300 LIFTS PER HOUR

C 1

C $0=$ No risk of injury 


\section{Lifting Task 29}

38. RATE THE RISK OF INJURY

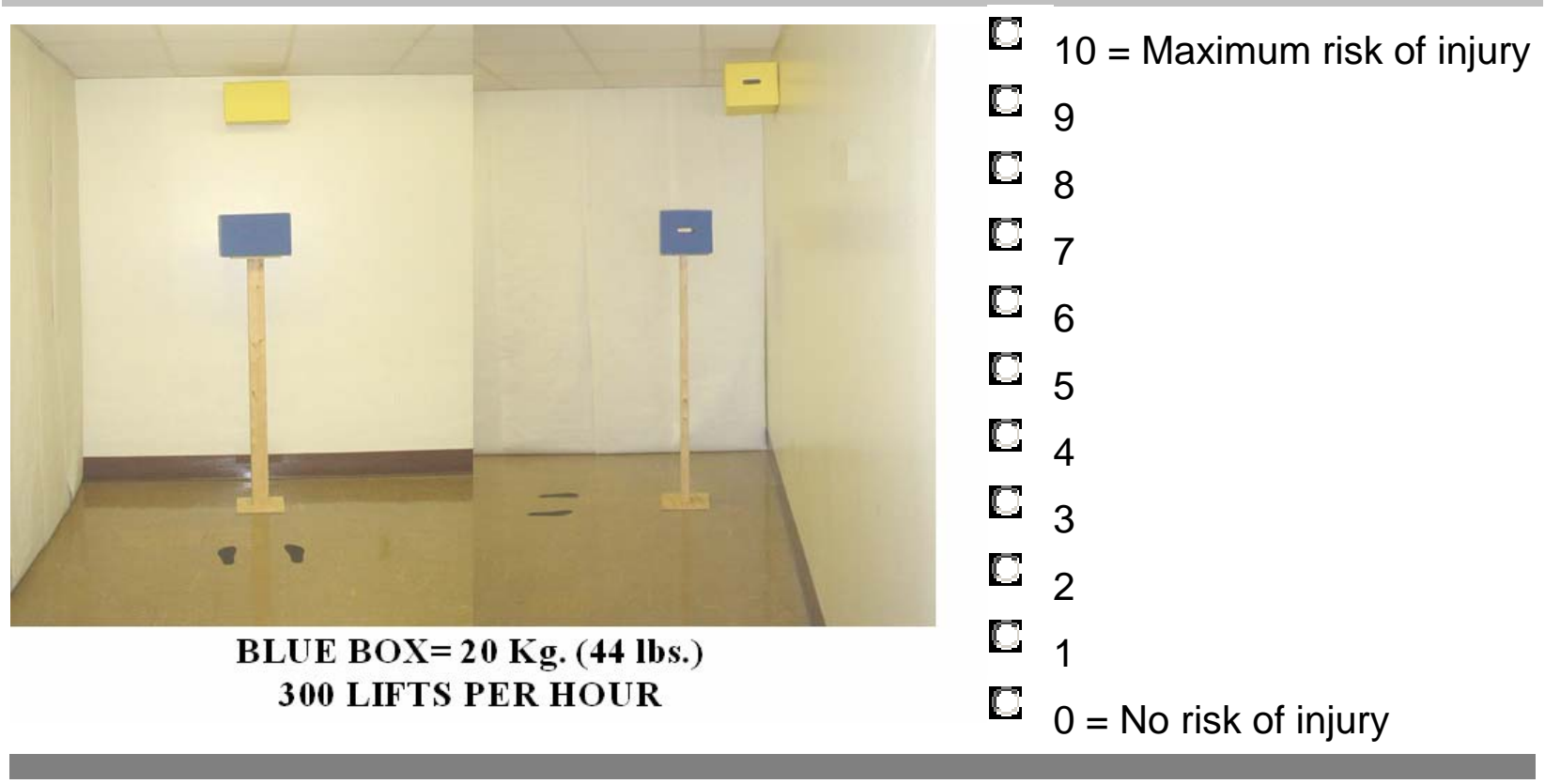

\section{Lifting Task 30}

39. RATE THE RISK OF INJURY

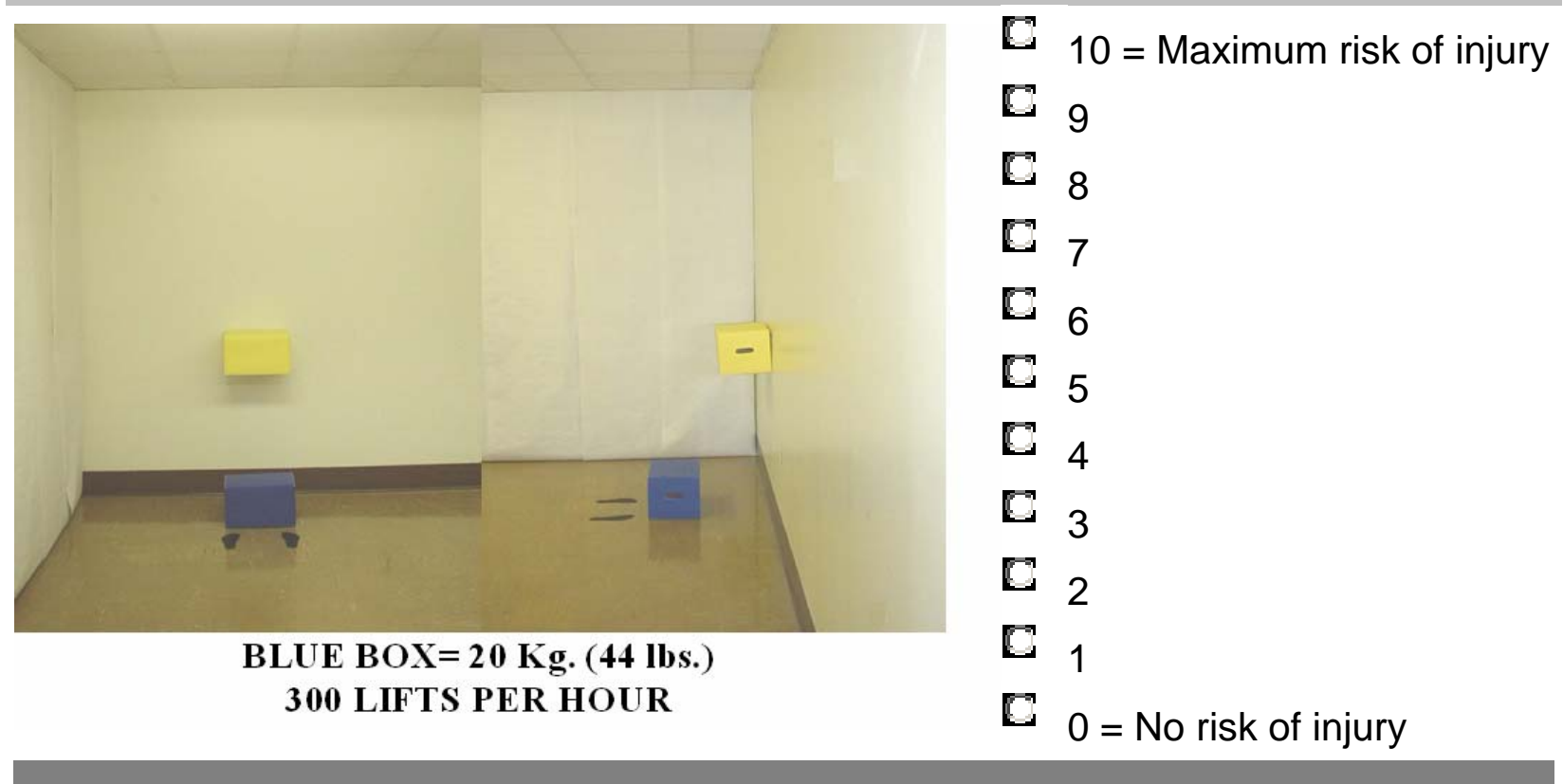




\section{Lifting Task 31}

\section{RATE THE RISK OF INJURY}

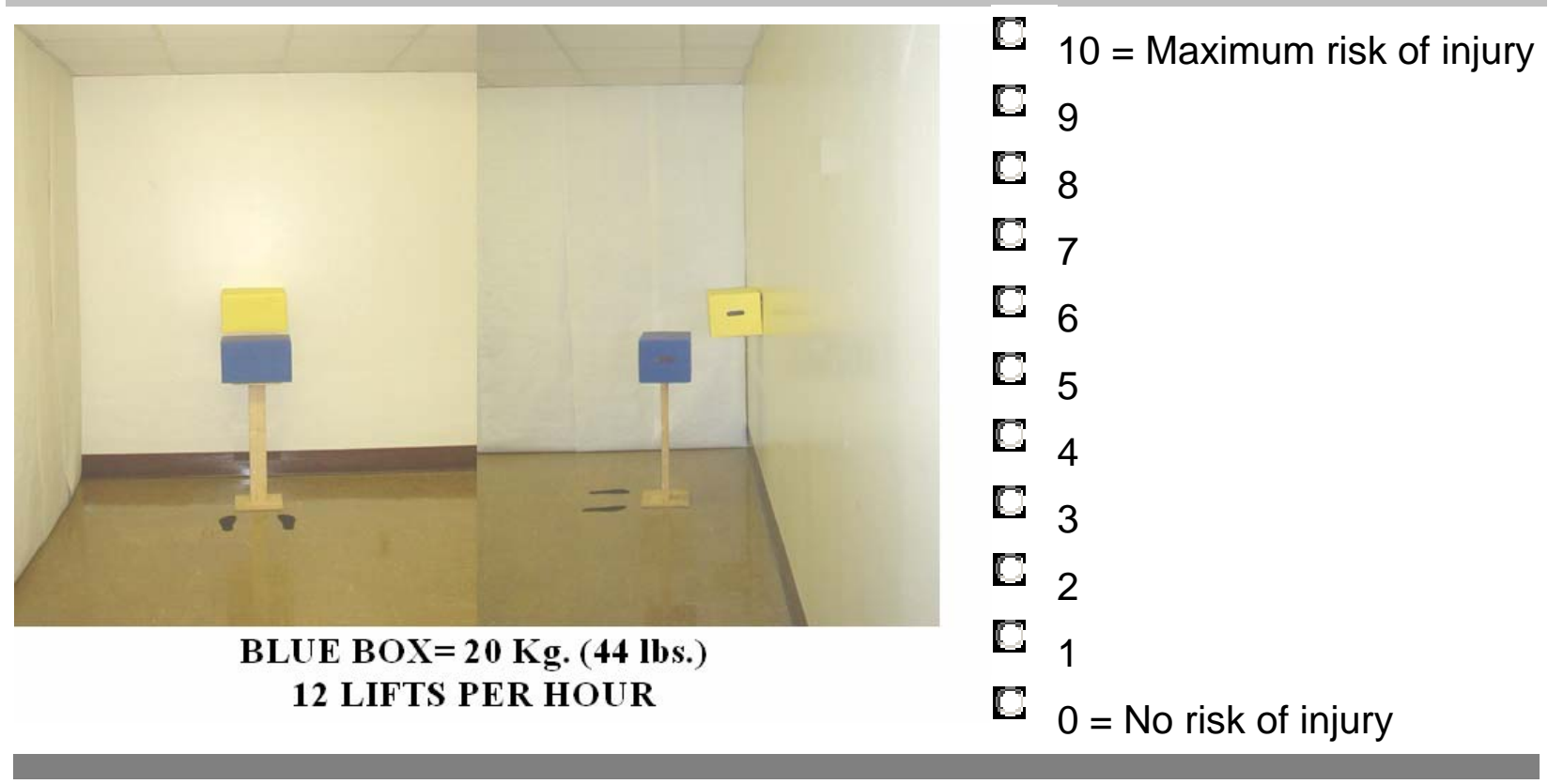

\section{Lifting Task 32}

\section{RATE THE RISK OF INJURY}

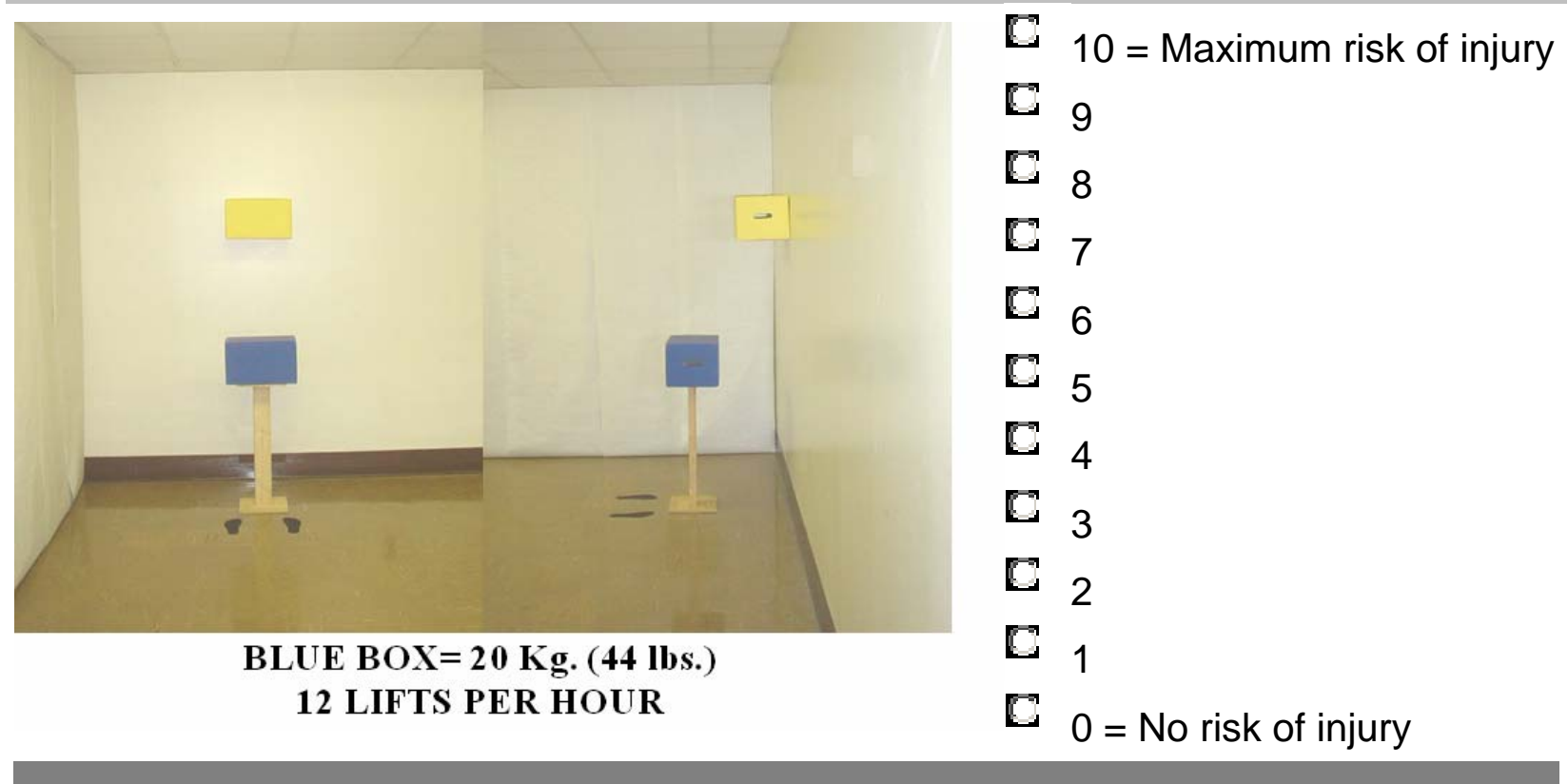




\section{Lifting Task 33}

\section{RATE THE RISK OF INJURY}

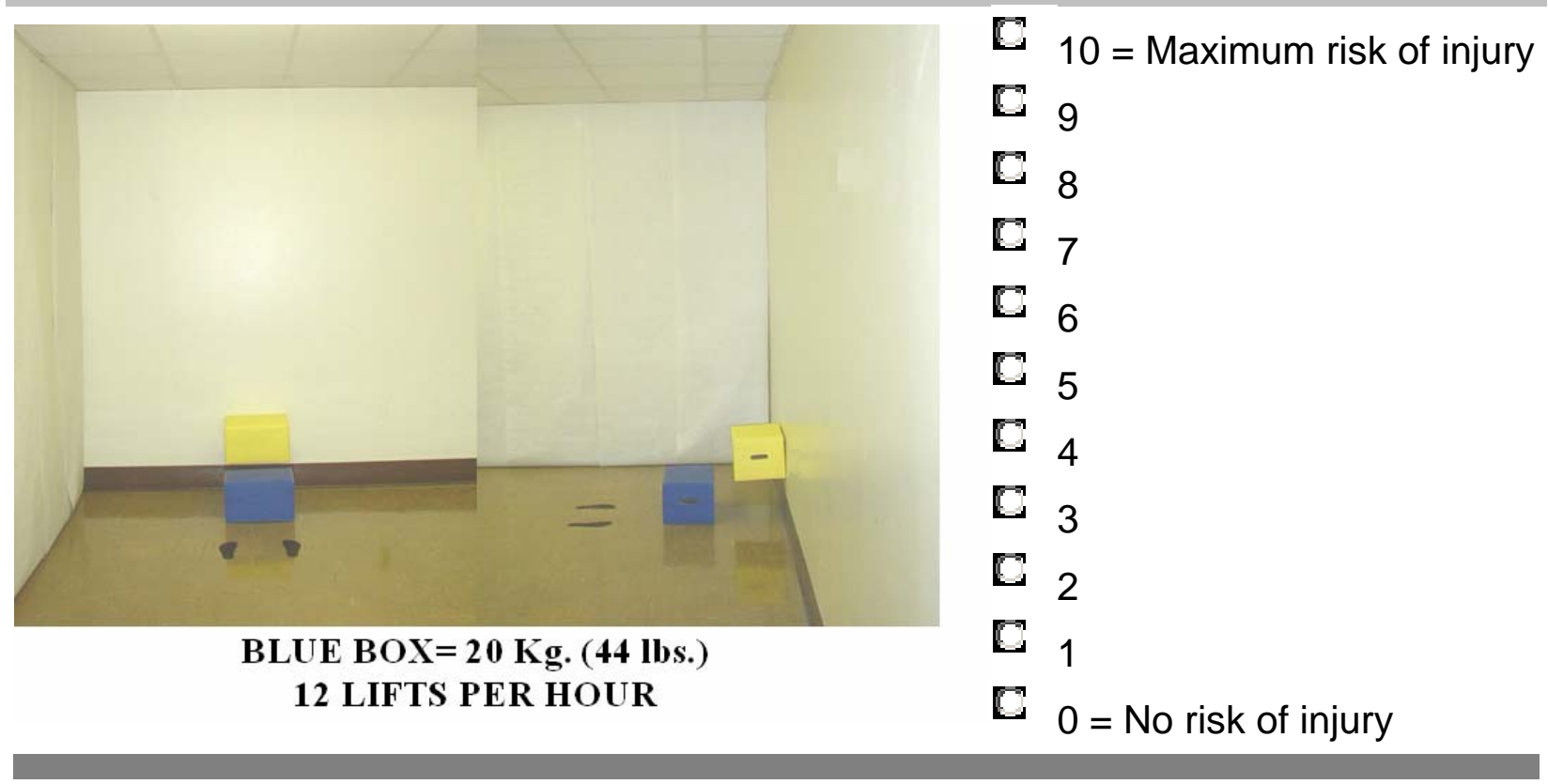

\section{Lifting Task 34}

\section{RATE THE RISK OF INJURY}

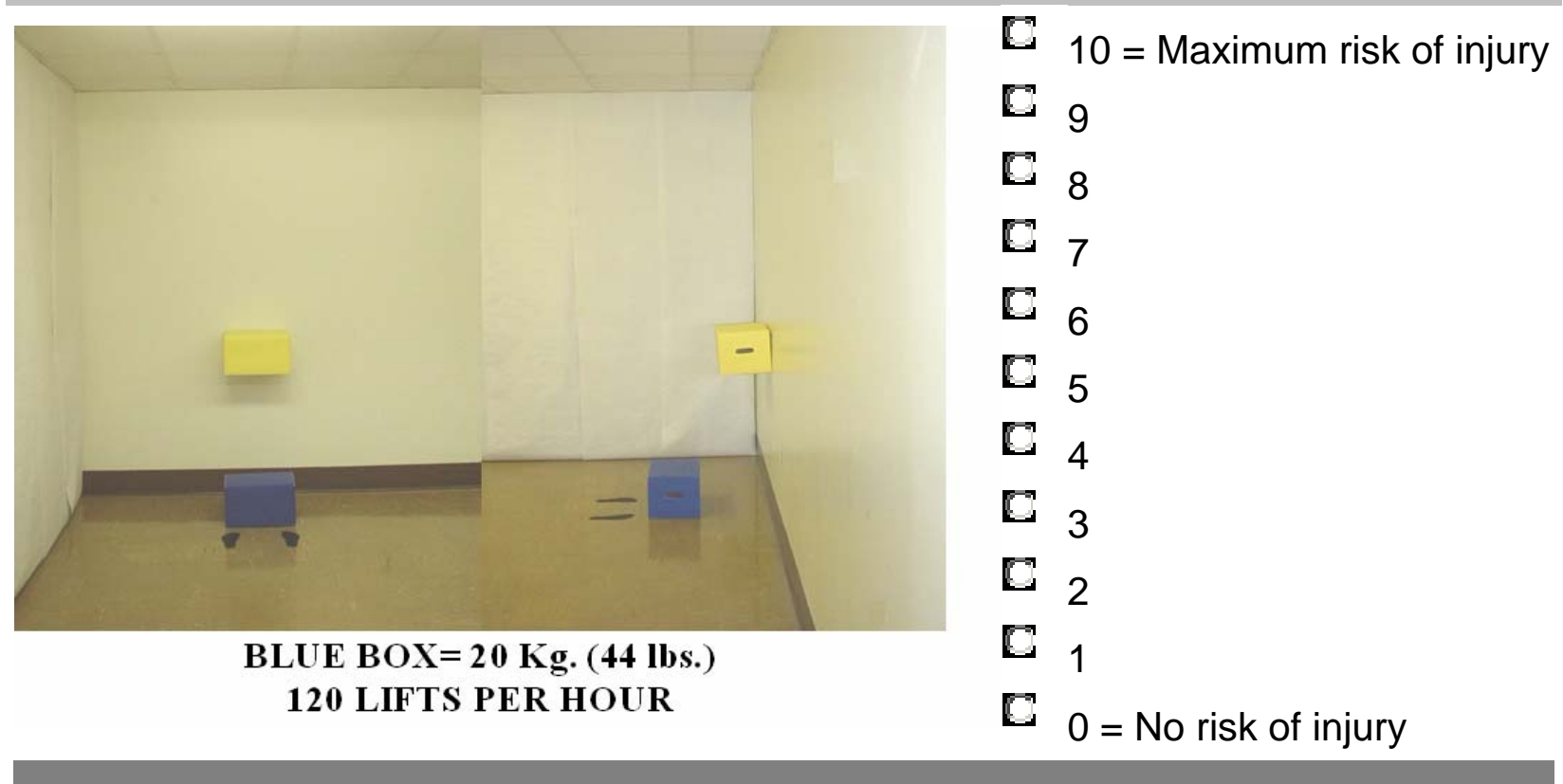




\section{Lifting Task 35}

\section{RATE THE RISK OF INJURY}

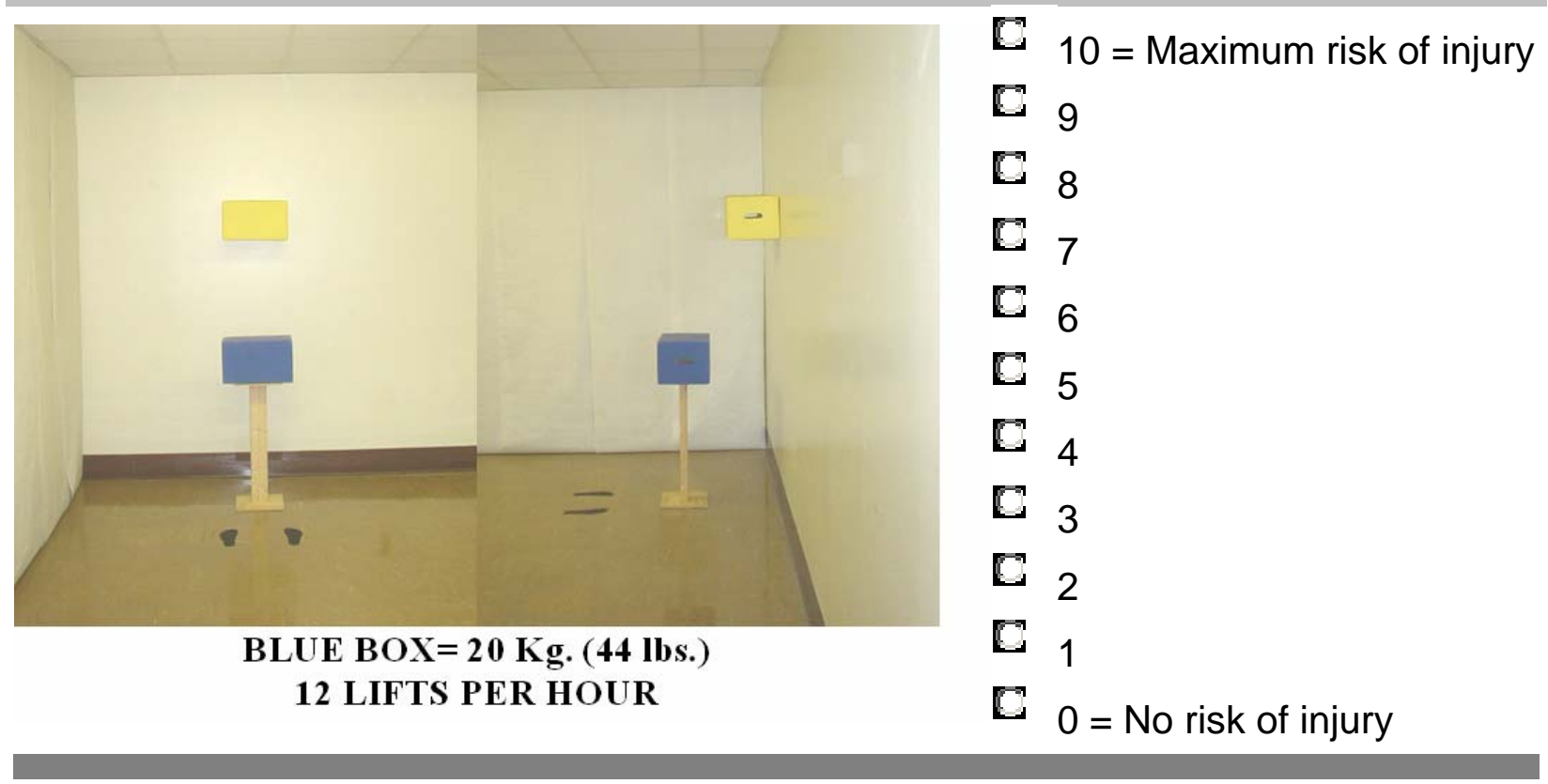

\section{Lifting Task 36}

\section{RATE THE RISK OF INJURY}

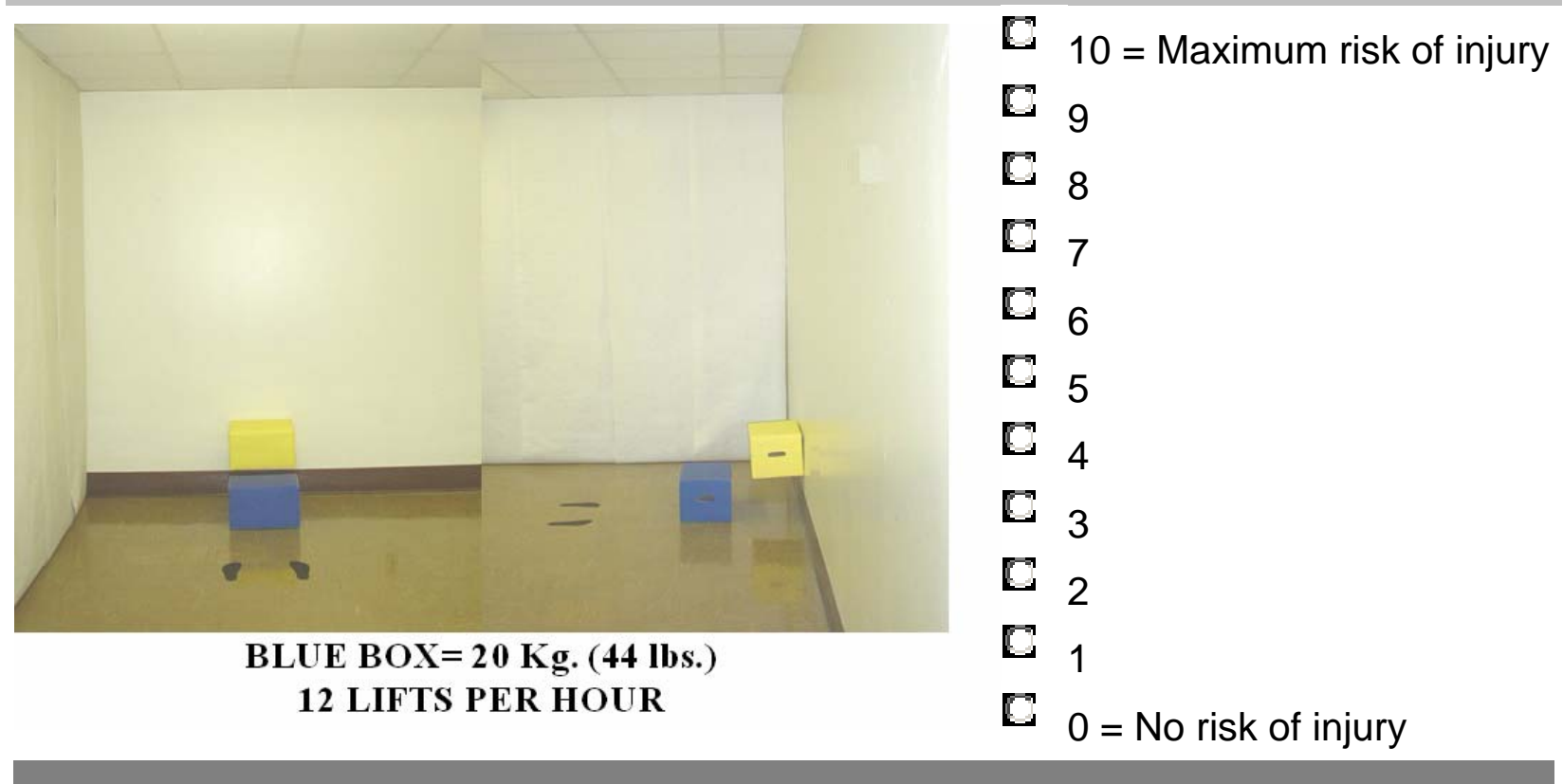




\section{Lifting Task 37}

\section{RATE THE RISK OF INJURY}

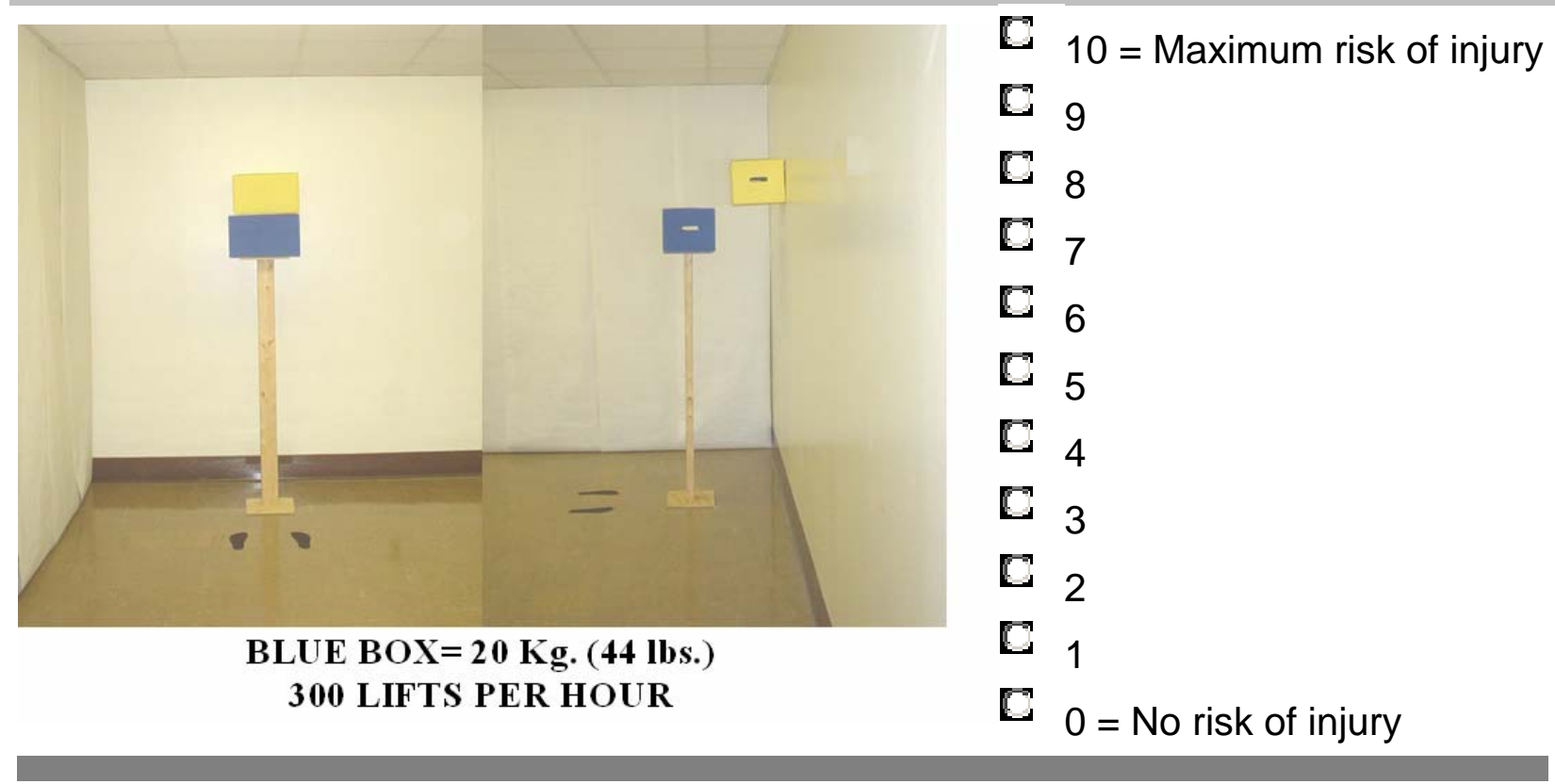

\section{Lifting Task 38}

\section{RATE THE RISK OF INJURY}

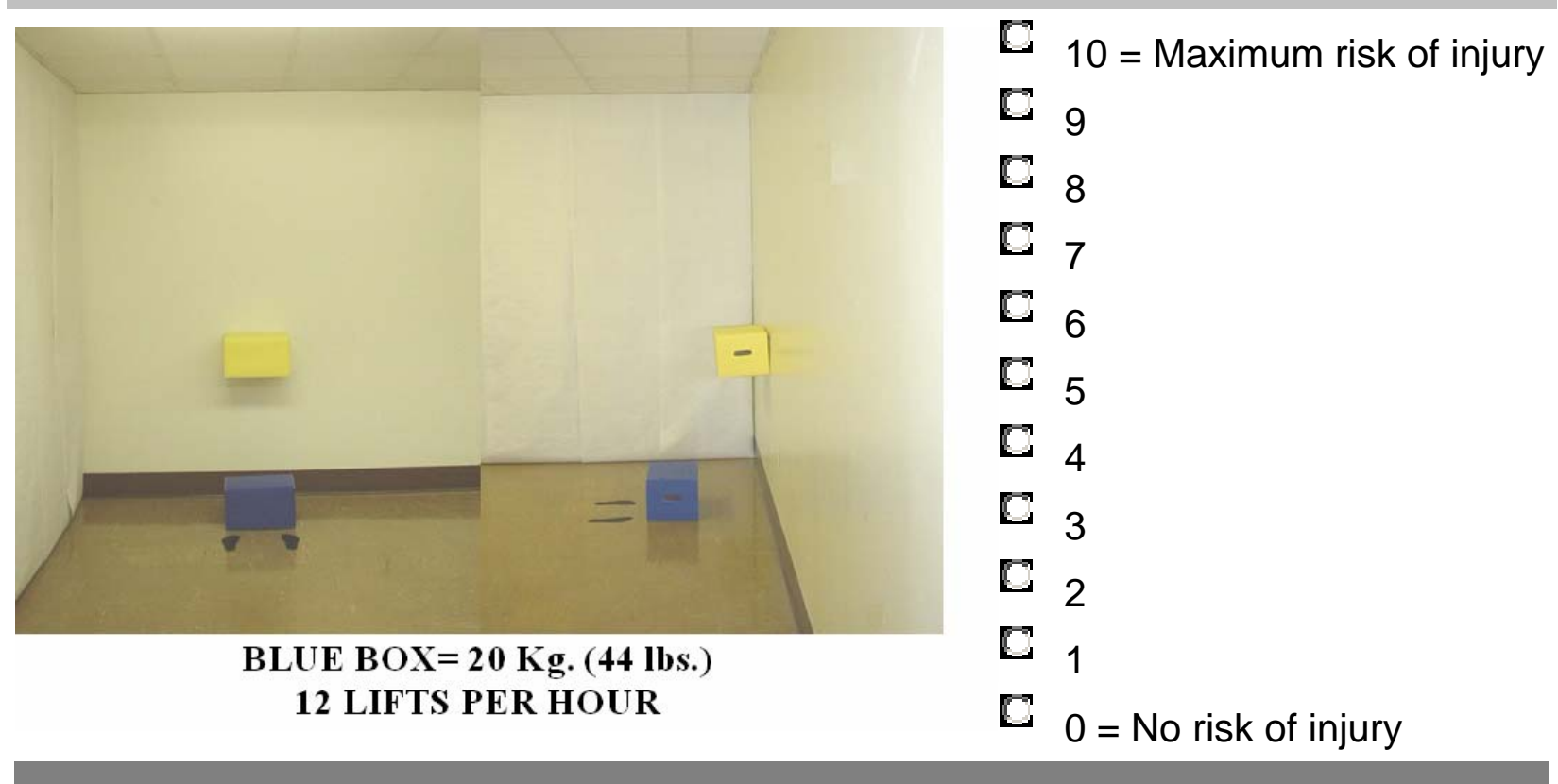




\section{Lifting Task 39}

48. RATE THE RISK OF INJURY

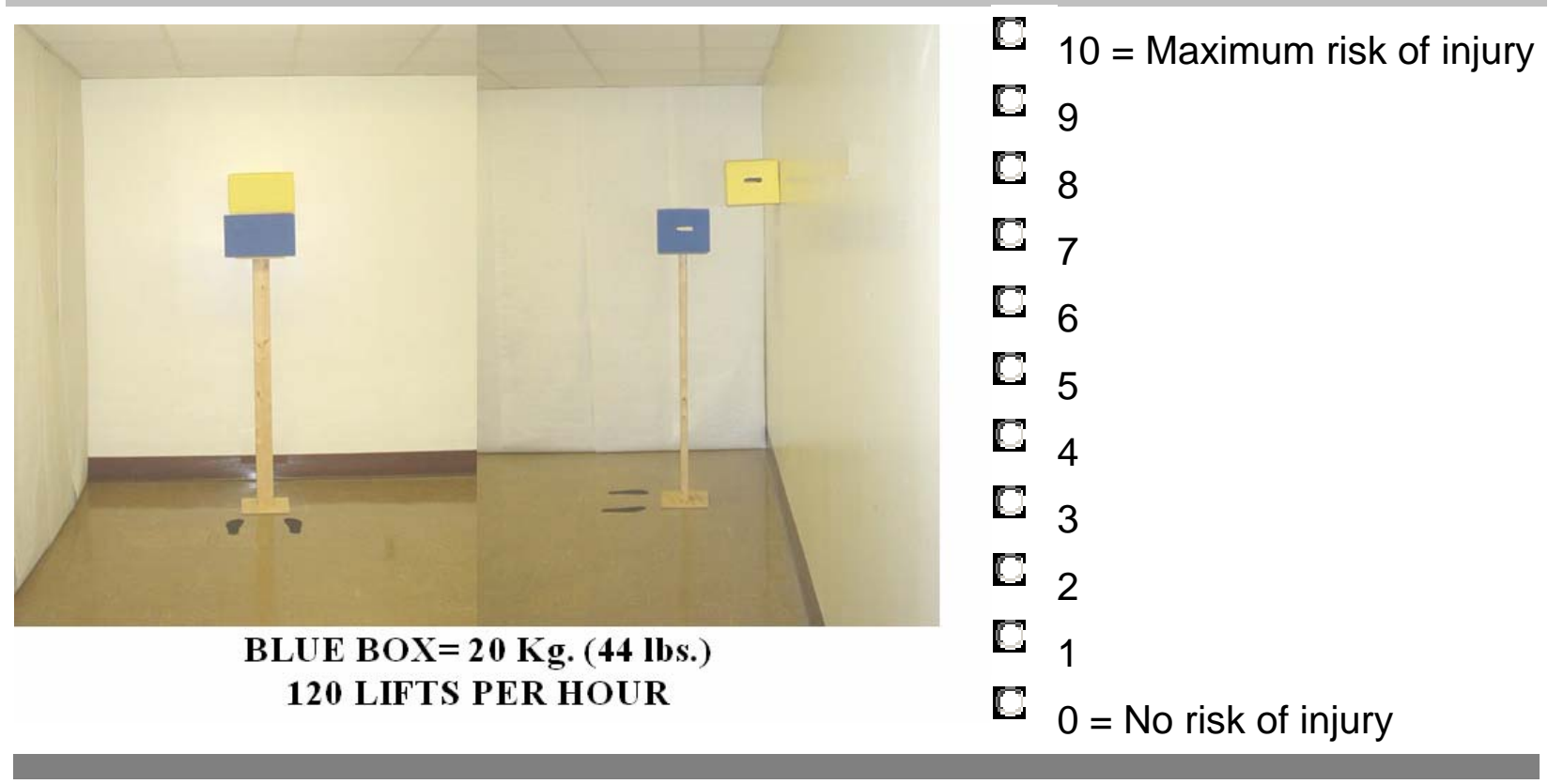

\section{Lifting Task 40}

\section{RATE THE RISK OF INJURY}

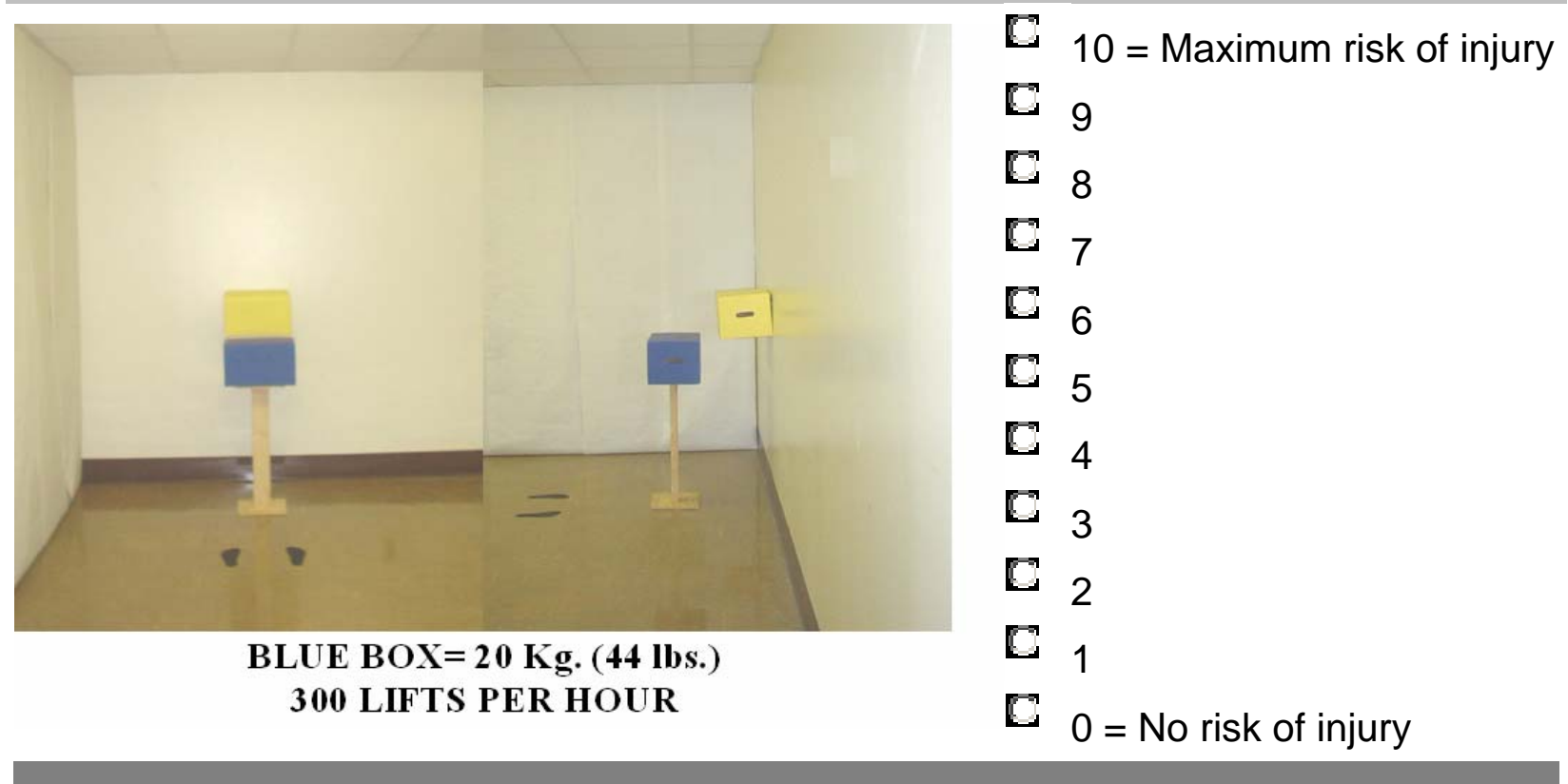




\section{Lifting Task 41}

50. RATE THE RISK OF INJURY

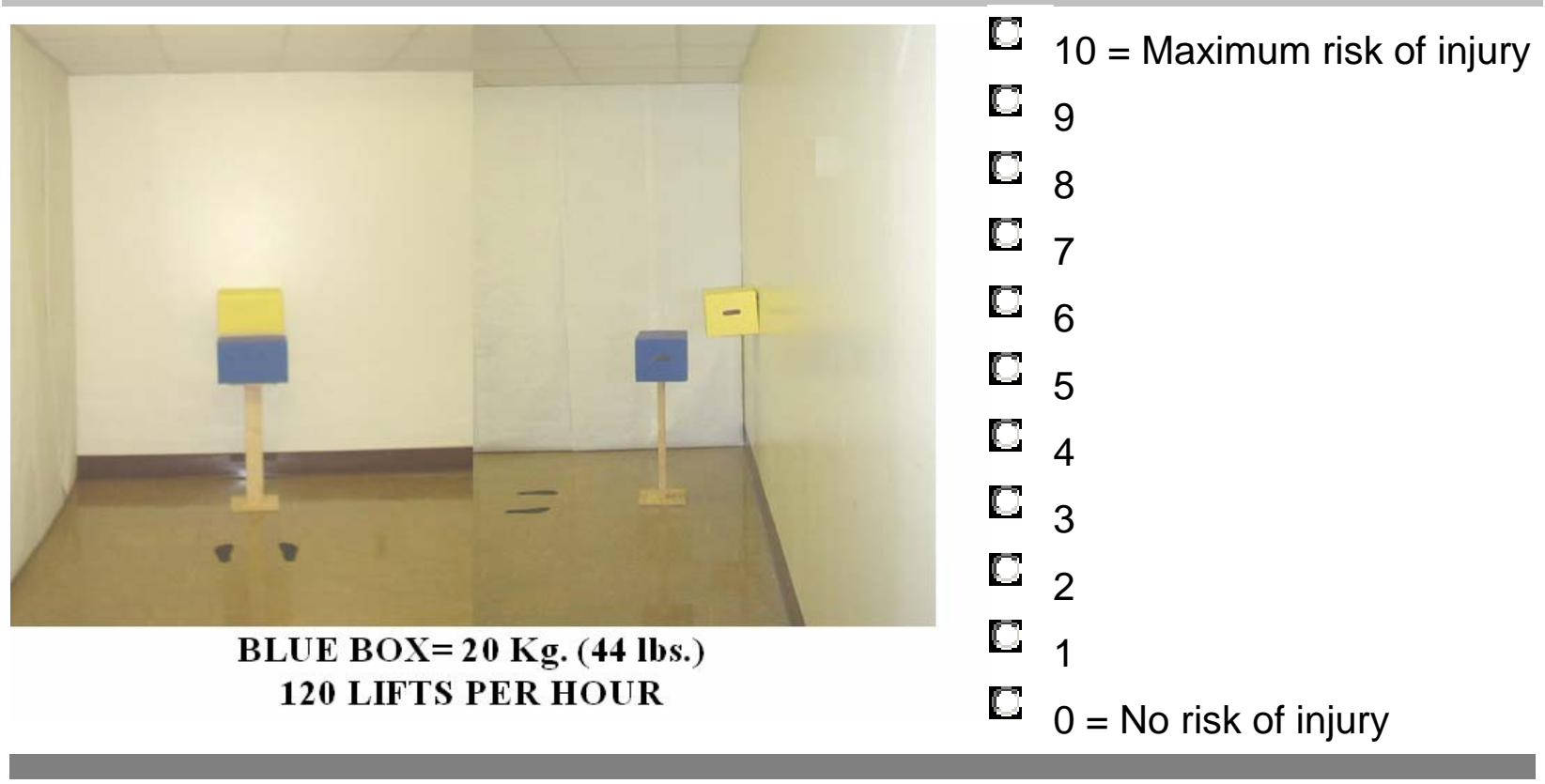

\section{Lifting Task 42}

\section{RATE THE RISK OF INJURY}

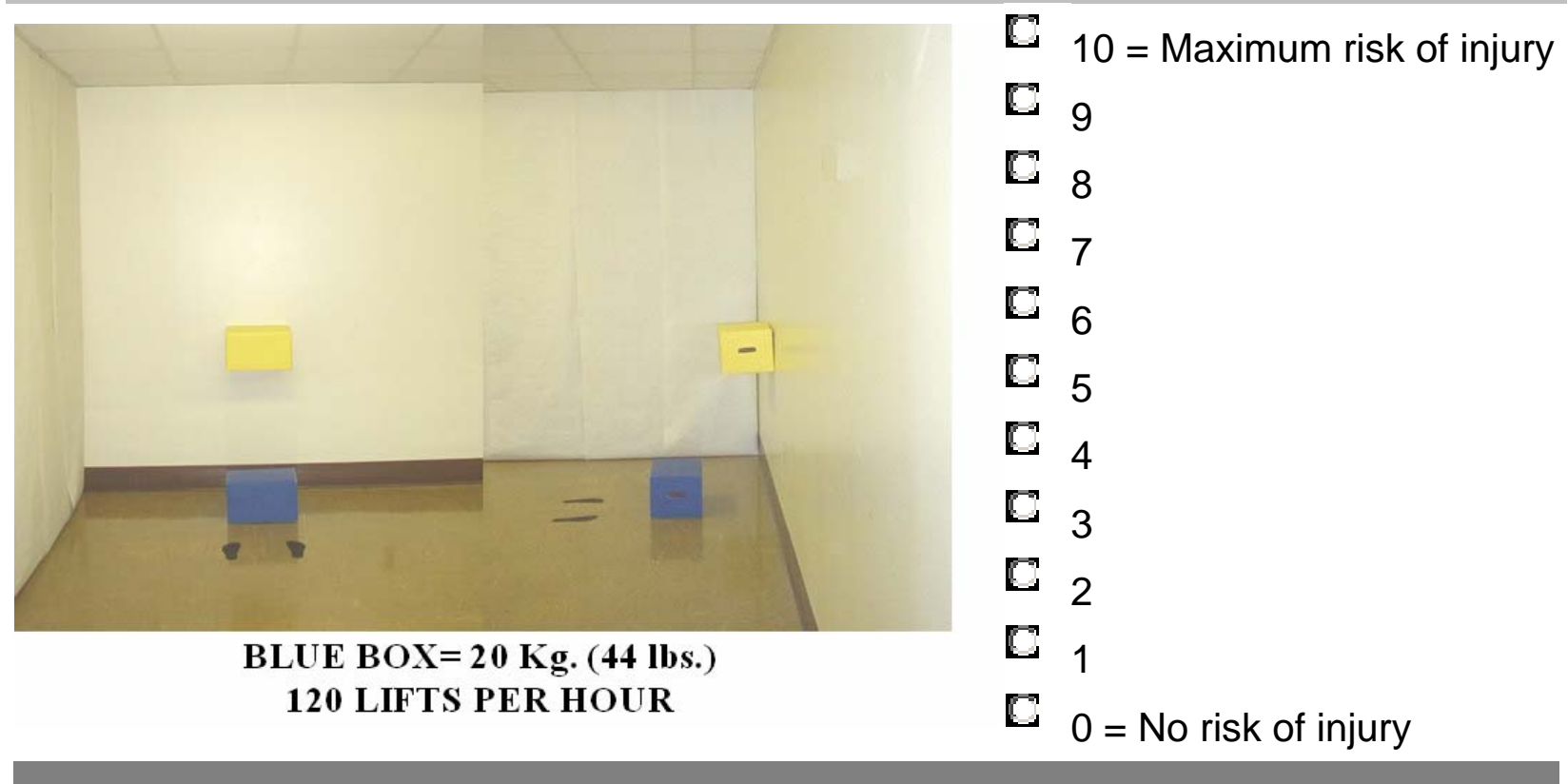




\section{Lifting Task 43}

52. RATE THE RISK OF INJURY

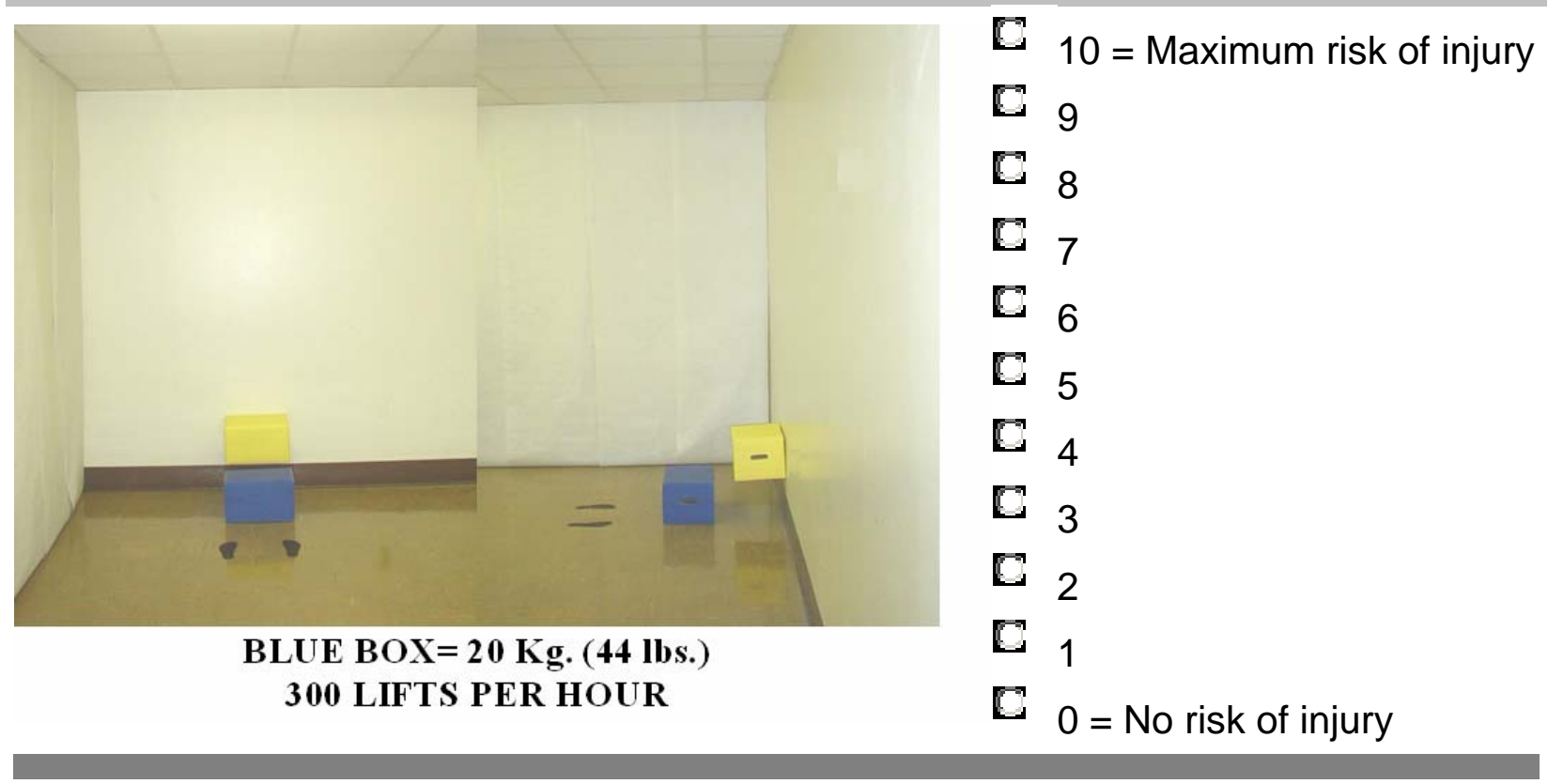

\section{Lifting Task 44}

\section{RATE THE RISK OF INJURY}

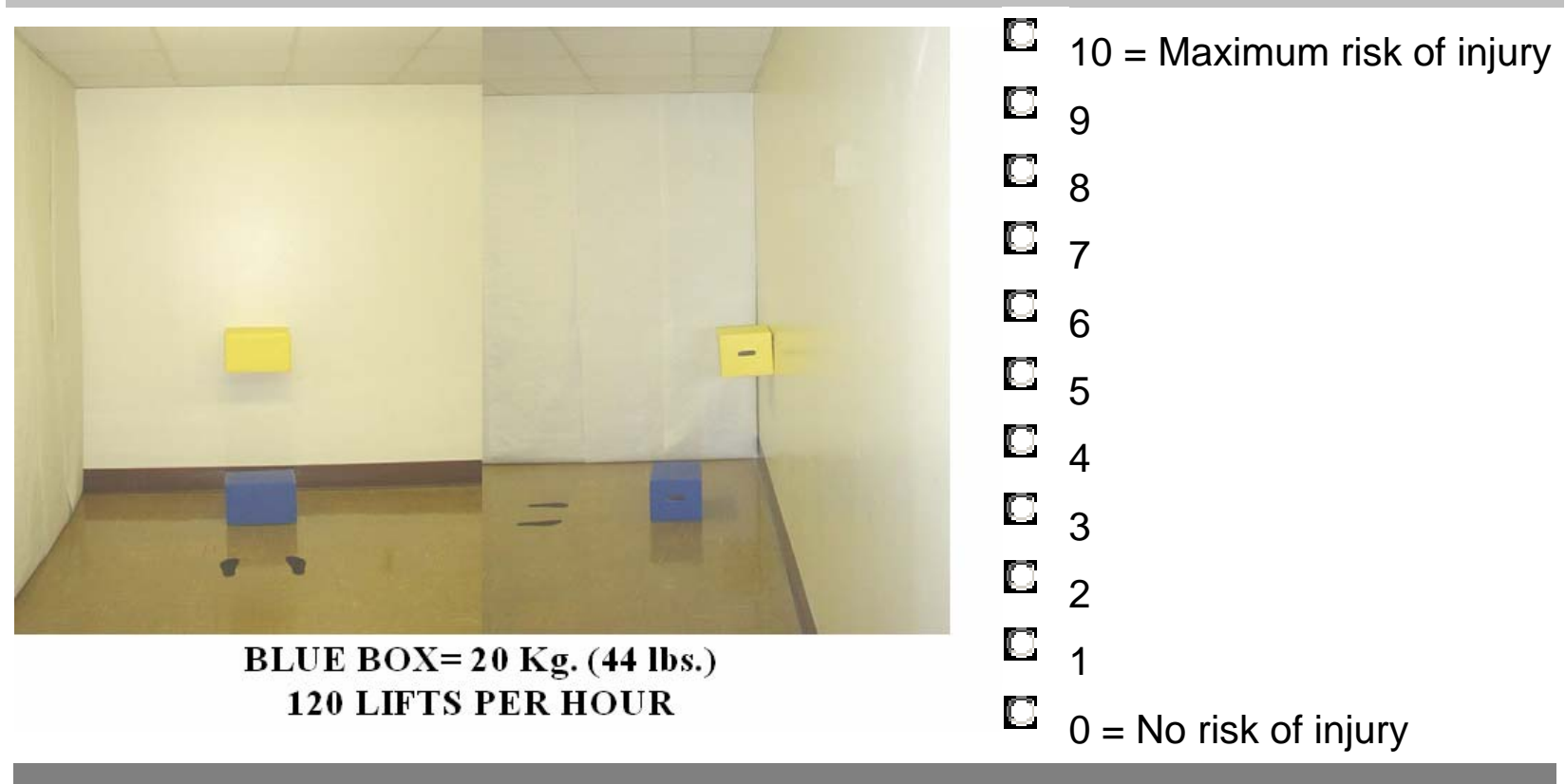




\section{Lifting Task 45}

54. RATE THE RISK OF INJURY

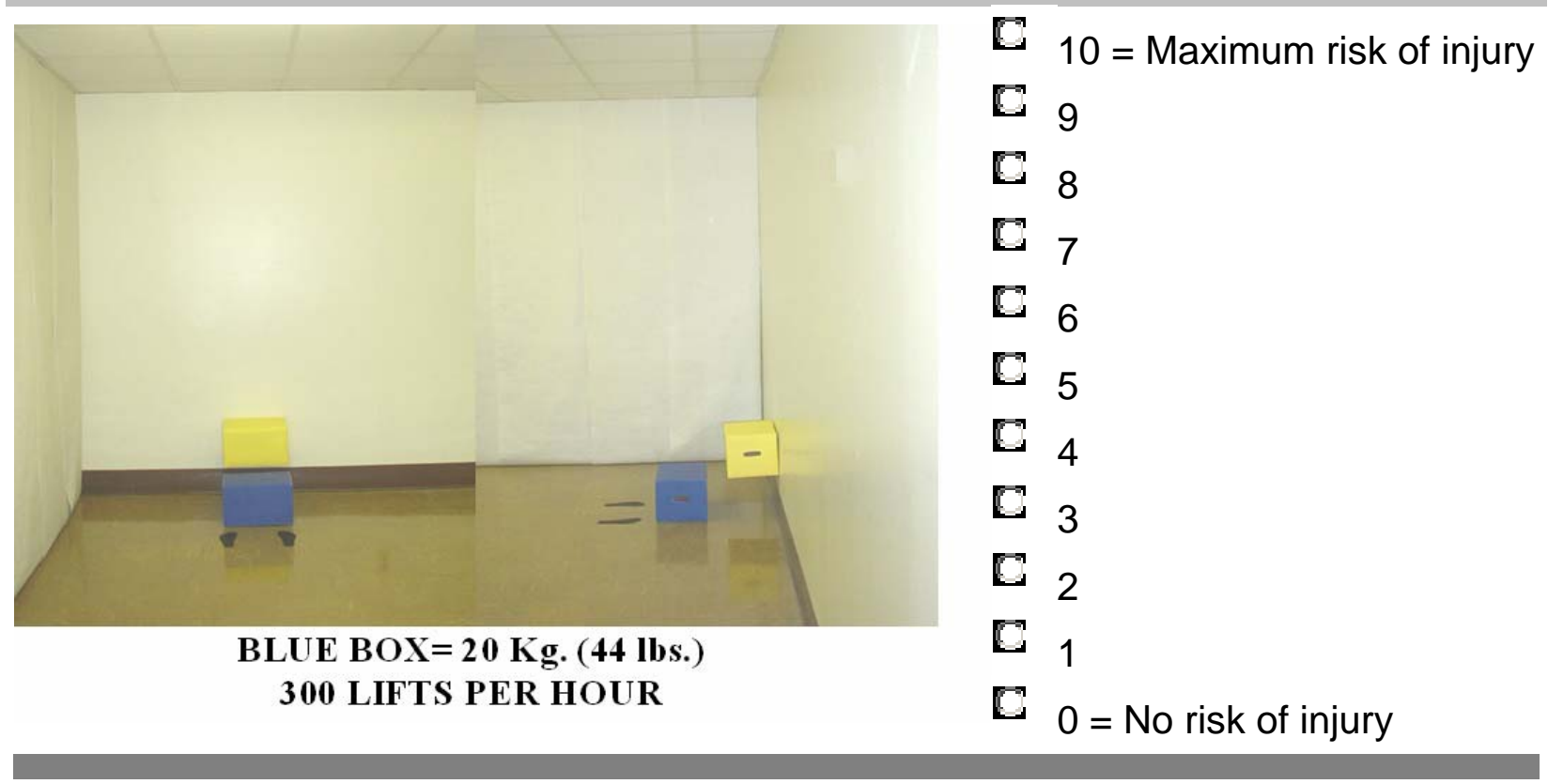

\section{Lifting Task 46}

\section{RATE THE RISK OF INJURY}

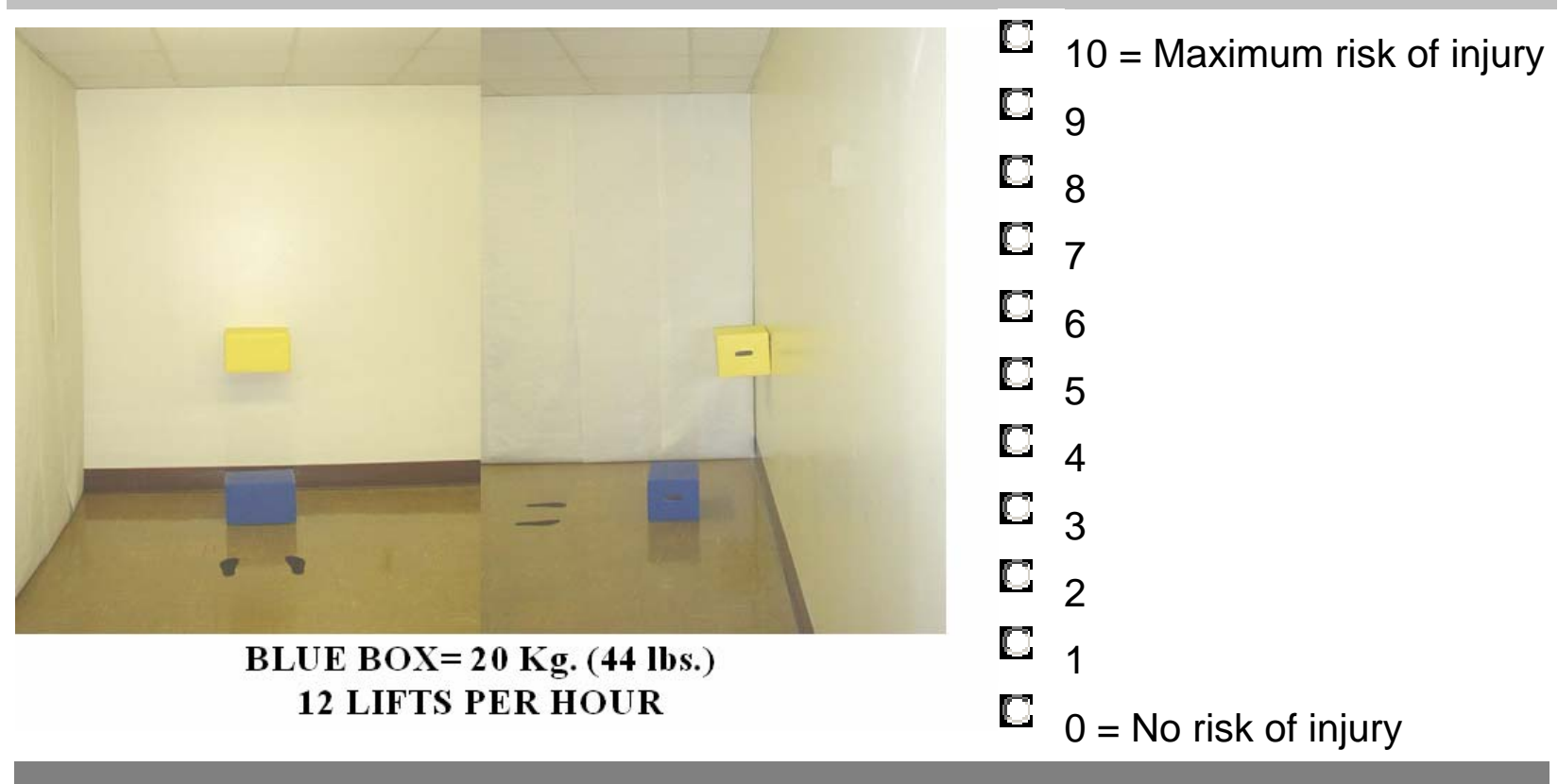




\section{Lifting Task 47}

56. RATE THE RISK OF INJURY

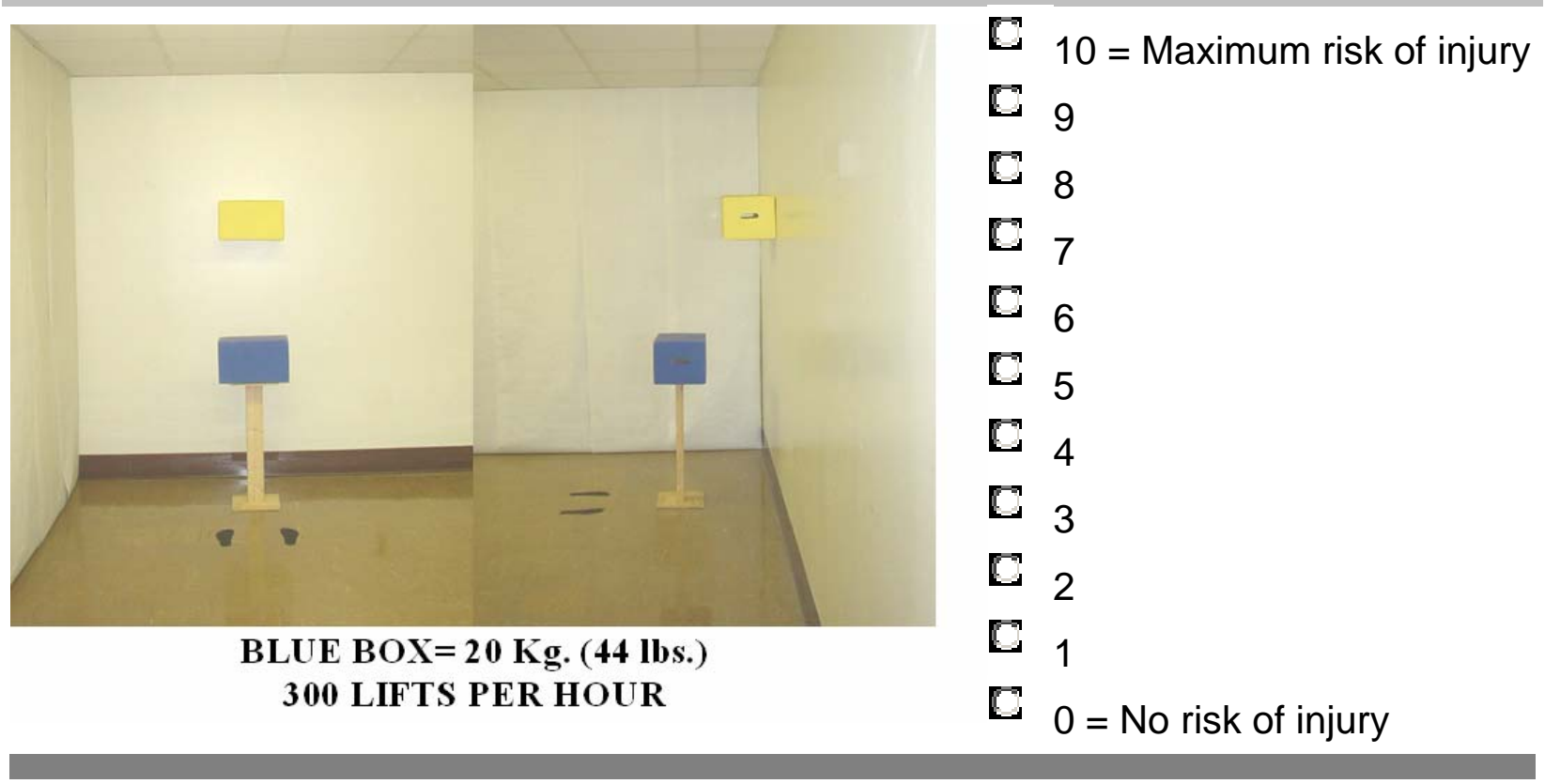

\section{Lifting Task 48}

\section{RATE THE RISK OF INJURY}

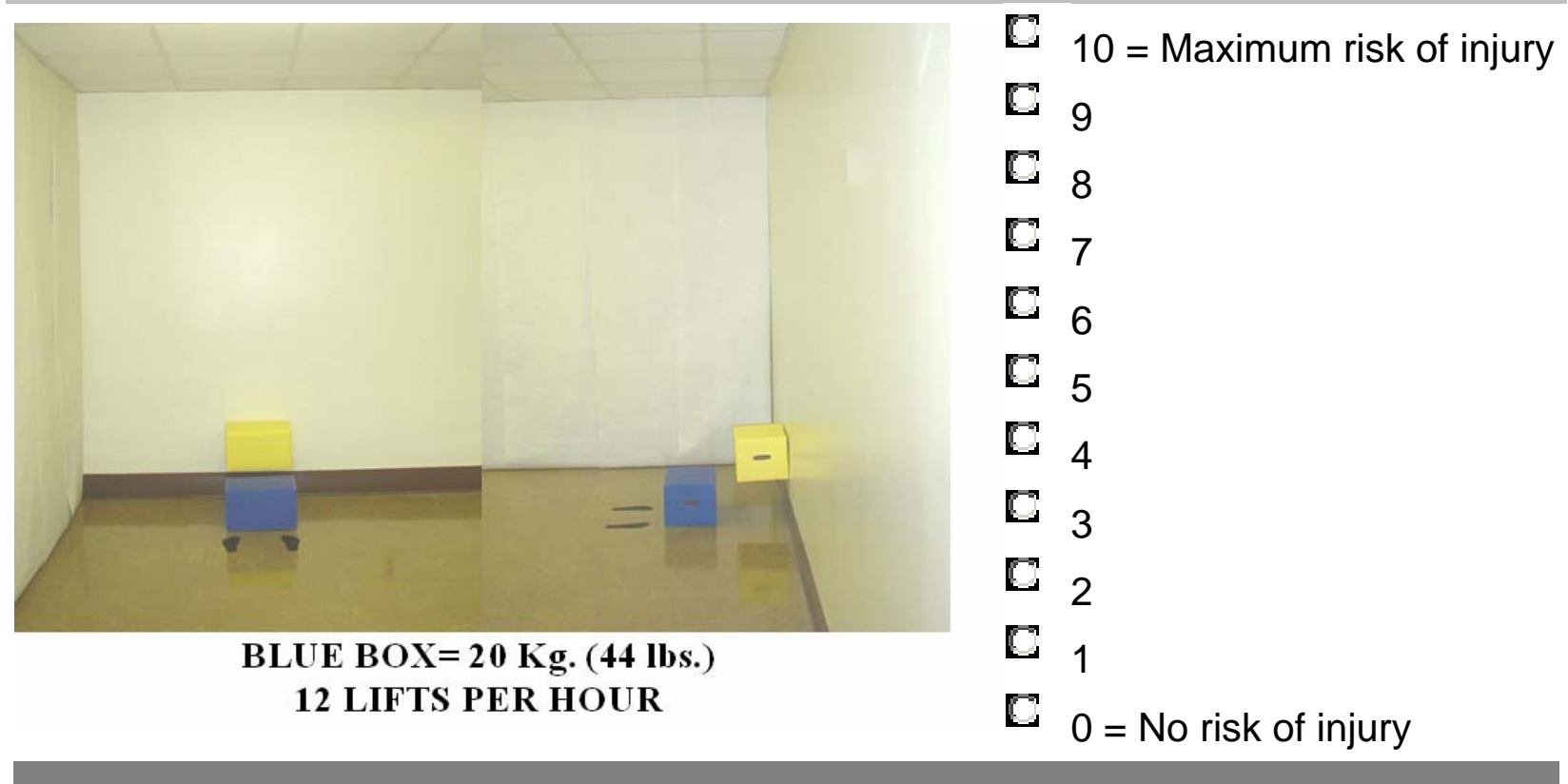




\section{Lifting Task 49}

58. RATE THE RISK OF INJURY

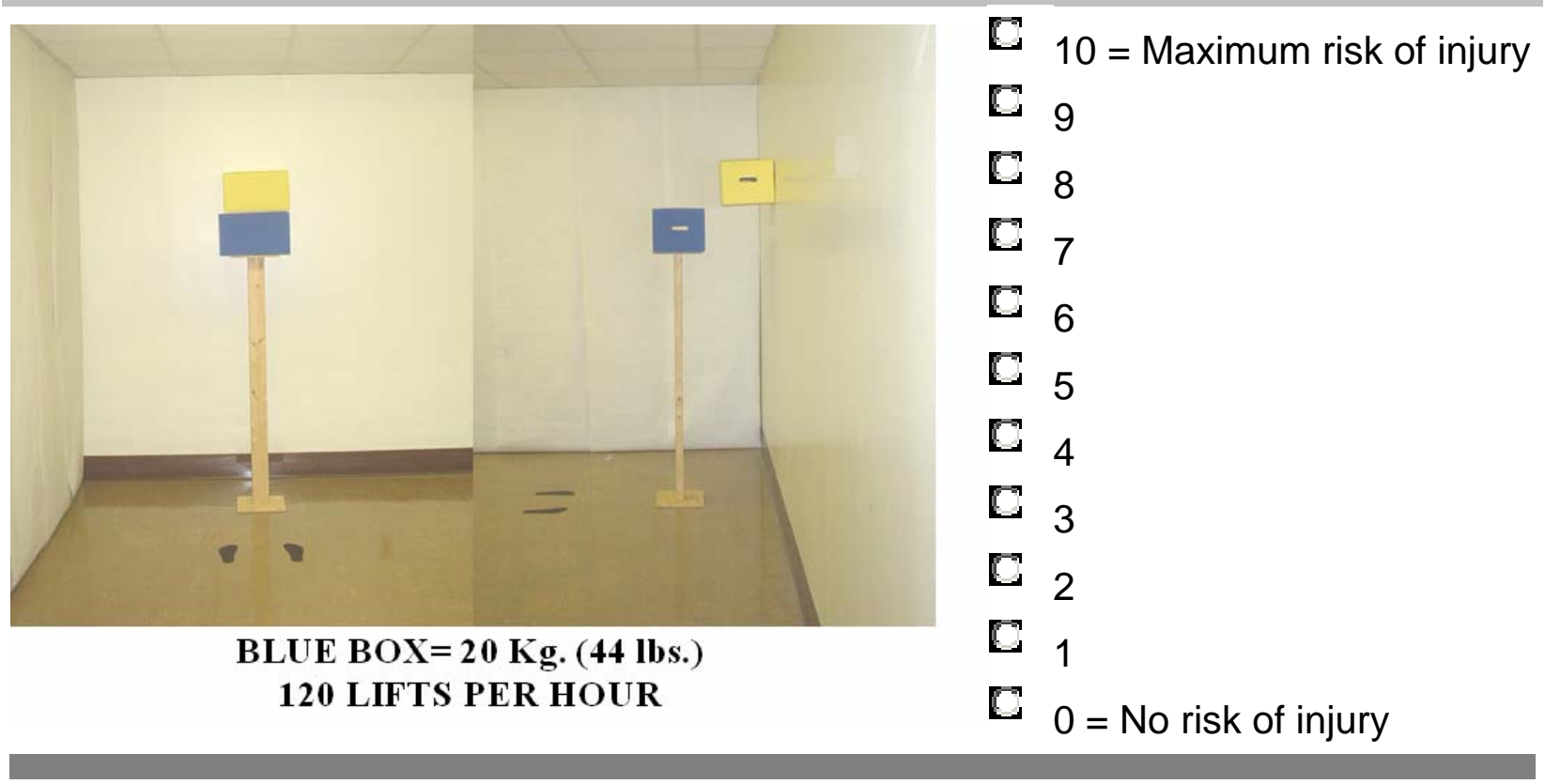

\section{Lifting Task 50}

\section{RATE THE RISK OF INJURY}

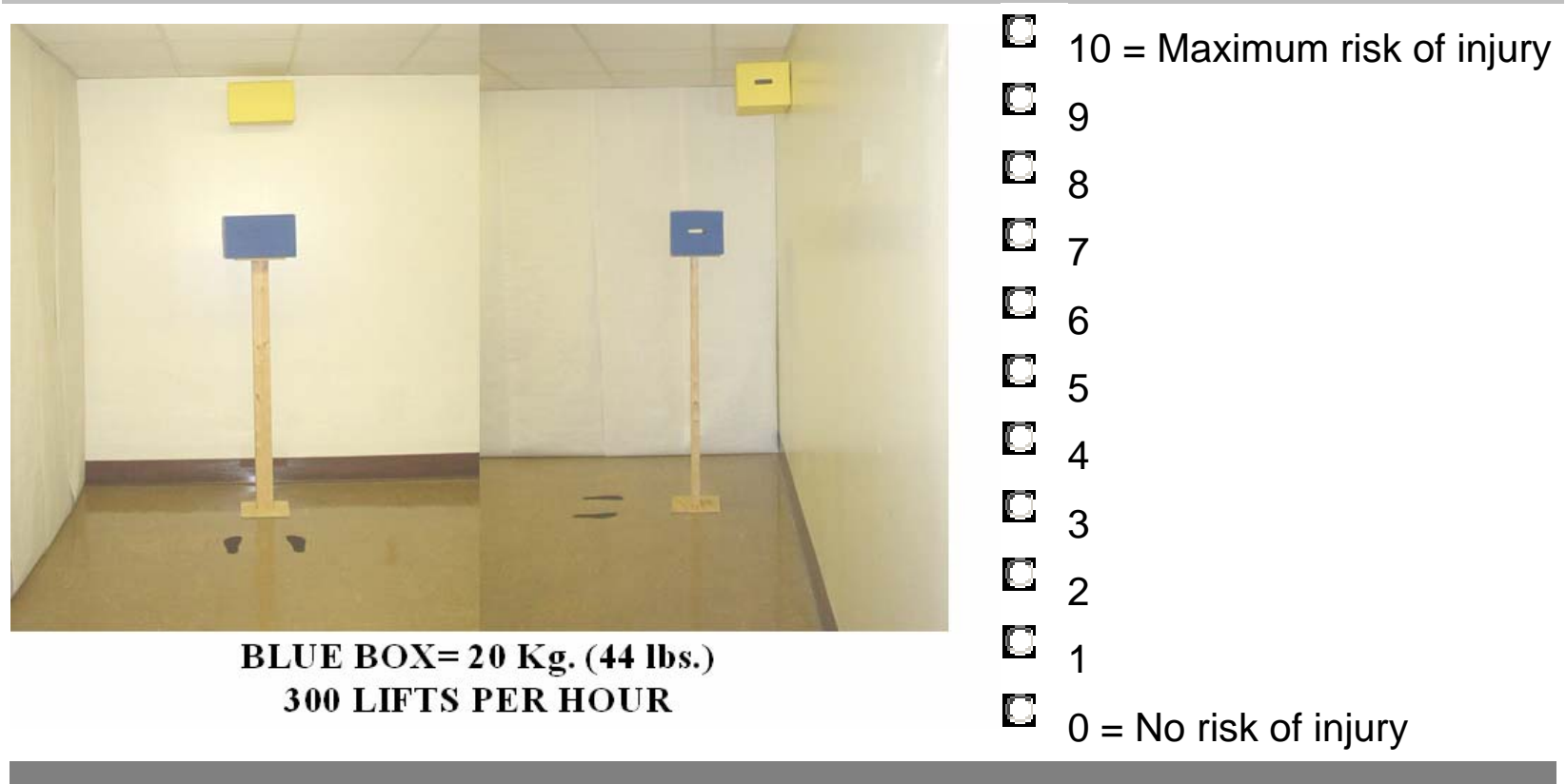




\section{Lifting Task 51}

\section{RATE THE RISK OF INJURY}

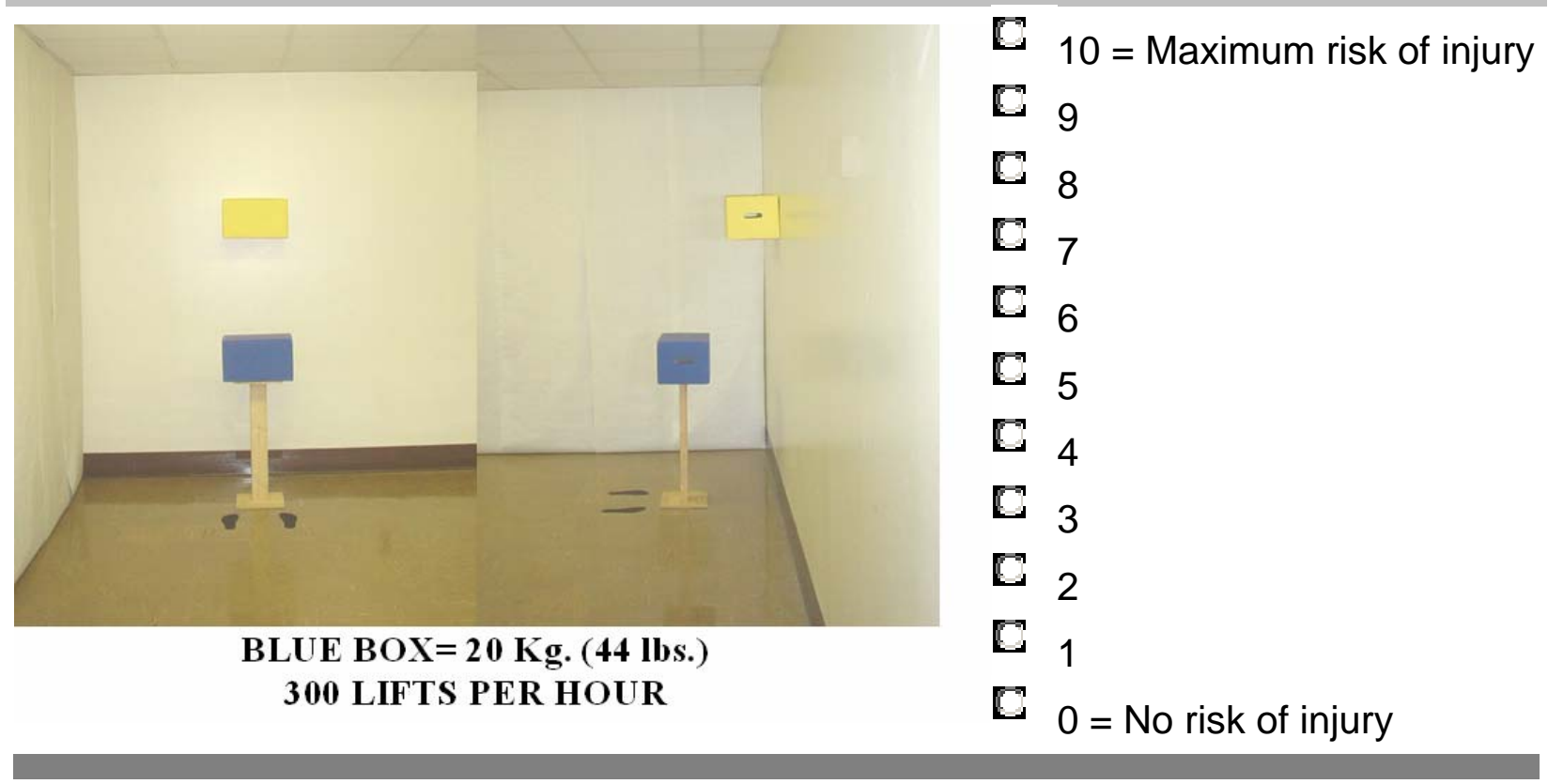

\section{Lifting Task 52}

\section{RATE THE RISK OF INJURY}

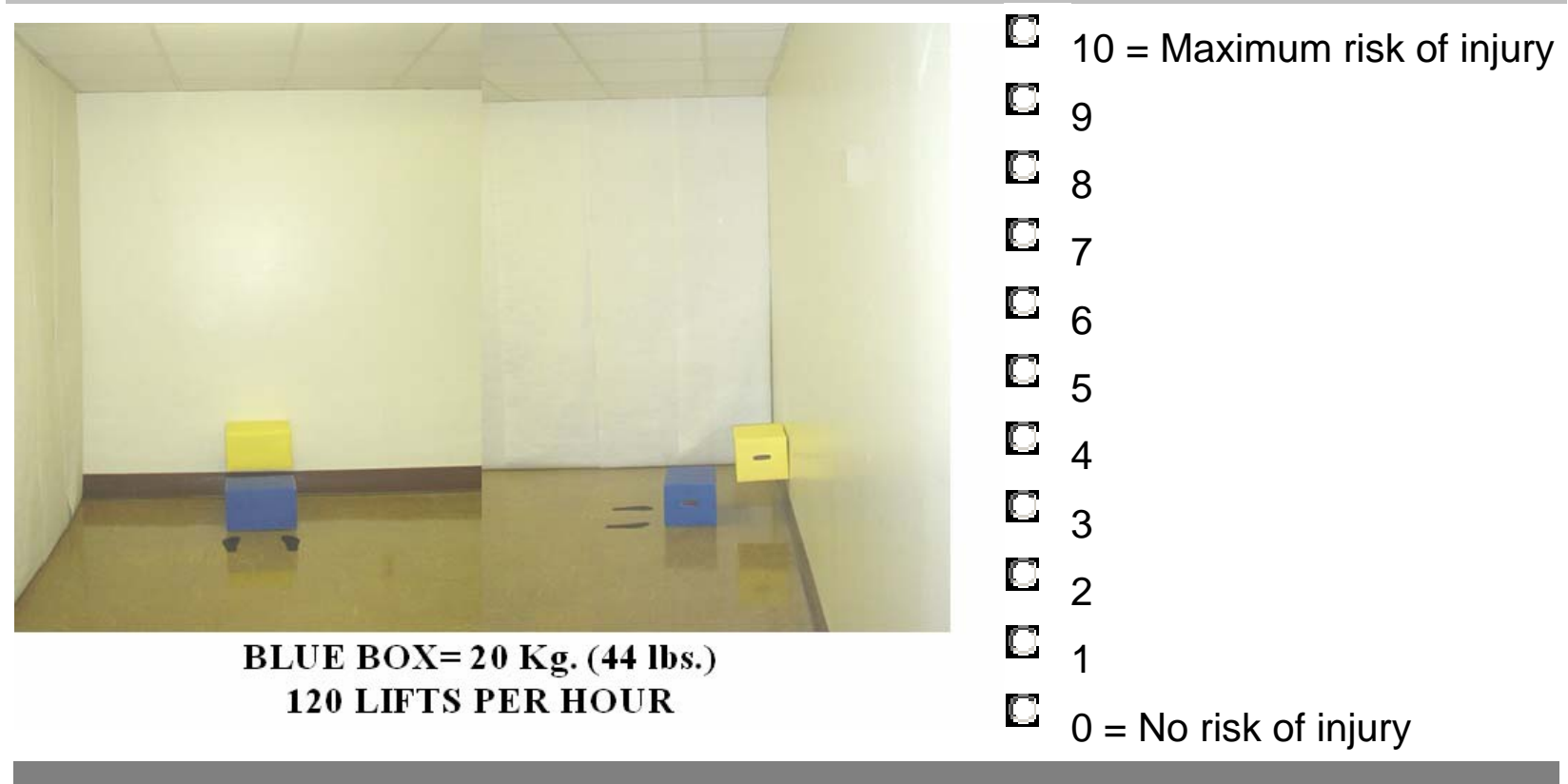




\section{Lifting Task 53}

62. RATE THE RISK OF INJURY

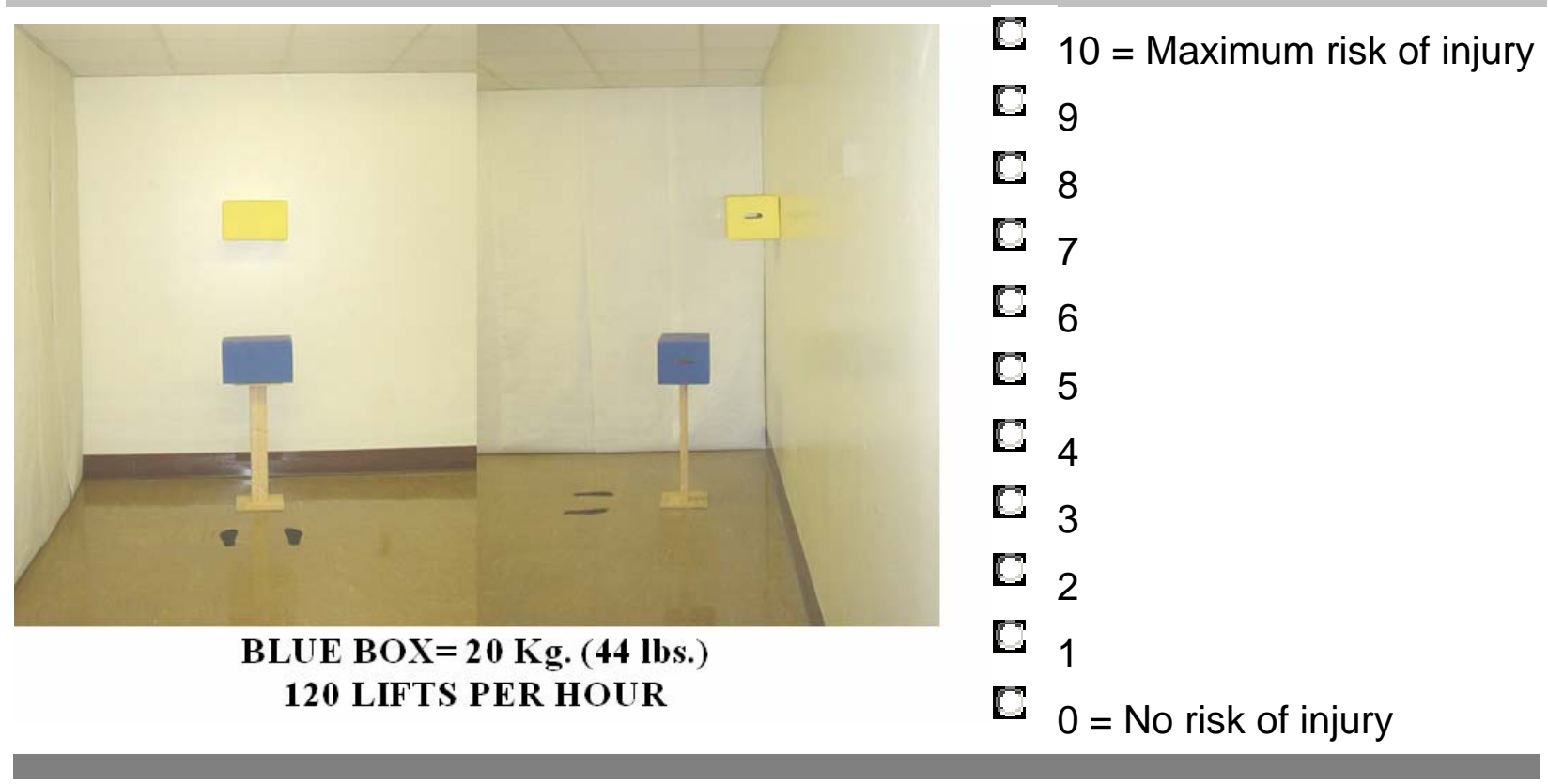

\section{Lifting Task 54}

\section{RATE THE RISK OF INJURY}

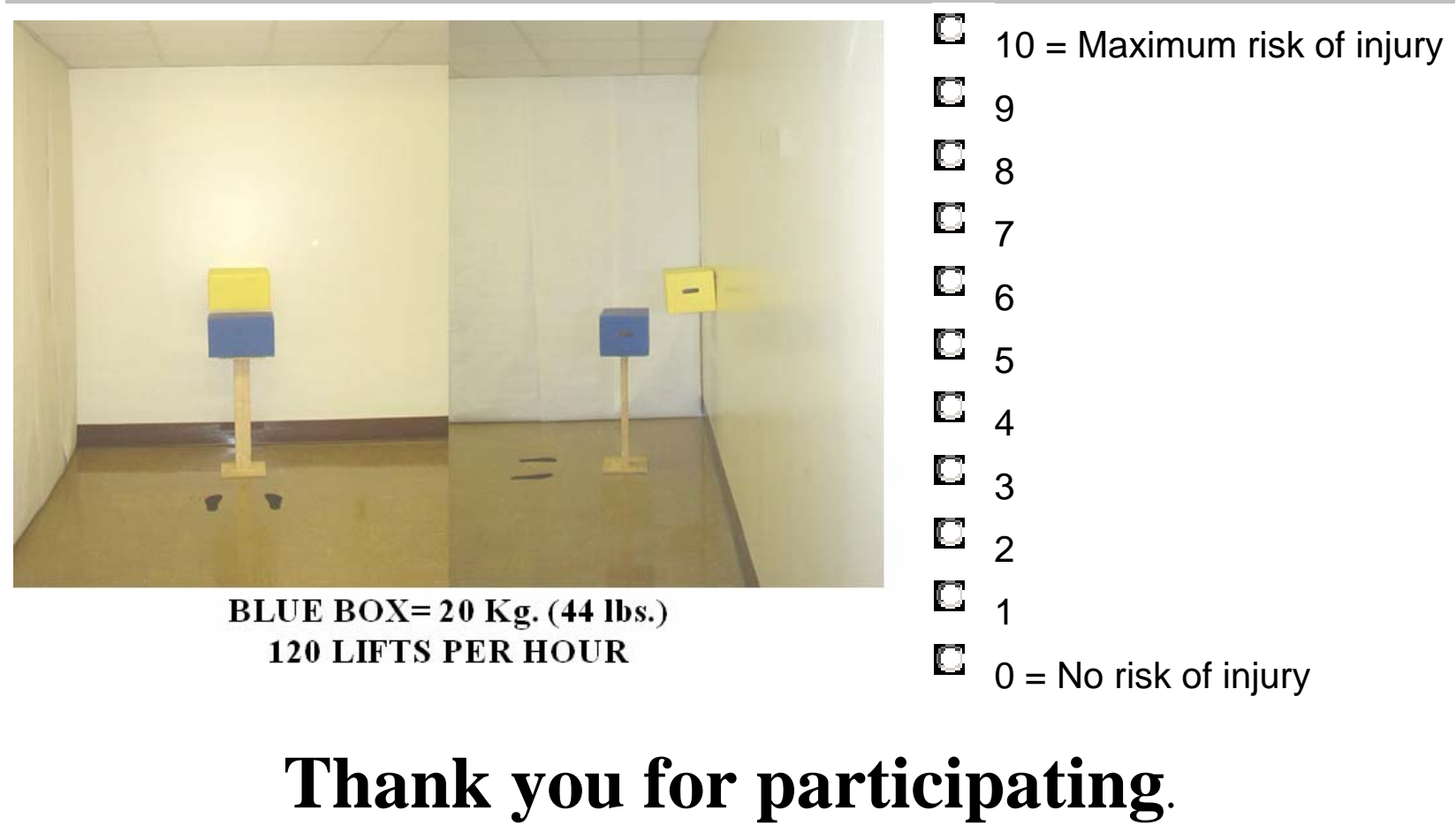




\section{APPENDIX 4. NIOSH 1991.}

Recommended Weight Limit (RWL) $=\mathrm{LC} \times \mathrm{HM} \times \mathrm{VM} \times \mathrm{DM} \times \mathrm{AM} \times \mathrm{FM} \times \mathrm{CM}$ Lifting Index $(\mathrm{LI})=$ Load Weight $/$ Recommended Weight Limit

Table 1. Discounting factors for NIOSH 1991.

\begin{tabular}{|c|c|c|}
\hline Factor Multiplier & $\begin{array}{l}\text { Metric Units } \\
\quad(\mathrm{kg}, \mathrm{cm})\end{array}$ & $\begin{array}{l}\text { U.S. Customary } \\
\text { System } \\
\text { (Ib, in) }\end{array}$ \\
\hline Load Constant (LC) & $23 \mathrm{~kg}$ & $51 \mathrm{lb}$ \\
\hline Horizontal Factor Multiplier (HFM) & $25 / \mathrm{H}$ & $10 / \mathrm{H}$ \\
\hline Vertical Factor Multiplier (VFM) & 1-(0.003|V-75|) & $1-(0.0075|\mathrm{~V}-30|)$ \\
\hline Travel Distance Factor Multiplier (DFM) & $0.82+(4.5 / \mathrm{D})$ & $0.82+(1.8 / \mathrm{D})$ \\
\hline Asymmetric Multiplier (AFM) & 1- $(0.0032 \mathrm{~A})$ & 1- $(0.0032 \mathrm{~A})$ \\
\hline Coupling Factor Multiplier (CFM) & $\begin{array}{l}\text { (See Table } 2 \text { in } \\
\text { Appendix 4) }\end{array}$ & $\begin{array}{l}\text { (See Table } 2 \text { in } \\
\text { Appendix 4) }\end{array}$ \\
\hline Frequency Factor Multiplier (FFM) & $\begin{array}{c}\text { (See Table } 3 \text { in } \\
\text { Appendix 4) }\end{array}$ & $\begin{array}{c}\text { (See Table } 3 \text { in } \\
\text { Appendix 4) }\end{array}$ \\
\hline
\end{tabular}

Asymmetry Angle (A): The angular measure of the perpendicular line that intersects the horizontal line connecting the mid-point of the shoulders and the perpendicular line that intersects the horizontal line connecting the outer midpoint of the hips. A=Asymmetry angle, absolute value of difference between the angles of midplane of the body from the start to the end of the lift; $A F M=0$ if $A>135^{\circ}$

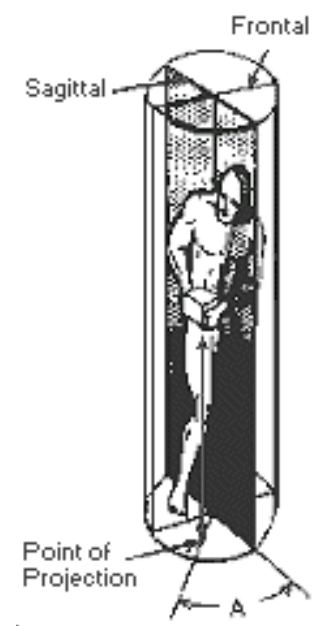

$1991 \mathrm{NIOSH}$ Asymmetric Angle. 
Object coupling (C): The classification of the quality of the hand-to-object coupling (rated as Good, Fair, or Poor).

Table 2. 1991 NIOSH Coupling Factor Values.

\begin{tabular}{|c|c|c|}
\hline \multicolumn{3}{|c|}{ COUPLING FACTOR QUALTY } \\
\hline GOOD & FAIR & POOR \\
\hline CFM $=1.00$ & $\mathrm{~V}<30$ " then $\mathrm{CFM}=0.95$ & CFM $=0.90$ \\
\hline & $\mathrm{V}>$ or $=$ to $30 "$ then $\mathrm{CM}=1.00$ & \\
\hline 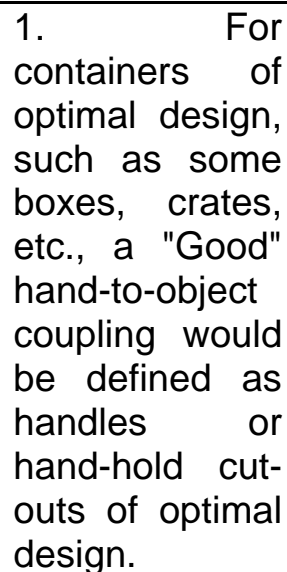 & $\begin{array}{l}\text { 1. For containers of optimal } \\
\text { design, a "Fair" hand-to- } \\
\text { object coupling would be } \\
\text { defined as handles or hand- } \\
\text { hold cut-outs of less than } \\
\text { optimal design. }\end{array}$ & $\begin{array}{l}\text { 1. Containers of less } \\
\text { than optimal design } \\
\text { or loose parts or } \\
\text { irregular objects that } \\
\text { are bulky or hard to } \\
\text { handle. }\end{array}$ \\
\hline 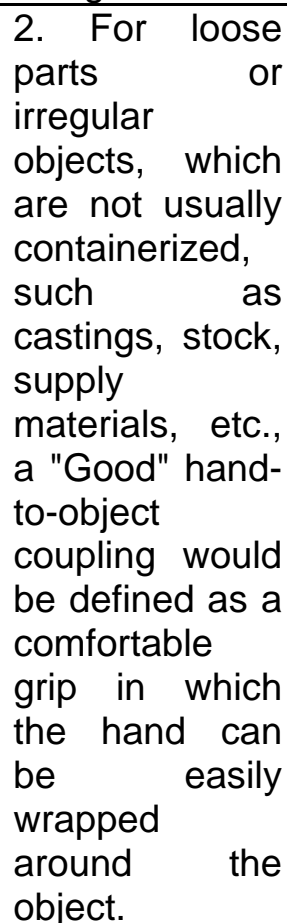 & $\begin{array}{l}\text { 2. For containers of optimal } \\
\text { design with no handles or } \\
\text { hand-hold cut-outs or for } \\
\text { loose parts or irregular } \\
\text { objects, a "Fair" hand-to- } \\
\text { object coupling is defined } \\
\text { as a grip in which the hand } \\
\text { can be flexed about } 90 \\
\text { degrees. }\end{array}$ & $\begin{array}{l}2 . \text { Lifting non-rigid } \\
\text { bags (i.e., bags that } \\
\text { sag in the middle). }\end{array}$ \\
\hline
\end{tabular}


Lifting Frequency $(\mathbf{F})$ : The average lifting frequency rate, expressed in terms of lifts per minute, must be determined. Duration is measured using the following categories: Short (Less than one hour); Moderate (1 to 2 hours); Long (2 to 8 hours).

Table 3. 1991 NIOSH Frequency Factor Multiplier

\begin{tabular}{|c|c|c|c|c|c|c|}
\hline \multirow{3}{*}{$\begin{array}{l}\text { Frequency } \\
\text { Lifts/min } \\
\text { (F) } \ddagger\end{array}$} & \multicolumn{6}{|c|}{ Work Duration } \\
\hline & \multicolumn{2}{|c|}{$\leq 1$ Hour } & \multicolumn{2}{|c|}{$>1$ but $\leq 2$ Hours } & \multicolumn{2}{|c|}{$>2$ but $\leq 8$ Hours } \\
\hline & $V<30 \dagger$ & $V \geq 30$ & $V<30$ & $V \geq 30$ & $V<30$ & $V \geq 30$ \\
\hline$\leq 0.2$ & 1.00 & 1.00 & .95 & .95 & .85 & .85 \\
\hline 0.5 & .97 & .97 & .92 & .92 & .81 & .81 \\
\hline 1 & .94 & .94 & .88 & .88 & .75 & .75 \\
\hline 2 & .91 & .91 & .84 & .84 & .65 & .65 \\
\hline 3 & .88 & .88 & .79 & .79 & .55 & .55 \\
\hline 4 & .84 & .84 & .72 & .72 & .45 & .45 \\
\hline 5 & .80 & .80 & .60 & .60 & .35 & .35 \\
\hline 6 & .75 & .75 & .50 & .50 & .27 & .27 \\
\hline 7 & .70 & .70 & .42 & .42 & .22 & .22 \\
\hline 8 & .60 & .60 & .35 & .35 & .18 & 18 \\
\hline 9 & .52 & .52 & .30 & .30 & .00 & .15 \\
\hline 10 & .45 & .45 & .26 & .26 & .00 & .13 \\
\hline 11 & .41 & .41 & .00 & .23 & .00 & .00 \\
\hline 12 & .37 & .37 & .00 & .21 & .00 & .00 \\
\hline 13 & .00 & .34 & .00 & .00 & .00 & .00 \\
\hline 14 & .00 & .31 & .00 & .00 & .00 & .00 \\
\hline 15 & .00 & .28 & .00 & .00 & .00 & .00 \\
\hline$>15$ & .00 & .00 & .00 & .00 & .00 & .00 \\
\hline
\end{tabular}

Values of $V$ are in inches. For lifting less frequently than once per 5 minutes, set $F=2$ lifts/minute.

For purpose of calculation of LI in the study, the coupling factor was set as a good coupling CFM=1, since a carton box with cut out handles were used for creation of the pictures, and a $A F M=1$, since subjects were asked to stand in foot marks in front of the object, so no angle was created when lifting the object. 
Table 4. Lifting Index for each of the task generated based on NIOSH (1991) equation and used in the questionnaire.

\begin{tabular}{|c|c|c|c|c|c|c|c|c|c|c|}
\hline $\mathrm{H}(\mathrm{cm})$ & $V(\mathrm{~cm})$ & $\begin{array}{c}\text { F } \\
\text { (lifts/min) }\end{array}$ & $\mathrm{D}(\mathrm{cm})$ & HFM & VFM & DFM & FFM & AFM & CFM & LI \\
\hline 80 & 83 & 5 & 75 & 0.31 & 0.98 & 0.88 & 0.8 & 1.0 & 1.0 & 4.05 \\
\hline 40 & 150 & 0.2 & 25 & 0.63 & 0.78 & 1 & 1 & 1.0 & 1.0 & 1.80 \\
\hline 60 & 83 & 5 & 25 & 0.42 & 0.98 & 1 & 0.8 & 1.0 & 1.0 & 2.67 \\
\hline 80 & 16 & 5 & 75 & 0.31 & 0.82 & 0.88 & 0.8 & 1.0 & 1.0 & 4.80 \\
\hline 80 & 150 & 2 & 75 & 0.31 & 0.78 & 0.88 & 0.91 & 1.0 & 1.0 & 4.48 \\
\hline 80 & 150 & 0.2 & 25 & 0.31 & 0.78 & 1 & 1 & 1.0 & 1.0 & 3.59 \\
\hline 80 & 150 & 5 & 25 & 0.31 & 0.78 & 1 & 0.8 & 1.0 & 1.0 & 4.49 \\
\hline 80 & 150 & 0.2 & 75 & 0.31 & 0.78 & 0.88 & 1 & 1.0 & 1.0 & 4.08 \\
\hline 40 & 150 & 5 & 75 & 0.63 & 0.78 & 0.88 & 0.8 & 1.0 & 1.0 & 2.55 \\
\hline 60 & 150 & 0.2 & 75 & 0.42 & 0.78 & 0.88 & 1 & 1.0 & 1.0 & 3.06 \\
\hline 60 & 16 & 5 & 75 & 0.42 & 0.82 & 0.88 & 0.8 & 1.0 & 1.0 & 3.60 \\
\hline 80 & 16 & 5 & 25 & 0.31 & 0.82 & 1 & 0.8 & 1.0 & 1.0 & 4.23 \\
\hline 80 & 83 & 2 & 75 & 0.31 & 0.98 & 0.88 & 0.91 & 1.0 & 1.0 & 3.56 \\
\hline 60 & 150 & 0.2 & 25 & 0.42 & 0.78 & 1 & 1 & 1.0 & 1.0 & 2.69 \\
\hline 80 & 83 & 0.2 & 75 & 0.31 & 0.98 & 0.88 & 1 & 1.0 & 1.0 & 3.24 \\
\hline 40 & 83 & 2 & 25 & 0.63 & 0.98 & 1 & 0.91 & 1.0 & 1.0 & 1.57 \\
\hline 60 & 150 & 2 & 75 & 0.42 & 0.78 & 0.88 & 0.91 & 1.0 & 1.0 & 3.36 \\
\hline 40 & 83 & 5 & 25 & 0.63 & 0.98 & 1 & 0.8 & 1.0 & 1.0 & 1.78 \\
\hline 60 & 150 & 2 & 25 & 0.42 & 0.78 & 1 & 0.91 & 1.0 & 1.0 & 2.96 \\
\hline 60 & 16 & 2 & 25 & 0.42 & 0.82 & 1 & 0.91 & 1.0 & 1.0 & 2.79 \\
\hline 80 & 83 & 0.2 & 25 & 0.31 & 0.98 & 1 & 1 & 1.0 & 1.0 & 2.85 \\
\hline 40 & 83 & 2 & 75 & 0.63 & 0.98 & 0.88 & 0.91 & 1.0 & 1.0 & 1.78 \\
\hline 60 & 16 & 0.2 & 75 & 0.42 & 0.82 & 0.88 & 1 & 1.0 & 1.0 & 2.88 \\
\hline 60 & 83 & 0.2 & 25 & 0.42 & 0.98 & 1 & 1 & 1.0 & 1.0 & 2.14 \\
\hline 40 & 150 & 2 & 75 & 0.63 & 0.78 & 0.88 & 0.91 & 1.0 & 1.0 & 2.24 \\
\hline 80 & 16 & 2 & 25 & 0.31 & 0.82 & 1 & 0.91 & 1.0 & 1.0 & 3.72 \\
\hline 40 & 150 & 0.2 & 75 & 0.63 & 0.78 & 0.88 & 1 & 1.0 & 1.0 & 2.04 \\
\hline 40 & 150 & 5 & 25 & 0.63 & 0.78 & 1 & 0.8 & 1.0 & 1.0 & 2.24 \\
\hline 80 & 150 & 5 & 75 & 0.31 & 0.78 & 0.88 & 0.8 & 1.0 & 1.0 & 5.10 \\
\hline 40 & 16 & 5 & 75 & 0.63 & 0.82 & 0.88 & 0.8 & 1.0 & 1.0 & 2.40 \\
\hline 40 & 83 & 0.2 & 25 & 0.63 & 0.98 & 1 & 1 & 1.0 & 1.0 & 1.43 \\
\hline 40 & 83 & 0.2 & 75 & 0.63 & 0.98 & 0.88 & 1 & 1.0 & 1.0 & 1.62 \\
\hline 60 & 16 & 0.2 & 25 & 0.42 & 0.82 & 1 & 1 & 1.0 & 1.0 & 2.54 \\
\hline 40 & 16 & 2 & 75 & 0.63 & 0.82 & 0.88 & 0.91 & 1.0 & 1.0 & 2.11 \\
\hline 60 & 83 & 0.2 & 75 & 0.42 & 0.98 & 0.88 & 1 & 1.0 & 1.0 & 2.43 \\
\hline 80 & 16 & 0.2 & 25 & 0.31 & 0.82 & 1 & 1 & 1.0 & 1.0 & 3.38 \\
\hline 60 & 150 & 5 & 25 & 0.42 & 0.78 & 1 & 0.8 & 1.0 & 1.0 & 3.37 \\
\hline 40 & 16 & 0.2 & 75 & 0.63 & 0.82 & 0.88 & 1 & 1.0 & 1.0 & 1.92 \\
\hline 40 & 150 & 2 & 25 & 0.63 & 0.78 & 1 & 0.91 & 1.0 & 1.0 & 1.97 \\
\hline 80 & 83 & 5 & 25 & 0.31 & 0.98 & 1 & 0.8 & 1.0 & 1.0 & 3.56 \\
\hline 80 & 83 & 2 & 25 & 0.31 & 0.98 & 1 & 0.91 & 1.0 & 1.0 & 3.13 \\
\hline 60 & 16 & 2 & 75 & 0.42 & 0.82 & 0.88 & 0.91 & 1.0 & 1.0 & 3.17 \\
\hline 60 & 16 & 5 & 25 & 0.42 & 0.82 & 1 & 0.8 & 1.0 & 1.0 & 3.17 \\
\hline 80 & 16 & 2 & 75 & 0.31 & 0.82 & 0.88 & 0.91 & 1.0 & 1.0 & 4.22 \\
\hline 40 & 16 & 5 & 25 & 0.63 & 0.82 & 1 & 0.8 & 1.0 & 1.0 & 2.11 \\
\hline 80 & 16 & 0.2 & 75 & 0.31 & 0.82 & 0.88 & 1 & 1.0 & 1.0 & 3.84 \\
\hline 60 & 83 & 5 & 75 & 0.42 & 0.98 & 0.88 & 0.8 & 1.0 & 1.0 & 3.04 \\
\hline 40 & 16 & 0.2 & 25 & 0.63 & 0.82 & 1 & 1 & 1.0 & 1.0 & 1.69 \\
\hline 80 & 150 & 2 & 25 & 0.31 & 0.78 & 1 & 0.91 & 1.0 & 1.0 & 3.95 \\
\hline 60 & 150 & 5 & 75 & 0.42 & 0.78 & 0.88 & 0.8 & 1.0 & 1.0 & 3.83 \\
\hline 40 & 83 & 5 & 75 & 0.63 & 0.98 & 0.88 & 0.8 & 1.0 & 1.0 & 2.02 \\
\hline 40 & 16 & 2 & 25 & 0.63 & 0.82 & 1 & 0.91 & 1.0 & 1.0 & 1.86 \\
\hline 60 & 83 & 2 & 75 & 0.42 & 0.98 & 0.88 & 0.91 & 1.0 & 1.0 & 2.67 \\
\hline 60 & 83 & 2 & 25 & 0.42 & 0.98 & 1 & 0.91 & 1.0 & 1.0 & 2.35 \\
\hline
\end{tabular}

